Portland State University

PDXScholar

Spring 6-3-2014

\title{
The Values, Beliefs, and Attitudes of Elites in Jordan towards Political, Social, and Economic Development
}

Laila Huneidi

Portland State University

Follow this and additional works at: https://pdxscholar.library.pdx.edu/open_access_etds

Part of the Asian Studies Commons, and the Public Affairs Commons Let us know how access to this document benefits you.

\section{Recommended Citation}

Huneidi, Laila, "The Values, Beliefs, and Attitudes of Elites in Jordan towards Political, Social, and Economic Development" (2014). Dissertations and Theses. Paper 2017.

https://doi.org/10.15760/etd.2016

This Dissertation is brought to you for free and open access. It has been accepted for inclusion in Dissertations and Theses by an authorized administrator of PDXScholar. Please contact us if we can make this document more accessible: pdxscholar@pdx.edu. 
The Values, Beliefs, and Attitudes of Elites in Jordan towards Political, Social, and Economic Development

by

Laila Huneidi

A dissertation submitted in partial fulfillment of the requirements for the degree of

\author{
Doctor of Philosophy \\ in \\ Public Affairs and Policy
}

Dissertation Committee:

Masami Nishishiba, Chair

Bruce Gilley

Birol Yesilada

Grant Farr

Portland State University

2014 


\begin{abstract}
This mixed-method study is focused on the values, beliefs, and attitudes of Jordanian elites towards liberalization, democratization and development. The study aims to describe elites' political culture and centers of influence, as well as Jordan's viability of achieving higher developmental levels. Survey results are presented. The study argues that the Jordanian regime remains congruent with elites' political culture and other patterns of authority within the elite strata. However, until this "cautious liberal" political culture of Jordanian elites changes, a transitional movement cannot arise that would lead Jordan towards greater liberalism, constitutionalism and development. The study concludes with implications for transitional movements in other developing countries, particularly in the Arab region.
\end{abstract}




\section{Dedications}

To my three loving children: Naser, Hana, and Huda; My family and friends for their support throughout the years And for all those who value the fight for their rights

May we always stay resilient in what we believe. 


\section{Acknowledgments}

A special recognition to my daughter and editor Hana Abushaaban; and to

Masami Nishishiba and Bruce Gilley

for their belief in my potential. 


\section{Table of Contents}

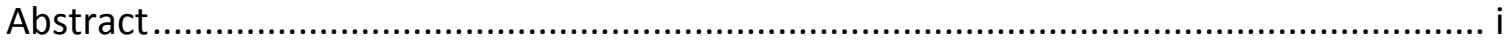

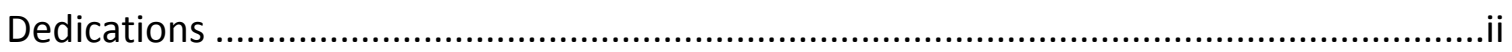

Acknowledgments..........................................................................................................

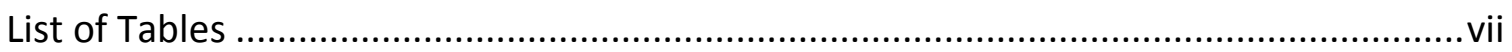

List of Figures .................................................................................................... vii

Chapter 1: Introduction ........................................................................................ 1

A Study Problem Overview ..................................................................................... 1

The Purpose, Research Question and Contributions of the Study ................................. 2

A Brief Summary of Analytic Methods ....................................................................... 5

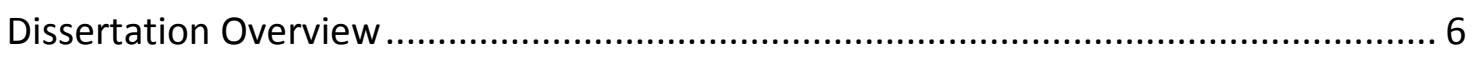

Chapter 2: Literature Review ................................................................................. 9

An Overview of Jordan: Geographical Location ....................................................... 10

Population, Religions, and Ideological Makeup: Jordanian Elite Socialization .............. 10

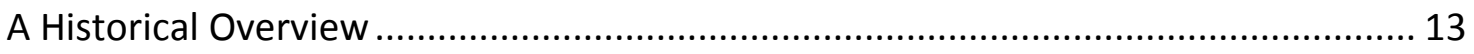

Elite Theory: The Center of Influence among Jordanian Elites ..................................... 16

Elites' Political Culture: Values, Beliefs, \& Attitudes................................................. 28

Political System: Democracy, Governance, and Development in Jordan ..................... 32

Political Development: Political Liberalization and Democratization............................ 36

Social Development and Civic Engagement ............................................................. 43

Tribalism vs. Jordanian Nationalism.................................................................. 47

Economic Liberalization and the State of Rentierism .................................................. 50

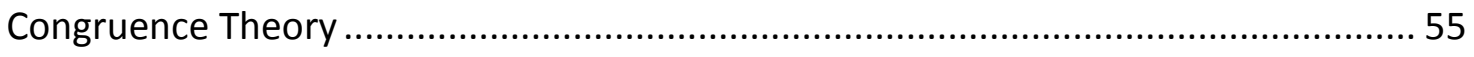

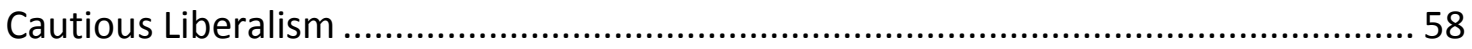

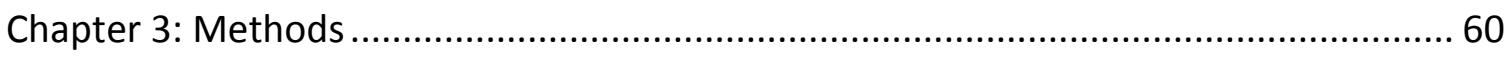

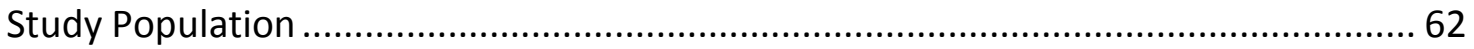

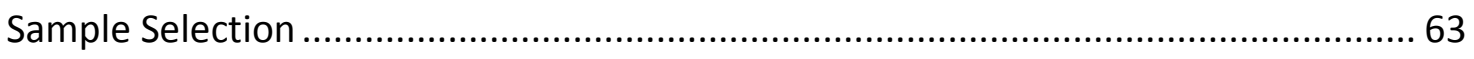

Survey Administration and Interview Procedures ...................................................... 66 


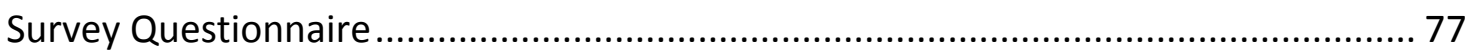

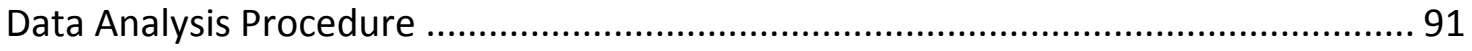

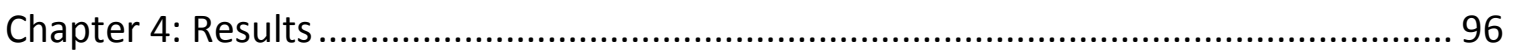

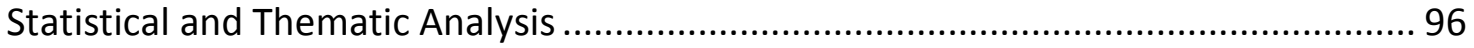

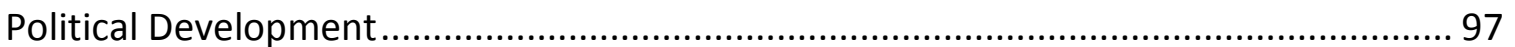

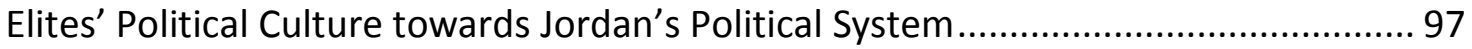

Elites' Political Culture towards Freedoms \& Civil Rights ......................................... 103

Elites' Political Culture towards Public Sector Administrative Reform ...................... 108

Elites' Political Culture towards Political Participation: Political Parties, Elections, and

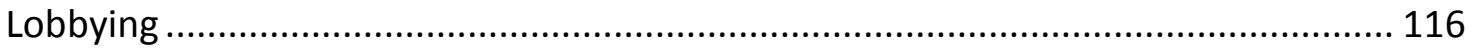

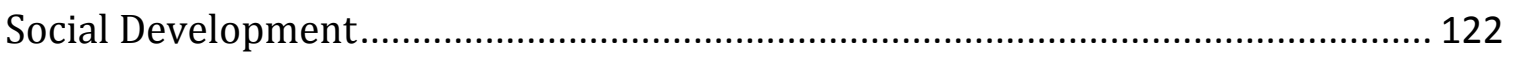

Elites' Political Culture towards Tribalism........................................................ 122

Elites' Political Culture towards Women Empowerment ....................................... 124

Elites' Political Culture towards Participation in Voluntary Organizations................. 125

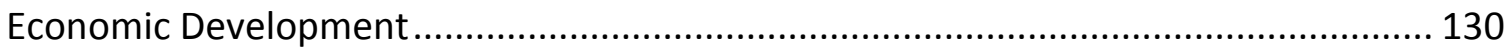

Elites' Political Culture towards Economic Liberalization and Prosperity ................. 130

Elites' Political Culture towards Economic Development vs. Political Development. 131

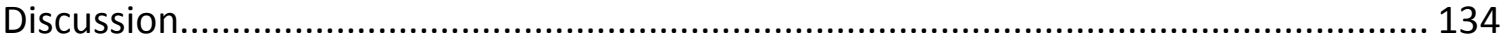

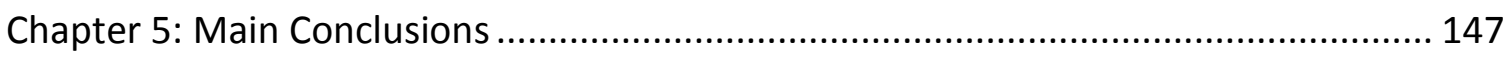

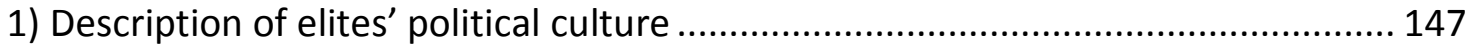

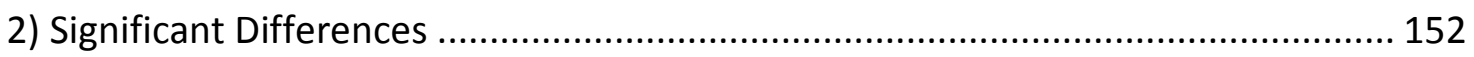

3) Jordanian Elites Political Culture Concerning the Centers of Power in Jordan ...... 153

4) The Congruence between the Regime and Elites' Political Culture ..................... 154

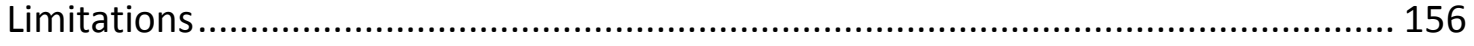

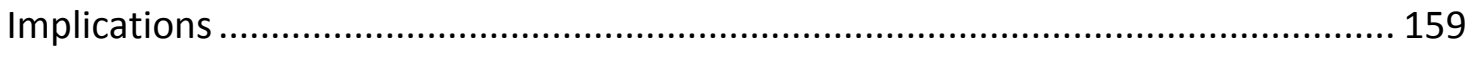

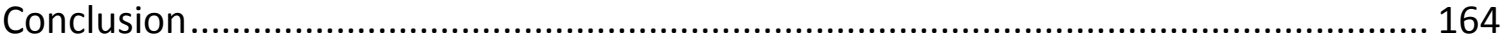

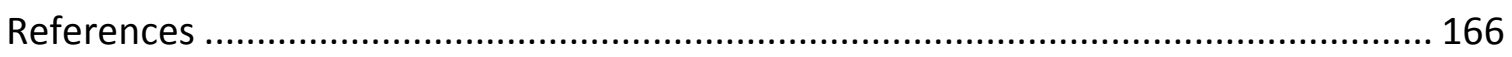

Appendix A: Geographical Location \& Map of Jordan ............................................... 174

Appendix B: Demographics: Social and economic statistic of a human development .. 175 
Appendix C: Human Subjects, Informed Consent, \& Survey Questionnaire 183

Appendix D: Descriptive Statistics Tables and Figures 196 


\section{List of Tables}

Table 3.1 Closed-ended Value Questions 80

Table 3.2 Closed-ended Belief Questions 82

Table 3.3 Closed-ended Attitude Questions 85

Table 3.4 Open-ended Value Questions 86

Table $3.5 \quad$ Open-ended Belief Questions 88

Table $3.6 \quad$ Open-ended Attitude Questions 90

Table 3.7 Example from the Survey: Thematic Categorization of 94

Core \& Subordinate Themes of all Quantitative Questions

Table 4.1 Qualitative Analysis of the Jordanian Democratization 102

Process Deficiencies

Table 4.2 Quantitative Data Analysis Results of Political System Efficiency 103

Table 4.3 Quantitative Data Analysis Results of Freedoms \& Civil Rights 108

Table 4.4 Quantitative Data Analysis Results of Administrative Reform 115

Table 4.5 Quantitative Data Analysis Results of Political Participation 121

Table 4.6 Quantitative Data Analysis Results of Social Development 129

Table 4.7 Quantitative Data Analysis Results of Economic Development 133 


\section{List of Figures}

Figure 4.1 Estimated Marginal Means of Elites' Self-Determination 104

Figure 4.2 Estimated Marginal Means of Elites’ Ideological Backgrounds 107

Figure 4.3 Estimated Marginal Means of Transparency \& Accountability 110

Figure 4.4 Estimated Marginal Means of Corruption Control 111

Figure 4.5 Estimated Marginal Means of Institution-building 114

Figure 4.6 Estimated Marginal Means of the Practice of Lobbying 126

Figure 4.7 Estimated Marginal Means of Involvement with Cultural 127

Institutions

Figure 4.8 Estimated Marginal Means of Involvement with National \& 128

International Institutions 


\section{Chapter 1: Introduction}

\section{A Study Problem Overview}

This study is designed to describe the political culture of three groups of Jordanian elites consisting of their values, beliefs, and attitudes towards democratization and development in light of Jordan's 1989 commitment to liberalization and reform. Since its independence in 1946, Jordanian political leaders, under the stewardship of the Palace, have promised to provide Jordanians with their political rights to elect a Parliament and to form and join political parties. As a result, Jordan witnessed two liberalization periods in 1952 and 1989, yet both promises remained incomplete. In fact, most previous studies on Jordan's political culture bypassed other exigencies for liberalization and democratization and the complexity of the transitional movement. In view of that, this study examines the perceptions, beliefs and values of how different types of elite consider different aspects of Jordanian society that leads to liberalization and democratization. It anticipates if elites' political culture will lead them to implement serious changes in the government and the political system, or, if it is their political culture that restricts them from implementing serious changes; due to believing that changes in the political system and government might lead Jordan to political degeneration.

This chapter presents an overview of the problem, and outlines the purpose of the study, including research questions and contributions. In addition 
it provides a summary of the analytic methods used, and the overview of a dissertation outline, where each chapter is briefly described.

\section{The Purpose, Research Question and Contributions of the Study}

This study intends to describe the values, beliefs, and attitudes that contribute to the formation of the political culture of three groups of Jordanian elites: political, social, and economic, regarding democratization and development; and seeks to define Jordan's centers of influence and the regime's congruence relative to this political culture. The values and beliefs structure both, the pace of, and the possibilities for social and political change (Almond and Verba, 1963; Fattah, 2006; and Putnam, 1971). This description is based on classical and modern elite theories that focus on elites' roles in shaping the values, beliefs, and attitudes of the masses, and their instrumental and influential abilities to mold public institutions by maintaining the flow of communications within the system, and enacting, interpreting, and enforcing the rules that govern the masses (Beatty 2003; Putnam 1973, 1976; and Welsh 1979). Moreover, the description of Jordanian elites' political culture is also based on John Locke's political theory of "cautious liberalism" that has discordant tendencies towards both liberalism and conservatism in terms of change in the political system (Grant, 1987, p.204). The theory of "cautious liberalism" in addition to Eckstein's congruent theory and several other elite, political culture, and development theories have formed the theoretical foundation for this study. 
In addition, personal knowledge and observations by the researcher, along with a number of practical, intellectual, personal goals have added to this study's inferences. The practical and intellectual goals of this study are compatible with the researcher's motivations, personal goals, and curiosity about the lagging behind situations, which stem from the researcher's desire to see the wheel moving towards achieving higher levels of liberalization, democratization, and development in Jordan and the rest of the region.

This study examines and compares the political culture of the three groups of elites consisting of influential and prominent political, social, and economic figures in the Jordanian society, with the intent to clarify the differences among elites' values, beliefs, and attitudes in regards to liberalization, democratization, and development. This study posits two key research questions and two hypotheses:

Q1: What is the political culture that consists of Jordanian elites' values, beliefs, and attitudes towards the processes of liberalization, democratization and political, social, and economic developments in the Hashemite Kingdom of Jordan?

Q2: Are there significant differences among the values, beliefs, and attitudes of the three groups of Jordanian elites?

H1: There are significant differences among the values, beliefs, and attitudes of the three groups of Jordanian elites towards political, social, and economic development. 
Q3: What are the values and beliefs of Jordanian elites concerning the center of power in Jordan?

Q4: Is Jordan's current political regime congruent with the values, beliefs, and attitudes of Jordan's elites?

H2: The regime is congruent with elite political culture.

Jordan is located in a turbulent region; see the map of Jordan and geographical location in Appendix A. Its security and stability is important to the United States and other international policymakers, and remains critical to the rest of the Arab region as its theoretical orientation is relevant to the conspicuous problems of the rapidly and constantly changing nature of Middle Eastern politics (Jureidini and Mclaurin, 1984). This case study departs from the typical approach taken by most studies on Jordan. It focuses on the values, beliefs and attitudes of Jordanian elites and guides their political behavior, providing a basis to explicate the political culture of Jordan and attempts to apply the insights of social psychology in the study of comparative politics. The study's findings are comparable with other political cultures that share common grounds with Jordan's political culture, and fill the academic gap in this field of study on Jordanian elites.

Arab elites that are influenced by its authors' biased inclinations. Further, the data gathering for this study is focused on materials that are more representative of the values, beliefs, and attitudes of Jordanian elites. This study was conducted by running face-to-face interviews with randomly selected elites. By putting emphases on the academic purpose of this study and on the confidentiality of the identities of its 
respondents, the researcher could minimize skepticism, raise the level of participation, and gather more data from the responses that were abundant and useful for the study.

Simultaneously, the absence of media affiliation steered the gathered data from any censorship that might impact its validity.

\section{A Brief Summary of Analytic Methods}

The data for this study was collected in Amman, the capital of the Hashemite Kingdom of Jordan, by meeting face-to-face with political, social, and economic elites administering a survey. The survey included both closedand open-ended questions which generated quantitative and qualitative data respectively. The survey questions explored the values, beliefs and attitudes of Jordanian elites that were important in shaping the political culture of Jordan, and influences the country's capacity to make changes in their government and political system. The respondents included current and previous incumbents of randomly selected 100 government and prominent social and economic figures.

The data collection took place over a period of nine months with the assistance of Jordan University's Center for Strategic Studies (CSS). Throughout the data collection phase careful attention was paid to the sensitive nature of the topic.

The data analysis of this study is mostly descriptive. In order to compare responses among the three groups of elites, namely political, social and 
economic elites, a one-way analysis of variance and Chi-square were conducted.

Qualitative data were coded and subjected to thematic analysis.

Lastly, the used techniques of close and persistent observation enabled the interviewer during the face-to-face interviews to improve both the validity and reliability of the gathered data. Kirk and Miller (1986) assert that "qualitative research is a particular tradition in social science that fundamentally depends on watching people in their own territory and interacting with them in their own language, on their own terms...qualitative research has been seen to be naturalistic, ethnographic, and participatory" (p. 9). Accordingly, being knowledgeable of Jordan's history and ethnic conditions, along with understanding elites' religious backgrounds and Arabic language have contributed to collecting valid and reliable data on elites' values, beliefs and attitudes as will be explained in chapter 3 .

\section{Dissertation Overview}

This dissertation is organized in five chapters. Chapter 1 has presented the introduction, statement of the problem, research questions, and the significance of the study. Following this introduction is Chapter 2, which provides a theoretical foundation presented in three bodies of literature relevant to this study: the first theoretical framework includes theories on classical and modern elite theories; the political, social, and economic Jordanian elites; and elites' political culture. The second body of literature is solidified with theories on authoritarianism, monarchy, and the Jordanian political system and regime 
verses theories of transition towards liberalization, democratization, and political, social, and economic developments. The third body of literature explains the theories of congruence and cautious liberalism applied to Jordanian elites' political culture. The theoretical framework in the literature review provides a foundational understanding for the discussion of this dissertation by supporting the researcher's argument and outcomes in describing the political culture of Jordanian elites.

Chapter 3 describes the methods. It provides explanations on the study population, and the identification of elites in terms of positions, incumbents and group classifications. It elucidates all the preparatory steps followed by the researcher with a detailed narrative on the sample selection, survey design, survey administration, and the procedures of the face-to-face interviews. The chapter unfolds the contents of the survey questionnaire that includes a mixture of open- and closed-ended questions. Collecting multiple types of data provided a more comprehensive understanding for the political culture of those who may impact the process of democratization and development in Jordan under its authoritarian monarchical political system. As a result, the randomly selected participants of the political, social, and economic elites were willing to participate in the face-to-face interviews and to provide responses and elaborations on the subjects of the entire questionnaire.

Chapter 4 summarizes the results of the study, portraying the outcomes of quantitative and qualitative data analysis. The presentation of the data is organized in conjunction with the two hypotheses of the study. The results are 
inferred in terms of their acceptance or rejection to each hypothesis with emphases on the seven significant questions out of the thirty-five survey questions.

Chapter 5 presents the discussion and conclusion of the results. It discusses the implications of the statistical analysis by highlighting the patterns of the cautious liberal political culture and the results that indicate significant differences between elite groups. The conclusion of this study describes the political culture of Jordanian elites and their cautious liberal nature that reflects on decisions relevant to change in Jordan's authoritarian monarchy and the achievement of liberalization, democratization, and development.

In sum, this study contributes to a deeper understanding of the political culture of Jordanian elites, along with other key factors of the Hashemites' authoritarian regime that influence the trajectory of Jordan's democratization and development movement. Such understanding is crucial in determining the success of the prospective transition from an authoritative monarchy to a constitutional monarchy. 


\section{Chapter 2: Literature Review}

The major themes of this study will emerge repeatedly in this review, focusing on the theoretical foundations of values, beliefs, and attitudes that constitute elites' political culture towards liberalization, democratization, and development; along with the ensued changes in the authoritarian monarchical political system in the Hashemite Kingdom of Jordan. This review provides the reader with three bodies of literature. First, it presents theoretical perspectives that focus on classical and modern elite theories; the political, social, and economic elites in the Middle East and Jordan; and elites' political culture. Subsequently, the second body of literature presents theoretical perspectives of authoritarianism, monarchy, political regimes and the centers of influence verses theories of transition towards liberalization, democratization, and political, social, and economic developments. The third body of literature explains the theories of congruence and cautious liberalism by focusing on their application to Jordanian elites' political culture, which may or may not shape the regime's political behavior pertaining to change and transitioning towards liberalization, democratization, and development.

Although historical, geographical, and demographic data and incidents are not directly factored into the analysis, these incidents will set this chapter's stage. This background information warrants an attempt to understand specific but important characteristics of Jordanian elites' political culture towards any 
changes in their political system; further in-sequence data will be included in Appendix B.

\section{An Overview of Jordan: Geographical Location}

The Hashemite Kingdom of Jordan is strategically located in the Middle East; bound by Syria to the north, Iraq to the northeast, Saudi Arabia to the east and south, the Red Sea to the south, and the West Bank in the Palestinian National Authority and Israel to the west. Jordan covers a diversity of landscapes over an area of 89,213 square kilometers, with a desert region that spans over approximately $75 \%$ of that area. The lowest point on earth lies at the Dead Sea, in Jordan, at 408 meters below sea level, verses 1854 meters above sea level, which is the peak of Jabal Umm El Dami. Amman is Jordan's capital and it is located in the northwest; Al-Zarqa and Irbid are two major northern cities; while Karak and Aqaba are two major southern cities.

\section{Population, Religions, and Ideological Makeup: Jordanian Elite}

\section{Socialization}

According to UNDP and World Bank 2013 reports, Jordan currently has a population of approximately 6.5 million people, where nearly 3 million reside in the capital, Amman. More than $70 \%$ of the population is under 30 years of age, which $22 \%$ of those are between the ages of 15 and 24 (See Appendix B, Figure 2.1). 
The main reason behind the high rate of population growth was ascribed to the influxes of Palestinian refugees since 1948 (Department of Statistics, 2008). According to the United Nations Relief and Works Agency (UNRWA) for Palestinian refugees, about 224,000 people were admitted to UNRWA refugee camps in the East Bank immediately after the June 1967 war. In 1986, UNRWA cited 826,128 registered refugees in the East Bank, where roughly 205,000 of which were in refugee camps. The estimate of Palestinians living in Jordan has ranged from 60 to 70 percent of the total population, but the exact numbers are unknown, particularly since official government statistics do not distinguish between the nomadic tribal members who lived east of the Jordan River and the West Bank urbanized groups that crossed the Jordan River to settle on the East Bank (UNRWA/United Nations).

The Transjordan area has been continuously inhabited with archaeological evidence suggesting sedentary settlements on both the East and West Banks of the Jordan River. The inhabitants on both sides of the river were extensively divergent, but the dominant form of social organization in Transjordan was that of the tribe. Early in the seventh century a fundamental change occurred in the predominantly Arab inhabited region. This change has influenced Jordan and its neighbors to this day bringing the arrival of Islam, a newly developed religion with strong roots in Christianity and Judaism. As a consequence, the inhabitants of Transjordan have embraced the Islamic religion particularly on the East Bank of the river which remained heavily nomadic or semi-nomadic. Hitherto, the 
West Bank remained multi-religious and dominated by an urban culture (Jureidini \& Mclaurin, 1984, p. 9).

The demographic components and location of Jordan has been inviting to national ideologies and movements (Salibi, 1993). Arab nationalism, for instance, was one of the most powerful ideologies of the sixties and seventies; however, it was considered one of the most radical threatening movements to the Jordanian monarchical regime.

Today's Jordanian population has a dominant Muslim majority, with a Christian minority of only 6\% (Mufti, 1999). The non-Arab population in Jordan comprises of 5\% of the population, most being: Circassians, Chechens, Armenians, Turkmen, and Gypsies, and all of which have maintained their separate ethnic identities. The loyalty of both the Circassians and Chechens to the Hashemites has guaranteed them fixed seats in the Parliament and important incumbencies in the government. Most importantly are the Eastern Jordanian prominent tribal leaders whose content and persuasion are important to the King himself. The prominent tribal members represent big and powerful tribe. Therefore, in order to keep these tribal figures and their tribal members gratified and loyal to the regime, the King bestows them various privileges and financial compensations. These figures were referred to, by several theorists and respondents who participated in this study, as the "Old Guards," who constitute the center of influence and the internal elite strata that remain fundamental to the stability of the regime (Al-Khalidi, 2011, Jureidini \& Mclaurin, 1984, Malik, 1999, Robins, 2004). 


\section{A Historical Overview}

Retrospectively, Sharif Hussein bin Ali Al Hashemi was a Caliph living in the province of Hijaz. In 1916, he proclaimed the independence of the significant Hijaz province, ascribed to the two holy cities of Mecca and Medina (Robins, 2004; Snow, 1972). Sharif Hussein was a grand Sharif, guardian of Mecca, and the ruler of the Hijaz. As a Hashemite he was styled Sharif; 'Sharif' means noble and signifies descent from the Prophet. The Hashemites family is the noblest in Islam, because they are affiliated with $\mathrm{Al} \mathrm{Hashem} \mathrm{clan} \mathrm{that}$ descends from Prophet Muhammad's tribe 'Al Quraish.' Until this day, this religious affiliation with Prophet Mohammad's descent has been the Hashemites source of legitimacy to their reign and extends their active pursuit of regime longevity in the face of all challenges to their throne (Gubster, 1983).

Later, in the aftermath of WWI, Transjordan and the rest of the Arab region were affected by two complicated British promises that were difficult to reconcile. The first was made to the Jewish people as a result of Hayim Weizmann's efforts in 1898. Weizmann pushed the British foreign secretary Arthur Balfour to send a letter to the leader of the British Jewish community Walter Rothschild, or Baron Rothschild, stating that the British government views in favor to a national home for the Jewish people to be established in Palestine, and will use all their endeavors to facilitate the achievement of this promise. According to the Jewish Virtual Library (2014), Weizmann was an active Zionist leader, the President of the Zionist organization, and statesman who convinced the United States government to recognize the newly established 
state of Israel. In 1949, Weizmann became the first President of the state of Israel. The second promise was made to Sharif Hussein promising him the creation of a new independent Arab Kingdom in the Transjordan desert (Shlaim, 1995, p. 22).

Indeed, the creation of the state of Israel in Palestine after the 1948 war has affected Jordan more than any other neighboring country due to its geographic location. Enormous Palestinian migrations took the eastern route, because of its smooth topographic land and close distance, making it easier on immigrants traveling by foot. Just by crossing the Jordan River from the West Bank in Palestine, influxes of Palestinian immigrants ended up and settled on the East Bank in Jordan. Jordan kept receiving a flooding amount of Palestinian immigrants due to several war conditions. Since then, large numbers of Palestinians have resided in Jordan, which affected the demographics of the Jordanian society to date (Shlaim, 1995, p. 20).

Consequently, the new state of Jordan emerged on the region's map after the British separated Transjordan from the mandate of Palestine. This separation was between the fertile lands and water resources of the West and the expansive barren lands in the East. Hence, it affected both states politically, demographically, and economically. The coastal area that is located west of the Jordanian River is known as Palestine, and together, the western and eastern lands were placed in a single mandate under the authority of the United Kingdom. Since its early history, Palestine was rural and its society was agrarian. Contrast to the Bedouins on the East Bank, the inhabitants on the West 
Bank settled there and valued land ownership, and this separation shaped the legacy of the Hashemites, as well as the political culture of the Jordanian society (Jureidini and McLaurin 1984, p. 9).

As a result to these political incidents, later in history, the regime used this split between the same families and tribal members to plant a social faction seed. In order to pursue particular political interests, the regime accentuated discrimination between East and West Bankers. For example, as it was previously mentioned in this study, Jordan's military forces remained exclusive and restricted to the members of Eastern Bedouin tribes (Robins, 2004). According to Jureidini and McLaurin (1984), anthropologically and politically, the West Bankers are those who settled west of the Jordan River, while the East Bankers are the nomadic and semi-nomadic tribes that dominated the east side of the River. The distinction between nomadic and cultivating societies has remained applicable to the civilizations of the East and West Banks, with the exception of some tribal nomadic elements on the West Bank, and towns on the East Bank. Thus, many tribes have east and west branches as in the case of Salt and Karak on the east of the River, and Jerusalem and Nablus on the west. Although the numbers of West Bankers compose the larger part of the population in Jordan and exceed the numbers of East Bankers, neither component of the Jordanian society regard Jordan as Palestine (p. 11). Since their early days, the East Bankers' interactions went south to the Arabian Desert, but the West Bankers' interactions went to the west and north responding to their urban and multi-religious character that was accentuated 
with the presence of a large Christian minority (Gubster, 1983; Jureidini \& Mclaurin, 1984). Some scholars emphasize and address this difference as a social cleavage that undermines the country's national legitimacy and unity; Mufti, for instance, considers it a division in Jordan's population. He further states that this division was violently manifested in Jordan's 1970 civil war, and it still undermines the national unity, which is identified by Rustow (1970) as a requisite for successful political liberalization (p. 101).

\section{Elite Theory: The Center of Influence among Jordanian Elites}

The classical theorists, Gaetano Mosca (1896) and Vilfrado Pareto (1916) stated that the purpose of elite studies is to examine the structure of power in communities, in order to know if power is in the hands of a cohesive minority and to respond to the question of the nature of power in a society. Accordingly, both classic and modern scholars define this minority group as the "elite," and they have acknowledged its members' possession for power and other notable traits (Parry, 1970, p. 34).

Mosca classified the elites in a society in terms of their exercise of political power, or their engagement in the struggle for political leadership such as the members of the government and of high administration, military leaders, members of politically influential families of an aristocracy or royal house, influential members of the intelligentsia, and leaders of powerful economic enterprises. Moreover, Mosca defined this group as a distinguished group that 
appears in every society behind the formal holder of power, and it possesses certain traits, exerts decisive political influence, and serves as a recruiting ground for the members of the government. This group is the elite, or, as labeled since ancient Greek times the oligarchy, or the aristocratic group in the society. Mosca, though, did not think of elites as a group that is raised high above the society, but they are connected with this classification through much larger strata of sub-elite that supplies the elite ruling class with new recruits (Bottomore, 1993; p. 5-7).

Consequently, the elites are defined in several ways, such as the ruling class, upper class, governing elite, or dominant stratum. In every society there are two strata: the superior upper one is the elite, while the inferior stratum is the masses, or the non-elite. Pareto stated that the governing elite possess enough wealth, power, and influence to lead the masses in collective actions (Bottomore 1993; Parry, 1970, 2005; Putnam, 1971).

In this respect, Pareto highlighted the appearance of two classes of people in all societies and under all political systems: a class that rules and a class that is ruled. The first is always the less numerous, performs all political functions, mobilizes power, and enjoys the advantages that power brings; whereas the second is directed and controlled by the first. The ruled are the masses, and the rulers are the "governing elites" (Parry, 1970; Lenczowski, 1975).

Hence, the dominant upper class in Jordan consists of the East and West Bank elites. Their wealth, power, and high governmental, social, and economic positions make them influential and the most prominent figures in the Jordanian 
society. The influence and prominence of East Bank elites, for instance, originate in the big tribes to which they belong. Through the years Jordan's big tribes have preserved power and affluence of resources; thus Jordan's big tribes have remained influential (Thomas, 2003, p. 543).

Accordingly, this study seeks to identify the specific group of Jordanian elites that are the center of influence in Jordan. Pareto's concept of "the circulation of elites," provides a theoretical foundation in responding to this research question (RQ3) concerning the center of power in Jordan. The two main aspects to Pareto's concept are: 1.) the replacement of individuals within the elite; and 2.) the replacement of one elite by another. These dynamic aspects generally take place in elites' strata due to mortality, attrition, and replenishment.

The process of individual replacement is exclusive, while in other cases, is an open process that allows less privileged individuals an opportunity to join the ranks of the most influential figures in the society. By the same token, Lenczowski (1975) asserts that behind the formal holders of power in the state, there is an enduring group with certain distinguishable traits that exerts decisive political influence. Moreover, this group serves as a recruiting ground for members of the government, and may have an informal, loose structure while enjoying economic and social power, and an inherited status in society (p. 3). In the Jordanian case, this explains the existence of the most influential "Old Guards" group of elites behind the formal holders of power in the Jordanian government, and their impact over the institution of Palace and the entirety of 
the Monarch. The "Old Guards" are the East Bankers that the institution of Army is constituted of with its soldiers and high rank officers. As Robin (2004) asserted, Jordan's military forces remained exclusive and restricted to the members of Eastern Bedouin tribes. Further, Brynen (1998) explained that the members of these Bedouin tribes are the regime constituents of East Bankers. The regime grants East Bank elites financial and other rewards and privileges. In return, these dividends protect, sustain, and guarantee the tribes' support to the regime, strengthen its circle of patronage, and enhance its legitimacy.

Ben-Dor (1984) conducted a comparative study on political elites in the Middle East, underlining the importance of sub-elites who belong to the military forces of few Middle Eastern countries. In the prelude of his study, Ben-Dor cited a well-known Egyptian elite who still belongs to the Egyptian intelligentsia, Mohammed Hassanein Haykal (1962) and whose socialization, ideology, and attitudes have not changed up until our recent time. In the aftermath of the military coup d'état and the Egyptian revolution of 1952, Haykal stated: "Under the conditions that are typical of the class struggle in the underdeveloped countries, and bearing in mind the feeling of the general public that the leaders in power represent only interests which by their very nature are opposed to those of the masses, the popular revolutionary movement has no choice but to base itself on the army in order to pave the way for the revolution."

Ben-Dor explains that when disintegration occurs in Middle Eastern societies, it is typically due to a breakdown of the established patterns of convergence, rather than class struggle, as he considers Middle Eastern societies 
to be based on convergence, and not on integration. He further emphasizes on the religious impact on individuals in Middle Eastern societies, and their conviction in 'obedience' whether spiritually, to God and the Prophet, or on a societal or cultural aspect, where the 'inferior' role obeys any 'superior.' Therefore, the obedience for political leaderships is stemmed from this culture. Accordingly, Ben-Dor argues against the notion of the military recruitment in the Middle East to be based on class or social background, but claims a strong association between the military and middle class in a society. Thus, the upper class domination over society gets penetrated by the middle class intervention through military revolutionary movements that can be described as endeavors against reactionary rules. An example provided to further exemplify this point, is the military recruitment sytem based on minorities in several Arab societies, particularly in Syria in the case of the 'Alawis' (p. 6-8). This system is relatively applied to the Jordanian case, as the regime exclusively recruits soldiers to join the institution of Army from East Bank tribes. Therefore, when these soldiers are promoted to high rank officer positions, they undergo a process of "civilianization" and are further granted higher incumbencies by the King. BenDor explains that the civilianization process increases the professionalization of the army and raises the proportion of civilian bureaucrats and technocrats in the formal organs of the elite (p. 21).

Further, Ben-Dor explains that linking the military with the middle class can transform society to more modern patterns, and asserts that the role of the military can be understood through its interactions with upper and middle 
classes in the society. When the upper class dominates the middle class, society, and the regime, the military intervention is considered revolutionary, whereas its intervention to stop mass domination is considered reactionary. However, Middle East elite theorists emphasized that the high echelons of bureaucracy remains substantial to the regimes of the Middle Eastern countries; where without their cooperation and expertise, the top elites find themselves incapable to exercise their power (Ben-Dor, 1984; Lenczowski 1980; Zartman, 1980).

For instance, the Jordanian military intervention of 1970 that eradicated the mass domination and led to a civil war was coupled with severe austerity measures as a result to East Bank elites' attitudes. Individuals that belong to the Hashemite family have started their reign by establishing a regime that is protected by the institution of Army exclusive to East Bankers in order to protect their monarchical legitimacy and the regime-based state. The endurance of this situation is based on the reciprocal relationship between the Hashemites, and the sub-elite strata, where the Hashemites receive emphasis on their status, and in return the sub-elites receive benefits, including financial dividends, and other privileges, such as joining the bureaucratic apparatus of the state, and occupying the highest incumbencies in Jordan's administrative institutions.

Zartman's approach in describing elites of Middle Eastern countries stems from describing elites on the bases of their recruitment and promotion; elite socialization, including formation, personalities, ideologies, and political culture; and elite decisions, behaviors, and organizations. In his theory, he focused on who elites are, how they acquire power, and what they do. The phenomenon of elite circulation generates from recurrent interactions between the incumbent elites and the relevant situations that 
generate new elites. Elite circulation, according to Zartman relates to the "who" and the "what" over time. Thus, there is no immediate prediction concerning who will be next in power, or when a change will occur, but there is a likelihood of outlining who may be next in power if specified conditions, assumptions, or consequences would suggest particular types of people to hold power in certain circumstances. Zartman's theory provides an ideal type of elite circulation (p. 92-8). This model explains King Hussein's strategy of recruiting and promoting certain influential figures among the West Bankers to join the Jordanian elite strata, forming the center of influence among Jordanian elites. Further, realizing the differences and similarities among elite structures in different Middle Eastern countries triggered Stone, (as cited in Zartman, 1980), to conduct a comparative study and test the influence of the following four independent variables: a.) recent history of elite circulation; b.) the current form of political structure; c.) the social background and preparation; and d.) elites' attitudes, personalities, and motivations. Stone used a typology to test the relationship between the four variables, where variables ' $a$ ' and ' $b$ ' represent studies that focus on political structures which elites operate under, and variables 'c' and 'd' represent elites' socialization, political culture, and personal characteristics, by examining the relationships between ' $a$ ' and ' $c$ ' and ' $b$ ' and 'd' variables.

However, the viability of his study remains limited particularly that it depended on existing data. Stone suggested other methods than the comparative analyses to study elites in the Middle East such as the longitudinal analyses that involves following a process of change over an extended period of time or a combination design but also these methods had their limitations, which confirmed the scarcity of the conducted studies on 
elites in the Middle East. Moreover, there is a particular scarcity in single elite case studies, which confirms that there has been a gap in the Middle Eastern elite literature.

Robins (2004) claims that the King selects the educated tribal members from the big and influential tribes to occupy high governmental posts. On one hand, this selection provides the regime with loyal and supportive influential tribal members, and on the other, it is a royal offer that remains contingent to the loyalty of the incumbent to the Monarch and his regime. Based on this equation, East Bank elites have always found their refuge in tribalism, and so has the regime, particularly the "Old Guards" who mostly form the center of influence. These elites do not follow the perceived description of the classical elites defined by Mosca and Pareto, but are more fitting to Lenczowski's (1975) description, as a new type of elite who has political influence, power and predominance that may be attributed to their manipulative skills, and in some nondemocratic cases, the use or threat of force. However the ultimate skill of these elites is organizational; for instance, an attorney, judge, or law professor can be appointed as a minister of justice, and this appointment under authoritarian regimes is considered "natural." As Lenczowski notes, this appointment conforms to the common-sense expectation, that the head of the department of justice "be a man with legal training and experience" (p. 5).

According to the CSS (1999), the old innate belief by East Jordanians reckons tribalism and tribal affiliation as the source of pride, solidarity, and power. Presently, the most important positions in the Jordanian government and society are still occupied by East Jordanian prominent figures, whose clans can be traced back in history of the Transjordanian tribes. Most of the well-known family names in Jordan are ramifications of the most salient Jordanian tribes, 
which are Bani-Hassan, Bani-Sakher, Le'abaidat, Al-Gharaibeh, Bani-Hamida, and Howaitat (see Appendix B, Map 2.1; Origins of East Bank Elites and the distribution of Jordanian tribes). Some East Jordanians go by the same surname of the original tribal name, such as Le'abaidat and Al-Gharaibeh, but many others go by a family name that is a branch from the original one. As an example, Bani-Hassan is known to be the biggest tribe in the Transjordanian area, whose members alone are $30 \%$ of Jordanians. The name of the current Prime Minister of Jordan, Abdulla Ensour, originates from Al-Nsoor clan, which is one of the ramifications of Bani-Hassan. Also, the tribe of Bani-Sakher is another example where its members are still famous, powerful, and wealthy. However, Bani-Sakher is not a large tribe due to its involvement in frequent wars in the past, causing a significant loss of members. Yet, today's most famous surnames root back from Bani-Sakher, such as Al-Lozi and Al-Fayez clans, who occupied the most prominent positions in the Jordanian government, such as the two Prime Ministers Ahmad Al-Lozi and Faisal Al-Fayez, also Nasser Al-Lozi, the Chief of "Al Diwan Al-Malaki” or the Royal Court.

Additionally, the prominence of the West Bank elites is due to their power and wealth that they established in Palestine. According to Smith (1986), in the 1930s Palestine had reached a level of prosperity that made it one of the most advanced countries in the Middle East. The new oil refinery at Haifa and the center of British communications during World War II rendered Palestine more urbanized than before. As a result, the Palestinians became involved in construction and in trade; particularly, the agricultural exports of citrus fruits, 
grain, and other crops. Also, they were employed in the railroads, huge military construction projects, and government departments along with their Jewish counterparts. In addition, the war brought Palestinians into the world market. Several Palestinian entrepreneurs invested in government bonds, shares, commodity stocks, and other forms of the 1930s financial papers, which enabled many Palestinians to recover some of their wealth after their dispersion in 1948. The sum of Palestinians’ investments was estimated by over $£ 39$ million sterling pounds. Out of these amounts, $£ 10$ million sterling pounds were transferred to Jordan alone, where the majority of exiles had taken refuge and at least $£ 1.5$ million was brought into the country in the form of banknotes prior to the abolition of the Palestinian currency (p. 22).

Smith asserts that only a few Palestinians with available wealth in exile were able to partially recoup their losses and, unlike the peasantry, to avoid the confinement of life in the camps. For example, The Tuqan family of Nablus used their funds in Jordan to expand their agricultural operations on the East Bank and to start related industries with Board of Directors that included some of the wealthiest merchants of Nablus, such as the Vegetable Oil Company of Jordan. Also, Yusif Baidas, a former bank clerk and foreign exchange dealer in Mandatory Palestine, used funds obtained from the release of accounts in Barclays and started a multi-million dollar business in money exchange, which started in Beirut and expanded throughout the Arab world, Europe, and Africa. The Shoman family of Jerusalem, as another example, was able to transfer the headquarters of the Arab Bank from Jerusalem to Amman and expanded its 
programs to become one of the largest banks in the Middle East today. Due to the development of new forms of corporate enterprise in Palestine during the 1940s, other merchants and traders found it possible to transfer their businesses abroad. The Arabian Insurance Company, for example, along with Middle East Airlines, both reopened in Lebanon after 1948; by the end of the 1950s their shareholders included some of the wealthiest Palestinians in the Arab world (p. 23-24).

Consequently, the wealthy Palestinian entrepreneurs who have become holders of the Jordanian nationality are the original Palestinian bourgeoisie class that formed the stratum of West Bank Jordanian elites. Similar to the stratum of East Bank Jordanian elites, who occupy prominent positions in the government and the army institution, West Bank Jordanian elites are the prominent entrepreneurs, whose wealth, high educational levels, and noticeable liberal exposure have enabled them to form the economic elite stratum. Their prominent positions triggered the King to offer some of the West Bankers high positions in the Jordanian government. In fact, Jordan's stability has been dependent on the King's ability to martial and exploit the tribal loyalty. All groups and ethnicities have their own elite prominent members who are close and loyal to both the regime and the Monarch (Mufti, 1999, p. 105).

Generally, Pareto is concerned with the governing elites, because they have power while the masses have none. The governing elites as Pareto defines them are influential politicians, who can impact political decision-making, directly or indirectly through their leadership positions in any of the industrial, 
labor, military or other fields. Also, Pareto emphasizes the capability of opposition leaders in influencing the political situations in a society (Parry, 1970; p. 34). Further, there are two kinds of elites, according to Pareto: the astute or cunning, referred to as 'the foxes,' and the courageous leaders, particularly military leaders, referred to as 'the lions.' According to Faulks (2000), throughout the state's history, the different stages and times determined which type of elite should govern.

Mosca sees the organizational skill as the key to elite rule, while Pareto is more militant concerning the suitable psychological and personal attributes for governing. The political elite's mental strength protects them from being overthrown. Most elite theorists based their theories on these two ideas. The first idea emphasizes that power lies in positions of authority in key political and economic institutions; while the second emphasizes the importance of some psychological traits. The psychological, personal attributes, and intelligence of elites set them apart; their intellectual superiority enable them to become the highest accomplishers in any field and lead the masses (Parry, 2005; p. 36).

Throughout Jordan's history, the regime's figures that belong to a tribal power base and are entrenched in state bureaucracy, the institution of the military, and the intelligence agency are its most powerful elites. These elites are East Bankers known as the "Old Guards," whose power and influence enables them to impact decision-making and state policies. With their power they can constrain every reform attempt, including the King's timid steps towards 
liberalization and to end riots and turmoil; as they consider reforms a threat to their political privileges and economic benefits (Al-khalidi, 2011).

\section{Elites' Political Culture: Values, Beliefs, \& Attitudes}

According to Beatty (2003): "It is [elites] who at once shape the values, beliefs, and attitudes...who set standards...mold public institutions...formulate demands and maintain the flow of communications within the system, and who enact, interpret, and enforce the rules that govern us." Therefore, elites are considered vitally interested in the theory and practice of shaping and changing other people's values, beliefs, and attitudes (p. 4).

According to Putnam (1971) the relationship between elites' attitudes and the different situations can be understood if plugged in an equation. He explains it is a push-pull relation: the stronger the attitudinal press, the less the need for situational stimuli, and vice versa. Thus, Putnam (1971) argued that elites' attitudes could be examined through investigating their opinions on current political topics to understand the significance of their views, and what they favor, in order to assess their attitudinal press in different situations (p. 651-2). Putnam (1976) argued that understanding elite behavior requires an understanding to how their opinions specifically fit in the broader pattern of beliefs.

Thus, understanding elites' attitudes requires understanding and defining their values and beliefs. Values are the beliefs that guide the behavior of an 
individual and their decision-making process that are expressed through words or actions. The value occurs in the heart, while the belief initiates in the mind. Basic values may move to the subconscious level of the individual's mind, and only when these values are translated into decisions do they become challenged by others, and their importance is recognized. A value is what the individual considers important to oneself; a belief is the way the individual thinks things are or should be; and an attitude is what the individual thinks and feels, which leads to a behavior. So, values and beliefs provide guidance and direction for one's attitudes and behavior.

Notwithstanding, the enclosed definitions of values and beliefs in previous value studies by different behavioral sociologists muddled the definition of 'values' with the definitions of 'beliefs' and 'attitudes.' Hutcheon (1972) highlights the changing prominence of values from Durkheim and other sociologists until 1959, and reveals a number of disturbing tendencies in their studies, one of which, considering values as a non-empirical study, but having fundamental religious roots. Also, during the 1960s several sociologists had a tendency to assume that society is antecedent to the individual and they emphasized an imbalance in value theory based on the assumption that values are independent variables. Moreover, other sociologists had the tendency to stress on conformity and minimization of the role of reason and the selective perception in human action, such in the over-socialized view of man and the over-integrated view of society (p. 174). Another tendency discussed the confusion in the value concept that made some define it as norms, cultural 
ideals, assessments of action, beliefs, objects, value orientations, behavior probabilities, and as generalized attitudes (p. 177). Yet Rokeach (1960) reflected a different approach in defining values and beliefs. His cognitive and experimental approach was a convergence of several theoretical orientations that emphasized structure rather than content. As a result, Rokeach defined values as the most important components of the belief system (p. 447).

Scheibe (1970) provided a distinction between behavior, values, and beliefs, gestating behavior as 'what the person does,' and values and beliefs as 'what the person wants to do' according to what they believe is true (p. 21). Scheibe operationalized these concepts and noted that when the question asks about 'what the person did or will do,' it is an attitude question. When it asks about 'what is good,' it is a value question. But, when it asks about 'what is true,' it becomes a belief question (p. 41).

Almond and Verba (1963), describe civic culture as the Anglo-American tradition, and refer to it as a gift to the world. They state that "every political system is embedded in a particular pattern of orientations to political action...the political culture." Thus, political culture can be defined as "...the specifically political orientations; the attitudes towards the political system and its various parts; and attitudes towards the role of the self in the system" as it underpins all systems of governance (Almond, 1956, p. 3). In later work, Verba (1966) defines the political culture as "the subjective orientation to politics" or the "system of empirical beliefs, expressive symbols, and values that define the situation in which political action takes place" (p. 513). 
The stability of the political system, according to Almond and Verba is contingent to its supportive value and belief system. In 1963, the authors ran a study on five different countries and their political systems. They considered Britain the best example of a stable civic culture based on their conducted study on one-thousand British individuals. They deduced from the responses of the interviewees that there is a high magnitude of cultural homogeneity, consensus, and respect among the British people for their government institutions. The results of the study indicated how the individuals' shared values towards their parliamentary rules and government decisions. The social trust between the individuals and their political institutions is an important association that is required for the success of civil society. In other words, this association is between individuals' behaviors and the state's behavior. Nevertheless, the aforementioned policies of the regime in Jordan that, for the most part, resulted in containing just one sect of the society and passing over the larger sect would impact the level of democracy in Jordan and the stability of its political system, which renders this theory unfeasible to be applied on the Jordanian case.

Putnam (1971) defines the set of politically relevant values, beliefs and habits of political leaders as the political culture. Understanding elites' political culture requires skills in interpreting their ideologies, in characterizing operational codes, and in defining the spirit and calculations that lie behind high-risk political behavior (p. 651). The political leaders' attitudes are a function of the environmental situations in which they find themselves, where they bring their psychological predispositions to these situations. Putnam 
considers the political culture approach illuminating and informative as it provides information about the nature of people in general, if evil or good; the society if harmonious or conflictual; what politics is all about; the importance of the social and political differences; and about how these differences should be dealt with. Besides, he considers the political culture approach useful in providing answers to various questions about politics, political issues, and political problems, as well as it is adequate for presenting solutions to these problems (p. 652).

\section{Political System: Democracy, Governance, and Development in Jordan The monarchical authoritarian regime of the Hashemite Kingdom of} Jordan. In a study on Jordan's monarchy, Lucas (2004) suggests that since its establishment, the Jordanian monarchical system has taken the lead in molding the country's national identity that suits its regime. The monarchical regime of Jordan has built a new state around itself rather than reconstructing an already existing state. In his study, Lucas mentions two common types of Middle Eastern monarchies: dynastic and linchpin; Jordan's monarchy is a linchpin monarchy. Contrary to the dynastic monarchy, the members of the ruling family of the linchpin monarchical system do not participate in the political institution of the monarchy or fill positions in the state bureaucracy except rarely. However, the King in Jordan does not rule alone, but forms a coalition and stays at its center. Hence, pluralism is allowed at a certain degree within the regime 
coalition. Even opposition is legalized, which maintains the country's political and social stability, because quiescence and political stability are vital for the endurance of the monarchical regime (p. 106).

Moreover, Jordan and its neighboring countries offer ample opportunities for the study on authoritarianism through their powerful national security apparatus. Jordan's national security apparatus, or the "Mukhabarat," has enjoyed fairly wide usage since the establishment of the state, and controls all of its activities (Hudson, 2001, p. 801). Similarly, Lucas asserts that linchpin monarchies encourage social pluralism and mobilize it along vertical lines to participate in the governing of the state, as long as all the activities are controlled by the national security apparatus, or the "Mukhabarat" (p. 108-9). This type of linchpin monarchy and social pluralism is seen in the rule of the Hashemites. During the era of King Hussein, Jordan's most popular King, several scholars wrote about the Hashemites' popularity. King Hussein was extremely capable through his personal relations with key power figures internally and within the region and beyond, to establish an unchallenged institution of monarchy. His charisma and wisdom in making policy had augmented the recognition of the Hashemite monarchical rule among Jordanians, many Arabs in the region, and the world (Shlaim, 2007; Snow, 1972; and, Kechihian, 2008).

Lucas (2004) describes Jordan as a regime-led state ruled by a monarch on the basis of kinship and hierarchy, as he sees a blurry line between the regime and the state of Jordan. "Regimes" are defined by Keohane and Nye (as cited in 
Krasner, 1983) as "sets of governing arrangements that include networks of rules, norms, and procedures that regularize behavior and control its effect" ( $p$. 2). Susan Strange (as cited in Krasner, 1983) defines regimes as, "the government of a society by an individual, dynasty, party or group that wields effective power over the rest of society." Strange contends that the concept of the "regime" is usually tied with authoritarianism, and believes that the "regime is biased towards authoritarian political structures" (p. 344).

Authoritarian political systems, according to Juan Linz (as cited in Linz, 2000, p. 159) have four characteristics: (1) limited not responsible political pluralism, which constrains political institutions; (2) a basis for legitimacy for accepting the regime as a necessary evil; (3) neither extensive nor intensive political mobilization, such in the use of the ventilation method that allow the masses to vent only during controlled demonstrations; (4) a formally ill-defined executive power that is often shifting. These four characteristics describe a political system that rules by using a mixture of austerity and forbearance strategies. A further elaborated study by Robert Bianchi (1986) describes the Middle Eastern political systems as hybrid, eclectic, and alterable political structures.

According to Bianchi's study, the authoritarian regimes of Middle Eastern countries have promoted corporatist associations as instruments of social control while avoiding high levels of repression and simultaneously perceiving interest group politics as inadequate attempts to replicate the classic democratic AngloAmerican models. Bianchi based his theoretical perspective on the two 
coexisting paradigms of Philippe C. Schmitter of corporatism and pluralism in the 'Third World.' Bianchi argued that within the same political system, the two concepts of corporatism and pluralism coexist and do not collide. Austerity and stringency coexist with forbearance and clemency, but in changing proportions and the two strategies interact in various ways.

The previous Latin American political structures are corporatist, robust, and stringent regimes. Schmitter (1982) defines them as systems of interest representation with units organized into limited numbers of singular, compulsory, non-competitive, hierarchically-ordered, and functionally differentiated categories; recognized and created by the state; and granted a deliberate representational monopoly within their respective categories in exchange for observing certain controls on their selection of leaders and articulation of demands and supports. Conversely, he defines the pluralist political structure as a constituent unit of pluralism, organized into unspecific numbers of multiple, voluntary, competitive, non-hierarchical, and self determined categories. The units of the pluralist political structure are not controlled or created by the state and do not exercise monopoly of representational activity (Bianchi, 1986, p. 507).

Accordingly, under the heterogeneous nature of political systems, a mixture of corporatist and pluralist interest of representation play key and enduring roles. Yet, neither paradigm is considered permanent, especially in the systems of ongoing tensions and competition between pluralist and corporatist that promote periodic and cyclical fluctuations in the predominant mode of 
representation. This theory is found pertinent to the authoritarian regime in Jordan as it imposes inconsistent austerity measures, while concurrently allowing some pluralism. Thus, the political system of Jordan is known for its hybrid political structure that does not entirely impose rigid authoritarian policies, or totally eliminate pluralism. As put by Bianchi, it is a political system that has "opted for strategies of corporatization that are far more tentative, partial, and inconsistent" (p. 509).

Pettygrove (2006) describes the regime in Jordan as patriarchic with traditional leadership. Hudson (1977) also argues that the patriarchic traditional ideology is adopted by the regime to inculcate an ideological legitimacy that counteracts anti-royalist doctrines. Hudson warns that authoritarian regimes' legitimacy crisis can only be avoided by implementing reforms and enhancing the transition movements to achieve liberal democracy. This warning was taken seriously in Jordan when King Hussein overcame the crisis of 1989 riots by his liberalization attempt (p. 209).

\section{Political Development: Political Liberalization and Democratization}

There are a number of issues that are important in Jordan and the entire Arab region, all of which deal with the delayed development. In 2006, the Center for Strategic Studies (CSS), at the University of Jordan undertook a survey of public opinion in various Jordanian governorates. The study was conducted in cooperation with the Arab Democracy Barometer that was established in 2005 by scholars and research centers in 
the United States and several Arab countries under the leadership of University of Michigan and Princeton University.

The project aims to create a database of opinions held in the Arab world concerning politics, society, religion, and culture. Additionally, this project measures a number of specific issues organized under five sections; views of democracy, focus on citizenship, the place of religion in public and private life, views of public institutions and confidence in their efficiency, and international and Arab affairs. This study will refer to some of these results in Chapter 4.

Most popular and academic discussions use the two terms of political liberalization and political democratization interchangeably, while they are in fact different. Political liberalization, as defined by Brynen, Korany, and Noble (1998), "involves the expansion of the public space through the recognition and protection of civil and political liberties," such as the ability of citizens to engage in free political discourse and to freely organize in the pursuit of common interests. Political democratization is the expansion of political participation, such as providing citizens with a degree of real and meaningful collective control over public policy (p. 3).

In its modern history, Jordan witnessed two liberalization movements in 1959 and 1989. The constitution of 1952 was an attempt to set forth the essential elements of a constitutional liberal democracy in Jordan. It stated the right of citizens to set up and join political parties and during that time, Jordan had active parties and held parliamentary elections that led to a coalition government formed by the whole of the country's political spectrum. Yet, in 1959, King 
Hussein instructed his government to impose severe authoritarian measures on political parties, restrict civil activities, and empower the investigation apparatus that surrounds and protects the regime, which interrupted the liberalization era by restrictive legislations that banned political participation for thirty years, (Majed, 2005, p. 15).

Similarly, in 1989, after thirty years of government's austerity measures, wide riots erupted in Jordan. These incidents triggered the King to adopt the second liberalization and socioeconomic development movements in order to keep the country under control. Kamrava (1998) and Mufti (1999) described Jordan's liberalization movement of 1989 as one of the most significant experiments in political liberalization in the Arab world despite the ultimate power of its unelected king and appointed officials. King Hussein's liberalization strategies entailed several governments to become engaged in initiating and implementing reformation policies at all levels, which made Jordan more liberalized and developed than any other Arab country in the region Mufti (1999).

As a result to the 1989 liberalization movement and its political reforms, and for the first time since 1967, a parliamentary election was held, martial law was rescinded, political parties were re-legalized, censorship was abolished, new press legislation was introduced, and a 'new National Charter committing the country to political pluralism and democracy was adopted. The parliamentary election of that year was the fairest and freest election in Jordan's history. It allowed the only opposition party, the Islamic Action Front (IAF) to participate 
in the elections. However, the results were unexpected to many liberals in the country. Out of 80 parliamentary seats, 33 were won by Islamist candidates, 22 of which were for the IAF, and 12 were won by liberal leftists. As a response to these results, the King appointed Tahir Al-Masri as a premier, who is known to be a liberal leftist. Al-Masri formed a committee from the most prominent intelligentsia members to put together the National Charter (Brynen, 1998, p. 75-79).

The King's decision of 1990 to appoint a Royal Commission in order to draw up the National Charter was significant in two respects: first it represents a consensus statement between the King and the parliamentarians, tribal notables, urban elites, East and West Bankers, conservatives, liberals, leftists, and Islamists on the political rules of the game under liberalization. Second, it is more elaborative and explicit in endorsing democratic politics than the constitution. The National Charter declares that the system of government in the Hashemite Kingdom of Jordan is parliamentary, monarchic, and hereditary and it calls for strengthening the democratic process on the supremacy of law and political pluralism bases. The Charter begins with a historical introduction followed by eight chapters of substantial details that lead to political, social, and economic developments in Jordan. The first chapter is a detailed rationale on the democratic choice followed by a detailed chapter on political pluralism and rule of law system. The rest of the chapters deal with particulars on national security; economy; the social aspect including culture, education, and science; 
information technology; Jordanian-Palestinian relations; and Arab, Islamic, and international relations (The Jordanian National Charter, 1990).

According to Al-madhoun (2010), the Charter has been the subject of national consensus and acquired a unique status subordinate to the constitution, but no mechanisms or procedures were formulated to implement it. Since the issuance of the National Charter it became the model for national reconciliation and it has been present in the political and intellectual meetings, discussions, and writings of the Jordanian intelligentsia. Among those benefits are the reconciliation among Jordanians, the termination of martial law, and the restoration of constitutional rights for political participation through elections and political party affiliations, which are all substantial issues for Jordan's stability and development. Drafting the National Charter has benefited all Jordanians although its implementation proceedings and mechanisms remained absent (p. 3-7).

The National Charter attempt was frustrated by some ruling elites. The government and the regime enforced a series of preemptive measures and defense mechanisms designed to help the ruling elites maintain their privileges by thwarting this liberalization and democratization movement, which, had it been approved, would have moved Jordan many steps forward in its transition towards liberalization, democratization, and development (Brynen, 1998).

Wiktorowicz (1999) claims that Jordan's liberalization attempts remained stalled, due to the regime's manipulation and exercise of power through legal codes and political repression, a situation that benefits the incumbent elites by 
perpetuating their political control. In his study of the limitations of democracy in Jordan, Wiktorowicz refers the floundering towards liberal democracy to the lingering authoritarianism. He describes what has been going on in Jordan since 1989 as just a "façade of democracy" with only symbols, such as political parties, elections, and civil society organizations. These symbols have become common; yet, they did not lead Jordan to liberal democracy (p. 607).

Hitherto, it has been possible to have some of the elements of political liberalization without having political democratization. As explained by Brynen et al., allowing some liberalization relaxes the political repression without expanding political participation, which assimilates the earlier theory of the mixed political system of interest representation by Bianchi. Also, this accommodates Linz's ventilation method used by authoritarian regimes to prolong their rule, and therefore proves that even a modest amount of liberalization under the control of the state guarantees, protects, and preserves the status quo for both the political system and political elites. Yet, as Brynen et al. confirm, political freedom remains essential for enabling citizens to participate effectively and choose a political alternative. Expanding political participation by elections under repression, highly distortional systems of electoral representation, or electoral fraud does not provide citizens with effective say in political decision-making.

Cheema (2005) argues that the political systems are not marked liberal and democratic for only holding fair and free elections. If democracy is defined in terms of elections, then it is possible to have an "illiberal democracy," but the 
democratic political system enforces rule of law, separation of powers, and protection of its citizens' basic rights. Jordan's liberalization movement of the 1990 slowed down and its efforts to achieve democratic governance fell in a state of stagnation. There is a need for serious implementation of reforms that guarantees the success of liberalization and democratic governance. The process of achieving democratic governance entails the coordination of "complex mechanisms, processes, relationships, and institutions through which citizens and groups articulate their interests, exercise their rights and obligations, and mediate their differences by allocating and managing all resources to respond to collective problems" (p. 5). By good governance Jordan will be able to eliminate corruption by imposing a rule of law system that enforces transparency, accountability, and other democratic principles.

Cheema asserts that democratization responds to a universal human yearning for freedom and life with dignity, undiminished by our cultural diversity and ethnic differences. Jordan needs a serious implementation of reforms managed by democratic governance. He also goes on to explain that the democratization process in developing countries does not slow down because democracy is inapplicable due to their political cultures, but because authoritarianism interrupts the progress of their liberalization and democratization movement.

Moreover, according to Jreisat (as cited in Jabbra, 1989), public administration in Jordan is crucial for the implementation of reform and development policies. However, confrontational issues, such as tribalism, 
remain challenging for the achievement of administrative development. The tribal loyalties have been more powerful than loyalties to the state, as well as centralism, clerkism, nepotism, incompetence, and corruption (p. 99). These challenges are frustrating to the implementation of administrative reforms that most elites confirmed have not been effectively managed.

\section{Social Development and Civic Engagement}

Civil society, according to Wiktorowicz (2000), is an essential component of democratization. It is viewed "as a mechanism of collective empowerment that enhances the ability of citizens to protect their interests and rights from arbitrary or capricious state power." The expansion of civil society requires several transitions to democracy, but under authoritarian rule the activities of non-governmental organizations (NGOs) remain under state control. In Jordan, all NGOs, such as women's organizations, journalists' associations, professional associations, and cultural societies are continuously challenged by the state. Keeping their activities under state control avoids the destabilization of the regime by limiting civic engagement and social empowerment. Jordan witnessed an expansion in the number of civil society organizations after 1989. However, the opportunity for creating new civil society organizations remained limited. As described by Wiktorowicz, once these organizations were created, they became embedded in a web of bureaucratic practices and legal codes that allow the state to monitor and regulate their collective activities. This strategy rendered civil 
society organizations in Jordan as an instrument of state social control rather than a mechanism of collective empowerment (p. 43).

According to Al-Attiyat (2005) and Pettygrove (2006), increasing women's participation and empowerment is significant to the social development and modernization in Jordan. Pettygrove believes that civil society organizations dedicated to women's issues have blossomed. Relatively, the participation of women has been empowered through several efforts, for example, the gender equality protection clause within the Jordanian constitution, which has led to many legislative advances in regards to women's rights, and women's suffrage. Further, while the percentage of universityeducated women is as high as it is for men, the government yet organizes campaigns and training programs to raise women's rights awareness, empower women in business and politics, and encourage women's participation in all sectors of the workforce (p. 4).

However, in spite of these advances women's civil society organizations inhibit their decision-making roles, which hampers their abilities to achieve empowerment. In addition, family and religious social structures, including gender roles in Jordan, remained resistant to change. These social structure and social value systems serve as obstacles to women's political empowerment, along with the Islamic value system that is manipulated in its interpretations to intentionally hinder women's participation at all levels; political, social and economic (p. 22-5).

Moreover, Kamrava (1998) describes the authoritarian nature of the Jordanian regime as restrictive, because it frustrates all reform implementations by constraining the meaningful political participation and development of an effective civil society. This restrictive nature is also emphasized by Wiktorowicz 
(1999) who elaborates on the regime's use of political repression in order to channel any mobilization or political participation within its formal and statedelineated institutions. The repressive barriers of the state still exist since the social movements, and political activists and actors prefer to mobilize through the grassroots voluntary organizations.

Currently, the activities of all types of NGOs are restricted and monitored by the government, including the ones that are concerned with human rights, democracy, the sentiment value of Jerusalem, and Islam as cultural activities. For instance, the government politicizes the cultural and religious activities of most NGOs in Jordan and has created clashes over the definition of their activities. The politicization of cultural and religious activities is intended by the regime to prevent, limit, or forbid any mobilization outside the formal channels. The government issued two laws to govern civil society and their activities; Law 33 was issued in 1966: "to provide social services without any intention of financial gains or other personal gains, including political gains." The second is the political party law: Law 32 of 1992 that stipulates: "The use of the premises, instrumentalities, and assets of associations, charitable organizations and clubs for the benefit of any partisan organization, shall be prohibited" (Wiktorowicz, 1999, p. 610). In Law 33, for instance, there is no explicit requirement that says all volunteers and administrative board members must be approved by the "Mukhabarat" or the security department and the public security of the interior, though all types of public activities in Jordan must first be cleared by the security apparatus and other state agencies (Wiktorowicz, 2000, p. 50). By the 
same token, Bayat (2002) argues that Jordanian NGOs are established to remain charity-driven organizations and to fulfill basic needs, which does not lead to social development.

Brynen (1998) states that prior to 1989 , the professional associations in Amman represented the main vehicle for political discussions, but other civil institutions in Jordan showed little independence or politicization, such as the press that followed the exact direction of the government, chamber of commerce, university campuses, and trade unions. All these institutions and associations were thoroughly under the government's control. After 1989, the number of civil society associations and organizations has grown tremendously, although the process of modernizing these organizations was deficient. Thus, the institutionalization process did not progress to match the growth in the number of NGOs. Brynen illustrates this problem by explaining how the government owns the media, even after the royal decree of 1997 that modified the press law, but later resumed their control and continued to limit freedom of expression. Also, most organized groups have remained passive and incapable of impacting the broad political agenda. This failure in modernizing and liberalizing civil society institutions was referred to a myriad of reasons. In addition to the government's limitations, bureaucratic complexities, and the "Mukhabarat," there were other reasons behind the passivity of civic engagement, such as tribal and clan connections that lessened the importance of the formal associational groups, the excessive involvement of royal members, former and current cabinet ministers in the social organizations, and the activation of the parliament and 
political parties. This expanded the formal mechanisms of political participation and caused some associational groups to drop their memberships or active participation, and to lose the political reason for their existence. The dilemma caused a conflict between the government and some opposition groups including leftist minorities and the IAF who endorsed the call for boycotting the 1997 parliamentary elections. Additionally, the legalization of political parties did not rotate power or create political elites. Ironically, the party that significantly gained support of the southern region was " $A l A$ 'ahd" party, meaning the Jordanian Pledge party. It is still headed by a strong East Jordanian advocate of the regime. "Al A'ahd" party has entered a coalition with eight other political parties to strengthen their support to the regime. Thus, the political party institution in Jordan did not meet the consideration of a fundamental mechanism for political participation, nor did it ensure political pluralism (Brynen, 1998, p. 84-89).

\section{Tribalism vs. Jordanian Nationalism}

Tribalism can be a double-edged sword. It promotes loyalty, unity, and cohesiveness among tribal members who share kinship relations; while simultaneously, it spreads prejudice and favoritism because it discriminates against others who do not have similar kinship affiliations. According to the Blackwell Dictionary of Political Science, tribalism can be defined in two ways: "the anthropological meaning of the term refers to the type of society which preceded the primitive state where groups of pastoralists linked by kinship, 
formed regular organizations in which chieftainship would later develop and these might be called clans or tribes. The term is also used to describe a sort of political system in which nepotism and clientilism predominate. Hereditary political families are prominent, programmatic and ideological conflict is still not intense. Policies tend to be implemented by trading favors" (p. 326).

In fact, the dichotomy and fluctuation in the concept of tribalism has caused Jordan more confusion on local and national levels regarding how the state system should work through its institutions. Jordan is not a highly tribalized country according to a recent tribalism study conducted by USAID (2010) that evaluates the relationship between traditional and modern institutions in Middle Eastern countries.

According to Oudat and Alshboul (2010) the relationship between the state and the traditional institution of tribalism, or the 'asha'eriyah' in Jordan is very special due to the security strategy that harnesses the traditional institution of tribalism to work as a defense mechanism for the regime. Retrospectively, the tribes have been the foundation on which the Jordanian government is grounded, as they form the fundamental part of the Jordanian army and the security apparatus that keeps the regime protected without relating the 'tribe' or the 'ashirah' to the importance of the nation state (p. 70). On the contrary, the regime defends the tribal honor and the institution of the monarchy as one entity, rather than defending the concept of the nation-state, which created an alliance between the regime, tribes, and the institution of monarchy that is represented in the slogan of "Jordan First" that enables the state system of political authority to 
make use of the traditional political authority by promoting tribal loyalties towards the monarch and his regime. Hence, the regime has gained control over the tribes through its reliance on their support and loyalty that was promoted towards the monarch, not the state. Yet, this alliance has produced incompatible and ill-assorted situations relevant to the issue of loyalty that has never included the Jordanian nation (p. 77, 83-85).

Additionally, the authors highlight very important points; firstly, they warn from the consequences of the regime's strategy of "Jordan First" and the recruitment of the traditional institution of tribalism, as they do not consider this strategy patriotic. The authors assume that the negative impact of tribalism on Jordanian nationalism and development will backfire; specifically in the strategy of "Jordan First."

Secondly, they emphasize that the regime's defense strategy has not brought Jordan any stability. It is anticipated that this strategy will encourage more opposition and trigger radical movements, widen the gap between the regime and the society, and weaken the traditional power of tribalism characterized by solidarity, social cohesion, power, and pride, among others. Accordingly, the regime's presumption of "Jordan First" defense strategy has been failing; it has neither empowered the traditional institution of tribalism, nor provided the regime with protection.

Thirdly, contrary to the regime's presumption, this strategy is becoming an instrument of modernization, as the new generations are beginning to define themselves according to their personal achievements rather than being defined 
by a tribal affiliation. Thus, according to Oudat and Alshboul (2010) this strategy is the new beginning for political liberalization in Jordan.

\section{Economic Liberalization and the State of Rentierism}

According to Knowels (2005) the Hashemite Kingdom of Jordan is one of the most vulnerable countries to the external political, economic, and security events. The country has been rocked by the effects of the regional instability and its numerous events including the ongoing Israeli/Palestinian conflict, the wave of the radical revolutions during the 1950s-1960s, the civil Lebanese war of 1974, various Gulf wars, the invasion of Kuwait, and the invasions of Afghanistan and Iraq. More recently, though Knowels' study reflects up to 2005, it is yet relevant to the ongoing war in Syria. The regional crises diminished Jordan's subsidies from the oil producing countries and placed further pressures on the economy as the country received hundreds of thousands of refugee influxes from each of its neighboring countries.

The government in Jordan struggles to meet the requirements and high demand of commodities and services, due to its scarce resources, and particularly since Jordan is classified as a rentier state. Rentier theory has been used since the 1970s to attempt to explain the political economy of Middle Eastern countries (Knowles, 2001). The rentier or semi-rentier states are dependent states on exogenous sources, since these states derive revenues from external resources rather than depending on domestic production or taxation 
(Greenwood, 2003). Jordan is characterized by aspects of rentierism since its establishment in 1921.

Brynen (1992) blames rentierism for social and political factions in Jordan; it has deeply divided the population in Jordan and played a key role in weakening the national integration by primarily directing state resources at East Jordanian elites. As a semi-rentier country Jordan has an average GNP, and lower-middle income levels with great disparity between its "haves" and "havenots." The state revenues in Jordan depend on the international market, not on domestic production. Its available financial resources support the country's authoritarian regime, which renders the legitimacy of the government less important.

In a later analysis by Brynen, Korany, and Noble (1998), they criticize the allocations and distributions of the financial resources by the government. They assert that the regime uses these resources to support the coercive apparatus of the state and to sustain massive social welfare programs that fuel powerful neopatrimonial networks based on family, the tribe, and proximity to the ruling elite. Also, under such circumstances coercion becomes less important for the regime when political legitimacy can be "purchased" through economic rewards. The rentier social contract is one in which the state provides goods and services to society such as subsidies on basic commodities without imposing economic burdens, while society provides state officials with a degree of autonomy in decision-making and policy. Legitimacy rests upon the ability to enhance quality of life rather than democratic principles (p. 15). 
According to political economy scholars, Jordan was one of the world's fastest-growing economies, as a result to the 1973 Arab-Israeli War. The increase of oil prices, increased remittances, and oil-producing Arab countries' assistance contributed to Jordan's economy and GDP growth of the 1970s. This economic rise continued through 1984 with low unemployment and poverty rates, and high per capita GNP and GDP levels to rise. However, Jordan did not maintain this economic growth, and the increment in revenues was mainly used by the regime to enhance its position among its patronage and East Bank constituents. Thus, the economy began to fall, especially with the aftermath of the economic crisis that befell the country in the 1990s; see Appendix B, Table 2.1 Jordan GNI per capita/PPP from 1989 to 2012 in.

Lipset's theory (1959) classifies the following most important prerequisites for achieving development and political democracy: the steady increases in Gross National Product (GNP) per capita; the legitimacy of the government and its ability to strengthen its citizens' beliefs in the appropriateness of their existing political institutions for the society; the effectiveness and efficiency of the political system to maintain political stability that enhances the economic development and sustains democracy; industrialization; urbanization; and citizens' high educational levels. The positive linear relationship between the levels of socioeconomic development and democratic development leads to a steady increase in the overall wealth of a society. Fulfilling these prerequisites enabled the Western democratic societies to achieve political and economic developments (p. 75). 
In order to achieve political stability and maintain an average level of socioeconomic development in Jordan, the regime found refuge in the International Monetary Fund's (IMF) and World Bank's stabilization methods. The international organizations' economic reform plans are designed to overcome economic deterioration manifested in low growth, high inflation rates, foreign exchange shortages, and budget deficits.

However, the economic reform is not a one-shot deal, but should be viewed as a stage-by-stage process (Barkey, 1992). It starts with a stabilization stage and continues in a structural adjustment stage. In the stabilization stage the imbalance gets remedied, such as balance of payments, budget deficits and high inflation rates, by devaluating the currency and increasing the prices of imported goods and domestic products that contain foreign inputs. Meanwhile, the second stage is more complicated as it requires an institutionalization process. In fact, most Middle Eastern countries fear the stabilization measures because they can harm the tenure of their regimes. This fear makes these countries delay the stabilization stage, which sets back the whole process of economic reform (p. 3).

The principle sources of Jordan's hard currency earnings are based on several different resources and industries: its mineral resources, such as phosphate, potash, and fertilizers; the tourism sector and other services that include healthcare, pharmaceutical, and the cosmetic sector; and finally, overseas remittances, and foreign aid. Nevertheless, the foremost obstacles of Jordan's economy are its regional instability, water scarcity, and complete 
reliance on oil imports for energy (See Appendix B for more information on Jordan's largest export sectors and Human Development Index).

As a result, the Jordanian government has taken wide steps towards rapid privatization. Privatization is the process of "converting state-run industries and firms into private ones" (Stiglitz, 2003, p. 54); particularly that Jordan attracts investments on a large scale. It has six special economic zones: Aqaba, Mafraq, Ma'an, Ajloun, the Dead Sea, and Irbid.

Jordan's success in privatizing state-owned enterprises (SOE) is discussed in the World's Bank report (2012), and used as an example for other governments in developing countries to overcome their citizens' fears of privatizing stemming from many scopes: employees' expectations to lose benefits; consumers' worries about price increases; and voters mistrust in government officials. During the period from 1998 to 2008, the government of Jordan has successfully privatized fourteen fully SOEs in the following industries: telecommunications, electricity, air transport, mining and other sectors. According to the World Bank, privatization strengthened Jordan's fiscal position and supported its macroeconomic stability by generating $\$ 2.3$ billion in sales proceeds, supporting the reducing debts from 100\% of GDP in 2000 to $89 \%$ in 2004 and $60 \%$ in 2008.

Although Jordan is mostly an arid desert land with limited water resources, and depends on external sources for the majority of its energy requirements, the World Bank has recently classified Jordan as an "upper middle income country.” Jordan's annual GDP growth between 2010 and 2011, 
according to UNDP (2013) report was $3.1 \%$ and the GDP per capita is $0.9 \%$. The IMF expects an economic growth to accelerate and expand by $3.5 \%$ and reach $4.5 \%$ in 2017. The UNDP per capita Gross National Income (GNI) rate is $\$ 4,380$. According to IMF, Jordan’s GDP per capita/Purchasing Power Parity (PPP) for 2012 is estimated by 5,977 (See Appendix B, Figure 2.3 for GNP growth rate, and Figure 2.4, for Jordan's Economic Liberalization and Freedom Index, 2013).

\section{Congruence Theory}

The relationship between the authority patterns of Jordanian elites with the Monarch on one hand, and the citizens of Jordan on the other, are relevant to Eckstein's congruence theory (1998). The core of the congruence theory consists of two hypotheses. The first finds pertinence to Jordan's political system and pertains to the congruence between the authority patterns of the political system and the authority patterns of other units of society. The viability and well performance of the political system is measured on the basis of this congruence; high performance requires high congruence. Thus, it is the capability of the political system to be in agreement and broadly correspond to different social organizations, agencies, and units. Predominantly, the units of the society are such institutions and organizations that include political parties, unions, businesses, professional societies, community and voluntary associations, schools and universities, film production teams, sport team 
leagues, religious worshiping associations, hospitals, social clubs, and families; these are the social units where the elites of the society are drawn from. The social units are subunits that directly affect and differ from the state in their scale and complexity, and require governance. Thus, governments perform well if their authority patterns are congruent with the authority patterns of other social units (p. 5).

The second hypothesis of the congruence theory is not separate from the first, but an extension of it. It suggests that in addition to the congruence condition, high performance will be satisfied if the political system is capable to make a balance among its disparities. This requires the ability to have mixedauthority relations. The effective transition towards democracy and the stability of the political system requires balanced interactions and relationships among all conflicting and consensual parties, or active and passive ones. This conductive environment, according to the theory, enhances the stability of the political system; while the authoritative or totalitarian authority patterns hamper the transition towards democracy and the stability of the political system (p. 10- 12).

According to Eckstein, the high performance of governments also pertains to how well a polity can do in preserving the following conditions and criteria: its durability over time; keeping a civil order and avoiding the existence of violence and coercive channels in the society; legitimacy of the regime and how much its members consider it worthy to them; and the government's decisional efficacy in carrying out policies in response to political demands and challenges (p. 13). 
The application of the first hypothesis of congruence theory to Jordanian elites, who are drawn from different social units within the society, indicates that congruence is always apparent between the authority patterns of the regime and the authority patterns of particular social units, but not all social units. The Jordanian authority pattern of Eastern elites for instance, remains responsive to only a minority of constituencies, particularly with the unrepresentative party system that does not allow devolution of power or recruitment of elites. This creates disparities within the Jordanian society, as this congruence is only representative to the minority of elites. As far as the second hypothesis of the congruence theory in terms of the ability of the political system to establish a balanced relationship with its disparities in the society, and in order to establish a consensual environment among all parties, the Jordanian political system has lately proven its ability to do so. After the eruption of the Arab Spring, the change in the regional political milieu planted the seed for some change in the Jordanian political system, in terms of responding to reforms. Relatively, the King acknowledged the demand for political reform, and yielded to the wish of certain Parliament members to select the Prime Minister. Therefore, the Jordanian political system proved that it can create a consensual environment and avoid coercion and disagreements.

However, the performance of the government and political system will be measured in terms of its ability to maintain civil order, legitimacy, and its efficacy in carrying out policies in response to political demands and challenges. But, the Jordanian political system lacks for governmental durability, and has 
used coercive and astute measures to keep civil order and enforce balance in the society, which impacts the transitional movement towards liberalization and democratization that has been slow and remained as a "form" rather than a "norm." These enduring conditions are constraining the progress of liberal democracy in Jordan.

\section{Cautious Liberalism}

John Locke's political theory does not guarantee an inevitable progress of human communities, as he deems the political order precarious. Locke's political theory is joined with a constant anxiety about a possibility of political degeneration caused by change. John Locke's political theory has two tendencies that are not very harmonious. On one hand Locke seems reluctant to change and inclined towards preserving the political order, due to believing that change might be for the worse; this tendency expresses conservatism. On the other hand however, Locke rejects tyranny and abuse and regards them as a state of war. In this rejection Locke expresses radicalism, as he urges that citizens should stay watchful and ready to act in order to oppose abuse before it is too late. Therefore, Locke tends to encourage what he calls "cautious liberalism," to avoid changes in the political system and government, which he believes might lead to political degeneration.

Rooted from the value of liberalism, John Locke theorized that in order to establish a legitimate rule, every society must approve consent among its 
members on the bases of freedom and equality. A citizen's entitlement to be free and equal enables them to come to consensus, and maintain legitimacy, avoiding any infringement on their rights. Further, a legitimate political authority must have separated powers, certain institutional arrangements that enable the polity to elect an assembly, and must replace traditionalism with constitutionalism in order to ensure the continuation of stability. Locke's liberal theory obeys legitimate authority, while allowing resistance against illegitimate power and tyranny. Therefore, power must be exercised within reason as a means for a legitimate end, and only then will the public good be served (Grant, 1987, p. 204).

Applying Locke's "cautious liberalism" theory to the analysis of the collected data on Jordanian elites' political culture will indicate whether Jordanian elites' values, beliefs, and attitudes are ambivalent towards liberalization, democratization, and development. This study will provide a description on elites' values, beliefs, and attitudes towards change and the implementation in reforms in Jordan's political, social, and economic orders as depicted in their responses to the survey questions of this study. Further, the analysis of their responses allows me to describe them as "cautious liberals" in terms of this theory, as they provide signs of acceptance for liberalization, democratization, and development, but simultaneously illustrate timid attitudes towards accepting change in their political order, fearing potential instability. 


\section{Chapter 3: Methods}

The core of the literature review suggests that what actually matters is what Jordanian elites appreciate, believe in, and want to act towards. Accordingly, this chapter explains the methods that were used in describing elites' political culture that consists of their values, beliefs, and attitudes. It examines the three types of values, beliefs, and attitudes questions of the survey questionnaire that were designed to respond to the study's four research questions and their two hypotheses.

Four research questions and two hypotheses were developed to describe the political culture of Jordanian elites that consists of their values, beliefs, and attitudes towards liberalization, democratization, and development; measure significant differences between the means of the three groups of elites; illustrate the values, beliefs and attitudes of Jordanian elites concerning the center of power in Jordan; and explain if Jordan's current political regime congruent with the values, beliefs, and attitudes of Jordanian elites. The two hypotheses were tested in terms of significant differences between the means of the three groups of elites as well as the congruence between the regime and elites' political culture. The following are the four research questions and their two hypotheses:

Q1: What is the political culture that consists of Jordanian elites' values, beliefs, and attitudes towards the processes of liberalization, democratization and political, social, and economic developments in the Hashemite Kingdom of Jordan? 
Q2: Are there significant differences among the values, beliefs, and attitudes of the three groups of Jordanian elites?

H1: There are significant differences among the values, beliefs, and attitudes of the three groups of Jordanian elites towards political, social, and economic development.

Q3: What are the values and beliefs of Jordanian elites concerning the center of power in Jordan?

Q4: Is Jordan's current political regime congruent with the values, beliefs, and attitudes of Jordanian elites?

$\mathrm{H} 2$ : The regime is congruent with Jordanian elites' political culture.

The following sections in this chapter illustrate and describe the data collection and analysis methods used in this research. The main data collection method for this study was a face-to-face survey, administered to three different groups of Jordanian elites. This data was collected during 2008, during the time I received the Sasakawa Young Leaders Fellowship Fund (SYLFF) scholarship and stayed in Jordan for one academic year. This chapter describes the following:

- Study population

- Sample selection procedure

- Survey administration procedures

- Survey questionnaire

- Data analyses approaches for both quantitative and qualitative data 


\section{Study Population}

The target population of this study is the elites in Jordan. As noted in the previous chapter, according to elite theorists, (Berry, 1989; Parry, 2005; Putnam, 1976; Tachau 1975) elites are a small minority that plays an exceptionally influential part in political, social, and economic affairs. The target population of this study is therefore, the most influential minority in the Jordanian society. The political elites include the highest governmental officers and policymakers, who currently occupy, or have occupied in the past, the highest rank positions in the government and public sector. The elites also include business owners and corporate CEOs from the Jordanian private sector; considered as economic elites. An assortment of intelligentsia members of thinkers, writers, and professors, as well as members of the prominent tribal groups are also covered within the study and considered as social elites. Traditionally, the King granted several social and economic elites high rank positions in the government, due to their prominent social and economic statuses. Therefore, frequently many political elites are also social or economic elites.

In this study the three groups of elites are identified based on the following titles and positions:

1.) The political elite group, consisted of those who held high governmental positions such as, former and present Prime Ministers and Ministers, former and present Parliament representatives from both the lower and upper houses, political party leaders, and the under secretaries, trustees, administrative executives, and general managers of ministries and public agencies. 
2.) The social elite group consisted of secretary generals of unions and syndicates, leaders of nonprofit organizations, and members of the intelligentsia, such as university professors and writers.

3.) The economic elite group included the private sector business owners, who are CEOs and chairs of companies that contain large numbers of shareholders.

\section{Sample Selection}

The study sample was selected with the help of the Center for Strategic Studies (CSS) at the University of Jordan. The CSS is a well-known research center highly recognized among University of Jordan's professors that have been providing the government bodies and organizations in the public and private sectors with high-impact social, economic and political studies on the local, regional, and foreign policies in Jordan. Since Jordan's democratization process was initiated in 1989, the CSS has been expanding its scope of activities to include planning and research in several other relevant fields. Their research areas include political pluralism, gender studies, and democratic governance. In addition, the CSS works in cooperation with other research centers in the region to present a variety of political, economic, socio-economic and environmental analyses. Projects by CSS are accompanied by extensive efforts to develop and launch an Arab academic and research network (http://www.jcss.org). 
This center (CSS) was regarded as a reliable information source for researchers and decision-makers by Sasakawa Young Leaders Fellowship Fund (Sylff) organizers, who grant researchers scholarships to conduct data collection. The University of Jordan (UOJ) is a Sylff institution; thus, when I arrived to Amman, Jordan, I contacted the Sylff representative professor at UOJ, who introduced me to the CSS researchers. The center is located on campus and provides researchers and students with academic training, access to its library, and allows them to participate in workshops and activities.

Through CSS, I obtained a list of Jordanian elites' names that were used as a sampling frame for selecting the sample for this study, containing six-hundredsixty-eight (668) names. This list contained names of prominent political, social, and economic figures in the Jordanian society. However, the social and economic prominent figures can be granted political positions by the King. For instance, many tribal influential figures serve as Prime Ministers and Ministers if chosen by the King to fill these positions. These social and economic figures would in most cases identify themselves as political rather than social or economic elites. This offers an explanation as to why the number of political elites is doubled and why the proportions of the three groups of elites in the sample are: 65:23:12 (political: social: economic).

Moreover, the appointment of Prime Ministers by the King is usually confined to a pool of a few prominent influential tribal figures, where in some cases some Prime Ministers have served in more than three governments. Similarly, the political elite stratum includes certain prominent figures that filled a variety of positions and are still 
part of the government, including elites with more than one affiliation according to the three elite categories, yet identify and introduce themselves as political verses social or economic. The sample of this study is affected by all these reasons. In addition, according to CSS researchers, the sample is representative, as the disproportions in the sample are a reflection of the disproportions in the population.

A systematic random sampling method was used to select one hundred (100) study participants. A table of random numbers was used to locate the initial sampling point. The following describes steps taken during the sampling procedure.

The total numbers of the list of names (668) were divided by the sample size (100). The derived number $668 / 100=6.68$ (approximately 7 ) provided the justification for the researcher to select every $7^{\text {th }}$ person from the randomly identified starting point.

The number 3 was selected, picked randomly between 1 and 10, in order to locate the initial sampling point. The selection process began by highlighting every third name as the starting point for the count, and every seventh name down the list was then highlighted for selection until achieving a list of onehundred-ten (110) names.

The extra ten names were selected and reserved for replacement purposes in case someone declined to participate in this study, or asked to be removed from the list of participants before or after the interview. Only one elite asked to be removed, and was replaced by one from those ten names. 
Using the contact information in the verified list of office addresses and phone numbers provided by CSS, I contacted each one of the hundred (100) people identified through the sampling procedure described above, by phone. The phone contact was made mainly to solicit their participation in the face-toface survey. After the elite who asked to be removed was replaced, all the contacted elites agreed to participate in the study.

\section{Survey Administration and Interview Procedures}

Initial phone contacts. Initial contacts with the study participants were made by phone to solicit their participation to the face-to-face survey. Prior to the phone contact, CSS staff members trained me to follow a certain protocol necessary for dealing with and talking to Jordanian elites. For instance, the Jordanian elites have certain designated titles endowed by the King. According to Jordanian protocol, it would be considered inappropriate to address the elites, who were designated by "His Majesty," without acknowledging their designation.

The main purpose of the phone contact was to describe the research and to introduce the researcher, develop a rapport with the study participants, solicit their participation to the face-to-face survey, and make appointments for conducting the interviews. Efforts were made to establish friendly and trustful relationships with the participants during the phone contact. The phone conversations began with a summary of the purpose of the study. In the 
conversations, I emphasized the academic nature of the study, assured confidentiality of the identity of the participants, and informed them of Portland State University's Informed Consent.

Elites were extremely concerned about their confidentiality, which was taken seriously due to their political environment. According to the blogs of Premium Data Processing \& Survey Research (http://www.sentenium.com/), confidentiality means only the researcher, who is conducting the survey, knows the respondents who are taking the survey, without any disclosure of that information. The notion of confidentiality and anonymity was raised and discussed with all interviewees prior to their participation in the interviews. Confidential research cannot be conducted; researchers have a duty to report on the findings of their research and they cannot do so if the data they collect is confidential. The researcher's duty is to report on the findings of the research; this duty cannot be fulfilled without revealing the collected data. Therefore, I ensured the interviewees to try my best to protect their identities through various processes designed to keep their identifiable information anonymous. So, all the potential participants, who were contacted by phone accepted to participate in this study, but their acceptance was conditional on guaranteeing them that their responses will not be linked to their names and identities.

During this phone contact, I discussed some key aspects of the Jordanian elites' power through their positions. We touched on the abilities of Jordanian elites through their influential positions in the public, private, and nonprofit sectors, and their role as intelligentsia. The confidentiality of identities was the most common concern emphasized by most elites. I assured them that this 
concern would be taken very seriously with complete understanding to their political environment and to the pressures coming from their authoritarian monarchical regime. Many elites were concerned about this study's association with any local or international media. I emphasized that although I had knowledge of the surveyed participants, the identities of the respondents, and any associated names within the information shared with me was in complete confidence. The participants were also noted that they would receive a copy of the "Informed Consent" in the Arabic language before beginning their interviews.

In addition, the participants were informed that this research was supported by a grant from Sasakawa Young Leaders Fellowship Fund (Sylff) for the students pursuing graduate studies. It was clarified that Sylff is not responsible for the content of this research. I also noted that CSS is providing assistance to this research with the identification of the study participants. At the end of the phone conversation, all potential participants accepted to participate in this study, under the condition that I guarantee the confidentiality of their names and identities.

The initial phone contact provided the study participants a chance to ask questions about me and other concerns they have about the study. This step turned out to be an important part of the data collection that had a psychological impact on elites. It allowed those who occupy the senior positions to stay in control of the interview situation and gave them the opportunity to ask questions 
to maintain this sense of control. It also removed any concerns about the research prior to the face-to-face survey/interviews.

Written and oral wording of survey questions. Initially, the survey questions were sketched in English with emphasis on their linkage to the objectives of the study. However, after consulting with question-crafters from the CSS, the questions were translated into standard Arabic. The design and wording of the questions followed the standardized survey questionnaire of Converse and Presser (1986) that stresses the effectiveness of keeping most questions short and choosing simple, clear, and precise vocabulary. According to Converse (1984), the wording was free of ambiguity and unnecessary adjectives and adverbs. Efforts were exerted while wording the questions in order not to choose any vocabulary that leads to assumptions. The consultation with the CSS question-crafters was important for the face-to-face questions during the interviews, in order to avoid the chatty, over-familiar language, and maintain professionalism and accuracy. In addition, consulting with the CSS question-crafters was essential for the appropriateness of the language that was used to address prominent political, social, and economic interviewees in the Jordanian government and society.

Face-to-face survey administration and interview. The face-to-face format was a suitable data collection approach for this study as it allowed me to elicit information from a group of former and present prominent elites. 
Questioning elites in a face-to-face setting led to collecting more accurate information and improved the quality of the obtained data. Whenever respondents' comments sounded elusive, irrelevant, or contradictory, I was able to ask follow-up questions to clarify the information. There were several reasons behind the elusiveness or irrelevance in elites' comments; first, as I learned from the local researchers at CSS, there is a tendency in the Jordanian media of falsifying any statistics on lagging behind situations on the social or economic levels in Jordan. In fact, the media proclamations reflect the official position of the government, a position that is complemented by the lack of accountability and transparency. Therefore, giving responses that contradict with this official stand can cause agitation, which drives some elites to evade from giving straightforward responses.

Second, Under the Jordanian monarchical system, there is a certain protocol for addressing ministers, under secretaries, chairs, and other high governmental officers. Each elite might have an additional title, which in formal settings he/she are addressed with. The additional titles are usually granted by "His Majesty" the King. For example, the Prime Minister is always addressed by "Ma'aleek” or "Your Highness," but sometimes the King might address a minister by "Ma'aleek" which makes it politically incorrect to address that particular minister without the prefix which he/she was granted by the King. The Jordanian under secretary is usually addressed by "Otooftak" or "Your Kindness," a chair must be addressed by "Sa'adtak" or "Your Honor," and a high governmental officer sometimes must be addressed by "Siyadtak" or 
"Your Excellency" before his/her name. The CSS question-crafters were consulted about the importance of including the additional titles in the orally repeated questions, such as "why, Sa'adtak, do you believe...?" or "how, Siyadtak, do you consider...?" According to CSS question-crafters these titles are important to be used while addressing most elites and might impact their reluctance verses willingness to answering the questions. Therefore, the additional titles were studied and added to all the face-to-face interviews, as well as while communicating with them over the phone. Learning titles was an essential step that took place prior to contacting any of the elites, as mistakes in addressing Jordanian elites could negatively affect the process of data gathering.

When respondents made elusive or irrelevant comments on questions pertaining corruption, or levels of poverty or unemployment, I repeated the question and challenged the succeeding answer by including statistics or other published facts within the question, which indicated my knowledge supported by evidential facts regarding the issue. This technique was useful to solicit answers that were more factual and direct. Thus, the face-to-face setting made it possible to use this approach and to collect more accurate responses and avoided a process of collecting politicized, terse, or generic media-based information and data. Finally, the face-to-face interviewing method minimized the "I do not know" and the "No response" answers.

Mail survey was not used for this study in order to avoid the discretion of the secretaries and office managers, who might forget, delay, or ignore the surveys. It was also not used in order to minimize the possibility of rejection to 
participate by projected participants, due to any misinterpretation or misunderstanding to the purpose of this survey. The uncertainty of the local postal system, according to its reputation among locals residing in the city of Amman, was another reason for not using the mail survey approach.

During the survey, strict attention was paid to the fact that this study was being conducted under an authoritarian monarchical system, and its participants were elements of the monarchical system. As VIPs of a monarchical system, the Jordanian elites had high expectations for receiving a favored treatment, which was expected in advance. Therefore, I learned the local protocols and formalities that met these elite's expectations to be treated with special care and courtesy.

At the beginning of the face-to-face survey session, all interviewees were handed a copy of the Informed Consent Form translated into Arabic (see Appendix C for an English copy of the Informed Consent Form). I reemphasized the information already shared over the phone prior to our meeting, and insisted on the academic purpose of this study. The procedures required for data collection by Portland State University were also communicated. In addition, in order to minimize any hesitations that might occur, the confidentiality factor was further stressed. Through this agreement, due to the sensitivity of the interviewees' positions and potential jeopardy of what their answers may lead to, the request for their signed endorsements was discarded, as many of elites' feedback expressed the question of how truly anonymous their identities would remain. 
Subsequently, each interviewee was handed a printed hard copy of the Arabic Informed Consent Form for their reference, and the survey questionnaire, so he/she could read and follow each question during the interview process. All interviewees saw the survey questions for the first time at the face-to-face interview session.

High response Rates. As mentioned in the Literature Review, the reasons behind the high responding rates to this study can be explained by the participation of Jordanians in other studies, such as their participation in the Arab Barometer study, which was conducted in Jordan in 2006 and had a poll that included a sample of 1200 residences and had a high response rate of $95.4 \%$, as only 55 households refused to take part. Likewise, this study has a high participation and responding percentages among its selected elites. The high responding rates are a precursor for the researchers in the field to overcome the previous research limitations. The ability to gather an abundance of data and to defeat different research limitations is an optimistic indication that heralds a new era for the researchers, who are concerned with filling the gap in the literature and for those who are interested in understating the centers of influence and elites in the Middle East.

Mishler (1986) defines the interview as a pattern of interaction in which the role relationship of interviewer and respondent is highly specialized; it has specific characteristics that is affected by the purpose and character of the interview (p. 8). In accordance with this definition, the authoritarian monarchical political culture and environment of Jordan had a vivid impact on the character of these interviews; hence, the researcher's familiarity with the political culture and environment of the country and the interviewees was 
substantial for achieving the purpose of these face-to-face interactions. For instance, during the interviews it was important to sense the sensitivity of certain political issues and to pay special attention to respondents' actions and reactions to certain subjects. The communication during the interviews was consistent with these actions and reactions, which kept the flow of collecting clear and valid responses with less skepticism and few hesitations.

Despite the regime's recent endeavors of allowing some freedom of opinion, several elites remained reluctant or hesitant to answer a number of questions that asked about the King's absolute powers, authoritarianism, or corruption, either because they did not believe that the regime was serious in its endeavors of implementing change, or because they were loyal to the regime. By the same token, lack of knowledge about certain questions' subjects, or the used terminologies, being unaccustomed to speaking up, or remaining skeptical about confidentiality were among the reasons that were taken under consideration, because they caused reluctance and hesitation to give direct responses.

I directed several follow-up questions to the respondents who showed negative reactions to any of the questions. I used several different approaches in a feedback form, such as repeating, restructuring, explaining, or delineating the original question. In fact, the face-to-face settings made it possible to use these approaches, as it allowed me to both hear and see the verbal and non-verbal responses and reactions. Thus, the setting enabled me to interfere whenever respondents portrayed negative reactions and to use different approaches that suited the different situations. As a result, I gathered an abundance of candid 
information and more accurate data since the respondents had adjusted it during the interviews.

For example, some questions were rephrased to include explanations or delineations about the question's subject or to explain the terminology. In some cases responses or comments were repeated, suggesting to the respondents that I had not understood what they meant, which triggered them to clarify their response and provided me with a more accurate one. Occasionally, there were some awkward situations when respondents would say or make irrelevant comments on questions, and where certain patterns of techniques were employed in response. For instance, my reactions to these situations were hypersensitive, as some elites, whose political environments were influenced by their positions in the society and/or the government, had to be treated carefully by using an indirect rephrasing of the question. The indirect rephrasing of the question was a successful technique, as it avoided any embarrassment to these respondents. Yet, whenever the questions needed to be rephrased, effort was made to maintain the intent and integrity of the original questions.

Other situations were treated differently, for example, if the respondent used nonverbal body language or gestures to answer a question instead of making a verbal response, I recorded the response accordingly. Also, in some cases the respondents answered sarcastically with either a "yes" or "no," while they have nodded their heads to mean the opposite, the responses were recorded to reflect the true intentions of the respondents. 
Additionally, when the respondents showed hesitation due to a question regarding the King's absolute powers, authoritarianism, or some newly enforced laws to eliminate corruption, it was noted that they were still skeptical and doubtful about confidentiality. I dealt with these cases by reassuring them that their confidentiality will be preserved; however in most cases, rephrasing the question was still necessary to solicit an answer. In this case, the question was reworded orally by framing it more broadly after reading it from the survey. Generally, verbally rephrasing the written question allowed the opportunity to ask the same question indirectly, by providing specific scenarios and examples, which gave the interviewee the confidence in answering the question, implying the same answer to the directly stated written question. Once an answer was provided from the indirect rephrased situational approach, I reverted back to the direct survey question and indicated parallelism in the question and answer discussed, which at this point, the respondent confirms.

In addition, personal family relations have played an important role in facilitating the gathering of data. The success behind the initial phone calls with potential participants and their acceptance to participate in the face-to-face interviews was in part due to the researcher's family name and relations. As a Middle Eastern country, Jordan has a culture that values the concept of family honor. For instance, expectations such as having low participation levels among elites and collecting brief, "no," or "I do not know" responses were overridden. Elites' perceptions of the quality, worthiness, and respectability of the researcher and the data gathering process relative to this study were further affected by this 
factor. Particularly, the researcher's family relation with Dr. Rima KhalafHunaidi, the Executive Secretary for United Nations Economic and Social Commission for Western Asia (ESCWA); listed in the Financial Times among the top fifty people who shaped the decade. She held several high-ranking ministerial positions in Jordan, including the Minister of Industry and Trade (1993-1995); the Minister of Planning (1995-1998); Deputy of Prime Minister and Minister of Planning (1999-2000); Assistant Secretary-General and Director of the Regional Bureau for Arab States (RBAS) at the United Nations Development Program (UNDP) from 2000 to 2006; and she has also served as the Chairperson of the Advisory Board of the United Nations Democracy Fund (2006-2007). These prominent positions held by Dr. Khalaf-Hunaidi directly strengthened the researcher's position and had a positive impact on the data gathering process.

\section{Survey Questionnaire}

A survey questionnaire with thirty-five questions, including both closedended and open ended-questions, was developed for this study (see Appendix C for the survey questionnaire). The questions in this survey questionnaire were designed to assess respondents' political environment, and to collect data that would address the aforementioned two research questions of this study.

The survey questions were designed to collect data about the respondents' perception of the political system, culture, and environment of Jordanian elites. This set of questions provided me with a set of standardized and structured 
quantitative data. On the other hand, the open-ended, free-response questions led to an abundance of qualitative data. The open-ended questions triggered the respondents to give more information and elaborate on the questions in their own words. In addition, the open-ended questions gave me an opportunity to ask follow-up questions for clarification and elaboration.

In designing this survey questions the political environment of the respondents was taken into consideration. By following up a closed-ended question with an open-ended question, allowed the respondents to elaborate and explain their answers when the question touched on the sensitive issues in the Jordanian politics. Appendix C is the English version of the survey form.

The survey questions were constructed to assess 1.) values, 2.) beliefs, and 3.) attitudes. In order to differentiate between the three types of questions of the survey, the definitions of values, beliefs, and attitudes according to Sheibe's (1970) theory were considered. As previously mentioned in the literature review, each of the three has different attributes, which affected how each question was differentiated from the other. For example, when the question asks about "what is good," it is a value question; as how "good" something is, or how "good" a matter is to a person is a means of value to them specifically. When the question asks about "what is true," it is a belief question. The belief system is based on how much truth a person thinks there is in what he/she believes in. Finally, when the question asks about how the person views, thinks about, or did/will do towards a specific matter, it is an attitude question. Accordingly, the questions of the survey were classified and labeled. 
Based on Sheibe's theory, the three types of survey questions were labeled and are displayed in the three following tables (Table 3.1, Table 3.2 and Table 3.3). The first table of the closed-ended/values questions is preceded with more explanations on how these questions were labeled.

Closed-ended 'value' questions. Values are identified as empirical elements in human behavior that arise out of human experience, invoked in social interaction to evaluate the behavioral goals or modes of action; thus became mainly defined as social norms, or as attitudes anchored in groups of norms and assumed to be central to the cognitive organization of the individual and to serve as a basis for the formation of beliefs, opinions, and attitudes (Hutcheon 1972, Rokeach 1970, 1973).

In reference to all these theories, question (103), as a ranking question, was designed to investigate the importance of certain values to respondents; the question of identifying oneself with an ideological affiliation indicated how much this person values the characteristics of this ideological affiliation and thought of it as 'good.' Question (108), asked about the effectiveness or the goodness of a particular law; and question (112) asked about the suitability of one out of four political systems, indicating which system is the most valuable or suitable according to the respondents. Question (115.a) rates the support of women's participation across the three fields of development. Question (117) defines elites' reason for lobbying, indicating how much they value lobbying. Question (121) results express how elites value the campaigning culture during parliamentary elections, particularly regarding campaign mottos, and vision and 
mission statements. Finally, question (129) inquires about elites' affiliations

with nonprofit organizations, and if the activities of nonprofits were considered

as a value to them, or not. The measurement of values in this survey follows the

ranking and rating model of Alwin,and Krosnick (1985). See (Table 3.1) below

for the closed-ended value questions:

Table 3.1 Closed-ended 'Value' Questions

\begin{tabular}{lll}
\hline Q\# Q. Type & Q. Structure \\
\hline
\end{tabular}

103 Value How would you rank the following values in terms of their

importance to the reformation and the current development policies?

$(1=$ Extremely unimportant; 2 = Unimportant; 3 = Somehow important;

4 = Important; 5 = Extremely Important)

105 Value Describe yourself ideologically:

1. Liberal

2. Independent

3. Conservative

108 Value

How do rate the effectiveness of the 'declaration of liability' law to ensure accountability and transparency?

1. Extremely ineffective

2. Ineffective

3. Moderately effective

4. Effective

5. I don't know

6. No Response

112 Value The following are models for political systems of some countries in the Middle East. Pick the most suitable for Jordan and rate its suitability on the below scale from 1-6:

$(1=$ Not suitable $; 2=$ Somewhat suitable; $3=$ Suitable $; 4=$ Very suitable; $5=$ don't know; $6=$ No response):

1. Parliamentary system that allows the nationalist, Islamic, and left and right wing parties to compete in transparent and impartial parliamentary elections 
2. Parliamentary system that allows only the Islamic parties to compete in parliamentary elections

3. Authoritarian system controlled and ruled by an ultimate power and authority without consent or consideration for opposing views

4. A system ruled by Islamic Shari'ah without any type of elections or political parties

115.a Value

Rate your support or opposition to women's participation in the political, social, and economic development:

$(1=$ Strongly oppose; 2 = Somewhat oppose; 3 = Moderately support; 4 $=$ Strongly support; $5=$ don't know; $6=$ No response)

117 Value What were your reasons for lobbying?

1. To implement important changes

2. To pursue my democratic values

3. To support pluralism

4. To participate in policymaking

5. All the above

$121 \quad$ Value

How do you describe the mottos, mission and vision statements of political parties and the parliamentary election campaigns in Jordan?

1. Appealing and engaging to most Jordanians

2. Appealing and engaging to some Jordanians

3. Neither appealing nor engaging

4. Used as campaign propaganda

5. I don't know

6. No response

129 Value Do/did you have an affiliation with any of the following nonprofit or civic organizations?

Closed-ended 'belief' questions. Scheibe (1970) defined the belief

system by a set of functional disposition, nature, or character; beliefs are the implicit expectations concerning what leads to what (p. 39). Accordingly, 
political beliefs reset the culturally defined goals for political processes;

therefore they play a major role in determining the operation of the political

process. This group of questions was categorized as belief questions, as they

asked about "what was true." See the closed-ended belief questions in the below

table (Table 3.2):

Table 3.2 Closed-ended 'Belief' Questions

Q\# Q. Type Q. Structure

101 Belief Do you think you currently have or have had any impact on policymaking in Jordan?

$$
(0=\text { No; } 1 \text { = Yes })
$$

102 Belief

As a policy maker, or as someone who has/had an impact on policymaking, to what extent do you believe that your political goals are/were achieved?

1. Not at all

2. To a little extent

3. To a moderate extent

4. To a large extent

5. Don't know

6. No response

104 Belief How would you rate the current administration's performance on implementing the following reforms?

$$
\begin{aligned}
& (1=\text { Very poor } ; 2=\text { Poor } 3=\text { Standard } ; 4=\text { Good; } \\
& 5=\text { Very good } ; 6=\text { Excellent })
\end{aligned}
$$

110 Belief Institutionalization is a required stage in administrative development. Do you think the institutionalization process in Jordan has been successful?

$$
(0=\text { No; } 1=\text { Yes })
$$

118 Belief "Pluralism" is the participation of all political forces in governance. Does pluralism exist under Jordan's authoritative monarchical political structure? 


$$
(0=\text { No; } 1=\text { Yes })
$$

125 Belief

126 Belief

128

130

Belief

132

Belief

134.a Belief

Belief
Is it true that parliament members stay connected with their constituencies after the elections?

$$
(0=\text { No; } 1=\text { Yes })
$$

In what way do you think tribalism impacts the political and social developments in Jordan?

1. Positive

2. Negative

3. Positive at times and negative at others

4. Don't know

5. No response

'The values, beliefs, and attitudes of Jordanian elites are influenced by their tribal affiliations;' how much do you agree with this statement?

1. Strongly disagree

2. Disagree

3. Agree

4. Strongly agree

5. I don't know

6. No response

The government interferes in the affairs of nonprofit organizations.

1. Never (Go to Q. 132)

2. Always

3. Sometimes

4. Don't know (Go to Q. 132)

5. No response (Go to Q. 132)

Do you think economic and political developments should go together or should one of them take precedence in order for the other to be achieved?

1. The economic development should take precedence

2. The political development and civil liberties should take precedence

3. Both developments should occur simultaneously

4. Neither, both are imposed by external powers

5. Don't know

6. No response

Do you believe the Prime Minister should be elected from the Parliament majority?

$$
(0=\text { No; } 1=\text { Yes })
$$


Closed-ended 'attitude' questions. An attitude, according to Rokeach (1970), is relatively an enduring organization of beliefs around an object or situation predisposing one to respond in some preferential manner (p. 112). So, it is a person's feeling towards an object or event, accompanied with an evaluation of this object or event. The components of an attitude, according to several researchers are emotional, cognitive, and behavioral, which makes individuals react differently towards any situation. According to Allport (as cited in Rockeach, 1970), different people react differently to the same situation (p. 112). Also, elites' attitudes, according to Putnam (1971), can be examined through investigating their opinions on current political topics to know how they view matters, what they favor, and how they think about certain issues in order to assess their attitudinal press in different situations (p. 651-2).

In other words, 'attitude' is usually assessed by defining its direction and measuring the intensity of the direction. For example, if the direction is on the positive side, that would respond to the 'what' factor in Putnam's theory; however, that is not a full assessment since we can still assess the 'how' factor; or how much positivity or negativity the attitude has by defining the intensity of the direction. This is how attitudes were measured in the analysis of this study; by their directions and intensities. The following table, (Table 3.3) displays all the closed-ended 'attitude' questions from the survey questionnaire: 


\section{Table 3.3 Closed-ended 'Attitude' Questions}

\begin{tabular}{lll}
\hline Q\# Type & Q. Structure
\end{tabular}

106 Attitude On a scale of 1-6, how do you favor the implementation of the following reforms by the Jordanian government?

$(1=$ Very unfavorable; $2=$ Unfavorable; $3=$ Neutral;

$4=$ Favorable $; 5=$ don't know; $6=$ No response)

107 Attitude In Jordan the relationship between the public and private sectors and civil society in the delivery of public services is lagging behind.

1. Strongly disapprove

2. Uncertain

3. Strongly approve

116 Attitude Have/had you ever practiced formal or informal lobbying to influence members of Parliament?

$$
(0=\mathrm{No} ; 1=\text { Yes })
$$

119 Attitude

Are you affiliated with a political party?

$$
(0=\text { No; } 1=\text { Yes })
$$

124 Attitude The one-person, one-vote law empowered tribalism at the expense of the partisan structure of the parliament and weakened political party and Parliament institutions. Please indicate your level of agreement:

1. Strongly disagree

2. Disagree

3. Agree

4. Strongly agree

5. Don't know

6. No response

Open-ended 'value' questions. Questions (109) and (120) are the only

two open-ended value questions. Question (109) is designed to gather free information on elites' values concerning the administrative development reform. 
It asks them to mention the three most important administrative reforms that enhance efficiency, effectiveness and productivity in all their organizations.

In question (120), the respondents are indirectly asked about their political party affiliations. This indirect design is suitable for this type of questioning, due to the negative heritage of political party affiliation in Jordan. Therefore, the focus of the question is on the most dedicated political party leadership, rather than focusing on respondents' personal affiliations.

The indirect design is more encouraging and it triggers respondents in some situations to provide more information. The coding and analysis of the open-ended questions follows the model of Boyatzis (1998) of thematic analysis and the development of codes. The below table, (Table 3.4) displays the two open-ended value questions in the survey:

\section{Table 3.4 Open-ended 'Values' Questions}

\begin{tabular}{lll}
\hline Q\# & Q. Type & Q. Structure \\
\hline 109 & Value & $\begin{array}{l}\text { Can you mention the three most important administrative reforms } \\
\text { that would lead to higher efficiency and productivity levels? }\end{array}$ \\
& & \\
120 & Value & Which political party, do you think, has most dedicated leadership? \\
\hline
\end{tabular}

Open-ended 'belief' questions. By responding to the two open-ended questions (113) and (114), the respondents explained in their own words how the political system, which they had chosen in a previous question, enhances the 
democratization and development processes. So, the two questions examined elites' beliefs in their chosen political system by asking them how this suitable political system would solve Jordan's political problems that impede democracy and political and administrative developments. At the same time, how they think this suitable political system would eradicate poverty and lower the unemployment rate.

By the same token, questions (115.b), (122), (127), (133), (134.b) were designed to gather more data on preceding closed-ended questions. A lot of data was gathered from these open-ended questions on several issues, such as women's political, social, and economic participation, political party activities, tribalism impact, and the economic and political developments. The open-ended design of these questions gave the respondents good opportunities to explain and elaborate on their structured responses from all those questions. Following some of the closed-ended questions with open-ended ones suited the political environment of the respondents and led to collecting more in depth information. The below table, (Table 3.5) displays all the open-ended belief questions of the survey questionnaire: 


\section{Table 3.5 Open-ended 'Belief' Questions}

\begin{tabular}{lll}
\hline Q\# & Q. Type & Q. Structure \\
\hline 113 & Belief & $\begin{array}{l}\text { Can you mention how your choice of political system would } \\
\text { enhance democratic governance and accelerate the political and } \\
\text { administrative developments in Jordan? }\end{array}$ \\
$114 \quad$ Belief & $\begin{array}{l}\text { Can you mention how your choice of political system would } \\
\text { enhance the country's economic development, improve living } \\
\text { standards in the suburbs, and find solutions for the high } \\
\text { unemployment and poverty levels? }\end{array}$
\end{tabular}

115.b Belief If you support women's participation in any of the three fields, why do you think women in Jordan are lagging behind?

122 Belief What are the reasons behind the weakness of political parties in Jordan?

127 Belief Why?

133 Belief Why do you think this is a better development plan for Jordan?

134.b Belief Why, or why not?

Open-ended 'attitude' questions. Questions (111), (123), (131), (135)

were preceded by closed-ended questions that asked about the

institutionalization process in Jordan, political party laws, and civil engagement and NGOs' activities. As open-ended questions they resulted in gathering more detailed data on the attitudes of the respondents. The free responses on the above 
issues enriched this data gathering with more information. Open-ended attitude questions would help the analyses, because the collected responses would be supplemental for identifying the problems and suggesting solutions.

To wrap up, the final survey question was designed to collect free responses and information about elites' views on how they see the practice of democracy in Jordan. Hence, it is considered an attitude question, as it investigated elites' opinions on a current political topic, which is the democratization process. This question contributed in figuring out how Jordanian elites view their democratization process, whether they favor it or not, and how they think about it. In its design, this question aims to assess elites' attitudes during this transitional period by triggering them with a definition for real democracy and asking them about the democratization process in their country. As shown in the below table, the question underlines the main characteristics of democracy, which are still hindered by the regime, such as the empowerment of citizens; practicing all freedoms and citizens' rights; having a rule of law system; and the occurrence of regular, competitive, transparent, and fair elections.

With their own words, the respondents answered this question by giving free responses on how they viewed democracy. They discussed their feelings and thoughts, and how those feelings were directed. Designing this question as a final open-ended question posed as a wakeup call for most respondents, providing them with an opportunity to have more realistic attitudes; particularly those who remained skeptic. 
In their own words, the respondents defined the directions and the intensities of their attitudes towards the subject of this question, which bundles up all the other issues that the survey questions inquired about earlier. So, this final question made respondents aware of the void they might have previously created when responding unrealistically to some questions. Finally, this question highlighted the gap between reality and the rhetoric of government officials, which would be emphasized in the discussion section of this study. The following table, (Table 3.6) displays all the open-ended attitude questions:

\section{Table 3.6 Open-ended ‘Attitude’ Questions}

\begin{tabular}{lll}
\hline Q\# Type & Q. Structure
\end{tabular}

111 Attitude If not, what should the government do in order to achieve administrative development through the process of institutionalization?

123 Attitude Name three elements that would activate the party system and empower political parties.

131 Attitude Tell me about the government's interference in the affairs of nonprofit organizations?

135 Attitude Democracy is not merely a motto; it is a way of life that serves and empowers citizens under a rule of law system. It assures freedoms, protects citizenship rights, and guarantees the occurrence of regular, competitive, transparent, and fair elections while practicing the two freedoms of choice and press. According to the above definition of democracy, how do you view the practice of democracy in Jordan? 


\section{Data Analysis Procedure}

The collected data from the Jordanian elites through the face-to-face interviews were analyzed to address the two main research questions of this study. There were two types of analyses that were conducted in this study: quantitative and qualitative. The responses of the closed-ended questions were subject to a series of statistical analysis, while the responses of the open-ended question were subject to a qualitative thematic analysis.

Statistical analysis. All responses for the closed-ended questions were entered into SPSS version 19. After examining the descriptive statistics, a series of One-way ANOVA analysis were conducted to ascertain the differences in the values, beliefs, and attitudes among the three groups of Jordanian elites. Prior to the statistical analysis, the raw data was subject to a series of data cleaning and organizing processes.

Qualitative thematic analysis. Responses to the open-ended questions that were designed to gather elaborated information on the values, beliefs, and attitudes of Jordanian elites were analyzed using thematic analysis approach. Qualitative data analysis followed the following steps: segmenting, coding, thematic categorization, sorting, and identifying themes.

The first step, of segmenting data, according to Johnson and Christensen (2008), involves dividing the data into meaningful analytical units. First, by reading the gathered data carefully, such as the respondents' answers, notes, and 
comments; and second, by searching for specifics and meanings that lead to defining different meaningful units. The process of segmenting is important for data analysis because it facilitates the process of defining similarities, differences, and relationships among the gathered words, sentences, and paragraphs (p. 534). By applying the segmentation of data to all responses from open-ended questions, the raw data was filtered, segmented, and organized into themes. Some survey questions, for instance, are answered by three steps, such as [What are the reasons behind the weakness of political parties in Jordan? 1..., $2 \ldots, 3 \ldots]$; or, [State three elements that would activate the party system and empower political parties]. These questions gathered an abundance of information, and in order to be analyzed, they needed to be filtered by segmenting and organizing them into meaningful units. The filtering of data minimized repetitions, redundancy, and wordiness, and segmenting added articulation by creating divisions and subdivisions to the gathered data. Finally, the organization stage included arranging and systemizing the data to prepare it for the coding process.

The second process of qualitative data analysis involves coding. According to Johnson and Christensen, it is the process of marking segments of data with symbols, descriptive words, or category names; "codes are tags or labels for assigning units of meaning to the descriptive or inferential information compiled during a study," (p. 534). For instance, the analytical meaningful units that shared descriptive words or category names were compiled and labeled together. Therefore, the segmented data resulted in several categories of 
connotations, which were classified as the meaningful units, and each of these units were coded by certain descriptions or themes. The coding process for this study was originally done in Arabic language since both data gathering and note taking were done in the country's formal language. After these steps were accomplished a codebook was then established.

The codebook captured the whole range of the meaning of the numerical code assigned to the open-ended responses. Also, the codebook served as an aid for locating data. Since all the responses were gathered and written in the Arabic language, the coding was also done in the Arabic language.

During this thematic categorization process, the data is compiled and grouped in terms of meanings and gets labeled in themes. All the themes that stem from the same original theme have one core theme. So, each core theme has more than one subordinate theme. The core theme in the thematic categorization is the source theme, or (Theme 1); while (Theme 2), and (Theme 3) are the subordinate themes that spring or emanate from the core. First, the researcher reviewed all responses and identified key themes. These initial main themes were used as a starting point to code the open-ended responses (Theme 1). As the researcher analyzed the data, sub-themes under the larger categories of Theme 1 had emerged. These subordinate themes were captured as Theme 2 . When there were further subcategories under Theme 2, these themes were captured as Theme 3. Overall, the three levels of themes emerged, and were used to code the qualitative data. 
Once all the data coded by themes were entered into Microsoft Excel, it was sorted by themes. Sorting the data allowed the researcher to assess the frequency of each theme appearing in the open-ended responses. The table below is an example from the Excel spreadsheet. These responses were given by one of the respondents on this survey's open-ended questions. The table displays how the data was compiled and grouped into three levels of themes (Table 3.7):

\section{Table 3.7 Example from the Survey: Thematic Categorization: Core \&} Subordinate Themes

\begin{tabular}{|c|c|c|c|c|}
\hline No. & Question Category & Theme Level 1 & Theme Level 2 & Theme Level 3 \\
\hline 109 & $\begin{array}{l}\text { Administrative } \\
\text { Development }\end{array}$ & $\begin{array}{l}\text { Improving } \\
\text { Individuals' } \\
\text { Performance }\end{array}$ & Training & \\
\hline 109 & $\begin{array}{l}\text { Administrative } \\
\text { Development }\end{array}$ & $\begin{array}{l}\text { Applying the } \\
\text { Codes \& Conducts } \\
\text { of the Hiring } \\
\text { System }\end{array}$ & Merit System & KSAs \\
\hline 109 & $\begin{array}{l}\text { Administrative } \\
\text { Development }\end{array}$ & $\begin{array}{l}\text { Improving } \\
\text { Individuals' } \\
\text { Performance }\end{array}$ & $\begin{array}{l}\text { Incentives \& } \\
\text { Motivational Rewards }\end{array}$ & \\
\hline 111 & $\begin{array}{l}\text { Administrative } \\
\text { development }\end{array}$ & $\begin{array}{l}\text { Implementing } \\
\text { Reforms }\end{array}$ & Amending Statutes & $\begin{array}{l}\text { Compliance } \\
\text { With the } \\
\text { Constitution }\end{array}$ \\
\hline 111 & $\begin{array}{l}\text { Political/ Admin. } \\
\text { Development }\end{array}$ & $\begin{array}{l}\text { Enforcement of } \\
\text { Democratic Values }\end{array}$ & Equality & \\
\hline 113 & $\begin{array}{l}\text { Political } \\
\text { Development }\end{array}$ & $\begin{array}{l}\text { The } 1 \text { st political } \\
\text { system is } \\
\text { extremely suitable }\end{array}$ & $\begin{array}{l}\text { Holding Officials } \\
\text { Accountable }\end{array}$ & \\
\hline
\end{tabular}

114 Econ. Dev. \& Liberal Economic Privatization 
Liberalization

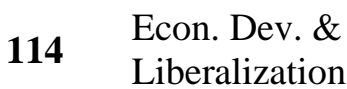

115.b Social Development

122 Political

Development

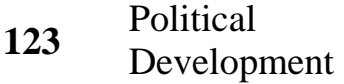

127 Social Development

131 Social Development

133

Econ/Political

Development

134.b Political Development

135
Political, Soc., \& Econ. Development
System

Significance Of

Work Value

Obsolete Customs

$\&$ Traditions

Centralized

Monarchical Political

System

Reinstatement of Institutional Freedom

Top Authority

Empowerment

Negative Impact

on Political

Development

Negative Impact

on Rule of Law

Great Interference

Security Reasons

Both

Developments

Simultaneously

The Prime Minister

Should Be

Appointed

Decreasing the

Authoritarian

Power
Impedes Fair

Elections

Weakens the Legal

System

Ensuring Security

Protective against

Globalization
Eliminating Security

Apparatus Discretion
Powerful Old

Guards \&

Security

Apparatus

Implementing

Change 


\section{Chapter 4: Results}

A one-way ANOVA design, cross tabulation, Chi-square, and thematic analysis were all conducted to evaluate the values, beliefs, and attitudes of Jordanian elites towards liberalization, democratization, and development. The result of the analysis will provide information for the researcher to answer the four research questions and respond

to their two hypotheses. The results provide analyses of data in four areas: description of elites' values, beliefs, and attitudes; variations among the three groups of elites' political culture; center of influence; and the regime's congruence with elites' political culture. Two hypotheses were developed and will be reported in this section. Qualitative data will also be included in this chapter followed by a discussion of the results.

\section{Statistical and Thematic Analysis}

This chapter presents findings from both analyses of open- and closed-ended questions that asked the respondents about the three domains of political, social, and economic developments. Quantitative and qualitative data analysis will be coupled together according to subject relevance, in order to answer the four research questions related to describing elites' political culture; variations among the three groups' values, beliefs, and attitudes; the evaluation of elites' political culture concerning the center of power in Jordan; and the congruence level between the regime and the values, beliefs, and attitudes of Jordanian elites. In addition, two hypotheses were developed. These hypotheses analyzed the data in the areas of differences among the three groups' political culture and the regime's congruence with elites' political culture. 
The two hypotheses are:

(H1: There are significant differences among the values, beliefs, and attitudes of the three groups of Jordanian elites towards political, social, and economic development).

(H2: The regime is congruent with elites' political culture).

The results of political development questions will be organized under the following topics: the type of political system and democratic governance; rights and freedoms; public sector reform; and political participation including: lobbying, political parties, and elections. Similarly, the main topics of social development consisting of women empowerment; tribalism; civic engagement; and economic liberalization will be the main topic of economic development.

Each one of these topics will represent more than one question from the survey, thus the reporting of results will be combined under the main abovementioned topics. The results of quantitative and qualitative data are reported in the following section. All survey questions are in Appendix C, Survey Questionnaire. Tables and figures are displayed in serial numbers in Appendix D.

\section{Political Development}

\section{Elites' Political Culture towards Jordan's Political System}

Elites' values in question (112) are assessed by using a 4-point scale (1= not suitable to $4=$ very suitable) of the suitability of the subsequent political systems for Jordan: 1) pluralistic parliamentary democratic; 2) parliamentary Islamic; 3) authoritarian 
system ruled by an ultimate power; and 4) religious non-democratic ruled by Shari'ah law. See Appendix D, Figures 1 and 2.

According to the cross tabulation results, $72 \%$ of all elites deem the pluralistic parliamentary political system "very suitable" for Jordan. A total of 5\% deem it "not suitable." However, $0 \%$ of all elites deem the authoritative monarchical political system, which represents the current political system in Jordan as "very suitable," while a total of 96\% of them deem it "not suitable;" see Appendix D, Table 5 for the N (\%) cross tabulation for the suitability of all four political systems, and Figures 1 and 2.

Most elites valued the suitability of the pluralistic parliamentary democratic political system, and did not value the other political systems, including the authoritative that is ruled by an ultimate power. By running one-way ANOVA tests, there are no significant differences between elites, indicating the following results, excluding the parliamentary Islamic that could not run the model: the pluralistic parliamentary system, $\mathrm{F}(2,97)=.224, \mathrm{p}=\mathrm{ns}$; the authoritarian ruled by an ultimate power, $\mathrm{F}(2,97)=.549$, $\mathrm{p}=\mathrm{ns}$; and the religious non-parliamentary, $\mathrm{F}(2,97)=.265, \mathrm{p}=\mathrm{ns}$. For more details on ANOVA, means, and standard deviations see Appendix D, Tables 1, 2, 3, and 4.

Thus, H1 is not supported, indicating no significant difference between the three groups of elites in the average means of their values, in terms of suitability of the four political systems. The current authoritarian monarchical political system is the opposite what the majority of elites value. This implication suggests that there is a lack of congruence between the regime and the values of its elites. The regime is not congruent with elites' political culture; therefore, the results do not support $\mathrm{H} 2$. 
As designated by the responses of the open-ended question (113), the majority of elites appreciate the pluralistic parliamentary democratic political system for its ability to present solutions for the problem of corruption in Jordan. Thus, the results assert that most elites value the pluralistic democratic political system as the most suitable for Jordan. See Appendix C for the Survey Questionnaire.

The enforcement of rule of law under the authoritative monarchical political system is rated in question (104.2) on a 6 -point scale $(1=$ very poor to $6=$ excellent). A concrete rule of law enforcement is fundamental for development, however the majority of elites believe that there is a "standard" rule of law enforcement by the Jordanian government is only a one.

The one-way ANOVA test indicated the following result: $\mathrm{F}(2,97)=1.94, \mathrm{p}=\mathrm{ns}$. There is no significant difference between elites. Thus, $\mathrm{H} 1$ is not supported. For more details see Appendix D, Figure 3 and Tables 6 to 8.

Most elites believed that the government's lack of seriousness in implementing reform policies remains the main reason behind Jordan's tardiness in the supremacy of rule of law. They criticized the consecutive Jordanian governments for their tardiness in implementing this reform, while ignoring the fact that they themselves are part of the current or any of the previous governments. The result indicates that there is congruence between the regime and elites' beliefs Thus, the result supports $\mathrm{H} 2$.

Democratic governance and the cooperation and coordination among the public, private, and nonprofit sectors were tested in questions (106.3), (106.4), and (107). The responses of the first two questions show elites' passive attitudes towards the 
coordination and collaboration among the three sectors; $57 \%$ of their attitudes are "neutral" towards the government's reform policies that ensure cooperation between the public and private sectors, and 50\% of their attitudes are "unfavorable" towards their government's implementation of reforms that ensure cooperation between public and nonprofit sectors. Similarly, 58\% remained "uncertain" while 39\% "strongly approved" of the question statement that "the relationship between the public and private sectors and civil society in the delivery of public services is lagging behind." Accordingly, the results of all three questions expressed traditional attitudes, conventional beliefs, and confirmed elites' cautious liberalism. See Appendix D, Figures 4 through 6 for more details.

The results do not support $\mathrm{H} 1$, as the two one-way ANOVA results indicate no significant difference between elites' attitudes: public/private: $F(2,97)=.089, p=n s$; public/nonprofit: $\mathrm{F}(2,97)=.962, \mathrm{p}=\mathrm{ns}$; and Chi-square result for coordination among the three sectors: $\chi^{2}(4, \mathrm{~N}=100)=2.44, \mathrm{p}=.654$. For more details see Appendix D, Tables 9 to 14.

The majority of elites' responses on the three democratic governance questions were "unfavorable," "neutral," or "uncertain." The higher percentages of unfavorable and nonaligned attitudes towards the government's reform policies to achieve democratic governance indicate that most elites agreed that democratic governance in Jordan is lagging behind. The results of these three questions are congruent with the regime, which supports H2.

Moreover, elites' beliefs in pluralism were assessed from their responses to the dichotomous question (118). A majority by $73.7 \%$ of elites believed that pluralism is 
absent in Jordan, versus $26.3 \%$ believed the opposite. Chi-square results do not indicate significance, $\chi^{2}(2, \mathrm{~N}=99)=2.33, \mathrm{p}=.312$, thus do not support H1. For more details, see Appendix D, Figure 8 and Tables 18 and 19.

Most elites admitted that there is an absence of real pluralism in Jordan, which indicates the regime's congruence with elites' beliefs; thus, the results support H2.

The dichotomous question (134.a) and the open-ended question (134.b) investigate elites' beliefs in electing the Prime Minister of Jordan, who is traditionally appointed by the King, as one of His prerogatives. The question also triggers responses touching on the absence of a Parliamentary majority in the Parliament structure. Elites' beliefs in this change were assessed, and the results of (134.a) were 51\% "no" and 49\% "yes" for the election of the Prime Minister. The majority of elites do not yet believe in making this change; see Appendix D, Figure 7 and Table 15 and 16.

H1 is not supported as Chi-square, as the results do not show significance, $\chi 2(2, \mathrm{~N}=100)=1.77, \mathrm{p}=.414$.

The majority of elites did not believe in the significance of this reform to the transitional movement. These unprogressive beliefs indicate that the majority of elites are approving of their regimes' policies. Accordingly, the regime is congruent with elites' political culture. Therefore, the results support $\mathrm{H} 2$.

Likewise, elites' elaborations on electing versus appointing the Prime Minister underlined their beliefs that "democracy in Jordan has not matured yet" or "not ready" for implementing such changes to its political system. The most frequent three themes in responding to the open-ended question (134.b) do not exemplify progressive beliefs. For more details on thematic analysis see Appendix D, Table 17. 
Finally for this section, elites' attitudes towards the seriousness of the democratization process in Jordan are assessed in the open-ended question (135). For details on the thematic analysis see Appendix D, Tables 20 and 21. The most frequent themes are displayed below:

Table 4.1 Qualitative Analysis of the Jordanian Democratization Process Deficiencies: Percentages of Elites' Attitudes

\begin{tabular}{lccc}
\hline Core Themes & $\begin{array}{c}\text { Political Elites } \\
(\mathbf{N}=\mathbf{6 5})\end{array}$ & $\begin{array}{c}\text { Social Elites } \\
(\mathbf{N}=\mathbf{2 3})\end{array}$ & $\begin{array}{c}\text { Economic Elites } \\
(\mathbf{N}=\mathbf{1 2})\end{array}$ \\
\hline Rule of law system & 42 & 14 & 7 \\
& $64.6 \%$ & $60.9 \%$ & $58.3 \%$ \\
Social change & 32 & 16 & 11 \\
& $49.2 \%$ & $69.5 \%$ & $91.6 \%$ \\
Political development & 27 & 11 & 6 \\
& $41.5 \%$ & $47.8 \%$ & $50.0 \%$ \\
\hline
\end{tabular}

The three core themes are substantial for achieving a successful transition towards democracy. The majority of political elites believe that Jordan still lacks for the rule of law system, while the social and economic elites believe that the democratization process is deficient because it lacks for a real social reform. The absence of the core themes represents the void in the democratization process in Jordan. In order to overcome this hindrance the Jordanian government must account for the implementation of rule of law, allowing social change to flourish, and encourage political participation and political development. 
The quantitative results for this section are summarized in the following table:

Table 4.2 Summary of Quantitative Data Analysis Results: Elites' Political Culture towards the Efficiency of the Political System

\begin{tabular}{|c|c|c|c|c|c|}
\hline & $\begin{array}{l}\text { Evaluating } \\
\text { Political } \\
\text { Systems }\end{array}$ & $\begin{array}{l}\text { Rule of } \\
\text { Law } \\
\text { System }\end{array}$ & $\begin{array}{l}\text { Democratic } \\
\text { Governance }\end{array}$ & Pluralism & $\begin{array}{l}\text { King's } \\
\text { Prerogatives/ } \\
\text { P.M. Election } \\
\text { vs. } \\
\text { Appointment }\end{array}$ \\
\hline $\begin{array}{l}\text { H1: } \\
\text { Significant } \\
\text { Difference }\end{array}$ & $\begin{array}{l}\text { Not } \\
\text { Supported }\end{array}$ & $\begin{array}{l}\text { Not } \\
\text { Supported }\end{array}$ & $\begin{array}{l}\text { Not } \\
\text { Supported }\end{array}$ & $\begin{array}{l}\text { Not } \\
\text { Supported }\end{array}$ & $\begin{array}{l}\text { Not } \\
\text { Supported }\end{array}$ \\
\hline $\begin{array}{l}\text { H2: } \\
\text { Congruence: } \\
\text { Regime with } \\
\text { Elites' } \\
\text { Political } \\
\text { Culture }\end{array}$ & $\begin{array}{l}\text { Not } \\
\text { Supported }\end{array}$ & Supported & Supported & Supported & Supported \\
\hline
\end{tabular}

\section{Elites' Political Culture towards Freedoms \& Civil Rights}

The question (101) measures elites' self-determination. Of those who believe in having self-determination, $90.9 \%$ said that they are able to impact policymaking, while only $9.1 \%$ said they do not. Chi-square results indicate significant differences: $\chi^{2}(2$, $\mathrm{N}=99)=.008, \mathrm{p}<.05$. For more details see Appendix D, Tables 22 and 23. 
Figure 4.1 Marginal means for elites' self-determination and liberty

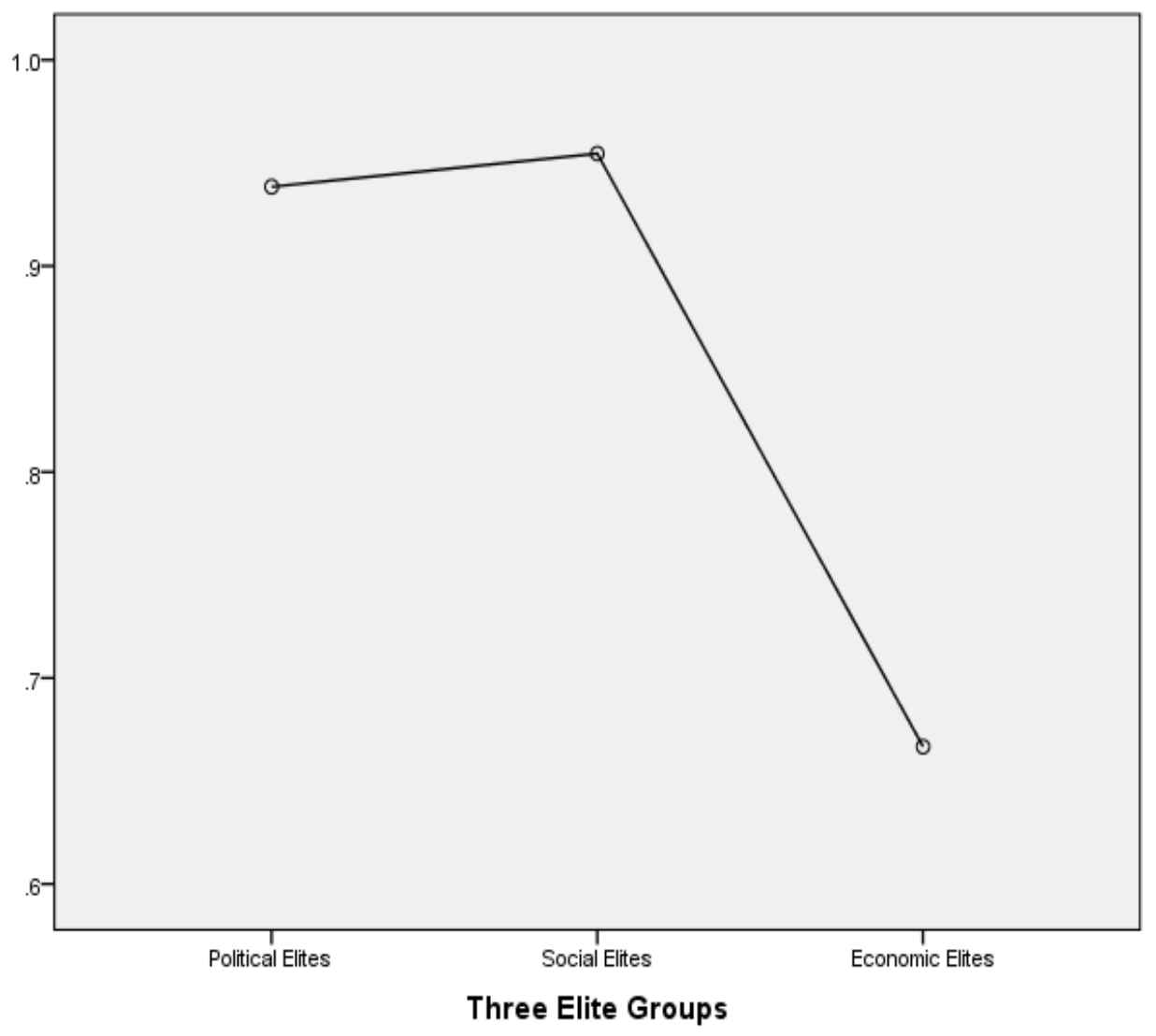


According to cross tabulation table, there is a significant difference between the social and political elites. Thus, the results support $\mathrm{H} 1$.

Elites' beliefs in their self-determination and abilities to participate directly or indirectly in policymaking are not unexpected under Jordan's authoritarian regime and government.

Therefore, the regime is congruent with elites' political culture and the results support $\mathrm{H} 2$.

Question (103.1) assesses the importance of the civil rights and freedom value in the making of reform policies on a 5-point scale (1= extremely unimportant to $5=$ extremely important). The two highest ratings on the scale of $15 \%$ "extremely important," and 43\% "important," sums up to 58\% of elites, and gives weight for this value in the making of policies.

All elites' values are similar according to one-way ANOVA indicating, F $(2,97)$ $=.194, \mathrm{p}=\mathrm{ns}$. This result does not support H1. For more details, see Appendix D, Figure 10, and Tables 25 and 26.

Thus, the value of freedom and civil rights is considered "important" by the majority of elites. These results of elites' political culture suit the nature of the Jordanian regime that is congruent with elites' value of freedoms and civil rights; thus the result supports $\mathrm{H} 2$.

The implementation of reform policies that allow having free access to information is assessed in question (104.3) on a 6-point scale $(1=$ very poor to $6=$ excellent). The results indicate that $72 \%$ of the ratings were distributed among the highest 
three ratings: 28\% "good," 35\% "very good," and 9\% "excellent." Further, one-way ANOVA indicates: $\mathrm{F}(2,97)=.056, \mathrm{p}=\mathrm{ns}$, with no significant difference between elites, rejecting H1. See Appendix D, Figure 11, and Tables 27 and 28 for further details.

There is no blocking of certain cites or social media in Jordan. The majority of elites believe that Jordan is relatively is a free country, and believe in the freedom of information; therefore, the results support $\mathrm{H} 2$.

The ideological affiliations are evaluated in question (105) on a scale of three ideologies: "liberal," "independent," and "conservative." The majority of elites, $61 \%$ described themselves as "liberal," 20\% “independents," and 19\% “conservatives." For the distribution of values, see Appendix D, Tables 29 and 30. Elites' responses reflect their liberal values ideologies.

Chi-square result: $\chi 2(4, \mathrm{~N}=100)=.032, \mathrm{p}<.05$. The results support H1. For more details and descriptive statistics see Appendix D, Tables 32 and 33. The significance was found between the political and social elites, as shown in the mean plot figure below.

Furthermore, the results indicate the importance of ideological freedom to elites. There is no coercion under Jordanian political system. Despite the endeavors of some influential elites to impose the ideology of "Jordan First," Jordanians remain free to affiliate themselves with other ideologies. This explains how the results indicated the high percentage of liberals among the respondents. The results support $\mathrm{H} 2$, as the regime is congruent with Jordanian elites' values. 
Figure 4.2 Marginal means for liberal, independent, \& conservative elites' ideological backgrounds with liberals being the highest

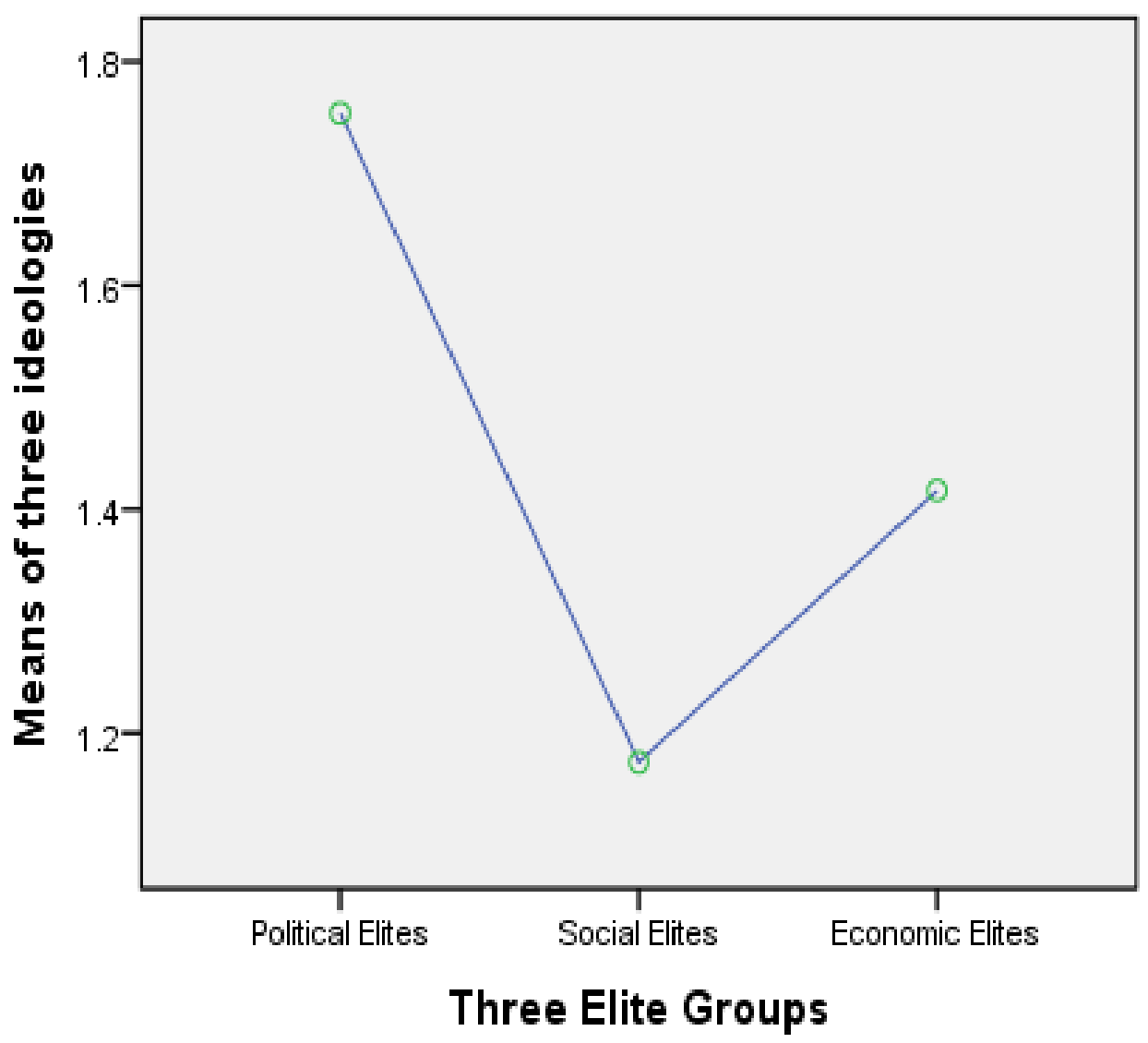


The results of the findings of this section are summarized in the following table:

Table 4.3 Summary of Quantitative Data Analysis Results: Elite's Political Culture towards Freedoms \& Civil Rights under the Jordanian Political Systems

$\begin{array}{llll}\text { Elites' Self- } & \text { Civil } & \text { Free } & \text { Freedom of } \\ \text { Determination } & \text { Rights \& } & \text { Access to } & \text { Opinion: } \\ & \text { Freedoms } & \text { Information } & \text { Ideological } \\ & \text { Value } & & \text { Affiliation }\end{array}$

H1:

Significant

Difference

Supported

Not Not

Supported Supported Supported

H2:

Congruence:

Regime with

Elites'

Supported Supported Supported Supported

Political

Culture

\section{Elites' Political Culture towards Public Sector Administrative Reform}

The following group of questions measure elites' attitudes towards the policies of public sector reform, by rating the government on its implementation of a series of reforms on a 4-point scale of ( $1=$ very unfavorable to $4=$ favorable). The first question (106.1) measures the implementation of reform policies that ensure transparency and accountability, and the second question (106.2) measures reforms of corruption control.

Cross tabulation results for transparency and accountability indicate a majority of $49 \%$ of attitudes that are "unfavorable" of this reform.

Besides, there is a majority of $52 \%$ of "unfavorable" attitudes towards the policy of corruption control. 
The one-way ANOVA results indicate a significant difference: $F(2,97)=5.21$, p $<.05$. Hence, a Chi-square was run to confirm this significant difference: $\chi 2(6, N=100)$ $=13.74, \mathrm{p}=.033$. There is a significant difference between the attitudes of political and social elites towards transparency and accountability. Thus, H1 is supported.

Also, one-way ANOVA indicates a statistical significant difference between the attitudes of the political and economic elites towards the policy of corruption control in question (106.2): $\mathrm{F}(2,97)=4.52, \mathrm{p}<.05$. By running Chi-square test the significance is confirmed: $\chi^{2}(6, \mathrm{~N}=100)=15.55, \mathrm{p}=.016$.

Therefore, $\mathrm{H} 1$ is supported. For more details on these two significant results see Appendix D, Tables 34 to 41.

The implementation of transparency and accountability and corruption control was not taken seriously by the government; thus the absence of laws that regulate them impaired the administrative and political development. The majority of elites demanded the government to be more decisive in corruption control. Although elites' criticism expresses reformist attitudes, it confirms the negligence of those who occupy the high incumbents in the Jordanian government. Therefore, the regime's negligence is congruent with elites' attitudes towards transparency, accountability, and corruption control. The results of all three questions support $\mathrm{H} 2$.

The following two figures of mean plots (Figure 4.3) and (Figure 4.4) display the differences between the means of elites' attitudes towards these two reform policies: 
Figure 4.3 Transparency and Accountability

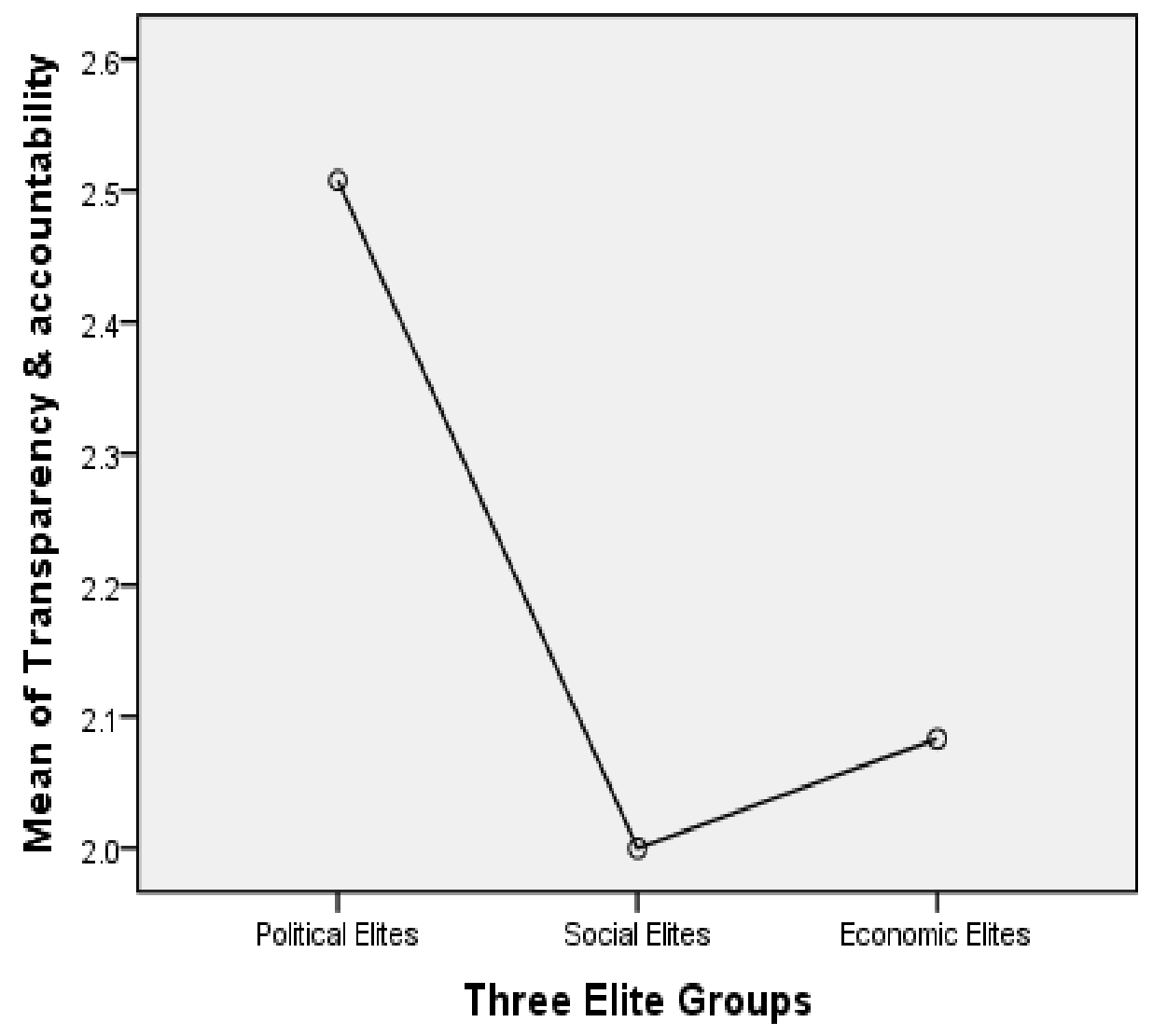


Figure 4.4 Corruption Control

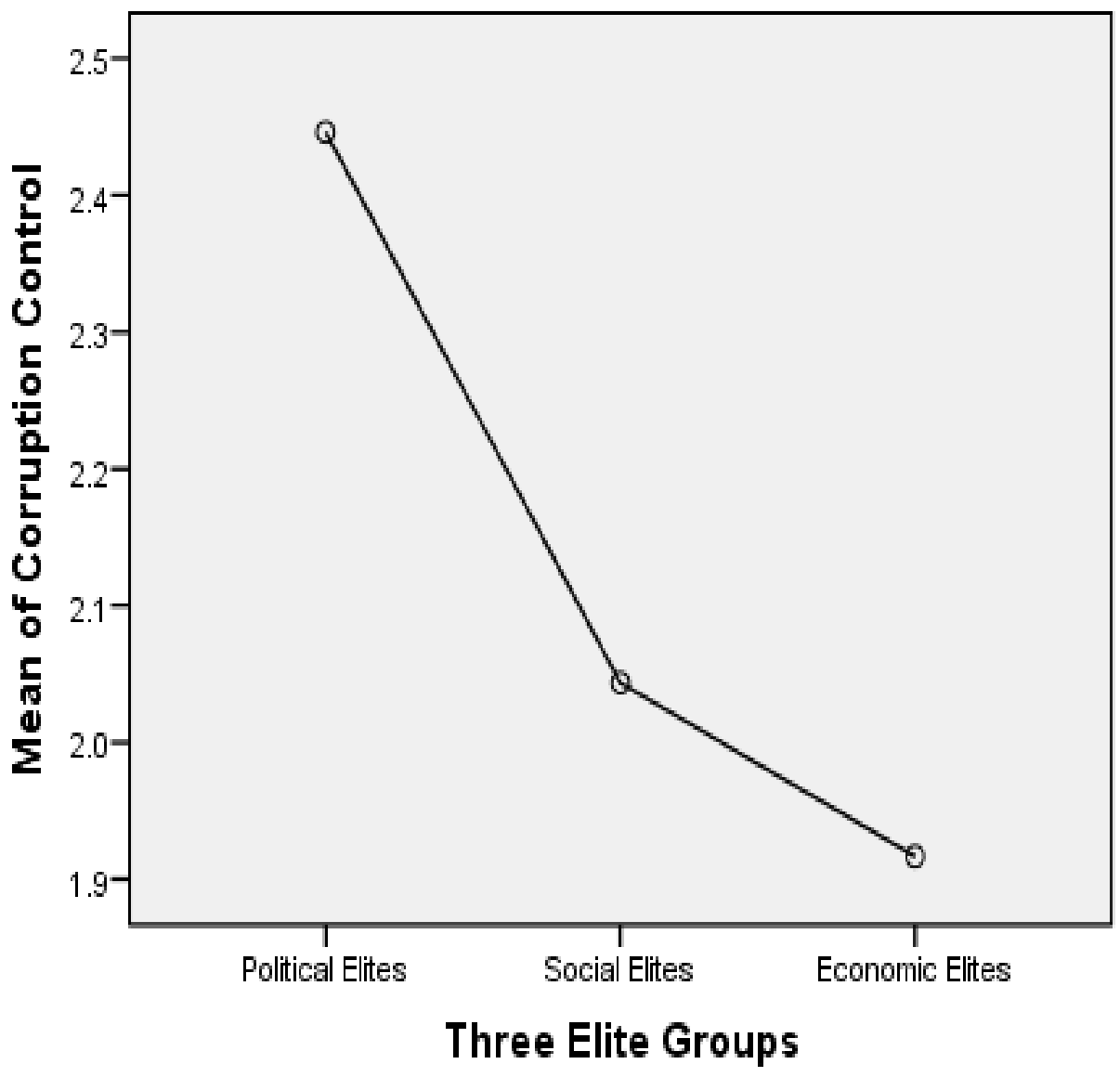


The result of question (106.5) indicates a majority of $43 \%$ of elites' attitudes that are "unfavorable" towards fighting nepotism. Besides, question (106.6) indicates a majority of $58 \%$ of "neutral" attitudes towards implementing a merit system. For more details see Appendix D, Figures 15 and 16, and Tables 42 to 45.

According to one-way ANOVA the result of fighting nepotism indicates: F $(2,97)$ $=.442, \mathrm{p}=\mathrm{ns}$. And for enforcing a merit system: $\mathrm{F}(2,97)=.229, \mathrm{p}=\mathrm{ns}$. Both results from both questions (106.5) and (106.6) do not support H1.

The nepotism in Jordanian public sector needs to be curtailed by enforcing a merit system, but the government's lack of seriousness in implementing reforms triggered elites to criticize their government for letting this problem prevail. The results indicate congruence between the regime and elites' attitudes; thus, the results support H2.

According to question (108) results, the majority of elites do not value the effectiveness of the "Financial Disclosure" corruption control law, as $45.2 \%$ rated this value "ineffective" and $19.4 \%$ said it is "extremely ineffective." This claimed ineffectiveness exemplifies that elites' possess more progressive values that would lead to a real reform.

The one-way ANOVA result indicating no significant difference between the means of elites' values is: $\mathrm{F}(2,90)=.113, \mathrm{p}=. \mathrm{ns}$. This result does not support $\mathrm{H} 1$; for more details see Appendix D Figure 17, and Tables 46 and 47.

These results are another confirmation on the government's lack of seriousness in imposing laws to end corruption. Most elites did not value this lack of seriousness, yet 
they remain responsible for it; therefore their values were found congruent with the regime. The result supports $\mathrm{H} 2$.

Furthermore, results from the qualitative question (109) on administrative development indicate that the most frequent theme across the three groups is "Improving the individual's performance," "Applying the hiring codes and conducts," and "Enforcing transparency and accountability." All elites agreed on these themes without any significant differences. Elites' elaborations are focused on improving the performance, efficiency, and effectiveness of administrators and other public and private sector employees by exposing them to new techniques and modernizing all procedures. Therefore, this result indicates that most elites have reformist values. See Appendix D, Tables 48 to 50, for more details on the qualitative thematic analysis.

The dichotomous question (110) of institution-building provides responses indicating that it is either absent or incomplete. An equal percentage of $42.9 \%$ "no" and 42.9\% "incomplete" is displayed in Appendix D, Tables 52 and 53.

Chi-square result: $\chi 2(4, \mathrm{~N}=100)=10.93, \mathrm{p}<.05$ confirms the significant difference; $34.9 \%$ political verses $83.3 \%$ economic elites believe that institution-building is incomplete. Thus, these results accept H1, as displayed in Figure 4.5.

The equal percentages of the "yes" and "no" answers, and the responses that were in between, reduced the percentage of those who do not agree; hence this means that there is congruence between the regime and elites' political culture. The results support $\mathrm{H} 2$. 
Figure 4.5 Institution-building

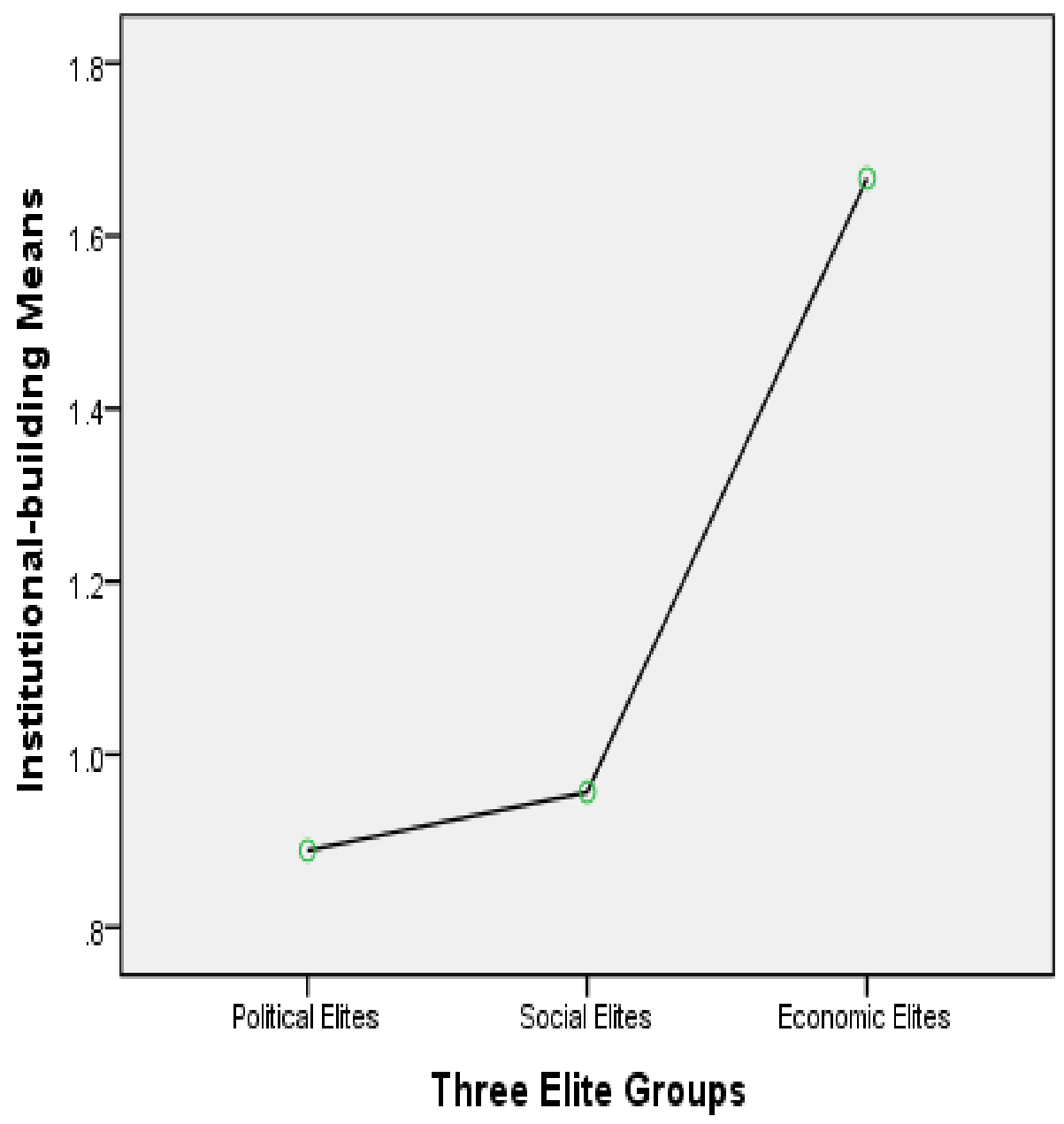


In the qualitative question (111), asking elites what should be done in terms of institution-building; the most frequent three themes are "seriousness in implementing reforms," "decreasing Royal Court authority," and "enforcing democratic values." For more details, see Appendix D, Tables 54 and 55 for qualitative thematic analysis. The lack of seriousness in implementing reforms can be the main reason behind the Royal Court's encroachment on other institutions in the political structure, which reflects the dominance of non-democratic values and attitudes. These results confirmed that institution-building is incomplete.

The results of the findings of this section are summarized in the following table:

Table 4.4 Summary of Quantitative Data Analysis Results: Elites' Political Culture towards Public Sector Administrative Reform

\begin{tabular}{llllll}
\hline & $\begin{array}{l}\text { Transparency \& } \\
\text { Accountability }\end{array}$ & $\begin{array}{l}\text { Corruption } \\
\text { Control }\end{array}$ & Nepotism & $\begin{array}{l}\text { Merit } \\
\text { System }\end{array}$ & \multicolumn{1}{c}{$\begin{array}{l}\text { Institutional- } \\
\text { Building }\end{array}$} \\
\hline $\begin{array}{l}\text { H1: } \\
\begin{array}{l}\text { Significant } \\
\text { Difference }\end{array}\end{array}$ & Supported & Supported & $\begin{array}{l}\text { Not } \\
\text { Supported }\end{array}$ & $\begin{array}{l}\text { Not } \\
\text { Supported }\end{array}$ & Supported \\
$\begin{array}{l}\text { H2: } \\
\begin{array}{l}\text { Congruence } \\
\text { Regime } \\
\text { with Elites' }\end{array}\end{array}$ & Supported & Supported & Supported & Supported & Supported \\
$\begin{array}{l}\text { Political } \\
\text { Culture }\end{array}$ & & & & & \\
& & & & & \\
\hline
\end{tabular}




\section{Elites' Political Culture towards Political Participation: Political Parties, Elections, and Lobbying}

The effect of the previous political culture that banned political party activities is assessed in the belief question $(\mathbf{1 0 4 . 6})$ on a 6 -point scale $(1=$ very poor to $6=$ excellent $)$. The result indicates that there is still no change in encouraging political party affiliations or activities by elites. The majority of elites are still holding on to the old culture; $52 \%$ of their responses rated this reform "very poor" in addition to $35 \%$ "poor," adding up to $87 \%$; the total of elites who believe that the government's reform policy of political party activities is not constructive.

The one-way ANOVA indicates: $\mathrm{F}(2,97)=.095, \mathrm{p}=\mathrm{ns}$. There is no significant difference between the means of elites' beliefs. This result does not support H1; see Appendix D, Figure 19, and Tables 55 to 57.

The majority of elites expressed a state of stagnation in regard to political parties without expressing any interest in modernizing and reforming the institution of political party. This political culture goes in harmony with the regimes' policies that restrict the activities of political parties. The regimen in this case is congruent with elites' political culture. Thus, the result supports $\mathrm{H} 2$.

The affiliation with the political party dichotomous question (119) indicated that majority of elites do not value the political party affiliation. The cross tabulation test indicates the following results: 89\% "no" and 11\% "yes." See Appendix D, Figure 20 and Tables 58 to 59 . 
There are no significant differences between elites' means according to Chisquare results confirmed this insignificance, indicating: $\chi 2(2, N=100)=3.8 \mathrm{p}=\mathrm{ns}$. Thus, the results of elites' attitudes do not support H1.

However, these attitudes agree with keeping the institution of political party in stagnation. The regime policy and elites' attitudes are in congruence; thus, these results support $\mathrm{H} 2$.

The campaigning culture of political party and Parliament elections is assessed in the value semi-structured question (121). The results indicate that $39.4 \%$ believe that the used rhetoric during election times, which consist of slogans, mission and vision statements are only "accepted by some people" and another $39.4 \%$ believe that this rhetoric is a mere "propaganda." Most elites were critical; they expressed disapproval of the campaigning culture.

There is no significant difference between elites' means. The one-way ANOVA result indicates: $\mathrm{F}(2,96)=.159, \mathrm{p}=\mathrm{ns}$. This result does not support H1; see Appendix D, Figure 21, and Tables 60 to 62 .

The majority of elites criticized the campaigning culture and did not believe in its effect or seriousness, claiming it as "mere propaganda" and "deceptive." The result confirms the lack of congruence between the regime and the majority of elites' political culture; thus, does not support $\mathrm{H} 2$.

The open-ended question (122) measures the reasons behind the weaknesses of political parties. The most frequent three themes are "authoritarianism," "absence of programs," and "past failures." In their elaborations on these core themes, most elites 
expressed subordinate themes that explained their forward-looking perspectives, by denouncing authoritarianism and its consequences, and representing a 'reformist' outlook. The political culture reflected in this question sounded progressive and liberal. See Appendix D, Tables 63 and 64 for further details on the thematic analysis on the weakness of political parties.

Likewise, the open-ended question (123) asked what attitudes should be taken towards empowering and activating the institution of political party. Elites' most frequent core themes are: "reforming political parties," "legislative amendment," and "raising awareness levels." Most responses included liberal and democratic changes that were never translated into real programs. See Appendix D, Tables 65 and 66 for further details on the thematic analysis on strengthening political parties.

The one-man, one-vote law is an unprogressive law used by the government as one of the tools to prevent the majority of the population from gaining political power in proportion to their numbers. Elites' beliefs in this traditionalistic law are measured in question (124), on a 4-point scale of ( $1=$ strongly disagree to $4=$ strongly agree). The majority of elites; $78.8 \%$, strongly agreed that this law is traditionalistic. For more details see Appendix D, Figure 22 and Table 67 to 69.

However, the one-way ANOVA indicates an insignificant difference: $F(2,96)=$ $.787 \mathrm{p}=\mathrm{ns}$, which does not support $\mathrm{H} 1$.

The one-man, one-vote law empowered tribalism, and those who agreed with this notion were the majority of the respondents, as $79 \%$ of elites consider this policy a 
reactionary one imposed by the regime. Hence, the regime is not in congruence with most elites' political culture. The result does not support H2.

Elites' attitudes are assessed towards lobbying in the dichotomous question (116). The results proved that most elites practice lobbying, despite the authoritative nature of the political system, and indicate that $82 \%$ of elites practice what they called "unorganized" lobbying, which reflects elites' democratic ideas.

Moreover, Chi-square result confirms a significant difference, indicating $\chi^{2}(2$, $\mathrm{N}=100)=9.45, \mathrm{p}<.05$. These significant test results are proved between political and economic elites. Accordingly, these results support H1. See Appendix D, Table 70 for more details.

The political system of Jordan lacks some of the main elements of democratic practices; thus elites' responses were found part of the pervasive democratic rhetoric. This rhetoric liberal political culture is congruent with the regime. The result supports $\mathrm{H} 2$.

The following mean plot displays the difference between the means of elites' attitudes: 
Figure 4.6 The practice of lobbying

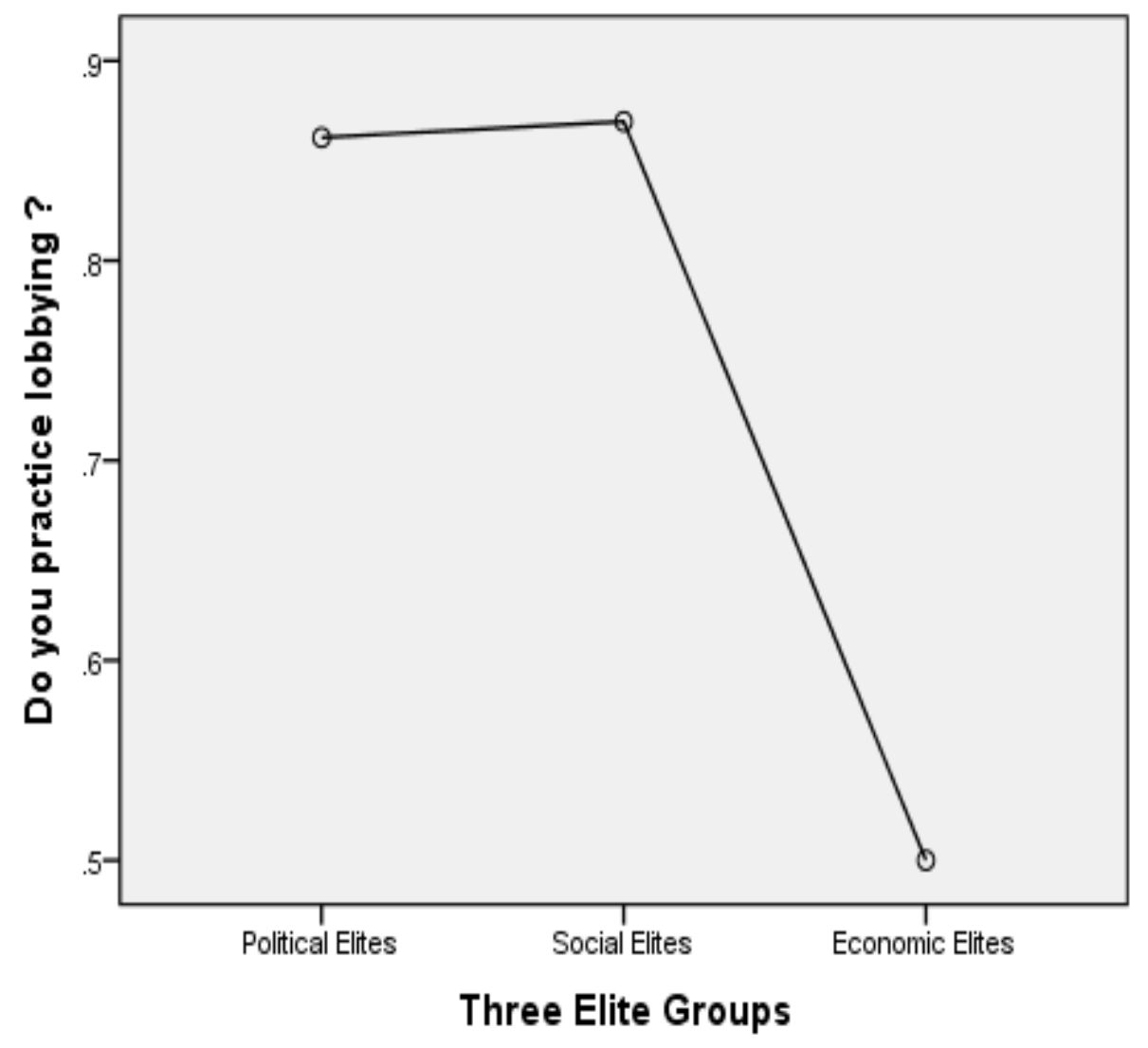


In a coupled semi-structured question (117), the respondents are provided five democratic purposes: "to implement important changes;" "to pursue my democratic values;" "to affirm pluralism;" "to participate in policymaking;" and "all the above." The total number of respondents for this question is $82 ;(\mathrm{N}=82)$. The results indicate that $64.6 \%$ of the $82 \%$ of elites specified their reason by "all the above."

There is no significant difference between elites' means according to the one-way ANOVA, indicating: $\mathrm{F}(2,79)=.738, \mathrm{p}=\mathrm{ns}$. The results do not support H1. For more information see Appendix D, Figure 24 and Tables 71 and 72.

Elites' responses confirmed their rhetoric liberalism that is congruent with the regime. The result supports $\mathrm{H} 2$.

The results of the findings of this section are summarized in the following table:

Table 4.5 Summary of Quantitative Data Analysis Results: Elites' Political Culture towards Political Participation

\begin{tabular}{|c|c|c|c|c|c|}
\hline & $\begin{array}{l}\text { Political } \\
\text { Party } \\
\text { Affiliation }\end{array}$ & $\begin{array}{l}\text { Campaign } \\
\text { Culture }\end{array}$ & $\begin{array}{l}\text { One-man } \\
\text { One-Vote } \\
\text { Legislation }\end{array}$ & Lobbying & $\begin{array}{l}\text { Lobbying } \\
\text { Reasons }\end{array}$ \\
\hline $\begin{array}{l}\text { H1: } \\
\text { Significant } \\
\text { Difference }\end{array}$ & $\begin{array}{l}\text { Not } \\
\text { Supported }\end{array}$ & $\begin{array}{l}\text { Not } \\
\text { Supported }\end{array}$ & $\begin{array}{l}\text { Not } \\
\text { Supported }\end{array}$ & Supported & $\begin{array}{l}\text { Not } \\
\text { Supported }\end{array}$ \\
\hline $\begin{array}{l}\text { H2: } \\
\text { Congruence: } \\
\text { Regime with } \\
\text { Elites' } \\
\text { Political } \\
\text { Culture }\end{array}$ & Supported & $\begin{array}{l}\text { Not } \\
\text { Supported }\end{array}$ & $\begin{array}{l}\text { Not } \\
\text { Supported }\end{array}$ & Supported & Supported \\
\hline
\end{tabular}




\section{Social Development}

\section{Elites' Political Culture towards Tribalism}

The respondents used a 5-point scale of ( $1=$ extremely unimportant to 5=extremely important) to answer question (103.5). The results indicate that $64 \%$ of respondents ranked the importance of tribal values in the making of policies "extremely important." Also, there are $17 \%$ of respondents who ranked this value as "important," which means that this traditional value undermines modernity, and is substantial for policymakers.

The one-way ANOVA results indicates: $F(2,97)=2.16, p=n s$. The insignificant difference between the means does not support H1. See Appendix D, Figure 26, Tables 76 to 78 .

Tribalism has been used by the regime as a tool to pursue political agendas; hence, policymakers that consider tribalism as a significant factor does not reflect a progressive stance. The results support $\mathrm{H} 2$, as the regime in this case is congruent with elites' values.

The impact of tribalism on development is measured in question (126) on a 3point scale (positive; negative; and positive at times, negative at others). The majority of elites believe that tribalism has a negative impact on political and social developments by $46 \%$ and $41 \%$ believe its impact is positive at times and negative at others.

The difference between elites' beliefs is insignificant; as indicated by Chi-square result: 
$\chi^{2}(4, \mathrm{~N}=100)=.659, \mathrm{p}<\mathrm{ns}$. Thus, the results do not support H1. For more information see Appendix D, Figure 27, and Tables 79 to 81.

Elites' beliefs were not in favor of tribalism in this question. There were more believers among elites in the negative impact of tribalism than the ones who believed in its positive impact. The regime is not congruent with elites' beliefs; thus the results do not support $\mathrm{H} 2$.

Also, see Appendix D, Tables 82 to 84 for information on the open-ended question (127). The tables display the thematic analysis of elites' beliefs explaining why tribalism impacts development in a certain way, and their responses revealed an unprogressive political culture.

The influence of tribalism on elites' political culture is evaluated in question (128). Elites ranked their agreements on this influence on a 4-point scale: (1=strongly disagree, $4=$ strongly agree). The results implied that $39.4 \%$ of the respondents answered by "agree," and $39.4 \%$ by "strongly agree," to the statement of the question. Thus elites' political culture is influenced by traditionalistic affiliations, which emphasizes their cautious liberalism.

There is no statistical significant difference between the means of elites' beliefs in the tribal affiliation influence, as indicated by the one-way ANOVA: F $(2,96)=.436$, p=ns, which rejects H1. See Appendix D, Figure 28, and Tables 85 to 87.

Agreeing that tribalism influences the political culture of elites means that the fluctuation in elites' responses from previous questions can be explained on the basis of their responses to this question. According to most respondents, tribalism impacts the 
making of policies, and elites agree that it does not have a positive impact on development. Tribalism influences elites' political culture; thus, the results from previous questions as well as this question suggest that the regime is congruent with elites' political culture, and supports $\mathrm{H} 2$.

\section{Elites' Political Culture towards Women Empowerment}

Elites' support verses opposition to women's participation is measured in question (115.a) on a 4-point scale (1=strongly oppose to 4=strongly support). The strongly supportive are $78 \%$ for women's political participation, $84 \%$ for women's social participation, and $81 \%$ for women's economic participation. The empowerment of women in Jordan is considered advanced, according to UNDP studies. For details on these values see Appendix D, Figures 30 to 32 and Tables 91 to 94 .

The one-way ANOVA results indicating; political participation $\mathrm{F}(2,97)=.100$, $\mathrm{p}=\mathrm{ns}$; social participation, $\mathrm{F}(2,97)=1.24$, $\mathrm{p}=\mathrm{ns}$, and economic participation $(\mathrm{F}(2,97)=$ $.309, \mathrm{p}=\mathrm{ns}$. None of the three results are significant; therefore, the results do not support H1.

Elites' responses about women empowerment and how women can be empowered under the authoritative system and a Patriarchic society are not different from the government's policies. Therefore, the discrepancies in elites' responses about women's participation in the three fields of development agree with the regime's policies of empowering women. The results show congruence between the regime and elites' values; thus the results support $\mathrm{H} 2$. 
More details are illustrated in the open-ended question (115.b). There are three frequent themes that can negatively impact women's empowerment: traditionalism, social underdevelopment, and unconstructive media. There are no reformers among elites who suggested a development plan to push the social development wheel and implement changes to achieve higher levels of women empowerment and participation. See Appendix D, Tables from 95 to 98 for further details on the thematic analysis on women's empowerment.

\section{Elites' Political Culture towards Participation in Voluntary Organizations}

Volunteerism is tested in question (104.5) on a 6-point scale of $(1=$ very poor to $6=$ excellent). Government's reform policy in the field of civic engagement and volunteerism is ranked "poor" by $36 \%$ and "very poor" by $9 \%$ of elites. See Appendix D, Figure 33.

The one-way ANOVA indicates: $\mathrm{F}(2,97)=.041$, $\mathrm{p}=\mathrm{ns}$. The insignificant results confirm elites' cautious liberalism, which in this case does not support H1. For more information see Appendix D, Tables 99 to 101.

The majority of elites' believe that the government hinders civic engagement and issue laws that restrict all NGO activities, $45 \%$ of elites condemn this restriction and they want their government to allow civic engagement, yet no actions were taken by elites to minimize the interference of the security apparatus in the affairs and activities of NGOs. These responses are in congruence with the regime; thus elites' beliefs support H2. 
The following dichotomous question (129) assesses civic engagement by asking elites' about their involvement in nine different types of voluntary organizations: (philanthropic organizations; syndicates; youth clubs; cultural institutions; sports clubs; religious organizations; family associations; cooperative groups; and national or international foundations). Involvement with cultural institutions registered the highest percentage of $67 \%$, followed by national and international foundations reaching $63 \%$, then the philanthropic organizations reaching $62 \%$.

Thus, over 50\% of elites are involved with some kind of nonprofit organization, whether passively or actively as donors or participants. Jordan has a developing civil society and the involvement degree and civic engagement is considered above average, which represents a good level of "activeness" in the Jordanian society in spite of the authoritarian political system. See Appendix D, Figures 34 and 35.

Only two affiliations tested statistically significant: the cultural institutions and the national and international foundations, as Chi-square result: $\chi^{2}(2, \mathrm{~N}=100)=11.091$, $\mathrm{p}<.05$ for the cultural organizations, and Chi-square result: $\chi 2(2, \mathrm{~N}=100)=9.809, \mathrm{p}<$ .05. Chi-square

for the national and international foundations, which support H1. See Appendix D, Table 103.

Elites' affiliation with cultural, and national and international organizations was expected to be high due to their positions. Elites' affiliation with the cultural and national and international organizations did not trigger any changes in laws that restrict civic engagement in Jordan. The regime is congruent with elites' political culture, and support $\mathrm{H} 2$. 
Figure 4.7 Elites' Involvements with Cultural Institutions

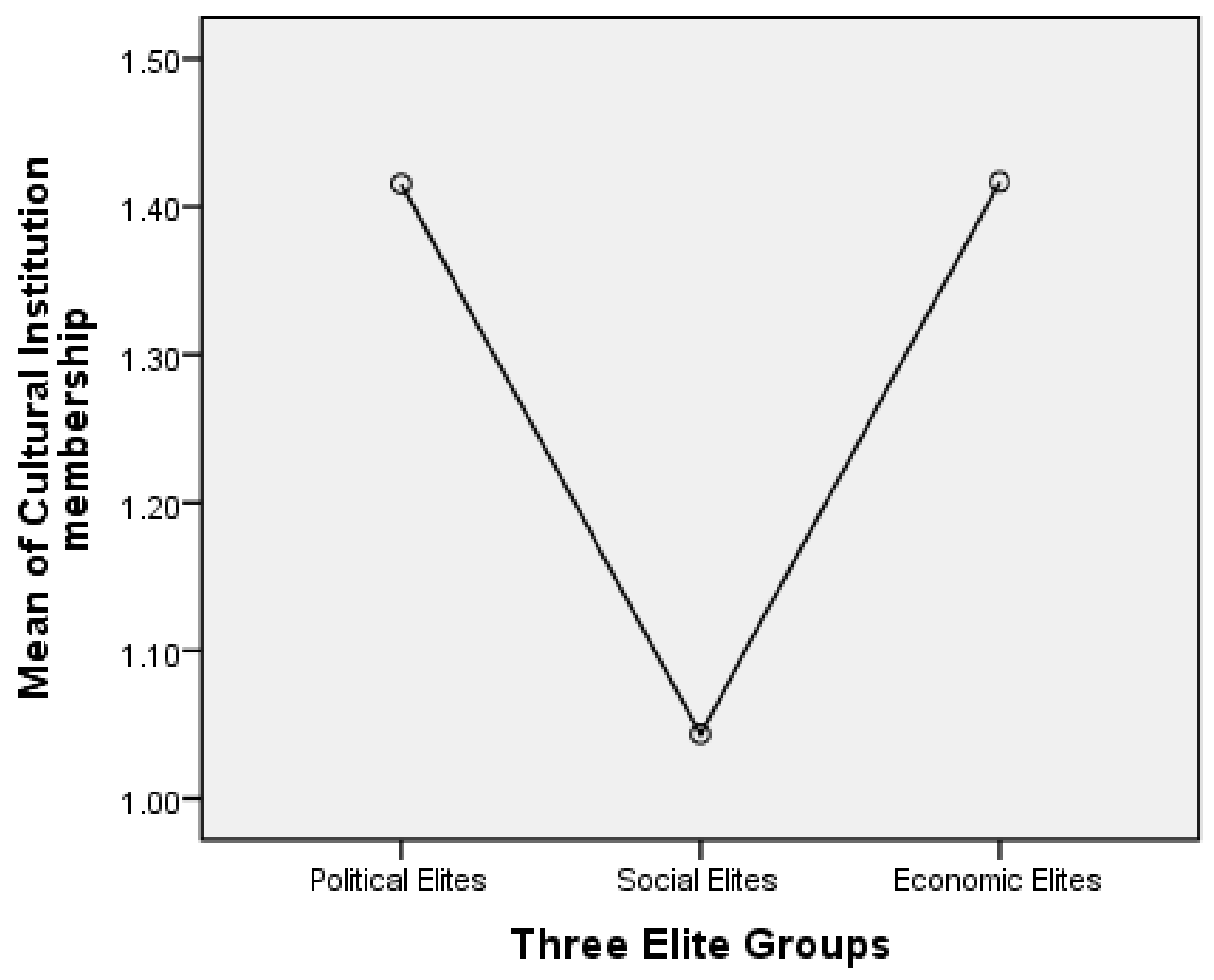




\section{Figure 4.8 Elites' Involvement with National and International Foundations}

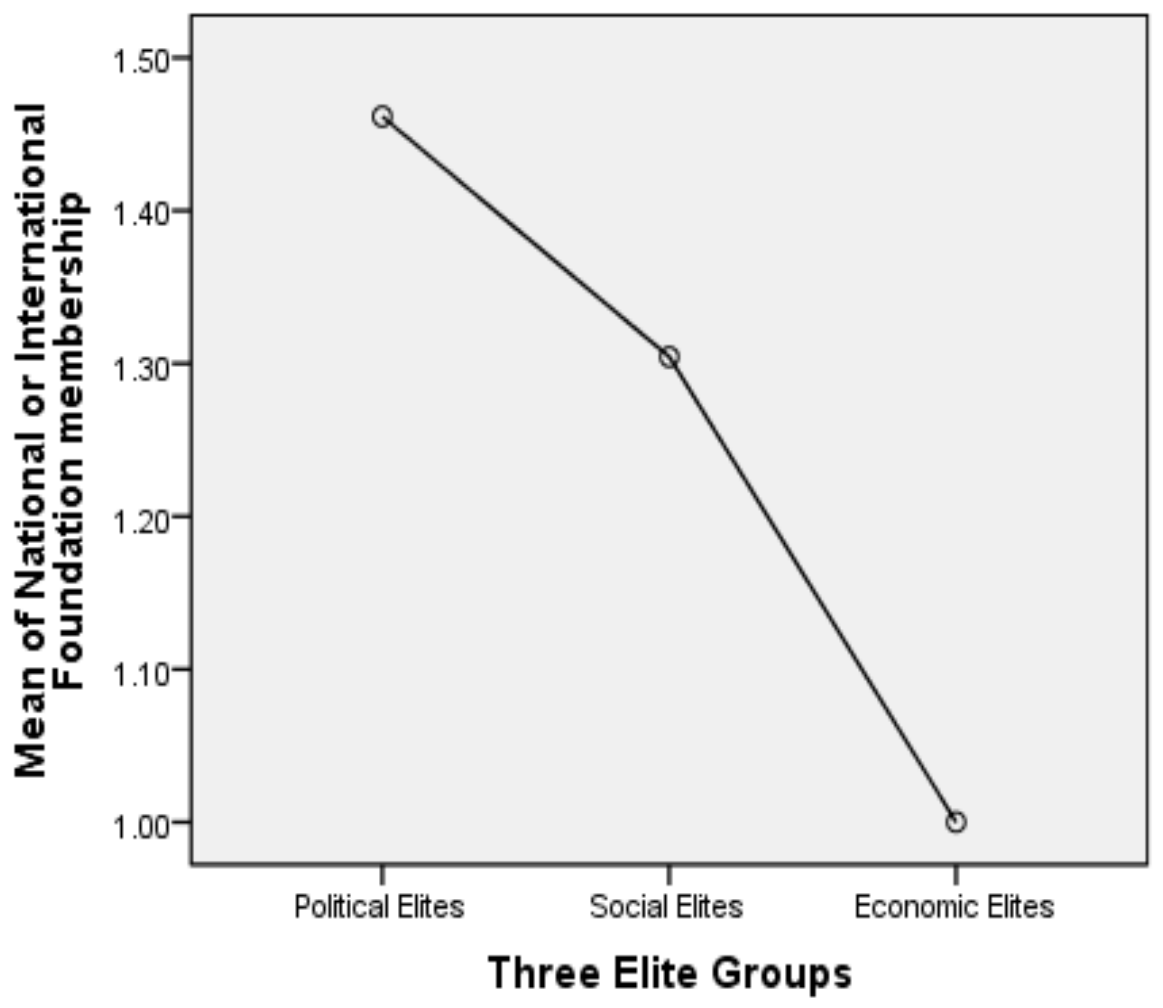

There is no serious reform implementation to liberate civic engagement due to authoritarianism and interference by the security apparatus. However, the results from 
question (130) specify more "no" responses to interference, than "yes" responses. Yet, the $37 \%$ of "yes" responses added to $23 \%$ of "sometimes" responses equate to $60 \%$ of elites approving of some kind of government interference in the affairs of the voluntary organizations. Chi-square result: $\chi^{2}(4, \mathrm{~N}=100)=4.883, \mathrm{p}<\mathrm{ns}$, thus the results do not support H1, but they support H2. See Appendix D, Figure 36, and Tables 104 and 105. In addition, this interference is confirmed by results from the open-ended question (131) demonstrating a one and only core theme of "authoritarianism and security apparatus interference" by $56 \%$ of elites. In their responses, most elites asserted that NGOs are not sovereign organizations due to several restrictive laws to their activities and the interference of the security apparatus in the type of activities they do.

The results of the findings of this section are summarized in the following table:

Table 4.6 Summary of Quantitative Data Analysis Results: Elites' Political Culture towards Social Development

\begin{tabular}{llllll}
\hline & $\begin{array}{l}\text { Importance } \\
\text { of } \\
\text { Tribalism }\end{array}$ & $\begin{array}{l}\text { Tribalism } \\
\text { Influence }\end{array}$ & $\begin{array}{l}\text { Women } \\
\text { Empower- } \\
\text { ment }\end{array}$ & $\begin{array}{l}\text { Civic } \\
\text { Affiliation }\end{array}$ & $\begin{array}{l}\text { NGOs } \\
\text { Sovereignty }\end{array}$ \\
\hline $\begin{array}{l}\text { H1: } \\
\text { Significant } \\
\text { Difference }\end{array}$ & $\begin{array}{l}\text { Not } \\
\text { Supported }\end{array}$ & $\begin{array}{l}\text { Not } \\
\text { Supported }\end{array}$ & $\begin{array}{l}\text { Not } \\
\text { Supported }\end{array}$ & Supported & $\begin{array}{l}\text { Not } \\
\text { Supported }\end{array}$ \\
$\begin{array}{l}\text { H2: } \\
\begin{array}{l}\text { Congruence: } \\
\text { Regime with } \\
\text { Elites' }\end{array}\end{array}$ & Supported & Supported & Supported & Supported & Supported \\
$\begin{array}{l}\text { Political } \\
\text { Culture }\end{array}$ & & & & & \\
\hline
\end{tabular}




\section{Economic Development}

\section{Elites' Political Culture towards Economic Liberalization and Prosperity}

Elites' beliefs in prosperity are assessed in question (103.6) on a 5-point scale (1=extremely unimportant, $5=$ extremely important). Elites' responses imply that the value of prosperity is $42 \%$ "important" and $25 \%$ "very important" for policymakers; a total of $67 \%$ of importance. This value is expressed in the enthusiasm towards economic liberalization in Jordan.

The one-way ANOVA confirms the insignificant difference indicating F $(2,97)$ $=.812, \mathrm{p}=\mathrm{ns}$. The result does not support H1. See Appendix D, Figure 37 and Tables 106 and 107.

The Jordanian government encourages economic liberalization policies, but the majority of elites elaborated on the economic liberalization question by emphasizing Jordan's high poverty and unemployment rates; particularly, in the suburbs. In their responses most elites criticized their government on its economic liberalization policies that did lead to ameliorating the standards of living in Jordan, which indicate that there is lack of congruence between the regime and elites' political culture. Thus, the results do not support $\mathrm{H} 2$.

The economic liberalization is measured in question (104.4) on a 6-point scale of ( $1=$ very poor to $6=$ excellent), through elites' beliefs in the seriousness of the implementation of economic reforms that lead to economic liberalization. The highest percentage of responses is $42 \%$ "very good," but $17 \%$ believe it is "excellent" and $23 \%$ believe it is "good." This implies that a total of $82 \%$ of elites believe that economic 
reform policy and economic liberalization are on the right track. See Appendix D, Figure 38.

There is no significant difference in the results of the one-way ANOVA indicating $\mathrm{F}(2,97)=.823, \mathrm{p}=\mathrm{ns}$; thus, the result rejects H1. See Appendix D, Tables 108 to 109 .

Most elites believe that the policies of economic liberalization and privatization have led Jordan to economic development, which agree with what the Jordanian government claims about the success of the economic liberalization policies. Accordingly, the regime is congruent with elites' political culture; therefore, the results support $\mathrm{H} 2$.

\section{Elites' Political Culture towards Economic Development vs. Political \\ Development}

Elites' political culture towards the precedence of economic development verses political development is tested in the semi-structured question (132). The majority of Jordanian elites' showed advanced attitudes towards some of the government's economic reforms that give economic development precedence over political development. These attitudes are demonstrated in the $67 \%$ of elite's that are in favor of the "both developments should occur simultaneously" option. See Appendix D, Figure 39 and Table 112.

The result of one-way ANOVA indicating no significance; $F(2,97)=.939, p=n s$, thus the result undermines H1 and H2; see Appendix D, Tables 113 and 114. 
Elites' political culture towards economic liberalization and development is enhanced in the open-ended question (133) that inquires about the chosen development plan and gave the respondents a chance to elaborate on Jordan's economic development in general. Elites' most frequent three core themes are (political and economic stability; reinstatement of freedoms, and economic development). See Appendix D, Table 115 for themes' frequencies.

Accordingly, $64 \%$ of elites believed that when both developments occur simultaneously they enhance each other and ensure growth and the achievement of higher productivity, as some elites added in their elaborations. This enhancement will lead the country to political and economic stability. Elites' core and subsequent themes reflect a reformist view. See Appendix D, Table 116 for the thematic analysis of core and subordinate themes, and Table 117 for the frequency of the core themes distributed in percentage. 
The results of the findings of this section are summarized in the following table:

Table 4.7 Summary of Quantitative Data Analysis Results: Elites' Political Culture towards Economic Development

\begin{tabular}{lll}
\hline Prosperity & Economic & Economic \\
Value & Liberalization & Development \\
& & Policy \\
\hline
\end{tabular}

H1:

Significant Not

Difference Supported

Not

Not

Supported Supported

H2:

Congruence: Not

Not

Regime with Supported

Supported

Not

Elites'

Political

Culture 


\section{Discussion}

This section addresses the issue of whether research findings add to or change the understanding of Jordanian elites' political culture by discussing findings from the analyses of the four research questions: 1) The description of Jordanian elites' political culture; 2) The significant differences among the three groups of elites; 3) The centers of influence among Jordanian elites; 4) The congruence level between the regime and elites' political culture.

Elaborated data was gathered in response to the open-ended questions; particularly for the neutral, standard, or uncertain responses to some closed-ended questions. During the interviews, the abundance of data that was registered was taken under the researcher's consideration to be used in the analyses, which helped in making the studied inferences that guided the discussion of the results.

The findings in the first section of political development portray elites' values, beliefs, and attitudes towards a number of political development issues: The type of political system; the supremacy of rule of law; democratic governance; pluralism; and the election of the Prime Minister.

In their evaluations for the different political systems, the majority of elites expressed their inspirations and enthusiasm towards constitutional monarchy. They claimed to value the parliamentary democratic political system rather than their authoritative system that is ruled by an ultimate power. They also emphasized their beliefs in the supremacy of rule of law, real pluralism, and democratic governance. 
Despite the claims made by most elites about their incompatibility with their government, elites' political culture was found congruent with the regime.

Elites' denunciation and criticism of the regime and their government's policies were expressed throughout the interviews, particularly while answering the open-ended questions.

Thus, in their elaborations on the open-ended question (135) elites comments and elaborated explanations benefitted both the data gathering and data analysis processes. Most elites, particularly the ones who participated in the National Charter Convention (1990) condemned the government for paralyzing the National Charter, which had it been applied, Jordan would have witnessed serious implementation of reforms and a great enhancement to all developmental activities.

The Arab Barometer study (2006) indicated that there is a high percentage of $73.5 \%$ of respondents who agreed to the following statement: "The democratic system has its problems, but it is better than any other." Also, in the Arab Barometer study, only $12.3 \%$ disagreed to the same statement.

In addition, most elites elaborated on the government's deficiency in achieving democratic governance and for lagging behind in achieving successful coordination processes that delay the delivery of social service in the country.

Similarly, the results confirm the absence of real pluralism, as most elites said that they did not believe that forces like the political parties, entrepreneurships \& businesses, NGOs, unions, decision making groups, pressure groups, and powerful personalities can participate in governance. Jordan is a regime led state, as described by Lucas (2004). Thus, the regime maintains the exclusive right to define pluralism and decides which 
forces should be restricted and deemed outside the boundaries of its accepted pluralism. The government's pluralism is coherent with Linz's theory of authoritarianism (1964), which suggests pluralism under authoritarian regimes is only social pluralism.

Nevertheless, the results from the question that inquired about the King's prerogatives indicated that the pattern that took place at the very beginning of data gathering was contradicted with elite's responses on this particular question. Most elites justified their positions of not sounding liberal in answering this question by emphasizing that democracy in Jordan has not matured for implementing this particular reform. Thus, their expressed beliefs that the King must practice all his prerogatives including the appointment of the Prime Minister underline Wiktorowicz's argument of the façade of democracy (1999). More importantly, these beliefs were found to go in coherence with John Locke's theory of "Cautious Liberalism" stating that revolutionary and progressive values, beliefs, and attitudes that lead to major changes in the political structure can cause political degeneration and major changes in the status quo of the holders of power under that political system.

The result of the qualitative questions confirmed the values, beliefs, and attitudes of elites which they expressed about the type of political system and its characteristics which they mainly criticized and considered non-democratic.

In summary, most of the quantitative and qualitative results in the first section indicate that Jordanian elites' values, beliefs, and attitudes towards the type of political system, rule of law, democratic governance, and pluralism suggest that they have a liberal political culture. Yet, in order for them not to jeopardize their tenures or security, they 
stayed guarded in regards to the implementation of one of the most important issues that cause political underdevelopment.

The analyses of the second group of political development responses indicate that elites' political culture has appreciation for freedoms and civil rights. The results indicate that Jordanian elites appreciate having self-determination that enable them to make or impact policies, freedoms and civil rights; access to information; and freedom of opinion and ideological affiliation. In addition, the results support the fact that they highly value civil rights and the liberal ideologies. They were also hopeful in having more freedom and access to information. Jordanian elites showed interest in expressing their ideological backgrounds that were different from the regime's ideology of "Jordan First," which was adopted by very few elites.

Democracy exists if citizens are free and their rights are not restricted or violated, and vise versa; although on one hand, some of these results do not agree with the Freedom House rating that considers Jordan "Not free." On the other hand, Jordanian elites took liberal stances by showing their eagerness to accomplish more advances in the realm of freedoms and civil rights, in order to keep Jordan ahead of its neighboring countries. More importantly, elites expressed a liberal political culture that is coherent with the democratic rhetoric of the regime. By the same token, the Arab Barometer study (2006) shows that $38.8 \%$ of Jordanians believe that disrespecting human rights for the sake of security is "not ever justified" and rejected the encroachment by the security apparatus, whereas $12 \%$ said it is "justified to a large degree." These results emphasize the government's encroachment on human rights; for the sake of security. 
The third section discusses the results of elites' political culture towards public sector reform. This section measures the quantitative and qualitative results of elites' political culture towards transparency and accountability, corruption control, nepotism, merit system, administrative development, and institution-building. According to Transparency International Index, the overall perception of corruption in Jordanian public sector has worsened; it rated $46 / 177$ and fell to $66 / 177$ in 2013 . These results are also confirmed by Jreisat (as cited in Jabbra, 1989) explaining the obstacles that hinder administrative development in Jordan. Elites' attitudes towards enforcing transparency and accountability, as well as corruption control were "unfavorable" towards the government's implementation of this reform. Elites expressed criticisms of the government's enforcement of the Financial Disclosure law. There is value in the expected consequences of this law, as it was ratified to hold administrative officials accountable and maintain transparency, yet the lack of seriousness in its enforcement rendered this law an ineffective tool in the combat of corruption. Likewise, most elites' attitudes were "unfavorable" towards the implementation of reforms that end nepotism. The majority of elites denounced the rampant phenomenon that is known as "Wasta," which means nepotism, cronyism, favoritism, and patronage.

Institution-building is another reform that was assessed through the political culture of elites who expressed reformist values, beliefs, and attitudes in what ought to be done to accomplish a complete and successful institution-building process in Jordan. Most elites' comments on the open-ended question regarding institution-building elaborated on the empowerment of institutions that takes place by enhancing their system of equilibrium of rules, norms, and beliefs and improving their capacity in the 
implementation of reforms. Furthermore, they emphasized the need for a public administration strategy to strengthen the Jordanian institutions and to increase efficiency levels in order to meet the requirements of Jordan's transitional period which is still deficient in Jordan. Wiktorowicz (1999) blamed authoritarianism for the deficiency of institution-building. Similarly, the majority of elites referred this underdeveloped situation of institution-building to the nature of the monarchical regime and the different roles which the institution of the Palace and the Royal Court play, as they believed that these institutions infringe on all other institutions in the country and interfere with their equilibrium that affects their development. The process of institution-building in Jordan is struggling to develop.

The qualitative results and elites' elaborations emphasized the significance of several enterprising values, which notes that their absence lowers the efficiency levels of all workers. They showed eagerness in fighting corrupt norms in all their organizations, such as “Wasta." The low efficiency levels in the public and private Jordanian organizations can be treated by the following reform plan: the assignment of training programs for improving the performance of individuals; strict enforcement of a merit system to hire on the basis of KSAs, codes, conducts, and by-laws; and for transparency and accountability to hold officials accountable to the public. In the open-ended question on institution-building, the result indicated that most elites have shared the following themes: seriousness in implementing reforms, decreasing Royal Court authority, and enforcing democratic values. Again, the seriousness in implementing reforms remains critical to the development process. 
The fourth section is concerned with political participation and Jordanian political parties. The Jordanian parties have been undeveloped institutions since their establishment. The parties have been unacceptable political institutions in Jordan and were never supported by the regime that claims parties as obstacles to democratic development. The Jordanian political parties are conflicted with alleged tendencies and they are centered on personalities rather than programs. Most elites and the Jordanian public are still averted with this reputation. The results display a high percentage of elites who avoid having any affiliation with political parties. Elites' beliefs in having affiliations with political parties are considered illiberal, submissive, and reactionary, since the party affiliation among elites has remained extremely low. Further, the party institution is considered incapable of forming effective parliamentary blocs, which has negatively reflected on the parliamentary elections and their campaigning culture. Most elites refused the campaigning rhetoric; as it is considered propaganda, or used to serve the interests of some individuals. The campaigning culture is discouraging to the Jordanian intelligentsia and to the younger generation; therefore, responding by selecting the abovementioned two options is considered progressive due to the importance of these options to the reformation process.

The legislations of organizing political parties and parliamentary elections are another important factor for controlling and restricting these institutions. The one-man, one-vote law is a traditional and conservative law imposed by the regime to empower tribalism and to keep the institutions of political party and the Parliament weak and incapable. The Arab Barometer (2006) study results revealed that there are differing 
levels of confidence among Jordanians in their public institutions. The results indicated that $56 \%$ of the people are "confident to a large degree" in the General Security forces, followed by the courts at 40\%, then the Prime Minister at 27\%, and the Parliament at $19 \%$, and finally political parties with only 10 percent. Similarly, this study's results did not show high levels of confidence among elites in the Parliament and political parties.

Lobbying is a democratic practice that is informally performed by Jordanian elites who believe in its effect, although they operate under an authoritarian political system. The majority of elites said that they practice lobbying to participate in policymaking, influence the policymakers, and to pursue democracy.

The qualitative results defined elites' beliefs in the reasons that contribute to the weakness of political parties and their attitudes towards reforming and activating the party institution in Jordan. According to elites' beliefs, the weaknesses of the party institution are: authoritarianism, absence of programs, and political parties past failures that led to their destructive reputation. Political parties remain the best way to deliver democracy; therefore, elites were asked to elaborate on a reform plan. However, most respondents were focused on the deficiencies of the available political parties and did not have a reform plan that can activate the dysfunctional party institution due to the authoritarian regime that restricts freedoms, and the absence of the royal decree that allows the reformation process. The core themes of reform, as mentioned by elites are: reforming the party institution, empowering democratic values to allow political participation and guarantees freedoms and rights, amending legislations to negate the 
flawed party legislations, raising the public awareness levels about the party institution, and allowing parties to have programs, recruit efficient leaders, and build popular bases.

Collectively, the political parties and the Parliament in Jordan remain weak institutions. This policy is described by Brynen as a step toward liberalization without real political development. Keeping the institutions of Parliament and political parties under the control of the state hinders democratization and political development (1998). Jordanian elites have expressed very liberal values and their responses were focused on criticizing the government, yet they are part of the government and part of the regime that they were criticizing. It can be inferred that Jordanian elites' political culture could not help them to get rid of their fears. Thus, they were described as cautious liberals.

The results of social development are discussed in three sections. First, the importance and consideration of tribal values in the making of policies; tribalism is another sensitive issue that generates inconsistencies in elites' responses. As displayed in the one-man, one-vote legislation, tribal values are very important not only to the regime, but also to the most influential elites. Oudat and Alshboul (2010) state that tribalism has been used by the regime as a tool to serve some Jordanians and their political interests; thus, those elites who emphasized the negative impact of tribalism express a progressive political culture. Using tribalism to serve a certain political agenda is an undemocratic practice that leads the society to conflicts.

The most frequent core themes on tribalism's effect on development are: causing degeneration and regression, causing confusion in loyalties, and enhancing development by playing a role in protecting the national security. Two themes underlined the negative effect of tribalism, while the third theme was positive. However, the positive theme was 
the less frequent theme, which confirms that using tribalism as a tool to pursue certain political agendas by the regime has a negative impact on development.

The second section under social development is women empowerment. There was no opposition to women's participation in the political, social, and economic fields among Jordanian elites. However, most elites supported women's social and economic participation more than their political participation. The level of women's political participation in Jordan was 7 percent to 16.9 around the world. Therefore, Jordan depends on the quota system to raise women's representation in the Parliament. Women's quota has been recently raised to 12 percent. Nevertheless, the UNDP studies on Jordan consider the participation of Jordanian women in the three fields is restricted by numerous obstacles and challenges. The qualitative results from elites' elaborations on this issue confirm the impact of tribalism and traditional social norms on women's participation. In addition, the Jordanian society, particularly in the suburbs, is Patriarchical and hierarchical. This impacted the social identities of women who tend to be more dependent on male figures in their family relations. These challenges affect the policymaking under Jordan's political system that is described by Hudson as a patriarchic and traditional political system (1977). The status of women is taken under the consideration of different international studies on Jordan. Several elites referred to these studies and disagreed with their findings. They do not consider women in Jordan to be less liberated than other women in the world. One of their core themes referred to the role of destructive media as a reason for any alleged deficit in women's participation.

Although volunteering is carried out through nonprofit organizations, it is also valuable for governments. Volunteerism supplements several services that governments 
provide. It is necessary for several communities in Jordan, but the lower incomes and standard of living makes volunteers look for paid jobs instead of seeking volunteer opportunities. The result that assessed elites' value of volunteerism points out their inflexible outlook towards this value. Particularly, the lack of governmental subsidies illuminates any urgency in taking steps to promote volunteerism or to allocate budgets to fund volunteer programs. Financial hardship is present among both the government and the population in general, which limits peoples' will to volunteer. These results were not expected from the majority of elites who were responding as liberal activists through the survey because through voluntary organizations activists can mobilize the grassroots of the society (Wiktorowicz, 1999).

In their assessment for the sovereignty of their nonprofit organizations, most elites condemned their government for its interference in the affairs of the governmental organizations. As a matter of fact, in accordance with Kamrava's theory, the authoritarian government of Jordan and its security apparatus politicize the activities of most NGOs in Jordan in order to put restrictions on most of their activities (1998). Hence, Jordanian elites realize that the nonprofit sector in Jordan is not considered free. As they also know that the only permissible activities are the charitable ones. Yet, Jordanian elites' political culture does not indicate their willingness to amend the policy that restricts NGOs' activities, or to activate civic engagement that creates social harmony and builds social trust.

Elites' values, beliefs, and attitudes towards economic development confirmed their appreciation for economic growth to achieve prosperity and higher living standards. 
Therefore, the results indicated their enthusiasm to liberate their economy and achieving economic liberalization. Although Jordan has taken bigger steps than other countries in the region towards economic liberalization, the government's economic reform policies have lagged behind. According to the Human Development Index (HDI) Jordan's current economic status has not achieved better poverty and unemployment rates and most Jordanians do not have a prosperous living.

Therefore, most elites condemn their government on its economic policies. They criticized the privatization policies that led to privatizing Jordan's most important national resources. Most elites critiqued the government's policies of economic liberalization that lack for regulations and laws that should be promulgated to protect the national economy, as most elites consider the absence of government surveillance in the government's economic liberalization policies led did not lead the country to economic liberalization, but widened the gap between the haves and have-nots and increased the levels of poverty and unemployment.

The third issue is the policy of economic development. This assessment essentially measures elites' beliefs in the interconnected relationship between economic and political reform. The majority of elites believe in the interconnectedness between these two developments. They emphasized that neither form of development should be separate of the other. This is because underdeveloped economic issues impact political development, and political underdevelopment can in turn hinder any economic growth. Although Jordan has grown economically, due to a lack of democracy and political participation in decision-making, economic development remains threatened. Freedoms 
remain to be a vital factor for both forms of development to succeed to their full potential. If freedoms and rights are guaranteed under the Jordanian political system, the poverty and unemployment levels would drop and the economic growth rate would in turn rise.

Accordingly, most elites denounced the precedence of economic liberalization over the political liberalization. In response to the first research question, the results of elites' political culture on economic development contrast with the regimes economic liberalization policies, as they ruthlessly criticized their government for the privatization of several public sector entities. However, elites' criticisms of the government's economic policies have remained rhetoric. 


\section{Chapter 5: Main Conclusions}

In response to the four research questions and their two hypotheses, this chapter offers valuable insights into Jordanian elites' political culture. It provides illustrations on elites' most crucial challenge, imposed by the centers of influence that impacts their values, beliefs, and attitudes and their pursuits of achieving liberalization, democratization, and development. It displays the main conclusions and inferences from the analyses by describing the political culture of Jordanian elites; explaining the scarce significant differences among elites' three groups; elucidating the centers of power concerned with elites' political culture; and defining the regimes' congruence with Jordanian elites' political culture.

In consummation, the limitations of this study will be discussed, and the following three areas will be addressed in the implication section: to decide whether theory, research, and practice of the findings are consistent with selected theoretical framework or not; if the study helps in advancing the research methodology, issues of measurement, and research design; and finally, on the practical level, how the findings are anticipated to add to this field and to lead for changes in interviewing elites in authoritarian political systems.

\section{1) Description of elites' political culture}

In response to the first research question, the results indicated a certain pattern in elites' political culture. In the first section of questions on political development, most elites expressed democratic, progressive, and advanced values, beliefs, and attitudes 
towards a type of political system, supremacy of rule of law, democratic governance, and pluralism. All the results that were inferred from the analysis of this group of questions indicated that elites' political culture contrasted with the reform policies of the regime or the approaches which the regime adopted in the implementation of reform policies. For example, continuously criticizing the government on its lack of seriousness in reform policy implementation and explaining with much elaboration the reasons behind their criticisms showed the difference in the way they think versus the reality of the stagnant political development in Jordan. Many aspects of political development such as the supremacy of rule of law can be superseded by tribal laws, which defeats one of the main pillars of a modern state. The analysis of the last quantitative question in this section that inquired about the King's prerogatives confirmed that the majority of Jordanian elites' liberalism on which they elaborated appeared to be more timid than progressive in certain areas. Unfortunately, this particular reform remains vital for the transitional movement towards liberalization, democratization, and development. This is because the transition from an authoritative monarchical political system to a constitutional monarchical political system contradicts with the notion of the ultimate power that accompanies authoritarianism. However, Jordanian elites' beliefs revealed a sentiment of fear of real change and they showed inability and weakness in achieving a constitutional monarchy that is anti-royalist and anti-ultimate power. Therefore, on the basis of these results, Jordanian elites can be described as cautious liberals whose political culture does not really vary from the pervasive democratic rhetoric of Jordan.

In the second section of the analysis, Jordanian elites responded by evaluating a number of freedoms and rights such as the freedom of self-determination, civil rights, 
freedom of access to information, freedom of choice, and freedom of affiliation with certain ideologies. The analyses show that elites' values, beliefs, and attitudes were inconsistent with liberalism. They expressed a dynamic ability in affecting policy-making in Jordan, in considering the value of civil rights and freedoms in the policy-making, maintaining Jordan's leading position in the freedom of accessing information, and more importantly in their ability to express their ideological affiliations despite the regime's endeavors to emphasize its ideology "Jordan First." The results of the ideological background question indicated that the majority of Jordanian elites described themselves as liberals.

In the third section of the analysis, the Jordanian elites' political culture towards public sector reform followed a reformist pattern on all questions in this section. All of the results indicated that Jordanian elites were capable of diagnosing one of the most important deficiencies that can cause underdevelopment on the political, administrative, economic, and social levels which is corruption. Elites showed a progressive political culture in fighting this developmental ailment as well as fighting nepotism and the absence of transparency, accountability, and a merit system. This reformist stance most elites took accentuates their liberal values, beliefs, and attitudes and their eagerness to have serious implementation of reforms on the political, administrative, and social levels. This inference stems from the analysis of their responses to all the questions in this section.

Moreover, elites' attitudes towards institution-building reform reflected their understanding of the requirements necessary to achieve serious reforms that would lead to development. Most authoritarian regimes take bits and pieces of the reform plans and 
avoid the institutionalization of these reforms in order to delay any possibility of a change in their status quo. Nevertheless, the majority of Jordanian elites' political culture towards institution-building emphasized the presence of a progressive political culture.

The fourth section assesses elites' political party affiliation, evaluates the weakness of political party institution, political party reform, the one-man one-vote election law, the practice of lobbying, and elites' reasons for lobbying. The analysis of this section on political development puts more emphasis on Jordanian elites' liberal political culture that can be better described as rhetorical liberal culture. It is known that political parties and parliament institutions are the vehicles for political participation under the democratic political systems. However, the political party institution under the authoritative political system of Jordan was paralyzed and put under austerity measures that banned all their activities for decades. As mentioned in the literature review chapter of this study, Jordan represents a mixed system of representation that uses pluralism to stabilize authoritarianism as pluralism eases the pressure in society by allowing the masses to vent. The austerity measures of the ruling regime buttress an invisible form of authoritarianism. Therefore, the institutions of political parties and parliament are to remain weak institutions through the promulgation of laws that restrict their activities or hinder democracy such as the one-man one-vote law. Furthermore, such laws promote the campaigning culture that enhances the democratic rhetoric and façade.

By the same token, the practice of lobbying under the authoritarian regime of Jordan is another example of superficial democratic practices in an atmosphere that lacks political parties, parliament majorities, and fair and free elections. Therefore, Jordanian elites' political culture towards political development highlighted many symptoms that 
hinder liberalization, democratization, and development due to the fact that this political culture is deficient and incapable of implementing real reforms.

Likewise, Jordanian elites' political culture towards the importance of tribalism as a value for policy-makers and tribalism influence on political and social development, women empowerment, civic affiliation, and NGO sovereignty also indicated a similar cautious political culture that underlined the problems of underdeveloped social situations without presenting any solution. For instance, Jordanian elites' values, beliefs, and attitudes condemned the regime's use of tribalism as a tool to pursue certain political agendas, yet they would consider filling the gap that the regime created by curtailing the activities of political parties by tribes and tribal affiliations. In addition, some elites consider tribalism to be a substantial phenomenon for political and social stability. The analysis shows that Jordanian elites expressed their political culture with modern and liberal language, yet they simultaneously reveal traditionalistic and conventional thinking.

In the field of women empowerment, liberalism and modernity followed the conventional mentality that is proportionate to the regime's policies of women empowerment. Their ideas are suitable for the regime's policies; however both men and women after all, are Jordanian citizens ruled by the same authoritarian political system. If men are not empowered, then women are not empowered. Under an authoritarian political system, all citizens are not empowered because political participation remains restricted. Therefore, Jordanian women will remain only empowered to a certain extent under the current authoritarian regime. 
Civic engagement and the affiliation with cultural national and international organizations are subject to several restrictive rules enforced by the government to curtail and restrict all the activities of the nonprofit organizations and keep them under the control of its security apparatus. The abundance of nonprofit organizations in Jordanian society can be confusing to some because to have over 6,000 nonprofit organizations in a lightly populated country is alarming. However due to the lack of democracy and strict supervision of the regime and security forces, these nonprofit organizations will remain toothless; particularly with cautious liberal elites.

The analysis of the economic development field underlined a political culture that sounds radical, yet incapable of enforcing and implementing real economic liberalization that would tighten the gap between the haves and have-nots in the society and help ameliorate the economic situation in Jordan. Elites' political culture sounded extremely enterprising and reformist, but the majority of elites expressed that unless change comes from the institution of the palace, there will be no real implementation of reforms.

\section{2) Significant Differences}

The purpose of this analysis and the hypothesis testing was to look for different patterns among elites' values, beliefs, and attitudes to assess whether the three groups of elites are different in their political culture or not. The analysis of results concluded that there are very few significant differences between the means of the three groups of elites. The first section of the analysis on political development indicated no significant differences between the means of the three groups. However, the second and third 
sections contained some significant differences between the political culture of one group and the political culture of the other two groups.

The absence of significant difference stresses the similarity among the values, beliefs, and attitudes of the three groups of Jordanian elites, which implies that there is a strong consensus among the values, beliefs, and attitudes of the political, social, and economic Jordanian elites towards liberalization, democratization, and political, social, and economic development.

\section{3) Jordanian Elites Political Culture Concerning the Centers of Power in}

\section{Jordan}

Most of elites' responses to the open-ended questions consisted of a repeated term of the "Old Guards." There is a strong belief among Jordanian elites that the main culprit for the country's stagnant state of development is the influence and power of the Old Guards whose grip on the country and all its institutions has been tightened and supported by the institution of the Palace. Most elites believe that the monarchical system guarantees the political and social stability in the Jordanian society that has a greater majority of Palestinians. Thus, most elites believe monarchy balances both components of the society believe it should be sustained.

Some East Bank elites expressed their beliefs very loudly by criticizing the most influential elites who are in the center of power and considered them the most responsible for the deterioration of the liberalization and development movement.

The Old Guards are mainly the army generals, highly ranked security apparatus officers, some of the ex-Prime Ministers, and other influential tribal members who 
occupy high incumbents in the government and the Royal Court. These influential figures are in the center of the Jordanian elites' strata; they were criticized and condemned throughout the interviews for all the deterioration and stagnation in Jordan.

The Old Guards hinder the progress of development through their positions in the security forces. According to the majority of elites, they are the ones to be blamed as they thwart any endeavor of serious reforms that might weaken their influence and powerful grip.

Some of the literature that studied the Jordanian case explained who the Old Guards are and how they have become since the establishment of the state in the center of power. The patron-client relationship has taken place between the Old Guards and the King through a series of bargains and mutual interests that resulted in a similar situation for both sides. Each side depends on the other, and each side defends the existence, strength, and legitimacy of the other. Using tribalism as a tool for the pursuit of certain political agendas, the empowerment of the East Bank Jordanians, the discrimination against the West Bank Jordanians, emphasizing the political culture of "Jordan First," and the creation of social factions are methods used by the regime for enhancing the power and influence of the Old Guards over the rest of the society. This political culture is justified by the Palace and is considered the backbone of Jordan's social and political stability.

\section{4) The Congruence between the Regime and Elites' Political Culture}

The analysis of these results indicated that most Jordanian elites have expressed criticism of the government's reform policies and lack of seriousness in the 
implementation of reforms which led to the deterioration of the liberalization, democratization, and development. Most of the elites, who condemned the regime and the Old Guards for the stagnant situation in Jordan, are themselves responsible for this deterioration, as they occupy the highest incumbents in the government and army. Additionally, some of them were Ex-Prime Ministers or Ex-security apparatus highly ranked officers.

The criticism did not provide alternatives or agendas for correcting underdevelopment, but rather illuminated all the flaws without a plan or mechanism for improvement. This criticism was destructive and did not offer any solutions for how the country can aim to get on the right track for liberalization and democratization. Whether these figures who made critiques of the situation where legislators, ministers, political party leaders, or CEOs in the private sector, they are all actually the participants who play the main role in Jordanian governance. At the beginning of each interview, each of these figures expressed that they enjoy their self-determination and ability to make policies or impact policy-making; hence their criticism suggests that they themselves are the culprit.

Conclusively, this is the reason why the analysis suggests that the regime is congruent with the political culture of Jordanian elites and in most cases, $\mathrm{H} 2$ was supported. This confirms that Jordanian elites are weak legislators, explaining why they are cautious liberals and reformers. The passivity of their stances implied great fear in any change to the political system which would jeopardize their positions in the government or negatively affect their rankings. 


\section{Limitations}

One of the potential limitations of this study is in its methodological premise. In accordance with Putnam's (1971) study on elite political culture and ideology, this study underlines the sophisticated and complex political belief systems of political leaders that cannot be justified by crude techniques of survey research design. The cruder techniques of a survey design, for instance, cannot do justice in perceiving the subtleties and nuances in elites' responses to various political issues. This becomes critical when analyzing and understanding their philosophies. Everything they say adds weight to the precision of critiquing their values, beliefs, and attitudes. This is the reason why elite theorists who studied elites' political culture reflected on the consequent methodological difficulties and provided a solution for overcoming this difficulty by linking the problem to psychoanalytic techniques. So the "true" insights and what demonstrably "feels true" can create a validity dilemma. This necessitates a method of inquiry that is cable of drawing these conclusions without doing any injustice to the validity of data. However, this dilemma remained without a perfect solution.

Accordingly, the researcher's fundamental methodological premise of this study on Jordanian elites' values, beliefs, and attitudes was to communicate with them systematically by listening carefully to their responses and additional elaborations, which they tended to make even while responding to the closed-ended questions. As explained in Chapter 3 of this study, in an attempt to avoid any possible injustice to the validity of the gathered data, the researcher used paraphrasing as a method to confirm respondents' answers and additional comments by repeating their words back to them. This allowed the researcher to receive feedback to confirm the internal validity of the gathered data. 
Furthermore, the nature of the Jordanian political environment that is subject to the authoritarian government and political system is another potential limitation of this study. The limitations that are a consequence of this nature made it difficult for elites to criticize the regime and its policies. This resulted in having to design the questionnaire according to this political environment. The consequences of designing the questionnaire this way presented themselves in both the closed- and open-ended versions of the question. This is because operating under an authoritarian regime comes with implications that high governmental officials approve of the regime's approach to governance. Thus, elites were hesitant at first when voicing true thoughts and beliefs about the government. They persistently required confirmation that their identities were to remain anonymous for this study and that their names would not be published in any work.

The very first question in the survey asked elites if they personally have any impact on policymaking. The purpose of designing the survey so that this question was asked first was to measure their self-determination in making and implementing policies. The goal was also for them to define their own responsibilities. Formulating the questions and translating them from English to Arabic as suggested by Jordan University's Center for Strategic Studies (CSS) aided in ensuring the reliability and internal validity of the research. The accuracy and precision of the data were heavily taken under consideration of the researcher through the coding process of qualitative data.

When the following questions asked about the administration or the government, it was implied that the questions asked the elites about themselves personally, as they are the policymakers who are representing the government. Designing some of the survey 
questions indirectly aimed to prevent elites from responding with "I don't know" or rejecting the question altogether.

The imbalance among the three groups of elites, as explained in Chapter 3, is not a limitation, but it is due to an imbalance in the population. The numbers of elites who belong to the three groups were 65/23/12. This imbalance was uncontrollable and had its reasons, as the governmental incumbencies were granted by the King to certain intelligentsia members or to prominent economic elites. In this case, the prominent economic elites who have become members of the Senate would classify themselves as political elites rather than economic elites. Therefore, the disproportionate sample of this study represents the disproportionate distribution in the population.

Another limitation is that when elites were asked dichotomous questions that could be answered with "yes" or "no," many strayed away from these two options and instead would answer with "sometimes." Similarly, when they were asked to describe a situation as "positive" or "negative," many would respond with "sometimes negative and sometimes positive." Because of the high frequency of receiving this middle-point response, this option was added to all surveys and considered in the scale during the analysis.

In terms of the external validity of this research, this case study of political culture of Jordanian elites who operate under the monarchical authoritarian political system can be generalized to other elites' political cultures operating under presidential or sheikhdom political systems in the Arab region. Whether the country is under a presidential system or a sheikhdom, they operate similarly to a monarchical regime. The other common factor is authoritarianism which prevails in the Arab region. This is in addition to the 
similarity of the culture in general among all Arab nations which impacts the values, beliefs, and attitudes of their policymakers. This creates a similar political culture for Arab elites. Thus, this study does not lack for generalizability.

It can be argued that these limitations did not override the findings, including the unexpected and insignificant ones. The sensitive issues and subjects under the authoritarian monarchical regime highlighted the importance of activating the liberalization and democratization transition by triggering the policymakers and people who have the most influence on the progression of development in Jordan to take a more assertive role.

\section{Implications}

The available literature on elites' political culture provides minimal insight into the values, beliefs, and attitudes of Jordanian elites. This study fills this gap by the existing consistency between the selected theoretical framework and its results. It provides answers for the research questions on the bases of its theoretical foundation. The response of the first research question that is concerned with political elites describing their political culture consists of their values, beliefs, and attitudes, and confirms all inferences that strongly support Locke's "cautious liberalism" theory.

First, on the basis of the theoretical foundation of this study, the instability of political order in Jordan remains precarious; especially when considering the slow process of liberalization, democratization, and development. Therefore, the regime, particularly the "Old Guards," or the East Bank elites who benefit from this stagnation 
are responsible for causing constant anxiety about the possibility of political degeneration caused by change.

The lack of harmony in John Locke's political theory echoes Jordanian elites' values, beliefs, and attitudes which they expressed when responding to the survey questionnaire. They answered with ambivalence due to their duel tendencies towards change. In all of their responses to questions that presented a more developed political system, elites were pro change and seemed extremely liberal; yet in response to questions that discussed implementing prime changes, they expressed conservatism by showing their reluctance to change. These types of passive-aggressive leaders who are more inclined to preserve the political order are largely responsible for the delayed journey towards liberalism and development.

For instance, the initial expectation that interviewing a group of conservative elites would yield conservative responses was not met, as elites responded quite liberally. The questionnaire consisted of certain sensitive questions which led elites to be critical of the regime and the government of which they are affiliated. However, the successful survey design enabled the researcher to overcome this limitation. As a result, the researcher collected an abundance of data expressing a progressive and reformist political culture, which did not meet the initial expectation. Nevertheless, the responses that articulated liberal values, beliefs, and attitudes were altered when the questions asked about changes in the King's prerogatives or the issues that would lead to changes in the political system. This alteration in the expressed political culture did not meet the second expectation. 
Some of the elites were more liberal than others, while the conservative "Old Guards" among them were the reluctant ones to any change in the political system. Those elites from the Old Guards are the promoters of authoritarianism, tribalism, patriarchy, the notion of "Jordan First" that deepens the social faction in the society, and intolerance. Thus, they fight against any change in the regime or the political system because it will lead to changes or put limitations in their privileges. They thwart reforms such as corruption control and consider the endeavors of activating civil society organizations or the institution of a political party an external or foreign interference that is threatening to their national security. Therefore, these institutions get deactivated by the use of the security apparatus suppression. As a consequence, the existence of the "Old Guards" lowers the activists' ceiling of liberalization and makes their mission more challenging.

In addition, the weakness of the state and its institutions remain the main reasons behind elites' apprehensions, feelings of insecurity, and ambivalence, as they fear what change will bring them; including the more liberal elites. As a matter of fact, most liberal elites in Jordan have been calling for a constitutional monarchy. There is a demand among the Jordanian intelligentsia for ending authoritarianism. However, most liberals in Jordan are not advocating for change in the monarchical system. On the contrary, they are calling for altering the rule from an authoritarian monarchy, where the power is ultimately in the hands of the King, into a constitutional monarchy ruled by rule of law. Hence by valuing a political system that contradicts with their existing political system, and ranking it "very suitable" was surprising, particularly after they expressed conservative beliefs towards other reforms that would make such a change in their political system possible. 
The conclusion can be drawn that Jordanian elites are cautious liberals, fitting with Locke's theory of 'cautious liberalism.' They opt for liberalism and democratization and for changing the status of authoritarianism in their political system, but remained fearful of the consequences of promoting changes in the political system, or expressing a political culture that is anti-Royalist.

Further, the interpretation of the findings implies, on one hand, the type of relationship between the authority patterns of the monarchical authoritarian political system and its regime that is materialized in its elites. On the other hand, the authority pattern of the various social units is incorporated in the general public and their different institutions and organizations. This relationship reflects the level of congruence between the two patterns of authority (Eckstein, 1998). The congruence theory contributes to understanding the political culture of Jordanian elites by understanding their performance level and their capability to be in agreement with their constituents from the general public and their different institutions that require governance.

The elites are part of the executive organizations of the state; thus they participate in making and implementing policies and are responsible for the achievement of good governance. This, according to Cheema, entails the coordination of "complex mechanisms, processes, relationships, and institutions through which citizens and groups articulate their interests, exercise their rights and obligations, and mediate their differences by allocating and managing all resources to respond to collective problems." If the authority patterns of the government are congruent with the authority patterns of all other units in the society, the government performs well. 
Accordingly, achieving good governance would improve the congruence in the relationship between two authority powers of the Jordanian state and society. The ability of elites to defeat the obstinate and underdeveloped political culture will help Jordan in this struggle and push the development wheel forward. This happens when all forces coordinate and collaborate to achieve stability of the political system through balanced interactions and relationships among all conflicting and consensual parties, or active and passive ones. This conductive environment, according to the theory, enhances the stability of the political system; while the authoritative or totalitarian authority patterns hinder the transition towards democracy and the stability of the political system.

However, the findings from elites' attitudes towards the lagging situation of democratic governance and their criticism of the implementation of reforms that lead to this accomplishment confirms the government's low performance level. In other words, the relationship between authority patterns of the state, government, regime, and their Jordanian elites and the authority patterns of the society forces and institutions is lacking congruence.

In capsulation, the state in Jordan, which is built on its regime, stabilized itself by allocating privileges for East Jordanians and depriving the rest of the society from the same privileges, creating disparities and factions. This contradicts with the second hypothesis of the congruence theory that suggests that the government can achieve high performance if its authority patterns are capable to make a balance among its disparities. As mentioned earlier, the Old Guards are the most influential elites whose interests are served by creating factions and disparities and by putting the spikes in the liberalization 
and democratization wheel. They are the conservative elites who carry reactionary values, beliefs, and attitudes.

\section{Conclusion}

On the basis of these results and the theoretical foundation of this study, the Jordanian elites' cautious liberal political culture does not place enough urgency on implementing serious reforms and changes to enable Jordan to achieve liberalization, democratization, and development. In addition, the requirements for achieving good governance are compound and multifaceted. The achievement of coordinated complex processes remains the chief challenge that all Jordanian authority patterns of both the state and society can face during the transitional period towards liberalization, democratization, and development. The findings signified that Jordanian elites' cautious liberal political culture; the consensus among the three groups of elites due to the scarcity of significant differences among them; the rhetorical liberalism of elites' political culture concerning the centers of power; and the congruence between the regime and Jordanian elites' political culture are all factors that contribute to the continuation of this stagnant state, which Jordan has been struggling to end.

Further, these findings provide a new perspective that emphasizes on the mutual relationship that exists between the most influential centers of power under Jordan's political system being, the King and the East Bank internal elites, and describes the political culture of Jordanian elites, illustrating the discrepancies between their claimed 
values, beliefs, and attitudes and their real political culture that remains congruent with the regime's policies of liberalization, democratization, and development. 


\section{References}

\section{Elite Theory}

Beaty, B. (2003). Democracy, Asian Values, and Hong Kong: Evaluating Political Elite Beliefs. Westport, Connecticut, London: Praeger.

Ben-Dor, G. (1984). State, Society And Military Elites In The Middle East: An Essay In Comparative Political Sociology. Tel Aviv: Tel Aviv University. Dayan Center for Middle Eastern and African Studies.

Bottomore, T. (1993). Elites and Society, Second Edition. Great Britain: T.J. Press Ltd., Padstow, Cornwall.

Lenczowski, G. (Ed.). (1975) Political Elites in the Middle_East. Washington D.C: American Enterprise Institute for Public Policy Research.

Mosca, G. (1939). The Ruling Class, First Edition. New York and London: McGraw-Hill Book Company, Inc.

Mufti, M. (1999). Elite Bargains and the Onset of Political Liberalization in Jordan, Comparative Political Studies, 32 (1), 100-129.

Pareto, V. (1974). The Ruling Class in Italy before 1900. New York: Howard Fertig.

Parry, G. (2005). Political Elites. UK: ECPR Press.

Putnam, R. D. (1976). The Comparative Study of Political Elites. New Jersey: Prentice Hall Inc.

Welsh, W. A. (1979). Leaders and Elites. United States of America: Holt, Rinehart and Winston. 
Zartman, I. W. (1980). (Ed.) Elites in The Middle East. New York, USA: CBS Educational and Professional Publishing, Inc.

\section{Political Culture}

Abdel Fattah, M. (2006). Democratic Values in the Moslem World. The American University of Cairo, Egypt : University in Cairo Press.

Almond, G. (1956). Comparative Political Systems. Journal of Politics, 18 (3), 391-409.

Almond, G. A. \& Verba, S. (1963). The Civic Culture: Political Attitudes and Democracy in Five Nations. Princeton, New Jersey: Princeton University Press.

Grant, R. W. (1987). John Locke's Liberalism. Chicago and London: The University of Chicago Press.

Hutcheon, D. P. (1970). Sociology and the Objectivity Problem. Sociology and Social Research, 55 (January), 153-171.

Hutcheon, D. P. (1972) Value Theory: Towards Conceptual Clarification. The British Journal of Sociology, 23 (2), 172-187.

Putnam, R. D. (1971). Studying Elites Political Culture: The Case of Ideology. The American Political Science Review, 65 (3), 651-681.

Putnam, R. D. (1973). The Beliefs of Politicians: Ideology, Conflict, and Democracy in Britain and Italy. New Haven and London: Yale University Press.

Putnam, R. D. (1976). The Comparative Study of Political Elites. New Jersey: PrinticeHall, Inc.

Pye, L. W. \& Verba, S. (Ed.). (1967). Political Culture and Political Development. Princeton, U.S.A: Princeton University Press. 
Rokeach, M. (1960). The Open and Closed Mind: Investigations into the Nature of Belief Systems and Personality Systems. New York: Basic Books.

Rokeach, M. (1970). Beliefs, Attitudes, and Values: A Theory of Organization and Change. San Francisco: Jossey-Bass Inc., Publishers.

Rokeach, M. (1973). The Nature of Human Values. New York: Macmillan Publishing Co., Inc.

Scheibe, E. K. (1970). Beliefs and Values. United States of America: Holt, Rinehart and Winston, Inc.

Verba, S. \& Norman H. \& Nie Jae-On Kim (1966). Political Participation and Equality In Seven Nations, 1966-1971. Ann Arbor, MI: Inter-university Consortium for Political and Social Research. Retrieved from http://doi.org/10.3886/ICPSR07768.v1

\section{Political Development}

Al-Khalidi, S. (2011, June). Jordan's Old Guards Thwart Reform Drive. Reuters Editions. Retrieved from http://www.reuters.com/article/2011/06/30/us-jordan-reformsidUSTRE75T1X120110630

Bellin, E. (2004). The Robustness of Authoritarianism in the Middle East: Exceptionalism in Comparative Perspective. Comparative Politics, (January) 139-153.

Bianchi, Robert (1986) Interest Group Politics in the Third World, Third World Quarterly, 8 (2), 508-512.

Brynen, R., \& Korany, B., \& Noble, P., (1995). Political Liberalization and Democratization in the Arab World: Volume I. United Kingdom, London: Lynne Reinner Publishers.

Brynen, R., \& Korany, B., \& Noble, P., (1998). Political Liberalization and Democratization in the Arab World: Volume II. United Kingdom, London: Lynne Reinner Publishers. 
Brynen, R., \& Moore, P. M., \& Salloukh, B. F., \& Zahar, M. J. (2012). Beyond the Arab Spring: Authoritarianism \& Democratization in the Arab World. United Kingdom, London: Lynne Reinner Publishers.

Cheema, Shabbir G. (2005). Building Democratic Institutions: Governance Reform in Developing Countries, CT, USA: Kumarian Press, Inc.

Eckstein, H. \& Fleron. F. J. Jr., \& Hoffmann, E. E., \& Reisinger, W. M. (1998). Can Democracy Take Root in Post-Soviet Russia? Explorations in State Society Relations. New York: Rowman \& Littlefield Publishers, Inc.

Freedom House (2013).

Retrieved from http://freedomhouse.org/report/freedom-world/2013/jordan\#.UvPUe3-YbIU

Hudson, M. C. (1977). Arab Politics: The Search for Legitimacy. New Haven: Yale University Press.

Hudson, M. C. (2001). The Middle East. Political Science and Politics, 34 (4), 801-804.

Kamrava, M. (1998). Frozen Political Liberalization in Jordan: The Consequences For Democracy. Democratization, 5 (1), 138-157.

Linz. J. J. (2000). Totalitarian and Authoritarian Regimes. Boulder, London: Lynne Rienner Publishers.

Lucas, R. E. (2004). Monarchical Authoritarianism: Survival \& Political Liberalization in a Middle Eastern Regime Type. International Journal of Middle East Studies. 36, 103-119.

Lust-Okar, E. M. (2001) The Decline of Jordanian Political Parties: Myth or Reality? International Journal of Middle East Studies, 33 (4).

Lust-Okar, E. (2004). Structuring Conflict in the Arab World: Incumbents, Opponents, And Institutions. U.K.: Cambridge University Press.

Majed, Z. (Ed.) . (2005). Political Conditions in Jordan. In Building Democracy in Jordan. International Institute for Democracy and Electoral Assistance (IDEA) 
and the Arab NGO Network of Development (ANND). Stockholm, Sweden: Trydells Tryckeri AB.

Krasner, S. (1983). What is a Regime? International Regimes. p. 344. Ithaca: Cornell University Press.

The Jordanian National Charter. June (1991).

The National (May 28, 2010). In Jordan, one man, one vote, one controversy. Retrieved from

http://www.thenational.ae/news/world/middle-east/in-jordan-one-man-one-voteone-controversy\#ixzz2mdA5zNAR.

Wiktorowicz, Q. (1999) The Limits of Democracy in the Middle East: The Case of Jordan. Middle East Journal, 53 (4), 606-620.

\section{Social Development}

Al Attiyat, I. (2005). Building Democracy in Jordan: Women's Political Participation. International Institute for Democracy and Electoral Assistance (IDEA) and the Arab NGO. Retrieved from http://www.idea.int/publications/dem_jordan/upload/Jordan_country_report_En glish.pdf

Al Madhoun, S. (2009). Advancing Access to Information in the Middle East and North Africa Region: Supporting Coalitions and Networks. Supported by the World and the World Bank MNA. Jordan. Retrieved from http://wbi.worldbank.org/wbi/Data/wbi/wbicms/files/drupalacquia/wbi/Almadhoun-ATI_in_MNA_Region_ENGLISH.pdf

Al Oudat, M. A. \& Alshoboul, A. (2010). Jordan First: Tribalism, Nationalism and Legitimacy of Power in Jordan. Intellectual Discourse, 18 (1) 65-96.

Bealey, F. (1999). The Blackwell Dictionary of Political Science. Massachusetts: Blackwell Publishers.

Center for Strategic Studies. Al-Nitham Al-Qabali fi Al-Urdon. The Tribal System in Jordan. (1999). Amman, Jordan. 
Faulks, K. (2000). Political Sociology. Washington Square, New York: New York University Press.

Gubster, P. (1983), Jordan Crossroads of Middle Eastern Events. Boulder, Colorado: Westview Press.

Jabbra, J. G. (Ed.) (1989). Bureaucracy and Development in the Arab World. Netherlands: E. J. Brill.

Jureidni, P. A. \& McLaurin, R.D. (1984). Jordan: The Impact of Social Change on the Role of the Tribes. New York: Praeger.

Kechihian, J. A. (2008). Power and Succession in Arab Monarchies: A Reference Guide. London: Lynn Reiner Publishers.

Metz, H.C., (1989) ed. Jordan: A Country Study U.S. Library of Congress Retrieved from http://countrystudies.us/jordan/29.htm

Pettygrove, M. W. (2006) Obstacles to Women's Political Empowerment in Jordan: Family, Islam, Patriarchic Gender Roles. Independent Study Project.

Robins, P. (2004). A History of Jordan. Cambridge. New York: University Press. Salibi, Kamal (1993) The Modern History of Jordan. I.B. London and New York: Tauris \& Co. Ltd.

Shlaim, A. (1995). War and Peace in the Middle East: A Concise History. New York: Penguin Books.

Shlaim, A. (2007). Lion of Jordan: The Life of King Hussein in War and Peace. UK: Penguin Books.

Smith, P. A. (1986). Wealth and Power in the Middle East: The Exile Bourgeoisie of Palestine. MERIP Middle East Report. (142), 23, 26-27.

Snow, P. (1972). Hussein: A Biography. New York: Robert B. Luce, Inc.

Thomas, M. (2003). Bedouin Tribes and the Imperial Intelligence Services in Syria, Iraq, \& Transjordan. Journal of Contemporary History, 38 (4).

Tribal Sentiments on the Rise among Jordanian Students. Amman, Jordan: The Jordan Times, 30 (October), 2009.

Wiktorowicz, Q. (2000). Civil Society as Social Control State Power in Jordan. Comparative Politics, 33 (1), 43-61. 


\section{Economic Development}

Barkey, H. J. (Ed.). (1992). The Politics of Economic Reform in the Middle East. New York: St. Martin's Press.

Brynen, Rex (1992) "Economic Crisis and Post-Rentier Democratization in the Arab World: The Case of Jordan” Canadian Journal of Political Science, 25 (1), 69-97.

Greenwood, S. (2003). Jordan's New Bargain: "The Political Economy of Regime Security.” Middle East Journal, 57(2), 248-268.

IMF Reaches Staff-Level Agreement with Jordan on its Request to Support a National Reform Program Through a Stand-By Arrangement (2012). International Monetary Fund (IMF). Retrieved from http://www.imf.org/external/np/sec/pr/2012/pr12275.html

Knowles, W. M. (2001) Changing Patterns of Rent: State, Private Sector, and Donors in Jordan, 1989-2000, Durham Thesis, Durham University. Retrieved from http://etheses.dur.ac.uk/3846/1/3846_1407.pdf

Lipset, S. M. (1959). Some Social Requisites of Democracy: Economic Development and Political Legitimacy. The American Political Science Review, 53 (1) 69-105.

Sitiglitz, Joseph E. (2003) Globalization and its Discontent. W. W. Norton and Company: New York and London.

The World Bank. (2014). GDP current (US \$). Retrieved from http://data.worldbank.org/indicator/NY.GDP.MKTP.CD

The World Bank. (2014). GDP per capita growth in Middle Eastern countries between the period 1973-1984: Jordan, Egypt, Syria, Morocco. Retrieved from http://search.worldbank.org/all?qterm=DP+per+capita+growth+in+Middle+Easter $\mathrm{n}+\mathrm{cou}$ ntries+between+the+period+1973$\% 091984 \% 3 \mathrm{~A}+\mathrm{J}$ ordan\%2C+\%09Egypt\%2C+Syria\%2C+Morocco.\&title=\&filety $\mathrm{pe}=$

Rostow, W. W. (1960). The Five Stages of Growth. In The Economic Growth: A NonCommunist Manifesto. Cambridge University Press.

United Nations (2007). Civic Engagement in Public Policies: A Toolkit. (2007). United Nations. New York: United Nations Publications. 
United Nations in Jordan, Country Profile (2013): Location, Politics, population, and Economy. Retrieved from

http://www.un.org.jo/index.php?page_type=pages\&page_id=393

\section{Methodology}

Alwin, D. F., \& Krosnick, J. A. (1985). The measurement of values in surveys: A Comparison of ratings and rankings. Public Opinion Quarterly, 49, 535-552.

Boyatzis, R. E. (1998) Thematic Analysis and Code Development: Transforming Qualitative Information. Thousand Oaks, California: Sage Publications, Inc.

Braizat, F. (2006). Jordan Report. Arab Barometer Survey Project. Amman, Jordan: Center for Strategic Studies. University of Jordan.

Converse, J. M. (1984) Strong Arguments and Weak Evidence: The Open/Closed Questioning Controversy of the 1940s, The Public Opinion Quarterly, 48 (1) 267282.

Converse, J. M., \& Presser, S. (1986). Survey Questions Handcrafting The Standardized Questionnaire. London: Sage Publications.

Kirk, J. \& Miller, M. L. (1987). Reliability and Validity in Qualitative Research. California: SAGE Publications, Inc.

Mishler, E. G. (1986). Research Interviewing: Context and Narrative. Cambridge, Massachusetts: Harvard University Press.

Organizations and Cultures: Attitudes. Retrieved from http://marialpanta.blogspot.com/2011/03/attitudes.html

Premium Data Processing and Research (2013). Confidentiality and Anonymity http://www.sentenium.com/ 


\section{Appendix A \\ Geographical Location \& Map of Jordan}

Map 1.1 The Hashemite Kingdom of Jordan

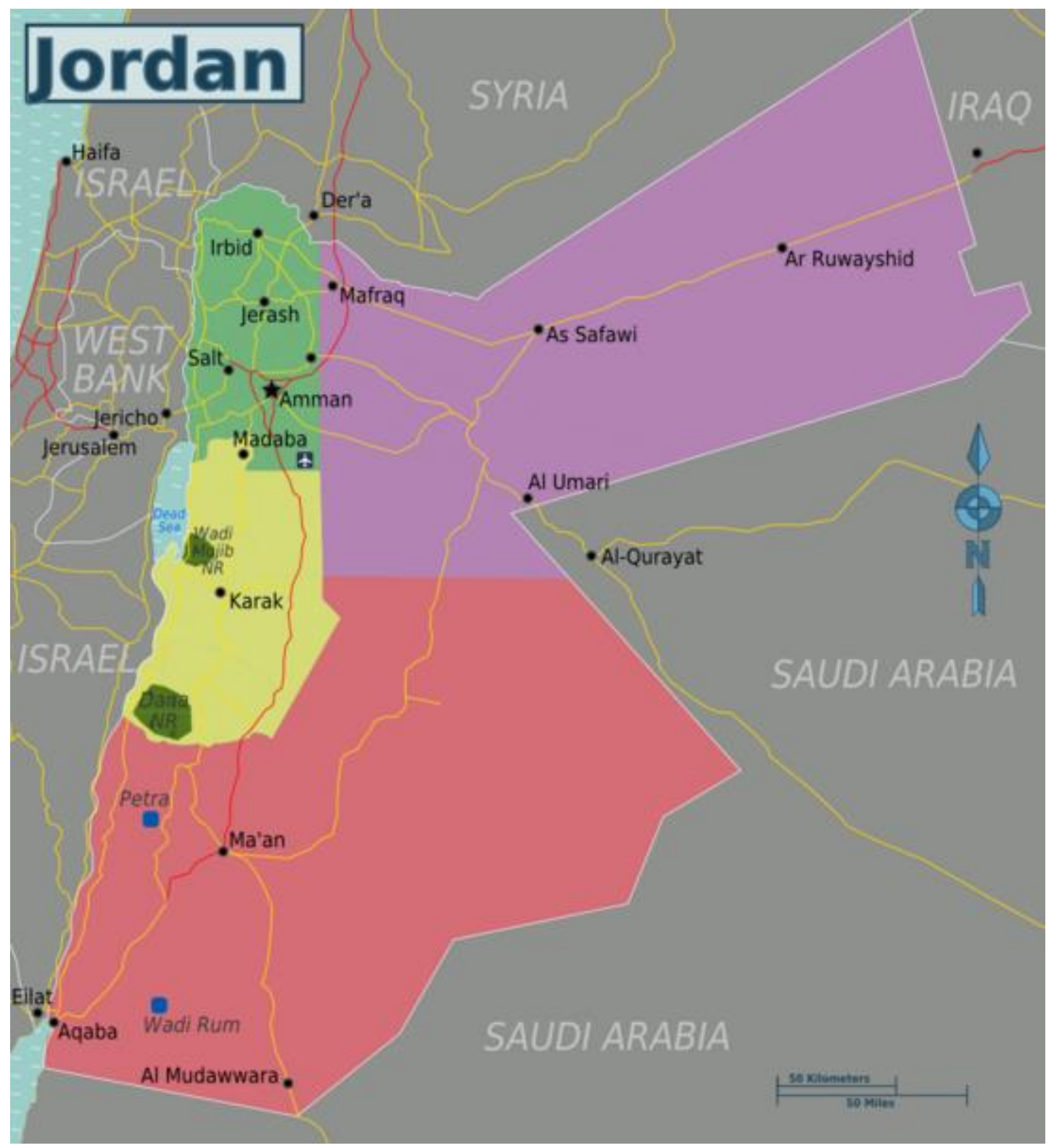




\section{Appendix B \\ Demographics: Social and economic statistic of a human development}

Figure 2.1 Population Growths in Jordan 2012-2013

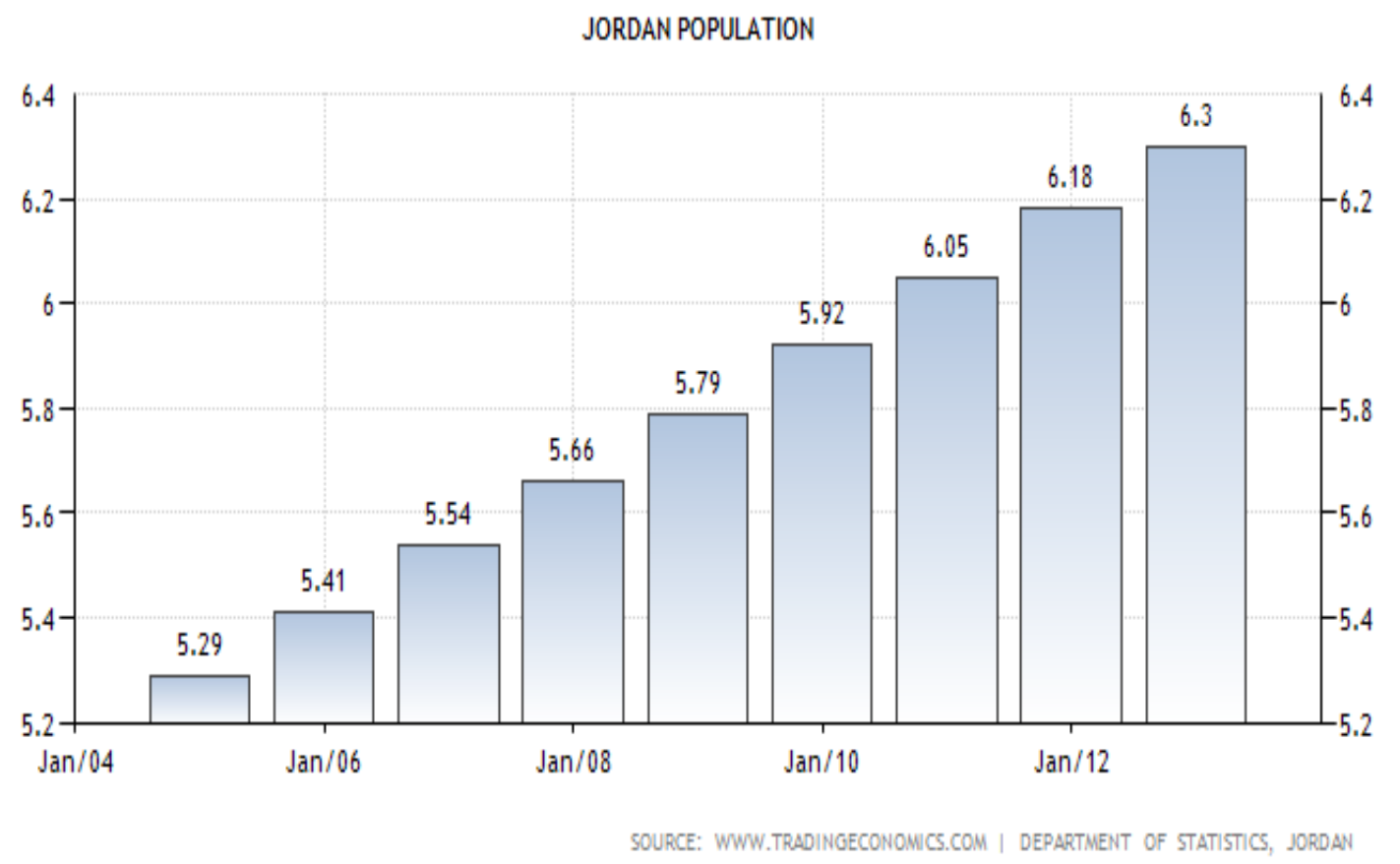
$2012-12-$
31
6.18
6.30
0.84
6.42
2013-12-
MILLION

\section{POPULATION}


Transjordanian Tribes

Map 2.1

Origins of East Bank Elites

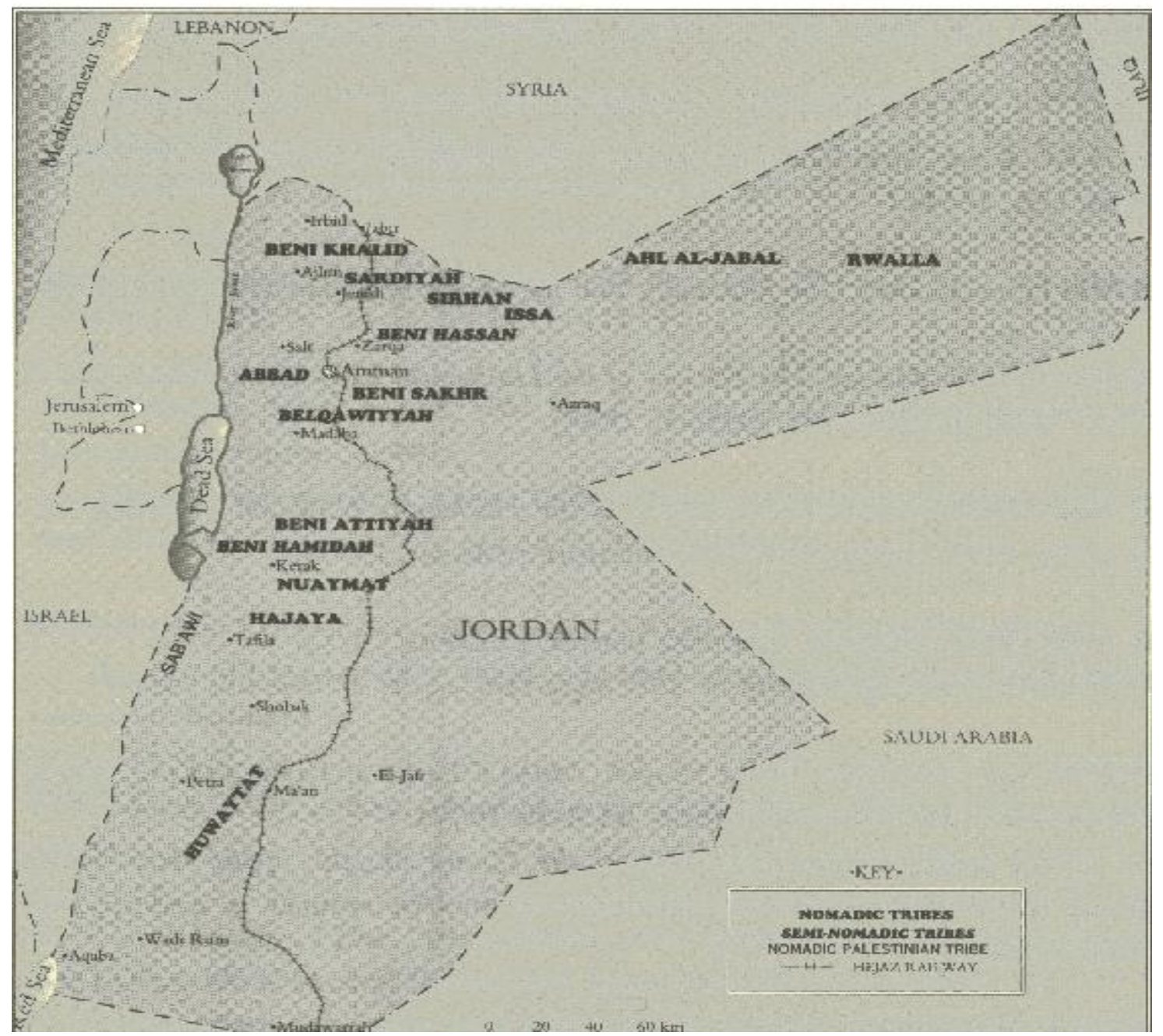


Table 2.1 GNI Ger capita / PPP from 1989 to 2012

\begin{tabular}{|c|c|c|c|c|c|}
\hline Country & 1989 & 1990 & 1991 & 1992 & 1993 \\
\hline Jordan & 2,260 & 2,270 & 2,060 & 2,420 & 2,510 \\
\hline Egypt & 2,180 & 2,310 & 2,410 & 2,540 & 2,620 \\
\hline Morocco & 1,740 & 1,890 & 2,040 & 1,980 & 1,950 \\
\hline Syria & 1,890 & 2,070 & 2,240 & 2,540 & 2,660 \\
\hline Country & 1994 & 1995 & 1996 & 1997 & 1998 \\
\hline Jordan & 2,600 & 2,750 & 2,770 & 2,870 & 2,930 \\
\hline Egypt & 2,760 & 2,920 & 3,090 & 3,280 & 3,400 \\
\hline Morocco & 2,180 & 2,040 & 2,310 & 2,270 & 2,460 \\
\hline Syria & 2,970 & 3,120 & 3,160 & 3,040 & 3,230 \\
\hline Country & 1999 & 2000 & 2001 & 2002 & 2003 \\
\hline Jordan & 3,010 & 3,230 & 3,420 & 3,550 & 3,690 \\
\hline Egypt & 3,590 & 3,810 & 3,970 & 4,020 & 4,160 \\
\hline Morocco & 2,470 & 2,530 & 2,760 & 2,870 & 3,090 \\
\hline Syria & 3,060 & 3,120 & 3,320 & 3,480 & 3,530 \\
\hline Country & 2004 & 2005 & 2006 & 2007 & 2008 \\
\hline Jordan & 4,070 & 4,450 & 4,860 & 5,330 & 5,660 \\
\hline Egypt & 4,370 & 4,630 & 5,210 & 5,540 & 5,940 \\
\hline Morocco & 3,310 & 3,500 & 3,840 & 4,020 & 4,270 \\
\hline Syria & 3,830 & 4,080 & 4,270 & 4,510 & 4,600 \\
\hline Country & 2009 & 2010 & 2011 & 2012 & 2013 \\
\hline Jordan & 5,820 & 5,750 & 5,870 & 5,980 & \\
\hline
\end{tabular}




\begin{tabular}{lllll} 
Egypt & 6,130 & 6,300 & 6,290 & 6,450 \\
Morocco & 4,410 & 4,580 & 4,840 & 5,060 \\
Syria & 4,760 & 4,800 & & 5,120 \\
\hline
\end{tabular}


Figure 2.2 GNP Growth Rate

GNP (PHP billion) and GNP growth rate ( $\%)$

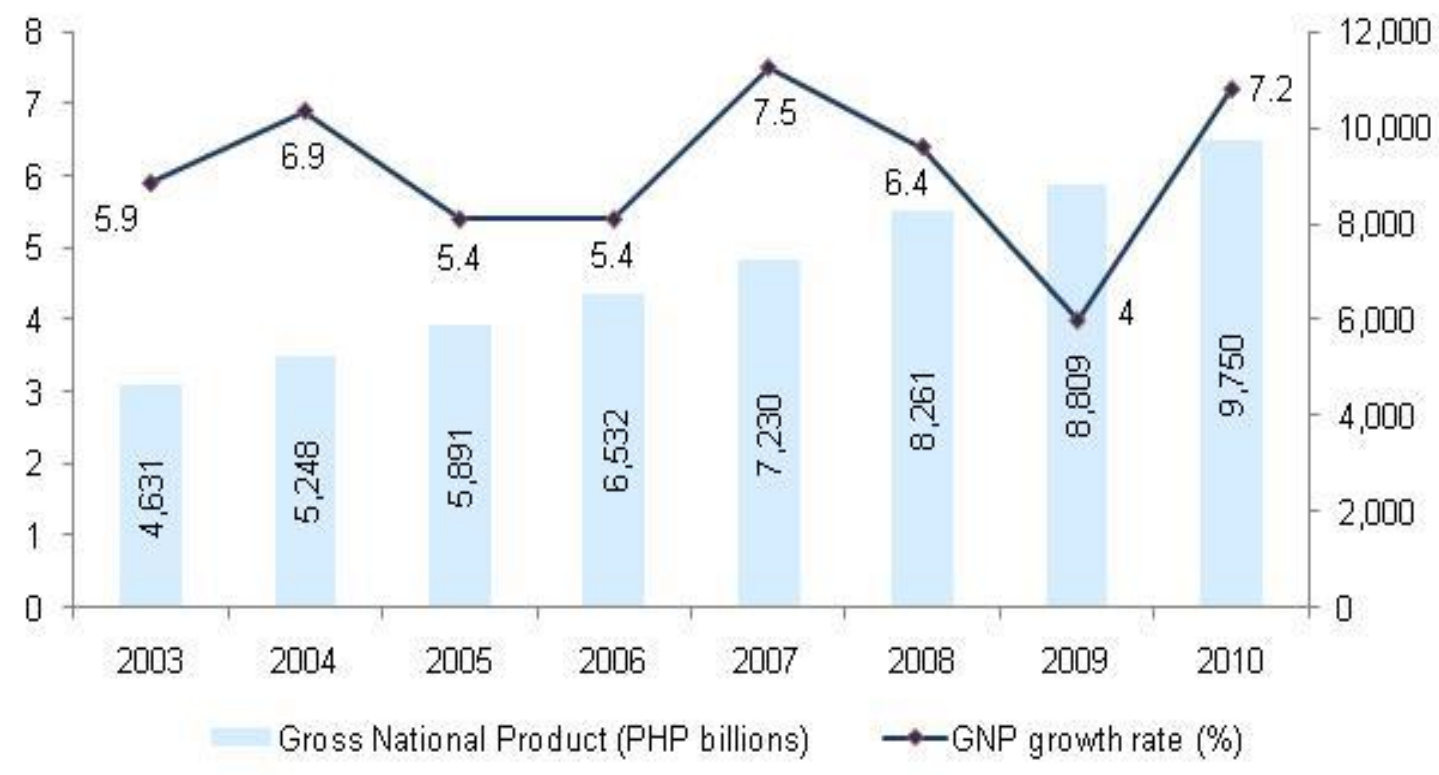


Services: Tourism and Health Sectors

Tourism is one of the Kingdom's largest export sectors. It enhances the national economy and GDP rates. Tourism is Jordan's second largest private sector employer and the second highest producer of foreign exchange contributing more than $\$ 800$ million to Jordan's economy and accounts for approximately 10\% of the country's GDP. Further, the health industry is one of the most important in Jordan's economy. According to Jordan's Private Hospital Association site, due to Jordan's rapidly developing international reputation for high quality, affordability and internationally competitive healthcare costs, its medical tourism is on the rise. There are nine Joint Commission International (JCI) accredited hospitals. Over 250,000 patients travelled to Jordan in 2012 and the number is growing each year. 
UNDP: Human Development Index (HDI)

United Nations Development Program (UNDP) tracks the economic health of a country from a human development perspective using the human development index (HDI); a composite of statistics of life expectancy, education, and income indices, and introduces these indices to view the potential human development level by ranking countries into different tiers. According to the UNDP report (2013), Jordan's HDI level is 0.700, which comparatively ranks Jordan's human development level as medium on a global scale. However, in comparison to other Arab countries in the regions, Jordan's rates of education, literacy, and measures of social well-being are relatively high. The macroeconomic stability that has been achieved since the 1990s is one of the most important factors in the government's efforts that contribute to the improvement of Jordanian citizens' well-being. 
Figure 2.3 Economic Liberalization and Freedom
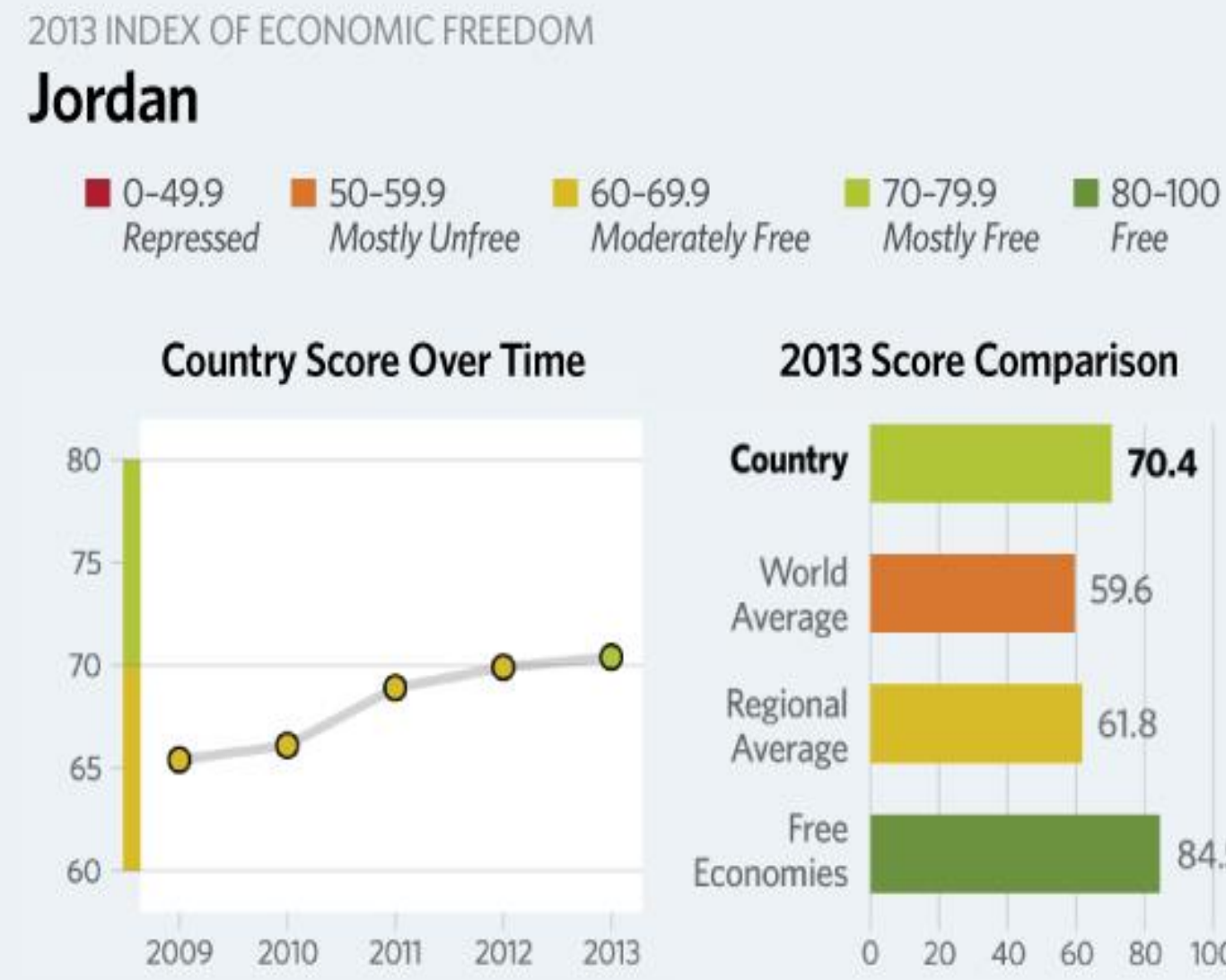

\section{Score Comparison}

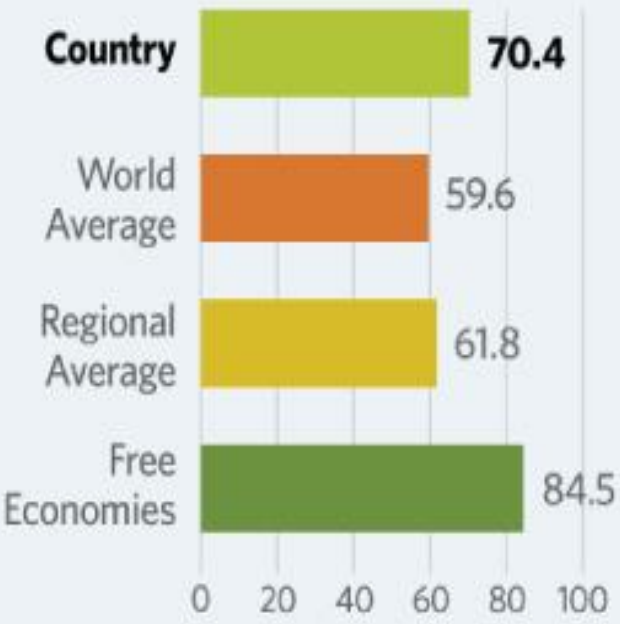

Sources: Terry Miller, Kim R. Holmes, and Edwin J. Feulner, 2013 Index of Economic Freedom (Washington, D.C.: The Heritage Foundation and Dow Jones \& Company, Inc., 2013), http://www.heritage.org/index. 


\section{Appendix C Human Subjects, Informed Consent, \& Survey questionnaire}

The Positions of the Survey Participants

The table below provides the list of positions held by the Jordanian elites, who participated in the survey.

Table 1 Political, social, \& economic elites' positions

Elites' Positions

$\mathrm{N}$

I. Political

65

I.1 High-level Governmental Positions

I.1. a) Present \& ex-prime ministers \& ministers 11

I.1. b) Present \& ex-Parliament members 16

I.2. Political Parties

1.2) Leaders \& Secretaries General

08

I.3) Administrations \& Bureaus of Ministries \& Divisions

$\begin{array}{ll}\text { I.3.a) Trustees \& under secretaries } & 07\end{array}$

I.3.b) Administrative \& Bureau Executives \& G.Ms 11

I.4. Unions \& Syndicates

I.4) Unions \& Syndicate Secretary General 
II. Social

II. Intelligentsia

II.1) University Professors 10

$\begin{array}{ll}\text { II.2) Writers } & 10\end{array}$

II.3) NGO Leaders 03

III. Economic

III Business

$\begin{array}{ll}\text { III. 1) CEOs } & 08\end{array}$

$\begin{array}{ll}\text { III.2) Business Chairs } & 04\end{array}$

Total

100 


\section{Informed Consent}

You are invited to participate in a research study conducted by Laila Huneidi from Portland State University, Public Administration and Policy. The researcher hopes to learn about the centers of influence and elites' political culture towards liberalization, democratization, and development in Jordan. This study is being conducted in partial fulfillment of the requirements for a doctoral degree, and it is under the supervision of a specific faculty member at PSU. You were selected as a possible participant in this study because you belong to the top officials in the Jordanian government.

If you decide to participate, you will be asked to sign an informed consent form, answer oral interview questions, and answer a short closed-ended questionnaire. All the activities can be done in one appointment if your time allows, or I can come back for the interview. Your answers are extremely valuable to my study, which its result will benefit the country in its transition toward democratization and will benefit all decision makers in the country and the rest of the Jordanian public. I can come to your office when your time allows for the interview and I will not take much of your time. I will take notes of your answers and there will be no audio- or videotaping through the whole meeting. While participating there will be no risks. All the activities will be anonymous and your identity will be kept confidential through the whole study. There will be no obligation to answer any of the questions if you chose not to answer.

Any information that is obtained in connection with this study and that can be linked to you or identify you will be kept confidential, or otherwise in a paper, thesis, dissertation, journal or newspaper article, on the web or in a presentation, a statement must be added to that effect. If information will be released, it will be released for educational purposes in a class lecture or for completion of a dissertation that will be presented for a committee from Portland State University professors. There will be no disclosure of names or identities and this information will be kept confidential during the data collection and data analysis stages by using a special coding system that I have created particularly for data storage procedures.

Your participation is voluntary. You do not have to take part in this study, and it will not affect my PhD or my relationship with Portland State University. You may also withdraw from this study at any time without affecting my $\mathrm{PhD}$ or my relationship with Portland State University.

If you have concerns or problems about your participation in this study or your rights as a research subject, please contact the Human Subjects Research Review Committee, Office of Research and Sponsored Projects, 111 Cramer Hall, Portland State University, (503) 725-4288 / 1-877-480-4400. If you have questions about the study itself, contact Laila Huneidi at 0779930099.

Your signature indicates that you have read and understand the above information and agree to take part in this study. Please understand that you may withdraw your consent at anytime without penalty, and that, by signing, you are not waiving any legal claims, rights or remedies. The researcher will provide you with a copy of this form for your own records. 
Signature

Date

\section{Survey Questionnaire}

A Survey on the Values, Beliefs, \&Attitudes of Jordanian Elites towards liberalization, Democratization \& Development

Application Number:

Interviewees Information

\begin{tabular}{|c|c|c|}
\hline \multicolumn{3}{|c|}{ Interviewees Information } \\
\hline I. Interviewees & $\begin{array}{l}\text { I.1. High-level Governmental Positions } \\
\text { I.1. a) Present \& Ex-Ministers } \\
\text { I.1. b) Present \& Ex-Parliament members } \\
\text { I.2. Political Party Leaders \& Secretaries General } \\
\text { I.2.a) Arab Land Party } \\
\text { I.2.b) Al-Ahed Party } \\
\text { I.2.c) Jordan Communist Party } \\
\text { I.2.d) Jordan Green Party } \\
\text { I. 2.e) Mission Party } \\
\text { I.2.f) Islamic Center Party } \\
\text { I.2.g) The Islamic Action Front } \\
\text { I.2.h) National Action Party (Haq) } \\
\text { I.3. Ministries, Bureaus and Administration Divisions } \\
\text { I. 3.a) Under Secretaries \& Trustees } \\
\text { I.3.b) Administrative Executives } \\
\text { I. 3.c) Bureau \& Division General Managers } \\
\text { II.1. Syndicates } \\
\text { II.1.a) Syndicate Secretary General } \\
\text { II.2.b) Union Secretary Generals } \\
\text { II.3.c) NGOs Leaders } \\
\text { II.2. Intelligentsia } \\
\text { II.2.a) University Professors } \\
\text { II.2.b) Writers } \\
\text { III. Business III.a) CEOs } \\
\text { IIL Business Chairs }\end{array}$ & $1 \_11 \ldots$ \\
\hline II. Interview Date & & \\
\hline
\end{tabular}

Research Procedures

Researcher Name : Laila Huneidi Date :

Coding Date :

Data Entry Date :

Interview Results:

1. Completed Interviews :

2. Rejected Interviews :

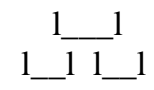


101. Do you think you currently have or have had any impact on policymaking in Jordan?

0. $\quad$ No (go to Q. 103)

1. Yes

5. Don't know (go to Q. 103)

6. No response (go to Q. 103)

102. As a policymaker, or as someone who has/had an impact on policymaking, to what extent do you believe that your political goals are/were accomplished?
1. Not at all
2. To a little extent
3. To a moderate extent
4. To a large extent
5. Don't know
6. No response

103. As a policymaker how do you rank the importance of the following values in the making of reform policies?

$(1=$ Extremely unimportant, $2=$ Unimportant, $3=$ Somehow important, $4=$ Important, $5=$ Extremely Important)

\begin{tabular}{|c|c|c|c|c|c|c|}
\hline \multicolumn{5}{|c|}{ Values Significance } & \multicolumn{2}{|l|}{ Other Concerns } \\
\hline \multicolumn{5}{|c|}{ 1. Civil rights \& freedoms } & & \\
\hline 1 & 2 & 3 & 4 & 5 & $\begin{array}{l}\text { 98. Don't know } \\
\text { 99. No Response }\end{array}$ & $1 \_1$ \\
\hline \multicolumn{5}{|c|}{ 2. Social reform through schools curricula } & 98. Don't know & $1 \_1$ \\
\hline 1 & 2 & 3 & & 5 & 99. No Response & \\
\hline \multicolumn{5}{|c|}{ 3. Economic independence of women } & 98. Don't know & 1 \\
\hline 1 & 2 & 3 & 4 & 5 & 99. No Response & \\
\hline \multicolumn{5}{|l|}{ 4. Religious values } & 98. Don’t know & $1 \_1$ \\
\hline 1 & 2 & 3 & 4 & 5 & 99. No Response & \\
\hline \multicolumn{5}{|l|}{ 5. Tribal values } & 98. Don’t know & $1 \_1$ \\
\hline 1 & 2 & 3 & 4 & 5 & 99. No Response & \\
\hline
\end{tabular}




\begin{tabular}{|cllllll|l|l|}
\hline $\begin{array}{rlllll}\text { 6. Prosperity values } \\
1\end{array}$ & 2 & 3 & 4 & 5 & & & $\begin{array}{l}\text { 98. Don't know } \\
\text { 99. No Response }\end{array}$ & \\
\hline
\end{tabular}

104. How would you rate the quality of the reform implementation by the current administration? $(1=$ Very poor, $2=$ Poor, $3=$ Standard, $4=$ Good, $5=$ Very good, $6=$ Excellent $)$

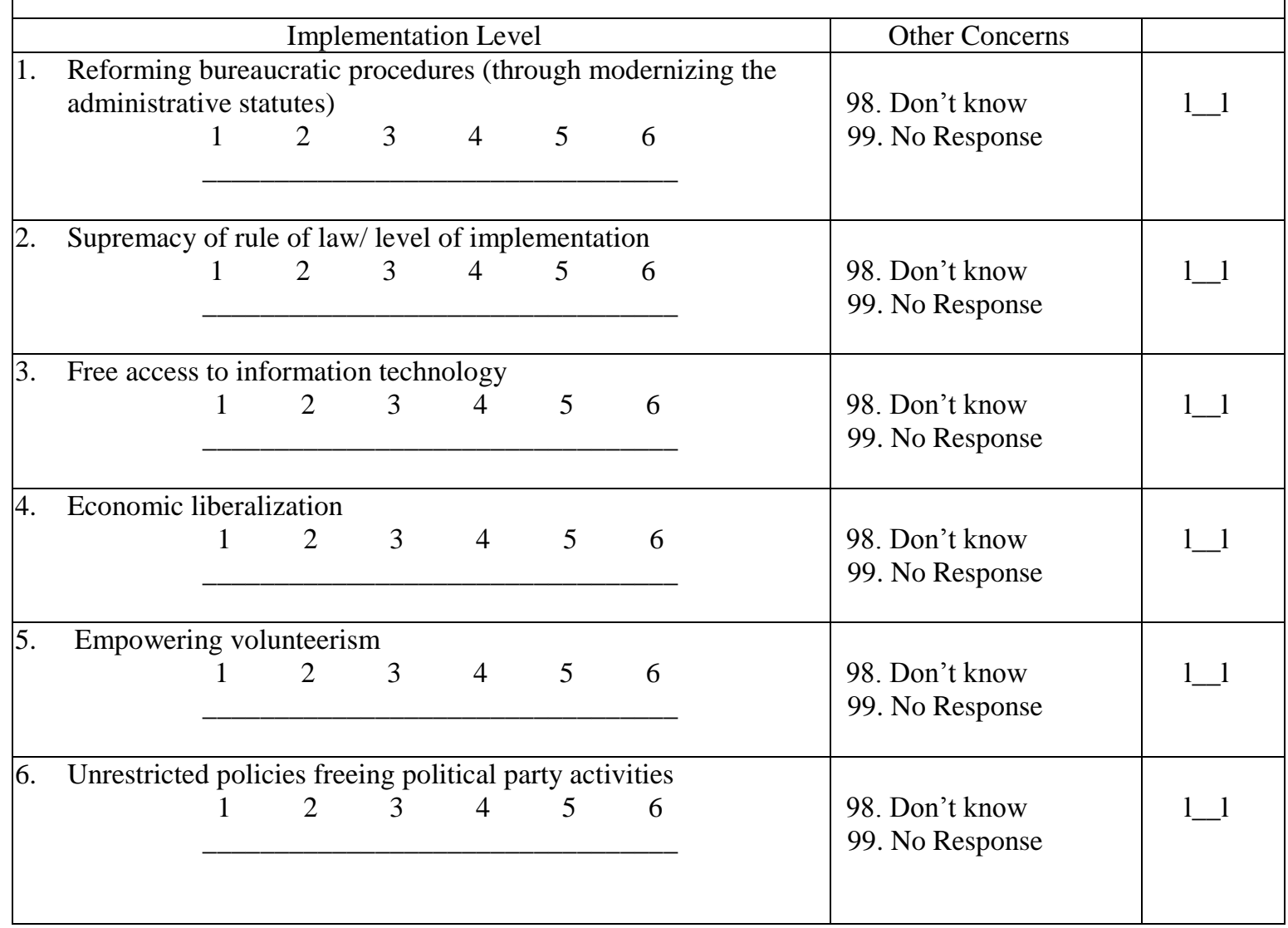

105. Describe yourself ideologically

1. Liberal

2. Independent

3. Conservative 
106. On a scale of 1-6, how do you favor the implementation of the following reforms by the Jordanian government:

\begin{tabular}{|c|c|c|c|c|c|c|c|}
\hline Reforms & $\begin{array}{c}\text { Very } \\
\text { unfavorable } \\
1\end{array}$ & $\begin{array}{c}\text { Unfavorable } \\
2\end{array}$ & $\begin{array}{c}\text { Neutral } \\
3\end{array}$ & $\begin{array}{c}\text { Favorable } \\
4\end{array}$ & $\begin{array}{l}\text { I don't } \\
\text { know } \\
5\end{array}$ & $\begin{array}{c}\text { NR } \\
6\end{array}$ & \\
\hline $\begin{array}{l}\text { 1. } \begin{array}{l}\text { Transparency \& } \\
\text { accountability }\end{array} \\
\end{array}$ & & & & & & & LI \\
\hline 2. Corruption control & & & & & & & LI \\
\hline $\begin{array}{l}\text { 3. Cooperation with } \\
\text { the private sector }\end{array}$ & & & & & & & LI \\
\hline $\begin{array}{l}\text { 4. Cooperation with } \\
\text { the Nonprofit } \\
\text { sector }\end{array}$ & & & & & & & LI \\
\hline 5. Fighting nepotism & & & & & & & LI \\
\hline 6. Merit system & & & & & & & LI \\
\hline
\end{tabular}

107. In Jordan the relationship between the public and private sectors and civil society in the delivery of public services is lagging behind.
1. Disapprove
2. Uncertain
3. Approve

108. How do you value the effectiveness of the 'Financial Disclosure Law' to ensure accountability and transparency?
1. Extremely ineffective
2. Ineffective
3. Moderately effective
4. Effective
5. I don't know
6. No Response

109. Can you mention the three most important administrative reforms that would lead to higher efficiency and productivity levels?

1__11_11_1

1_11_11_1

1_11_11_1 
110. Institutionalization is a required stage in administrative development. Do you think the institutionalization process in Jordan has been successful?
$0 . \quad$ No
1. Yes
2. Incomplete Process
5. Don't know
6. No response

111. How does the institution-building lead to reform and development?

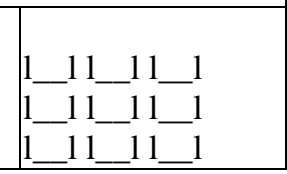

112. The following are models for political systems of some countries in the Middle East. Pick the most suitable for Jordan and rate its suitability on the below scale from 1-6:

\begin{tabular}{|c|c|c|c|c|c|c|}
\hline Political Structures & $\begin{array}{c}\text { Not } \\
\text { Suitable } \\
1\end{array}$ & $\begin{array}{l}\text { Somewhat } \\
\text { Suitable } \\
2\end{array}$ & $\begin{array}{c}\text { Suitable } \\
3\end{array}$ & $\begin{array}{c}\text { Very } \\
\text { Suitable } \\
4\end{array}$ & $\begin{array}{c}\text { Don't } \\
\text { Know } \\
5\end{array}$ & $\begin{array}{c}\text { No } \\
\text { Response } \\
6\end{array}$ \\
\hline $\begin{array}{l}\text { 1. Parliamentary system that allows } \\
\text { the nationalist, Islamic, and left } \\
\text { and right wing parties to compete } \\
\text { in transparent and impartial } \\
\text { parliamentary elections }\end{array}$ & & & & & & \\
\hline $\begin{array}{l}\text { 2. Parliamentary system that allows } \\
\text { only the Islamic parties to } \\
\text { compete in parliamentary } \\
\text { elections }\end{array}$ & & & & & & \\
\hline $\begin{array}{l}\text { 3. Authoritarian system controlled } \\
\text { and ruled by an ultimate power } \\
\text { and authority without consent or } \\
\text { consideration for opposing views }\end{array}$ & & & & & & \\
\hline $\begin{array}{l}\text { 4. A system ruled by Islamic } \\
\text { Shari'ah without any type of } \\
\text { elections or political parties }\end{array}$ & & & & & & \\
\hline
\end{tabular}

113. In light of your response to question 112, can you expand on your views regarding the political system that will best solve the problem of administrative corruption in Jordan?

114. What is the type of economic system that suits Jordan the most and presents solutions for the high levels of unemployment and poverty? 


\begin{tabular}{|c|c|c|c|c|c|c|c|}
\hline Type of Contribution & \begin{tabular}{|c|} 
Strongly \\
Oppose \\
1
\end{tabular} & $\begin{array}{l}\text { Somewhat } \\
\text { Oppose } \\
2\end{array}$ & \begin{tabular}{|c|} 
Moderately \\
Support \\
3
\end{tabular} & $\begin{array}{c}\text { Strongly } \\
\text { Support } \\
4\end{array}$ & $\begin{array}{l}\text { Don't } \\
\text { Know } \\
5\end{array}$ & $\begin{array}{c}\text { No response } \\
6\end{array}$ & \\
\hline 1. Political participation & & & & & & & I__ I \\
\hline 2. Social participation & & & & & & & I__ I I \\
\hline 3. Economic participation & & & & & & & I__ I \\
\hline
\end{tabular}

115.b If you support women's participation in the three fields, why do you think the participation of Jordanian

women is lagging behind?

116. Have/had you ever practiced formal or informal lobbying to influence members of Parliament?

0 . No (proceed to Q. 118)

1. Yes

5. Don't know (proceed to Q. 118)

6. No response (proceed to Q. 118)

117. What were your reasons for lobbying?

1. To implement important changes

2. To pursue my democratic values

3. To support Pluralism

4. To participate in policymaking

5. All the above

118. 'Pluralism' is the participation of all political forces in governance. Does pluralism exist under Jordan's authoritative monarchical political structure?

0 . No

1. Yes

5. Don't know

6. No response

119. Are you affiliated with a political party?

0 . No (proceed to Q. 121)

1. Yes

5. Don't know 


\section{No response}

120. Which political party, do you think, has the most dedicated leadership?

121. How do you describe the different mottos, missions, and vision statements as depicted in the campaigning culture of political parties and Parliament members?

1. Appealing and engaging to most Jordanians

2. Appealing and engaging to some Jordanians

3. Neither appealing nor engaging

4. Used as campaign propaganda

5. I don't know

6. No response

122. What are the reasons behind the weakness of political parties in Jordan?

1.

2.

3.

1_11_l1_1

1_11_11_1

1_11_11_1

123. State three elements that would activate the party system and empower political parties

1 .

2.

3.

1_11_l1_1

1_11_11_1

1_11_11_1

124. The one-man, one-vote law empowered tribalism at the expense of the partisan structure of the Parliament and weakened political party and Parliament institutions. Please indicate your level of agreement.
1. Strongly disagree
2. Disagree
3. Agree
4. Strongly agree
5. Don't know
6. No response

125. Is it true that Parliament members stay connected and follow through with their promises to their constituencies and communities after the elections?
0. No
1. Yes 


\section{Don't know \\ 6. No response}

126. In what way do you think tribalism impacts the political and social developments in Jordan?

1. Positive

2. Negative

3. Positive at times and negative at others

5. Don't know

6. No response

127. Why?

1.

2.

3.

128. Elites' tribal affiliations have influence on their political culture. What is your agreement level with this

statement?
1. Strongly disagree
2. Disagree
3. Agree
4. Strongly agree
5. I don't know
6. No response

129. Have you participated, donated, or done any voluntary work, or become a member of any of the following voluntary organizations?

\begin{tabular}{|l|l|l|l|}
\hline \multicolumn{1}{|c|}{ Type of NGO } & \multicolumn{1}{|c|}{ Yes } & No \\
\hline 1. Philanthropic institutions & & & \\
\hline 2. Syndicates & & & \\
\hline 3. Youth clubs & & & \\
\hline 4. Cultural organizations & & & \\
\hline 5. Sports clubs & & & \\
\hline 6. Religious organizations & & & \\
\hline 7. Family associations & & & \\
\hline 8. Cooperative groups & & & \\
\hline 9. National or international foundations & & & \\
\hline
\end{tabular}


130. Does the government interfere in the affairs of nonprofit organizations?

0 . No (proceed to Q. 132)

1. Yes

2. Sometimes

5. Don't know (proceed to Q. 132)

6. No response (proceed to Q. 132)

131. Tell me about the government's interference in the affairs of nonprofit organizations?

\begin{tabular}{|l|l|}
\hline \\
\hline
\end{tabular}$\quad$ 1_11_11_1

132. Do you think economic and political developments should occur together, or one should take precedence because it fosters the other?

1. The economic development should take precedence

2. The political development and civil liberties should take precedence

3. Both developments should occur simultaneously

$1 \_11 \_1$

4. Neither, both are imposed by external powers

5. Don't know

6. No response

133. Why do you think this is a better development plan for Jordan?

\begin{tabular}{|l|l|}
\hline$\overline{-}$ & 1_11_11_1 \\
\hline
\end{tabular}

134.a Do you believe the Prime Minister should be elected from a Parliament majority?
0. No
1. Yes
5. Don't know
6. No response

134.b Why or why not? 
135. Democracy is not merely a motto; it is a way of life that serves and empowers citizens under a rule of law system. It assures freedoms, protects citizenship rights, and guarantees the occurrence of regular, competitive, transparent, and fair elections while practicing the two freedoms of choice and press.

According to the above definition of democracy, how do you view the transitional process to democracy in Jordan?

1.

2.

3.

1_11_11_1

1_11_ll_1

1_11_11_1 


\section{Appendix D \\ Descriptive Statistics Tables and Figures}

(Q. 112) Democratic Governance: Political Systems

Figure 1 The suitability of a pluralistic parliamentary democratic political system

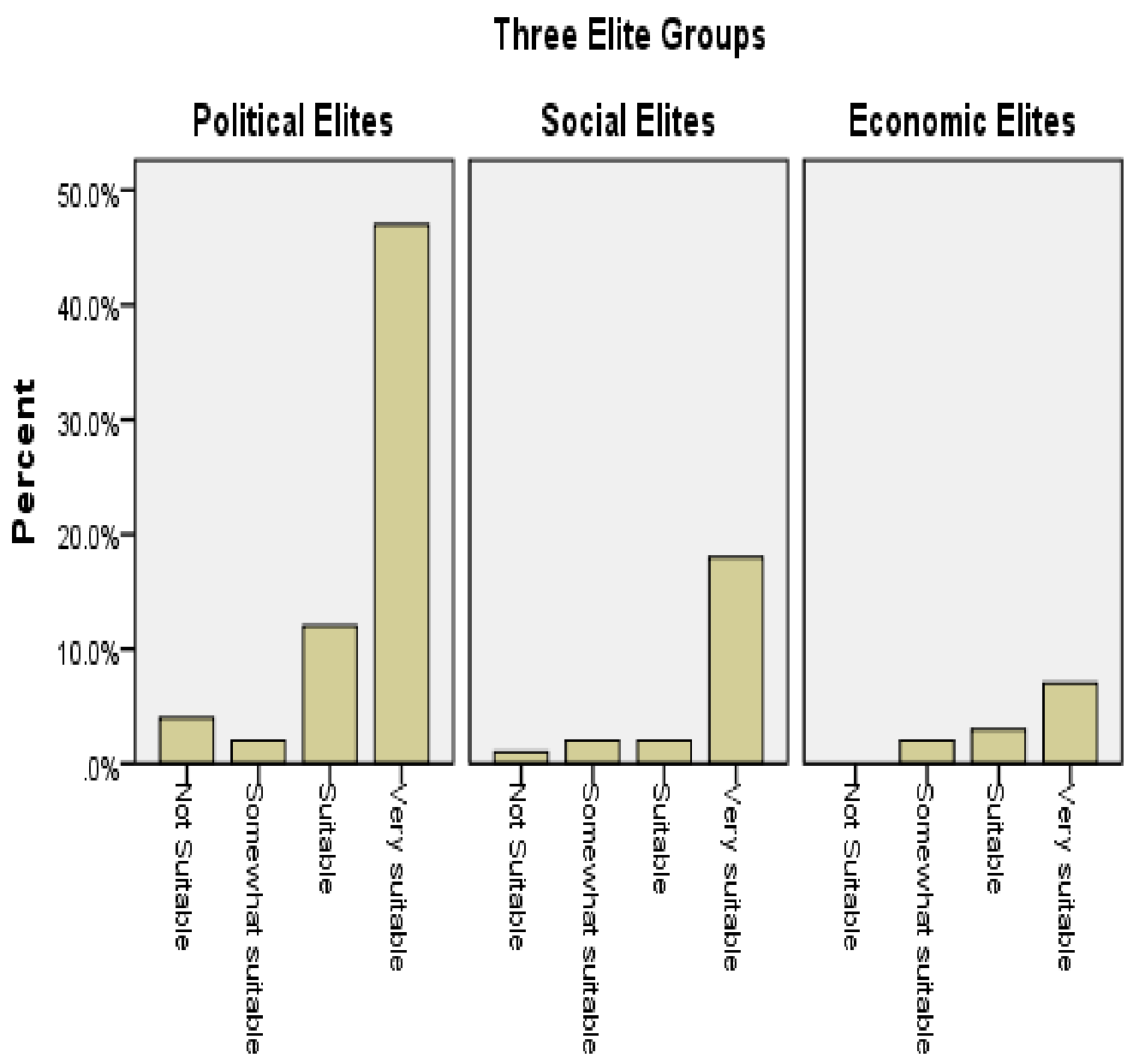

Elites' Values: Suitability of Democratic Parliamentary system 
Figure 2 The suitability of an authoritarian political system ruled by an ultimate power

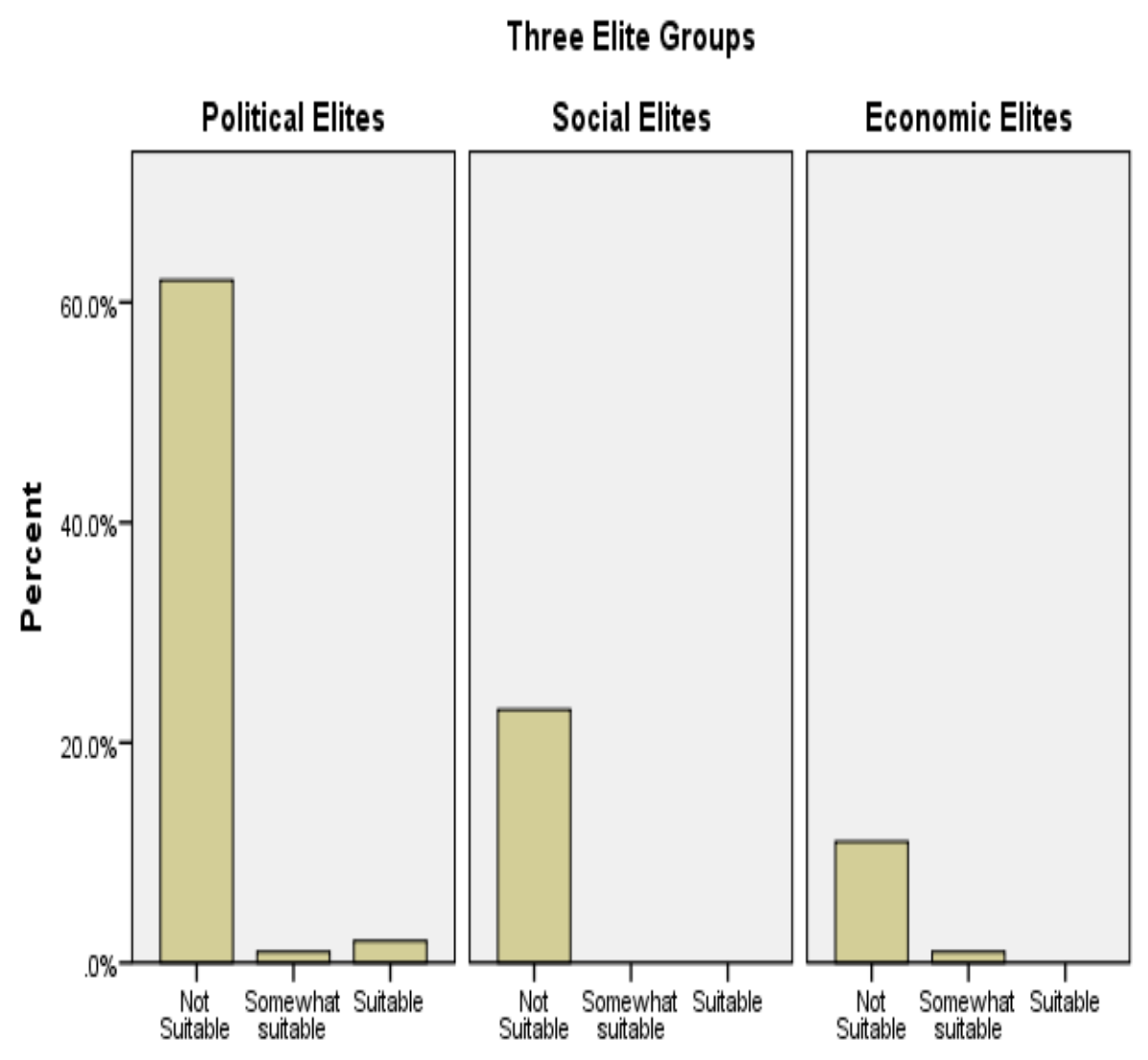

Elites' Values: Suitability of Authoritarian system controlled and ruled by an ultimate power

(Q.112.1) One-way ANOVA results for pluralistic parliamentary democratic political system

Table $1 \quad$ Pluralistic parliamentary democratic by three groups of elites 


\begin{tabular}{lrcccc}
\hline & SS & df & Mean Square & F & P \\
\hline Between groups & .307 & 2 & .153 & .224 & .800 \\
Within groups & 66.333 & 97 & .684 & & \\
Total & 66.640 & 99 & & & \\
\hline
\end{tabular}

$\mathrm{F}(2,97)=.224, \mathrm{p}=\mathrm{ns}$.

(Q. 112.3) Authoritarian with ultimate power

Table 2 Authoritarian Political System by three groups of elites

\begin{tabular}{lccccc}
\hline & SS & df & Mean Square & F & P \\
\hline Between groups & .108 & 2 & .54 & .549 & .579 \\
Within groups & 9.532 & 97 & .98 & & \\
Total & 9.640 & 99 & & & \\
\hline
\end{tabular}

$\mathrm{F}(2,97)=.549, \mathrm{p}=\mathrm{ns}$.

(Q. 112.4) Religious non-parliamentary

Table 3 Religious non-parliamentary rules with Shari'ah by three groups of elites

\begin{tabular}{lccccc}
\hline & SS & df & Mean Square & F & P \\
\hline Between groups & .048 & 2 & .024 & .265 & .768 \\
Within groups & 8.862 & 97 & .091 & & \\
Total & 8.910 & 99 & & & \\
\hline
\end{tabular}

$\mathrm{F}(2,97),=.265, \mathrm{p}=\mathrm{ns}$ 
Table 4 Four political systems suitability: Mean (SD) of by three groups of elites

Four political systems by

Three Elites Groups

Mean (SD)

$\mathrm{N}$

1. Parliamentary democratic

Political Elites

$3.57(.829)$

65

Social Elites

$3.61(.839)$

23

Economic Elites

$3.42(.793)$

12

2. Parliamentary Islamic

Political Elites
Social Elites
Economic Elite

an ruled by an

Political Elites

$1.08(.367)$

65

Social Elites

$1.00(.000)$

23

Economic Elites

$1.08(.289)$

12

4. Religious non-parliamentary

Political Elites

$1.05(.372)$

65

Social Elites

$1.00(.000)$

23

Economic Elites

$1.00(.000)$

12 
Table 5 Suitability percentage of four political systems - Cross Tabulation

\begin{tabular}{llllc}
\hline & & & & \\
& Not & Somewhat & Suitable & Very \\
Four Political Systems by & Suitable & Suitable & N $(\%)$ & Suitable \\
Three Groups of Elites & N $(\%)$ & N $(\%)$ & & N $(\%)$ \\
\hline
\end{tabular}

1. Pluralistic Parliamentary

Democratic

Political Elites

Social Elites

Economic Elites

Total \%

2. Parliamentary Islamic

Political Elites

Social Elites

Economic Elites

Total \%

3. Authoritarian Ruled by

an ultimate Power

Political Elites

Social Elites

Economic Elites

Total \%

4. Religious non

Parliamentary

Political Elites

Social Elites

Economic Elites

Total \%

$\begin{array}{llrr}4(6.2 \%) & 2(03.1 \%) & 12(18.5 \%) & 47(72.3 \%) \\ 1(4.3 \%) & 2(08.7 \%) & 2(08.7 \%) & 18(78.3 \%) \\ 0(0.0 \%) & 2(16.7 \%) & 3(25.0 \%) & 07(58.3 \%) \\ 5(5.0 \%) & 6(06.0 \%) & 17(17.0 \%) & 72(72.0 \%)\end{array}$

$\begin{array}{llll}65(100 \%) & 0 & 0 & 0 \\ 23(100 \%) & 0 & 0 & 0 \\ 12(100 \%) & 0 & 0 & 0 \\ 100(100 \%) & 0 & 0 & 0\end{array}$

$\begin{array}{lccc}62(95.0 \%) & 1(01.5 \%) & 2(3.1 \%) & 0 \\ 23(100 . \%) & 0 & 0 & 0 \\ 11(91.0 \%) & 1(08.3 \%) & 0 & 0 \\ 96(96.0 \%) & 2(02.0 \%) & 2(02.0 \%) & 0\end{array}$

$\begin{array}{lllc}64(98.5 \%) & 0 & 0 & 1(1.5 \%) \\ 23(100 \%) & 0 & 0 & 0 \\ 12(100 \%) & 0 & 0 & 0 \\ 99(99.0 \%) & 0 & 0 & 1(1.0 \%)\end{array}$


(Q. 113) In addition, the subsequent belief question, question (113) investigated the best political system type for solving Jordan's political and administrative challenges. The theme with the highest frequency reported by the three groups of elites was the "Democratic Parliamentary Pluralistic" political system.

(Q.104.2) The Implementation of Rule of Law

Figure 3 Beliefs in the Supremacy of Rule of Law System by Three Groups of

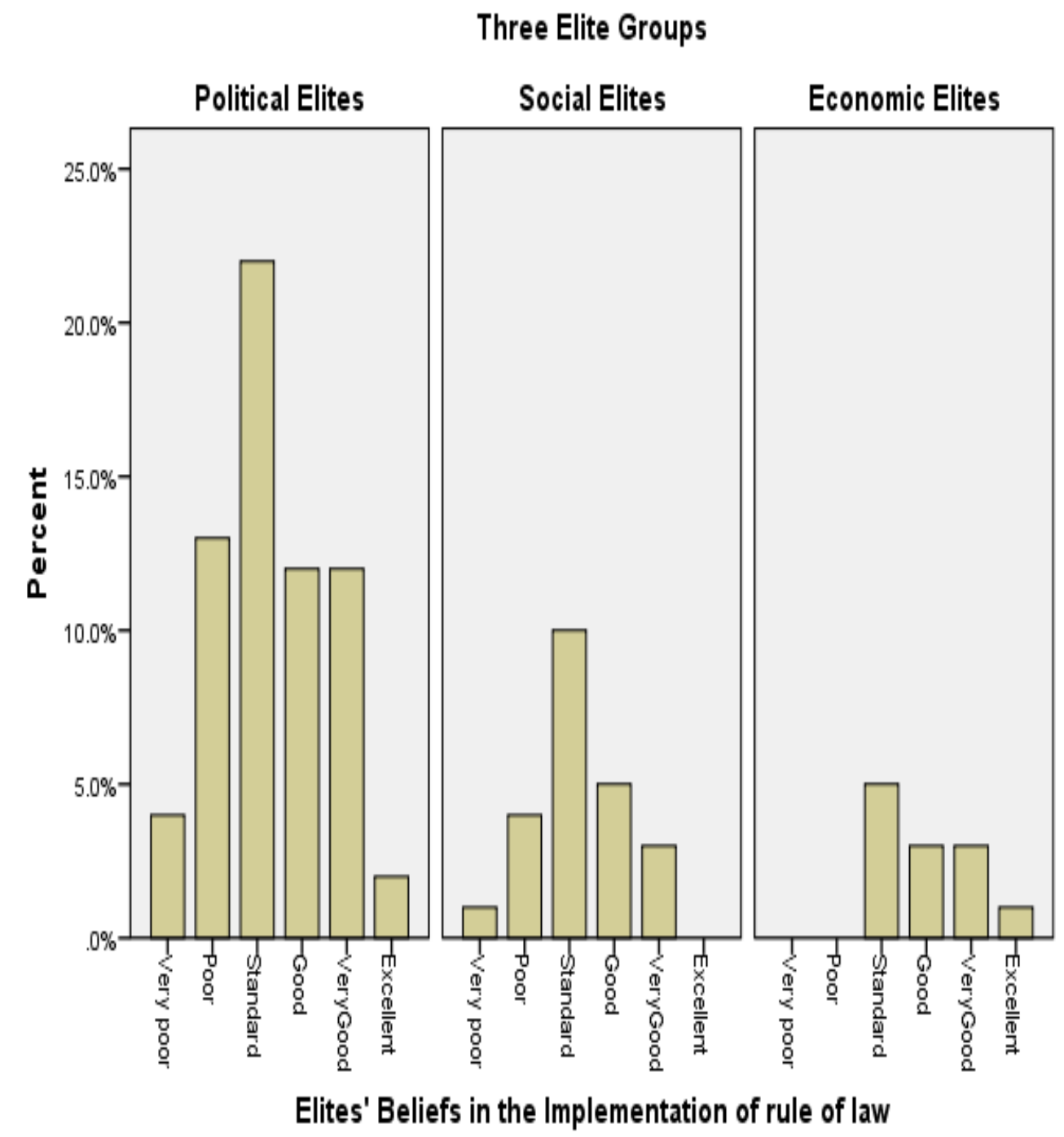

Elites 
Table $6 \quad$ Rule of Law by three groups of elites

\begin{tabular}{lccccc}
\hline & SS & df & Mean Square & F & P \\
\hline Between groups & 5.43 & 2 & 2.716 & 1.935 & .150 \\
Within groups & 136.12 & 97 & 1.403 & & \\
Total & 141.56 & 99 & & & \\
\hline
\end{tabular}

$$
\mathrm{F}(2,97)=1.94, \mathrm{p}=\mathrm{ns} \text {. }
$$

Table $7 \quad$ Rule of Law Means (SD)

\begin{tabular}{lcc}
\hline Three Elites Groups & Mean (SD) & N \\
\hline Political Elites & $3.32(1.566)$ & 65 \\
Social Elites & $3.22(1.087)$ & 23 \\
Economic Elites & $4.00(1.091)$ & 12 \\
Total & $3.38(1.196)$ & 100 \\
\hline
\end{tabular}

The following table displays the $\mathrm{N}$ and percentage values for elites' beliefs and a detailed distribution for the six ratings 
Table 8 Rule of Law Supremacy - Cross Tabulation

\begin{tabular}{|c|c|c|c|}
\hline \multicolumn{4}{|c|}{ Beliefs in Rule of Law Supremacy } \\
\hline & Three Elite Groups & $\mathrm{N}$ & $\%$ \\
\hline & Political Elites & 65 & $65 \%$ \\
\hline Very poor & & 4 & 6.2 \\
\hline Poor & & 13 & 20 \\
\hline Standard & & 22 & 33.8 \\
\hline Good & & 12 & 18.5 \\
\hline Very good & & 12 & 18.5 \\
\hline Excellent & & 2 & 3.1 \\
\hline & Social Elites & 23 & $23 \%$ \\
\hline Very poor & & 1 & 4.3 \\
\hline Poor & & 4 & 17.4 \\
\hline Standard & & 10 & 43.5 \\
\hline Good & & 5 & 21.7 \\
\hline Very good & & 3 & 13 \\
\hline Excellent & & 0 & 0 \\
\hline & Economic Elites & 12 & $12 \%$ \\
\hline Very poor & & 0 & 0 \\
\hline Poor & & 0 & 0 \\
\hline Standard & & 5 & 41.7 \\
\hline Good & & 3 & 25 \\
\hline Very good & & 3 & 25 \\
\hline Excellent & & 1 & 8.3 \\
\hline Total & & 100 & $100 \%$ \\
\hline
\end{tabular}


Q.106.3) Democratic governance: the coordination between public \& private sectors

Figure $4 \quad$ Attitudes towards the public/private sectors

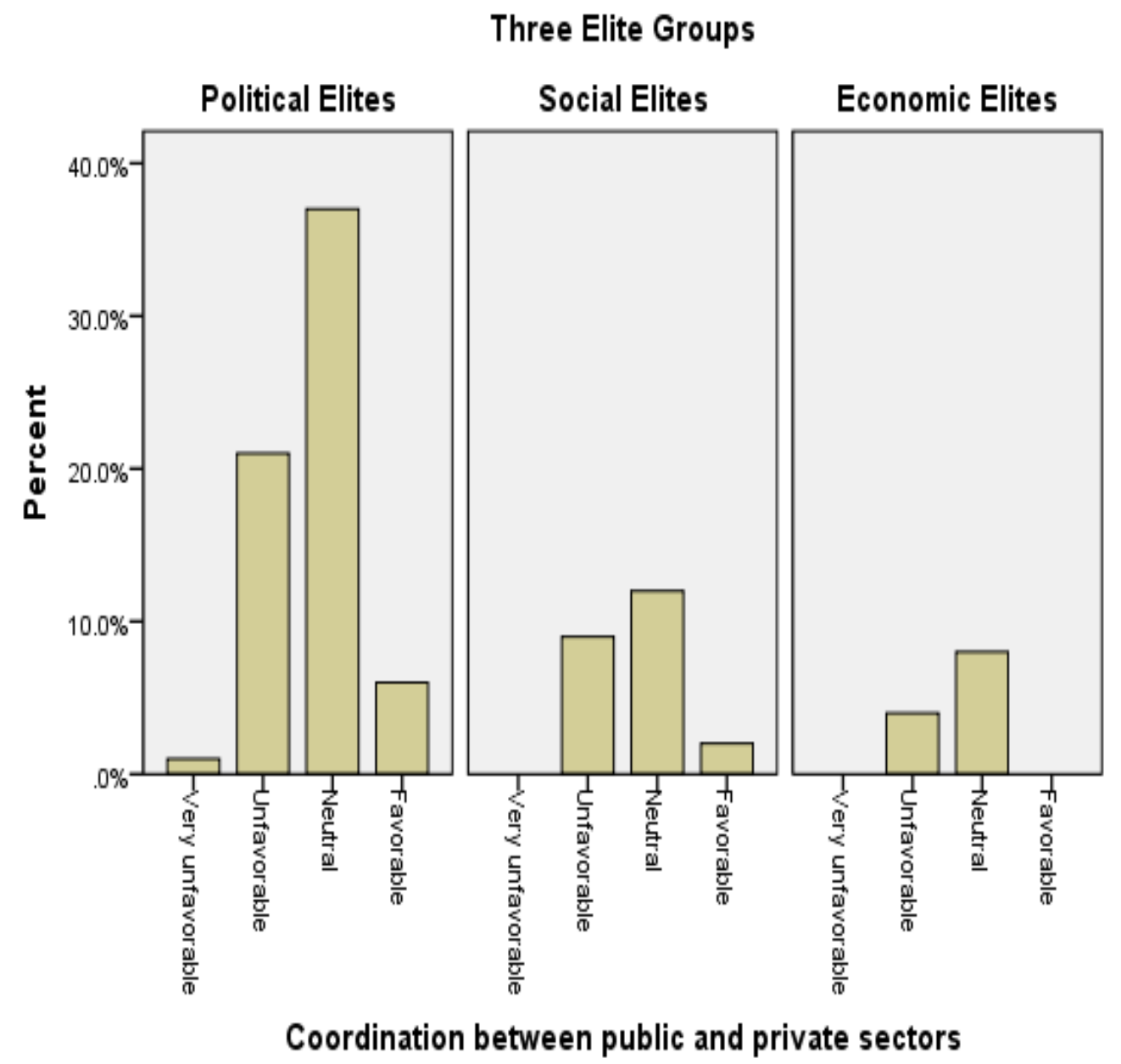


Table 9 Public/private coordination by three groups of elites

\begin{tabular}{lrcccc}
\hline & SS & df & Mean Square & F & P \\
\hline Between groups & .070 & 2 & .035 & .089 & .915 \\
Within groups & 38.090 & 97 & .393 & & \\
Total & 38.160 & 99 & & & \\
\hline
\end{tabular}

$\mathrm{F}(2,97)=.089, \mathrm{p}=\mathrm{ns}$.

Table 10 Attitudes towards Public/Private Coordination-Means (SD)

\begin{tabular}{lll}
\hline Three Elites Groups & Mean (SD) & $\mathrm{N}$ \\
\hline Political Elites & $2.74(.644)$ & 65 \\
Social Elites & $2.70(.635)$ & 23 \\
Economic Elites & $2.67(.492)$ & 12 \\
Total & $2.72(.621)$ & 100 \\
\hline
\end{tabular}


(Q 106.4) The Coordination between public \& nonprofit sectors

Figure 5 Attitudes towards the public/nonprofit sectors

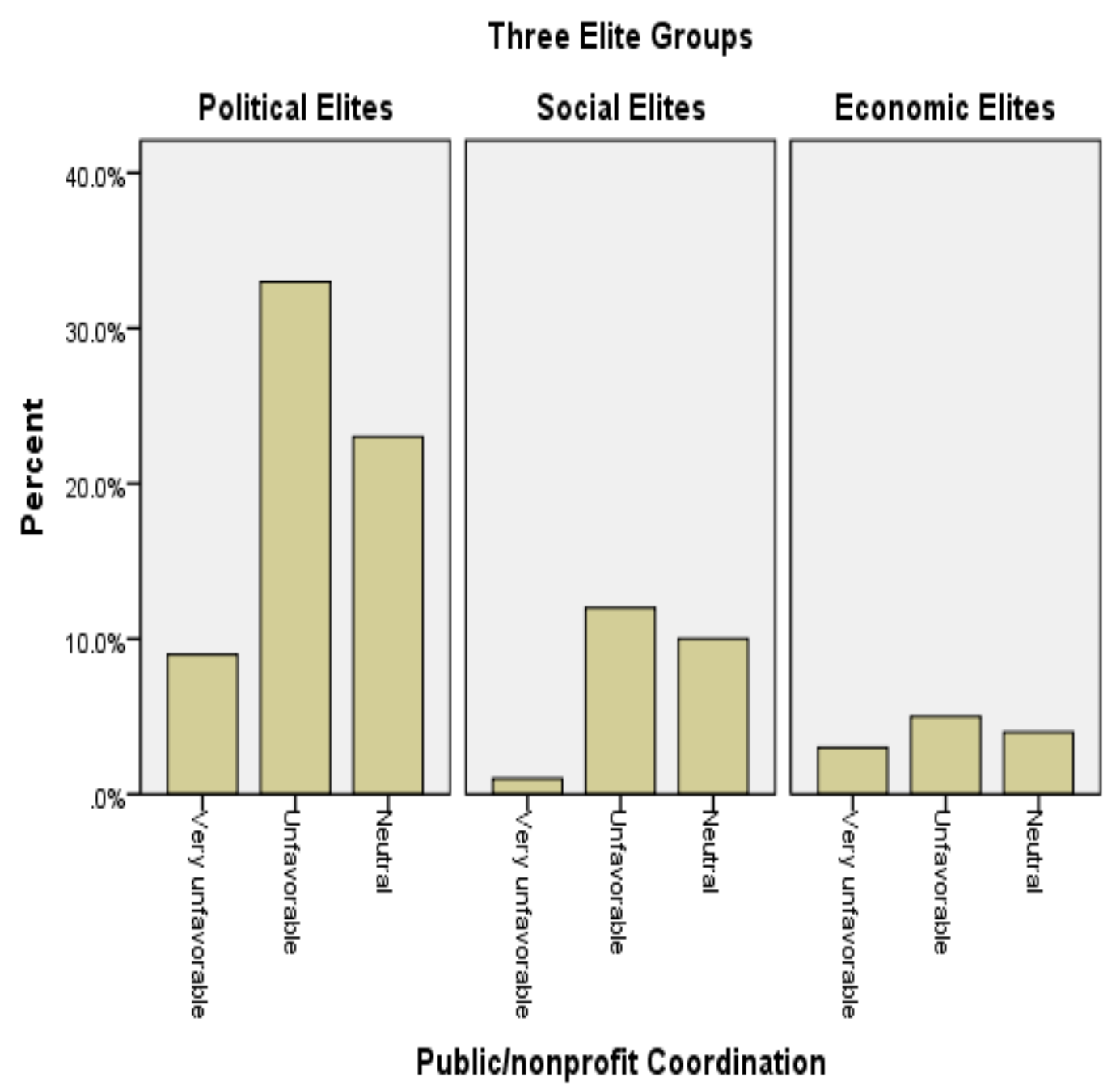


Table $11 \quad$ Public/nonprofit coordination by three groups of elites

\begin{tabular}{lrcccc}
\hline & SS & df & Mean Square & F & P \\
\hline Between groups & .860 & 2 & .430 & .962 & .386 \\
Within groups & 43.380 & 97 & .447 & & \\
Total & 44.240 & 99 & & & \\
\hline
\end{tabular}

$\mathrm{F}(2,97)=.962, \mathrm{p}=\mathrm{ns}$

Table 12 Attitudes towards public/nonprofit coordination - Means (SD)

\begin{tabular}{lll}
\hline Three Elites Groups & Mean & $\mathrm{N}$ \\
\hline Political Elites & $2.22(.673)$ & 65 \\
Social Elites & $2.39(.583)$ & 23 \\
Economic Elites & $2.08(.793)$ & 12 \\
Total & $2.24(.668)$ & 100 \\
\hline
\end{tabular}


(Q. 107) Coordination among the three sectors

Figure 6 The three sectors effectiveness in delivering services

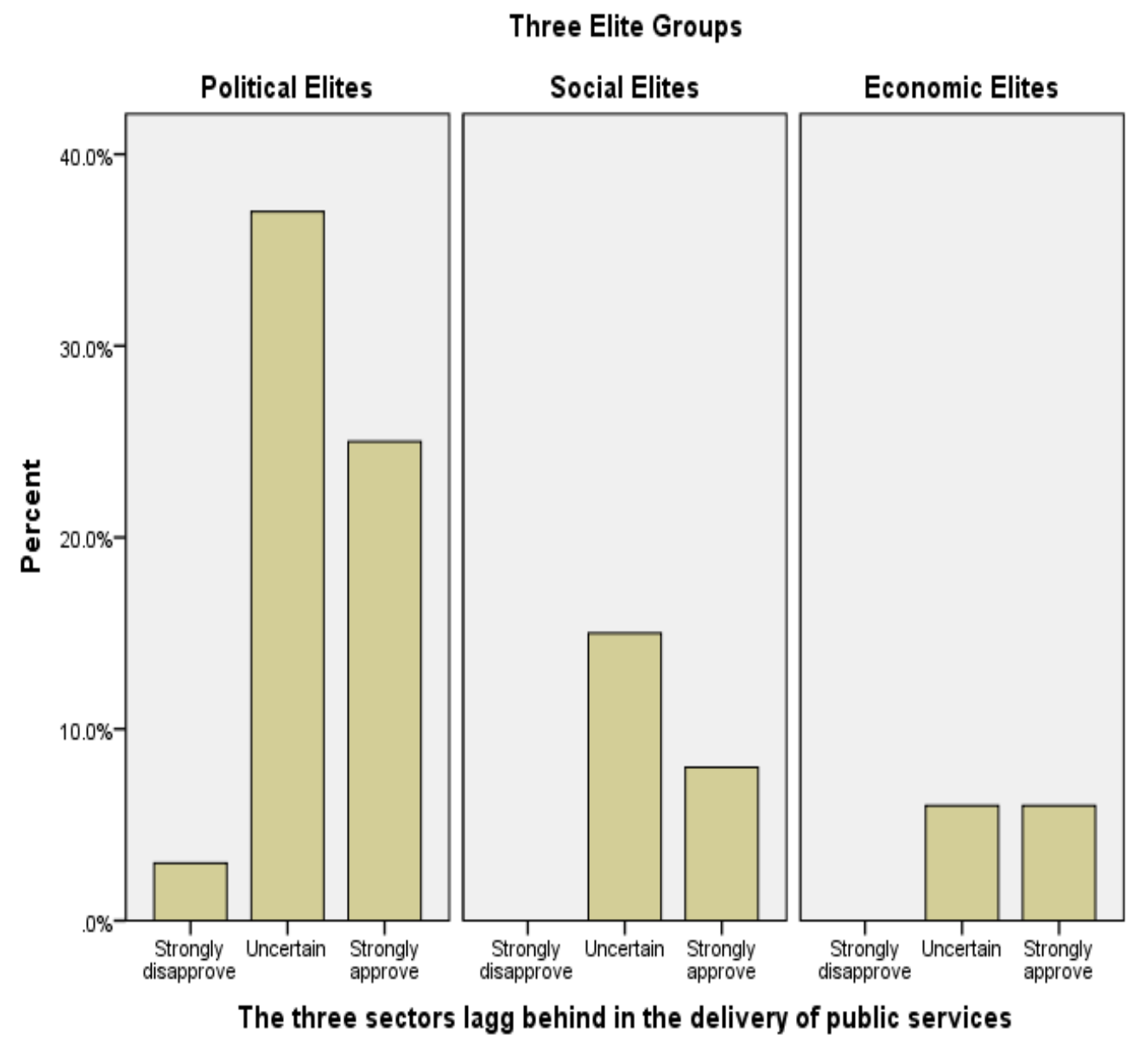


Table 13 Beliefs in democratic governance progress - Means (SD)

\begin{tabular}{lcc}
\hline Three Elites Groups & Mean (SD) & $\mathrm{N}$ \\
\hline Political Elites & $2.34(.567)$ & 65 \\
Social Elites & $3.35(.487)$ & 23 \\
Economic Elites & $2.50(.522)$ & 12 \\
Total & $2.36(.542)$ & 100 \\
\hline
\end{tabular}

Table 14 Attitudes towards democratic governance $-\mathrm{N}(\%)$ - Chi-square

\begin{tabular}{lcccc}
\hline $\begin{array}{l}\text { Three Elite Groups } \\
\text { Total }\end{array}$ & Disagree $\%$ & Uncertain $\%$ & Agree $\%$ & $\chi 2$ \\
\hline Political & $3(4.6 \%)$ & $37(63.8 \%)$ & $25(64.1)$ & .654 \\
Social & $0(0.0 \%)$ & $15(25.9 \%)$ & $8(20.5)$ & \\
Economic & $0(0.0 \%)$ & $6(10.3 \%)$ & $6(15.4)$ & \\
Total & $3(3 \%)$ & $58(58 \%)$ & $39(39 \%)$ & \\
& & & & \\
\hline
\end{tabular}

$$
\chi^{2}(4, \mathrm{~N}=100)=2.44, \mathrm{p}=.654
$$


Q. 134.a) King's Prerogative vs. Electing the Prime Minister

Figure $7 \quad$ Electing verses appointing the Prime Minister

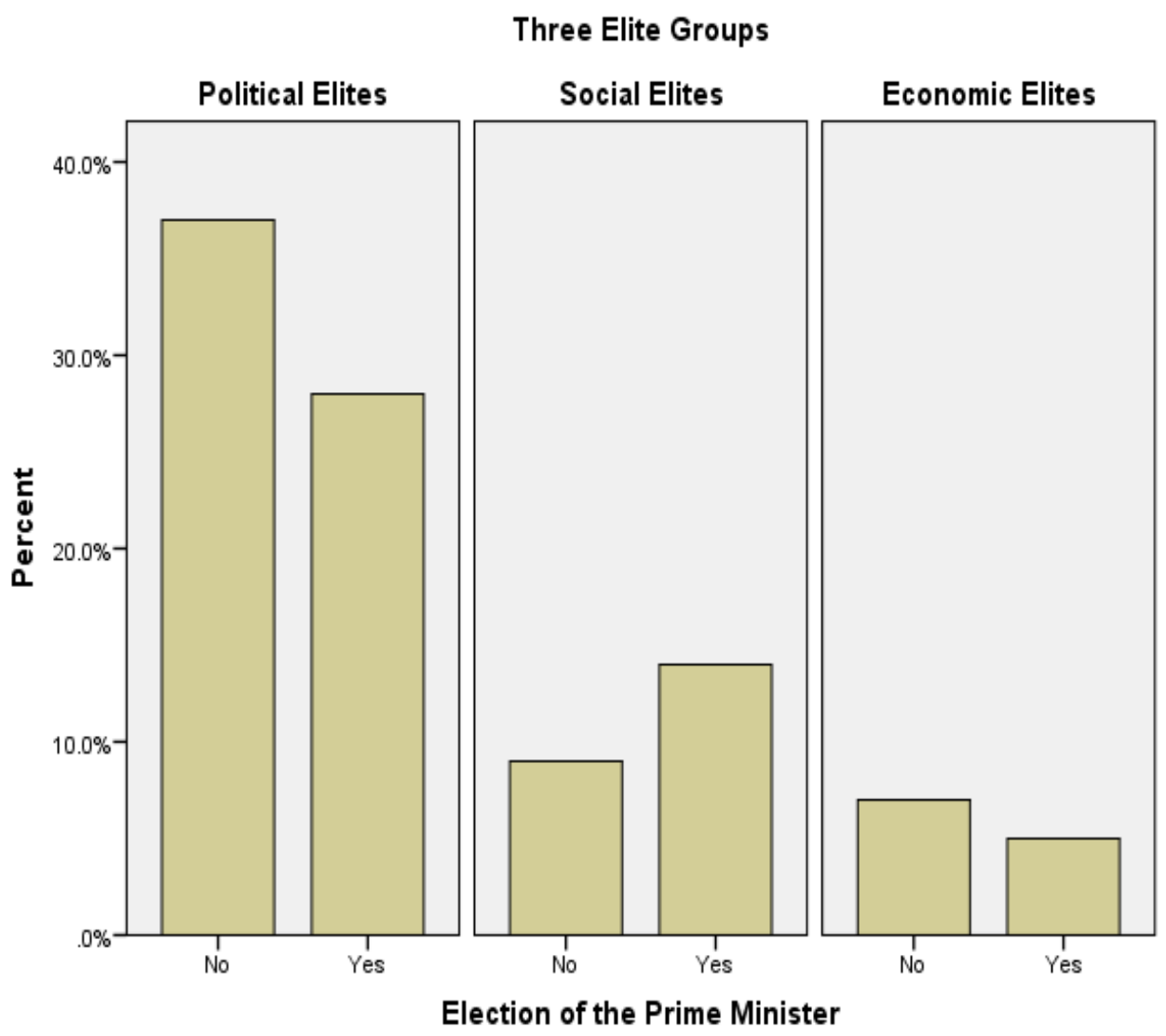


A one-way ANOVA test was used to check if there is any significant difference among the three means.

Table $15 \quad$ Electing verses appointing the Prime Minister Means (SD)

\begin{tabular}{lcc}
\hline Three Elites Groups & Mean (SD) & $\mathrm{N}$ \\
\hline Political Elites & $.46(.502)$ & 65 \\
Social Elites & $.61(.502)$ & 23 \\
Economic Elites & $.42(.502)$ & 12 \\
Total & $.49(.502)$ & 100 \\
\hline
\end{tabular}

Table 16 Electing verses appointing the Prime Minister - N(\%) - Chi-square

\begin{tabular}{lccc}
\hline Three Elite Groups & No $\%$ & Yes $\%$ & $\chi^{2}$ \\
\hline Political & $35(53.8 \%)$ & $28(46.2 \%)$ & .414 \\
Social & $9(39.1 \%)$ & $14(60.9 \%)$ & \\
Economic & $7(58.3 \%)$ & $5(41.7 \%)$ & \\
\hline
\end{tabular}

$\chi^{2}(2, \mathrm{~N}=100)=1.77, \mathrm{p}=.414$ 
(Q. 134.b) Qualitative Analysis: Thematic Analysis: Electing the Prime Minister

Table 17 Electing vs. Appointing the Prime Minister $-\mathrm{N}(\%)$

\begin{tabular}{|c|c|c|c|c|}
\hline Core Themes & $\begin{array}{l}\text { Political Elites } \\
(\mathrm{N}=65)\end{array}$ & $\begin{array}{l}\text { Social Elites } \\
\qquad(\mathrm{N}=23)\end{array}$ & $\begin{array}{l}\text { Economic Elites } \\
\qquad(\mathrm{N}=12)\end{array}$ & $\begin{array}{c}\text { Total } \\
(\mathrm{N}=100)\end{array}$ \\
\hline $\begin{array}{l}\text { Guarantees a } \\
\text { Parliamentary } \\
\text { Majority }\end{array}$ & $\begin{array}{c}28 \\
43 \%\end{array}$ & $\begin{array}{c}14 \\
60.9 \%\end{array}$ & $\begin{array}{c}5 \\
41.7 \%\end{array}$ & $\begin{array}{c}47 \\
47 \%\end{array}$ \\
\hline $\begin{array}{l}\text { Inapt Change a } \\
\text { the Present }\end{array}$ & at $\begin{array}{c}26 \\
40.1 \%\end{array}$ & $\begin{array}{c}8 \\
34.8 \%\end{array}$ & $\begin{array}{c}7 \\
58.3 \%\end{array}$ & $\begin{array}{c}41 \\
41 \%\end{array}$ \\
\hline $\begin{array}{l}\text { Encroachment } \\
\text { on King's } \\
\text { prerogative }\end{array}$ & $\begin{array}{c}11 \\
16.9 \%\end{array}$ & $\begin{array}{c}1 \\
4.3 \%\end{array}$ & $\begin{array}{c}0 \\
0 \%\end{array}$ & $\begin{array}{c}12 \\
12 \%\end{array}$ \\
\hline
\end{tabular}


(Q. 118) Pluralism

Figure $8 \quad$ Jordanian pluralism

Three Elite Groups

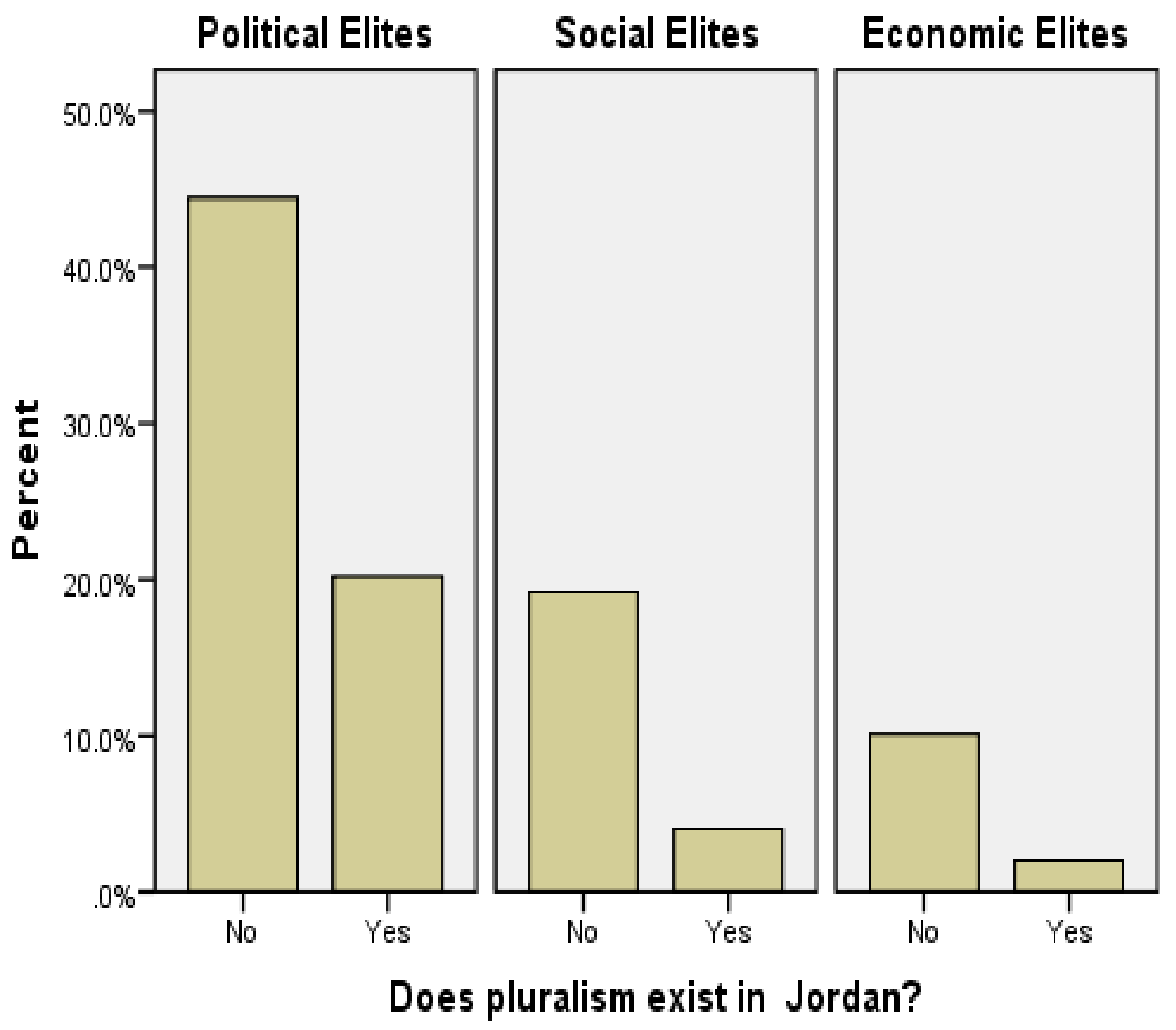


Table 18 Pluralism Means (SD)

\begin{tabular}{lccc}
\hline Three Elites Groups & Mean & $(\mathrm{SD})$ & $\mathrm{N}$ \\
\hline Political Elites & .31 & $(.467)$ & 64 \\
Social Elites & .17 & $(.388)$ & 23 \\
Economic Elites & .17 & $(.389)$ & 12 \\
Total & .26 & $(.422)$ & 99 \\
\hline
\end{tabular}

Table 19 Pluralism-N (\%)-Chi-square

\begin{tabular}{lcccc}
\hline Three Elite Groups & No & $(\%)$ & Yes $(\%)$ & $\chi^{2}$ \\
\hline Political & 44 & $(68.8 \%)$ & $20(31.3 \%)$ & .312 \\
Social & 19 & $(82.6 \%)$ & $4(17.4 \%)$ & \\
Economic & 10 & $(83.3 \%)$ & $2(16.7 \%)$ & \\
Within Three groups & 73 & $(73.7 \%)$ & $26(26.3 \%)$ & \\
\hline
\end{tabular}

$\chi^{2}(2, \mathrm{~N}=99)=2.33, \mathrm{p}=.312$ 
Q. 135) Qualitative Analysis: Democracy in Jordan

The beliefs of elites in the transition to democracy are assessed in this open-ended question that inquired about the necessary reforms for the success of the democratization process. The three most frequent core themes were enforcing a "rule of law system," “social reforms," and a serious implementation of "political reforms." Several subordinate themes to these three core themes are displayed in the tables below:

Table 20 Core and Subsequent Themes: Democracy in Jordan

\begin{tabular}{ll}
\hline Core Themes & Frequency
\end{tabular}

Rule of Law System

63

Social Development/Democracy a Way of Life

Political Development 
Table 21 Democracy in Jordan: Core and Subordinate Themes

\begin{tabular}{|c|c|c|c|}
\hline Theme 1 & Theme 2 & Theme 3 & $\begin{array}{l}\text { Elites' } \\
\text { Quotations from } \\
\text { the Survey }\end{array}$ \\
\hline Rule of law system & $\begin{array}{l}\text { Legislative } \\
\text { amendments }\end{array}$ & $\begin{array}{l}\text { Reforming } \\
\text { the } \\
\text { Parliament }\end{array}$ & $\begin{array}{l}\text { Amending } \\
\text { legislations and } \\
\text { implementing } \\
\text { reforms empowers } \\
\text { all institutions, } \\
\text { particularly the } \\
\text { Parliament. }\end{array}$ \\
\hline $\begin{array}{l}\text { Social } \\
\text { development/democracy } \\
\text { a way of life }\end{array}$ & $\begin{array}{l}\text { Curriculum } \\
\text { change }\end{array}$ & $\begin{array}{l}\text { Empowering } \\
\text { nationalism } \\
\text { \& Patriotism }\end{array}$ & $\begin{array}{l}\text { Infusing schools' } \\
\text { curricula with } \\
\text { democratic values } \\
\text { to teach new } \\
\text { generations the } \\
\text { meaning of } \\
\text { nationalism and } \\
\text { patriotism. }\end{array}$ \\
\hline Political development & $\begin{array}{l}\text { Political } \\
\text { participation }\end{array}$ & $\begin{array}{l}\text { Activating } \\
\text { political } \\
\text { parties }\end{array}$ & $\begin{array}{l}\text { The political } \\
\text { development } \\
\text { enhances political } \\
\text { participation and } \\
\text { restores freedoms } \\
\text { and political party } \\
\text { activities. }\end{array}$ \\
\hline
\end{tabular}


(Q. 101) Elites' self-determination and impact on policymaking

Figure 9 Estimated marginal means for elites' self determination and liberty

\section{Three Elite Groups}

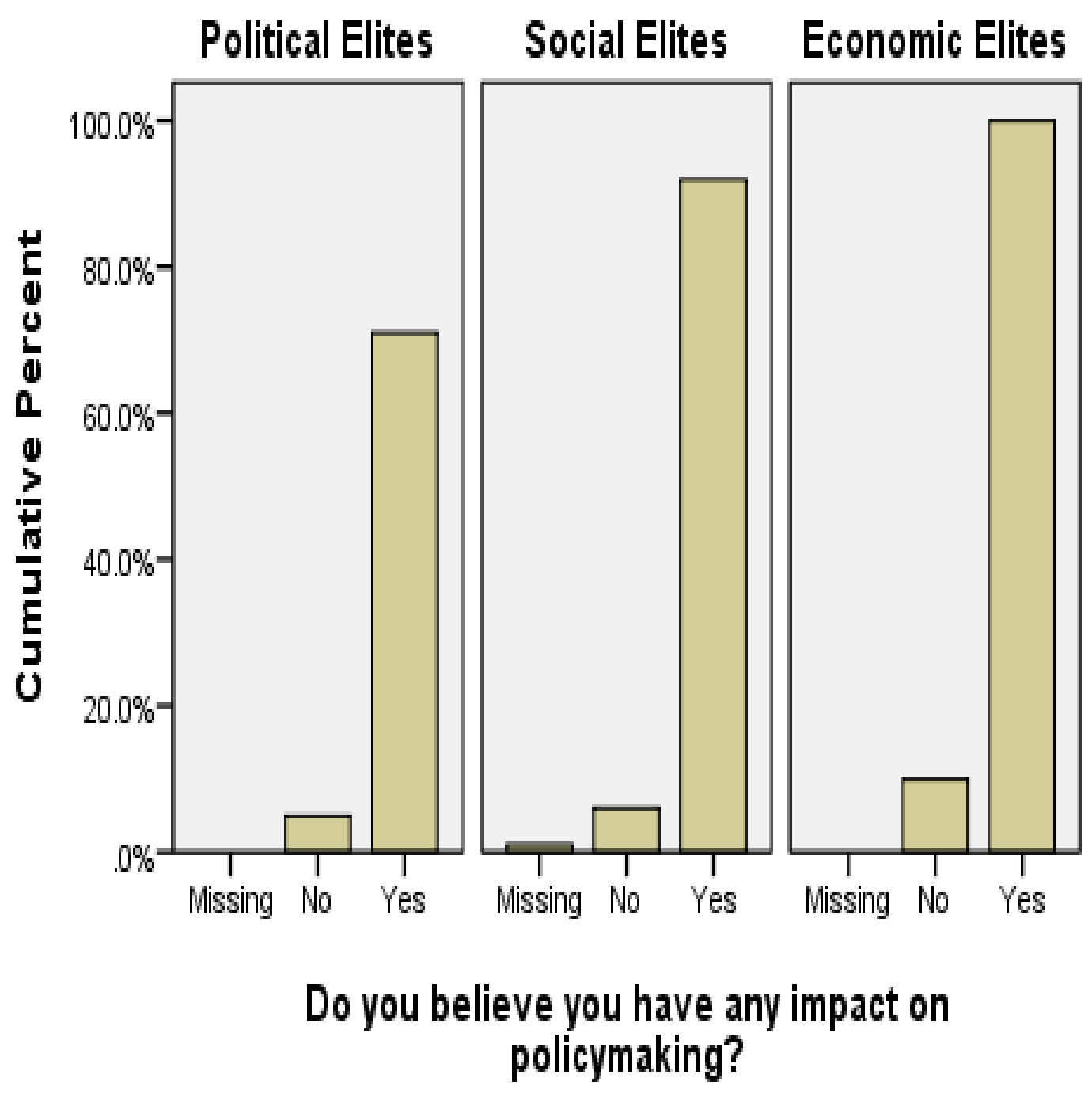


(Q. 101) Elites'self-determination and impact on policymaking

Table 22 Elites' impact on policymaking - Means (SD)

\begin{tabular}{lll}
\hline Three Elites Groups & Mean & $\mathrm{N}$ \\
\hline Political Elites & $.94(.242)$ & 65 \\
Social Elites & $.95(.213)$ & 22 \\
Economic Elites & $.67(.492)$ & 12 \\
Total & $.91(.289)$ & 96 \\
\hline
\end{tabular}

Table 23 Elites' impact on policymaking - N (\%) - Chi-square

\begin{tabular}{lcccc}
\hline Three Elite Groups & No $(\%)$ & Yes $(\%)$ & $\chi^{2}$ & Total \\
\hline Political & $4(44.4)$ & $61(67.8)$ & .008 & 65 \\
Soc & $1(11.1)$ & $21(23.3)$ & 22 \\
Econ & $4(44.4)$ & $8(8.9)$ & & 12 \\
\hline
\end{tabular}

The test indicates a significant difference at: $\chi^{2}(2, \mathrm{~N}=99)=9.76, \mathrm{p}=.008$

(Q. 102) Elites' accomplishment of political goals is measured on a 4-point scale of

Table 24 Accomplishment of Political Goals by Three Groups of Elites

\begin{tabular}{lrrccc}
\hline & SS & df & Mean Square & F & P \\
\hline Between groups & .376 & 2 & .188 & .341 & .712 \\
Within groups & 47.422 & 86 & .551 & & \\
Total & 47.798 & 88 & & & \\
\hline
\end{tabular}

$\mathrm{F}(2,86)=.341, \mathrm{p}=\mathrm{ns}$ 
(Q.103.1) Value of civil rights and freedoms

Figure 10 Civil rights and freedom Value by the three groups of elites

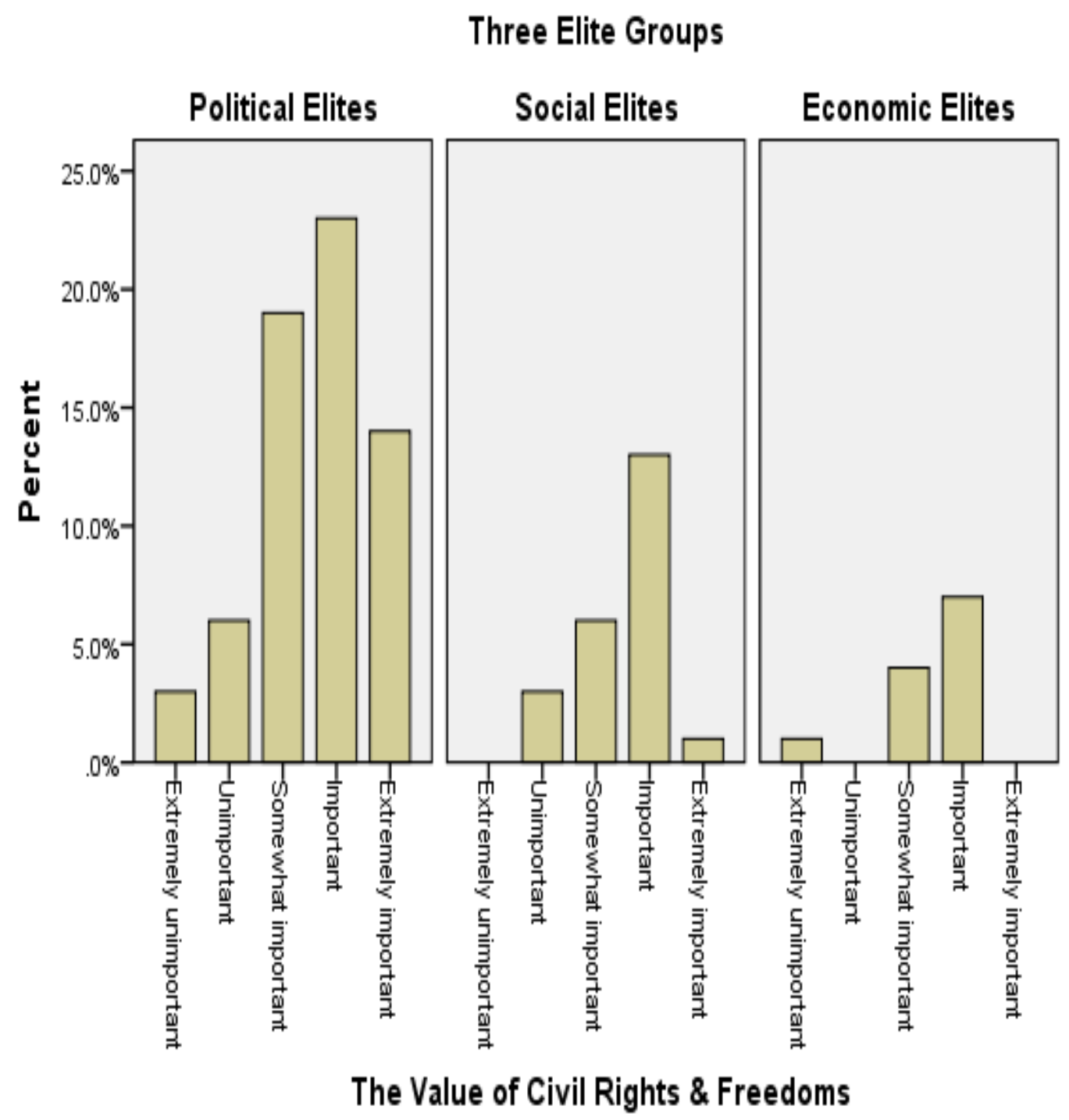


Table 25 Civil Rights and Freedoms by Three Groups of Elites

\begin{tabular}{lccccc}
\hline & SS & df & Mean Square & F & P \\
\hline Between groups & .384 & 2 & .192 & .194 & .824 \\
Within groups & 96.256 & 97 & .992 & & \\
Total & 96.640 & 99 & & & \\
\hline
\end{tabular}

$\mathrm{F}(2,97)=.194, \mathrm{p}=\mathrm{ns}$.

Table 26 Civil Rights and Freedoms Value - Cross Tabulation

\begin{tabular}{lll}
\hline Three Elites Groups & $\mathrm{N}$ & $\%$ \\
\hline Political Elites & 65 & \\
Extremely unimportant & 03 & $04.6 \%$ \\
Unimportant & 06 & $09.2 \%$ \\
Somewhat important & 19 & $29.2 \%$ \\
Important & 23 & $35.4 \%$ \\
Extremely important & 14 & $21.5 \%$ \\
Social Elites & 23 & \\
Extremely unimportant & 00 & $00.0 \%$ \\
Unimportant & 03 & $13.0 \%$ \\
Somewhat important & 06 & $26.1 \%$ \\
Important & 13 & $56.5 \%$ \\
Extremely important & 01 & $04.3 \%$ \\
Economic Elites & 12 & \\
Extremely unimportant & 01 & $08.3 \%$ \\
Unimportant & 00 & $00.0 \%$ \\
Somewhat important & 04 & $33.3 \%$ \\
Important & 07 & $58.3 \%$ \\
Extremely important & 00 & $00.0 \%$ \\
\hline
\end{tabular}


(Q.104.3) Free Access to Information

Figure 11 Free accesses to information by three groups of elites

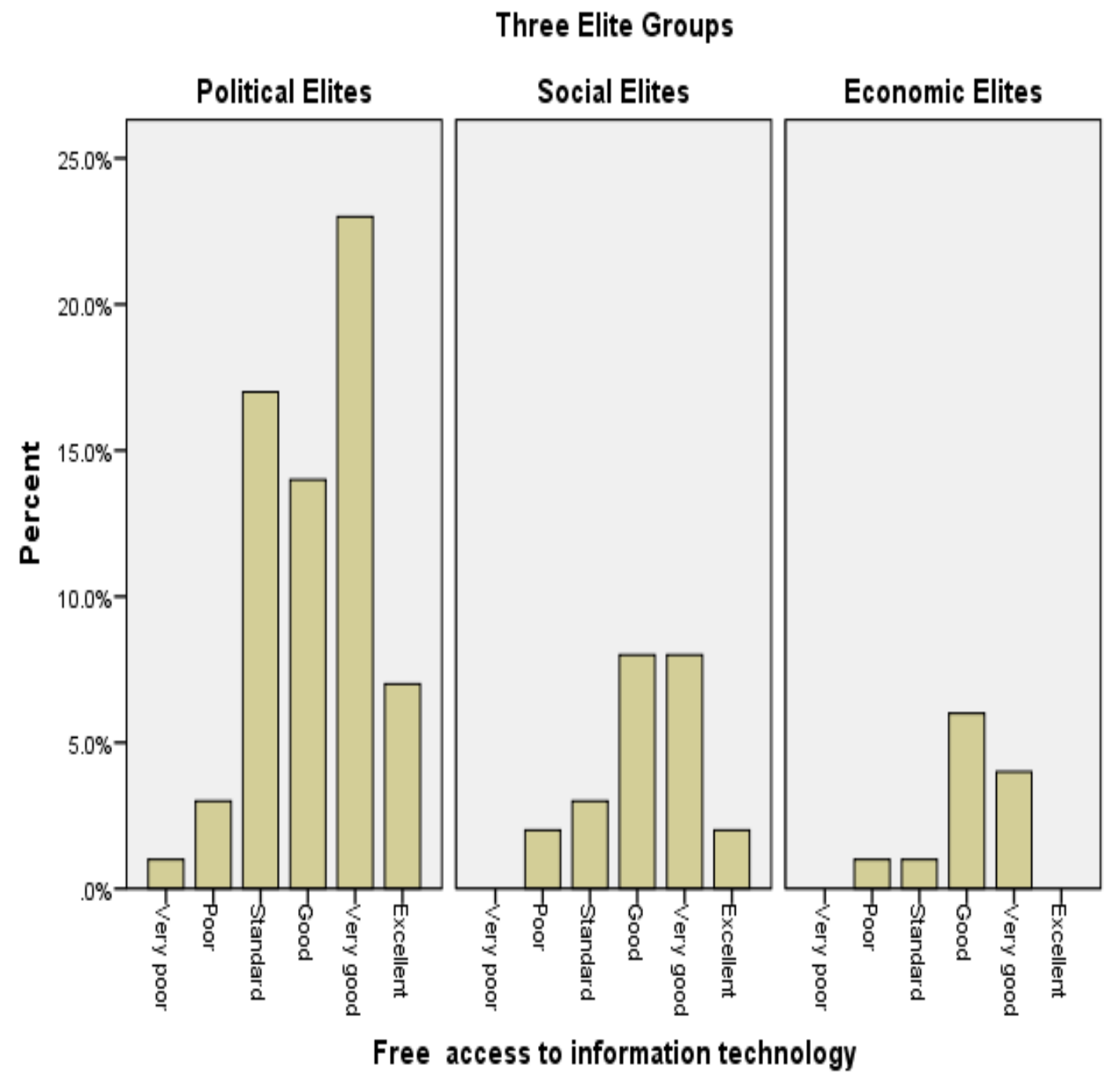


Table $27 \quad$ Free access to information- One way ANOVA

\begin{tabular}{lccccc}
\hline & SS & df & Mean Square & F & P \\
\hline Between groups & .142 & 2 & .071 & .056 & .945 \\
Within groups & 121.968 & 97 & 1.255 & & \\
Total & 122.110 & 99 & & & \\
\hline
\end{tabular}

$\mathrm{F}(2,97)=.056, \mathrm{p}=\mathrm{ns}$.

Table 28 Beliefs in the free access to information - Cross Tabulation

\begin{tabular}{|c|c|c|}
\hline Three Elites Groups & $\mathrm{N}$ & $\%$ \\
\hline Political Elites & 65 & \\
\hline Very poor & 01 & $01.5 \%$ \\
\hline Poor & 03 & $04.6 \%$ \\
\hline Standard & 17 & $26.2 \%$ \\
\hline Good & 14 & $21.5 \%$ \\
\hline Very good & 23 & $35.4 \%$ \\
\hline Excellent & 07 & $10.8 \%$ \\
\hline Social Elites & 23 & \\
\hline Very poor & 00 & $00.0 \%$ \\
\hline Poor & 02 & $08.7 \%$ \\
\hline Standard & 03 & $13.0 \%$ \\
\hline Good & 08 & $34.8 \%$ \\
\hline Very good & 08 & $34.8 \%$ \\
\hline Excellent & 02 & $08.7 \%$ \\
\hline Economic Elites & 12 & \\
\hline Very poor & 00 & $00.0 \%$ \\
\hline Poor & 01 & $08.3 \%$ \\
\hline Standard & 01 & $08.3 \%$ \\
\hline Good & 06 & $50.0 \%$ \\
\hline Very good & 04 & $33.3 \%$ \\
\hline Excellent & 00 & $00.0 \%$ \\
\hline
\end{tabular}


(Q. 105) Freedom of Opinion: Ideological Backgrounds

The freedom of opinion and ideological affiliation is tested in question (105) that provides the respondents with three different ideologies to choose the one that applies ideologically to them. The three ideologies were identified to the interviewees during the interviews as follows: Liberal values include the appreciation for free and fair elections, civil rights, freedoms, the rejection of absolute monarchy and the rejection of state religion. Conservative ideological background is the appreciation for traditionalism, rejection of modernity, and supporting the continuation of the status quo, which may also express the appreciation for the regime's notion of "Jordan First." The independent ideological background is described as free of control, not influenced by a particular opinion, conduct, or thinking. 
Table 29 Ideological backgrounds Means (SD)

\begin{tabular}{lcc}
\hline Three Elites Groups & Mean (SD) & N \\
\hline Political Elites & $1.75(.867)$ & 65 \\
Social Elites & $1.17(.388)$ & 23 \\
Economic Elites & $1.42(.669)$ & 12 \\
Total & $1.58(.794)$ & 100 \\
\hline
\end{tabular}

A Chi-square test was run to confirm this significance:

Table $30 \quad$ Elites' ideological backgrounds - N(\%) - Chi-square

\begin{tabular}{lccccc}
\hline Three Elite Groups & $\begin{array}{c}\text { Political } \\
\mathrm{N}(\%)\end{array}$ & $\begin{array}{c}\text { Social } \\
\mathrm{N}(\%)\end{array}$ & $\begin{array}{c}\text { Economic } \\
\mathrm{N}(\%)\end{array}$ & Total \\
\hline Liberal & $34(52.3 \%)$ & $19(82.6 \%)$ & $8(66.7 \%)$ & .032 & 65 \\
Independent & $13(20.0 \%)$ & $4(17.4 \%)$ & $3(25.0 \%)$ & 23 \\
Conservative & $18(27.7 \%)$ & $0(0.0 \%)$ & $1(8.3 \%)$ & 12 \\
\hline
\end{tabular}

$$
\chi^{2}(4, \mathrm{~N}=100)=10.53, \mathrm{p}<.05
$$


Public Sector Reform

(Q. 104.1) Administrative reforms

Figure 12 Minimizing bureaucracy and reforming administrative statutes

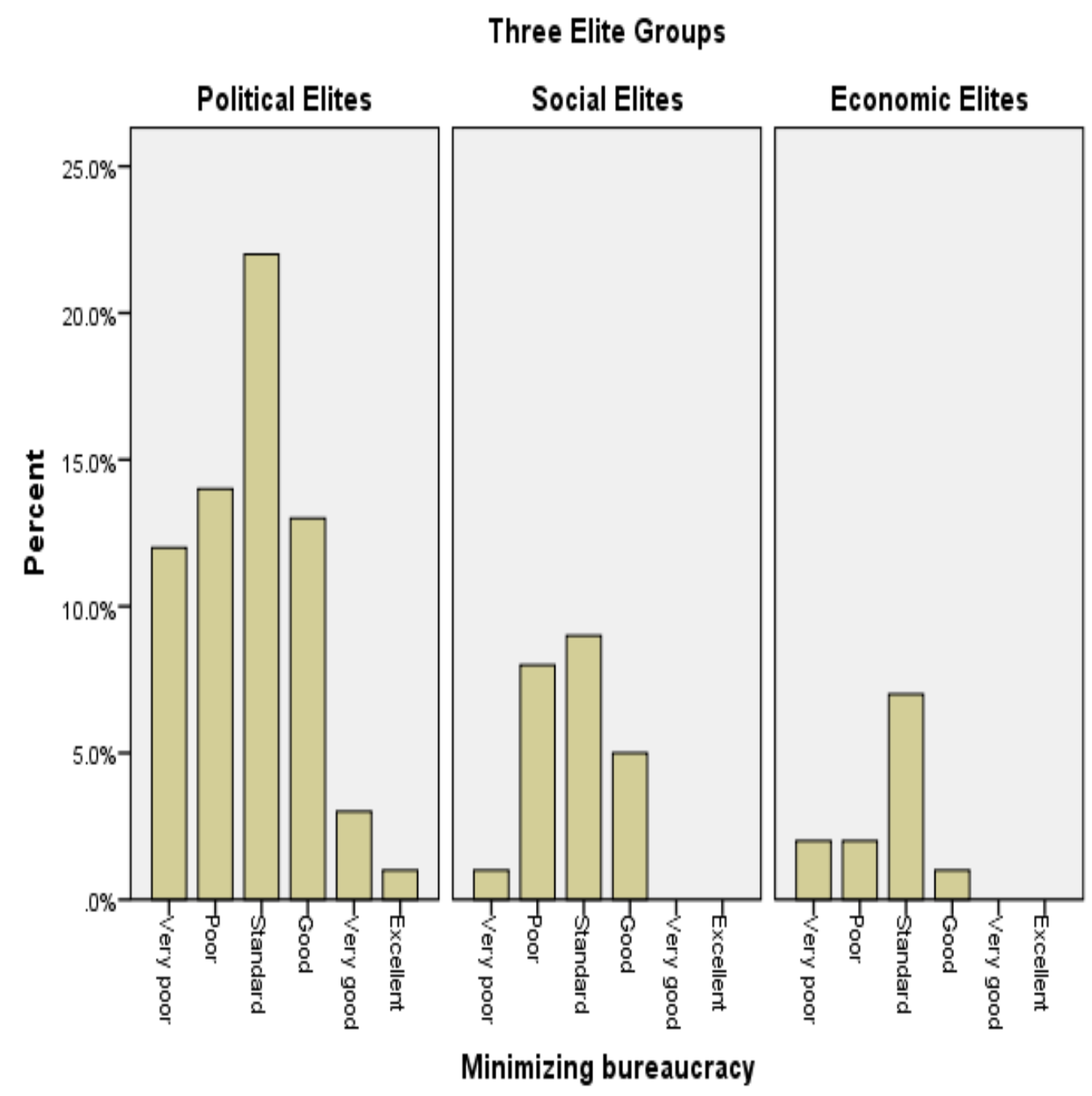


Table $31 \quad$ Administrative reforms by three groups of elites

\begin{tabular}{lrcccc}
\hline & SS & df & Mean Square & F & P \\
\hline Between groups & .349 & 2 & .174 & .145 & .865 \\
Within groups & 116.891 & 97 & 1.205 & & \\
Total & 117.240 & 99 & & & \\
\hline
\end{tabular}

$\mathrm{F}(2,97)=.145, \mathrm{p}=\mathrm{ns}$.

Table 32 Beliefs in administrative reforms - Means (SD)

\begin{tabular}{llc}
\hline Three Elites Groups & Mean (SD) & $\mathrm{N}$ \\
\hline Political Elites & $2.75(1.199)$ & 65 \\
Social Elites & $2.78 \quad(.850)$ & 23 \\
Economic Elites & $2.58 \quad(.950)$ & 12 \\
Total & $2.74(1.088)$ & 100 \\
\hline
\end{tabular}

The table below indicates the frequencies of the six ratings provided in the question by the three groups of elites. 
Table 33 Administrative reforms- Cross Tabulation

\begin{tabular}{|c|c|c|}
\hline Elites' Beliefs & $\mathrm{N}$ & $\%$ \\
\hline Political Elites & 65 & $65 \%$ \\
\hline Very poor & 12 & 18.5 \\
\hline Poor & 14 & 21.5 \\
\hline Standard & 22 & 33.8 \\
\hline Good & 13 & 20 \\
\hline Very good & 3 & 4.6 \\
\hline Excellent & 1 & 1.5 \\
\hline Social Elites & 23 & $23 \%$ \\
\hline Very poor & 1 & 4.3 \\
\hline Poor & 8 & 34.8 \\
\hline Standard & 9 & 39.1 \\
\hline Good & 5 & 21.7 \\
\hline Very good & 0 & 0 \\
\hline Excellent & 0 & 0 \\
\hline Economic Elites & 12 & $12 \%$ \\
\hline Very poor & 2 & 16.7 \\
\hline Poor & 2 & 16.7 \\
\hline Standard & 7 & 58.3 \\
\hline Good & 1 & 8.3 \\
\hline Very good & 0 & 0 \\
\hline Excellent & 0 & 0 \\
\hline Total & 100 & $100 \%$ \\
\hline
\end{tabular}


(Q. 106.1) Implementing transparency and accountability

Figure 13 Transparency and accountability

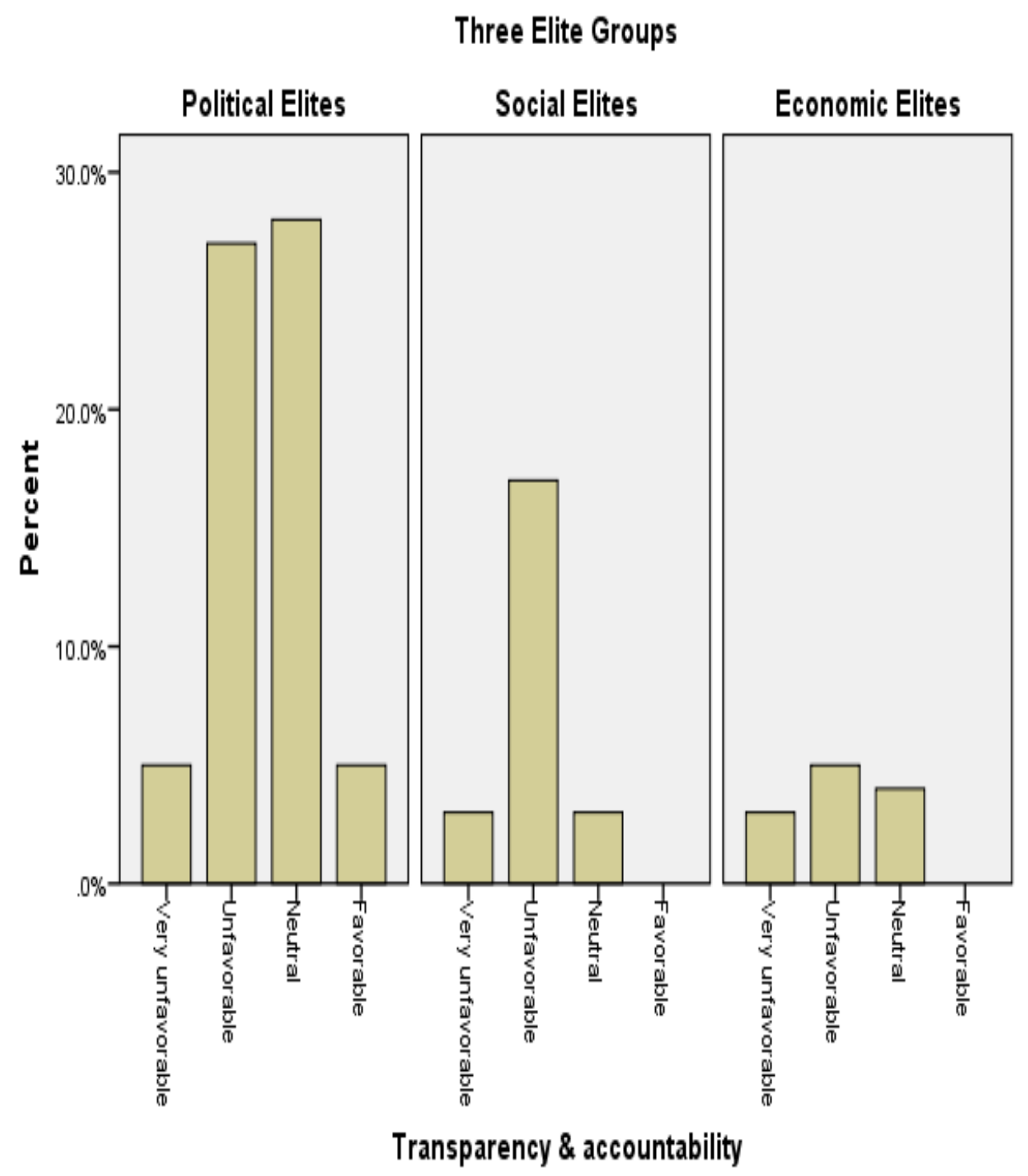


Table $34 \quad$ Transparency and Accountability by three groups of elites

\begin{tabular}{lccccc}
\hline & SS & df & Mean Square & F & P \\
\hline Between group & 5.277 & 2 & 2.639 & 5.206 & .007 \\
Within groups & 49.163 & 97 & .507 & & \\
Total & 54.440 & 99 & & & \\
\hline
\end{tabular}

$\mathrm{F}(2,97)=5.206, \mathrm{p}<.05$

Table 35 Transparency and accountability - Chi-square

\begin{tabular}{llll}
\hline & Value & df & $\chi 2$ \\
\hline Pearson Chi-Square & 13.737 & 6 & .033 \\
\hline
\end{tabular}

$\chi^{2}(6, \mathrm{~N}=100)=13.74, \mathrm{p}=.033$. The Chi-square result confirms the statistic

significance by .033 . The probability of significance $=(1-.033)=.967=96.7 \%$.

Table 36 Transparency and accountability -Means (SD)

\begin{tabular}{lcc}
\hline Three Elites Groups & Mean (SD) & $\mathrm{N}$ \\
\hline Political Elites & $2.51(.753)$ & 65 \\
Social Elites & $2.00(.522)$ & 23 \\
Economic Elites & $2.08(.793)$ & 12 \\
Total & $2.34(.742)$ & 100 \\
\hline
\end{tabular}


Table 37 Transparency and accountability - Cross Tabulation

\begin{tabular}{|c|c|c|}
\hline Three Elite Groups & $\mathrm{N}$ & $\%$ \\
\hline Political & 65 & $65 \%$ \\
\hline Very unfavorable & 5 & 7.7 \\
\hline Unfavorable & 27 & 41.5 \\
\hline Neutral & 28 & 43.1 \\
\hline Favorable & 5 & 7.7 \\
\hline Social & 23 & $23 \%$ \\
\hline Very unfavorable & 3 & 13 \\
\hline Unfavorable & 17 & 73 \\
\hline Neutral & 3 & 13 \\
\hline Favorable & 0 & 0 \\
\hline Economic & 12 & $12 \%$ \\
\hline Very unfavorable & 3 & 25 \\
\hline Unfavorable & 5 & 41.7 \\
\hline Neutral & 4 & 33.3 \\
\hline Favorable & 0 & 0 \\
\hline Total & 100 & 100 \\
\hline
\end{tabular}


(Q. 106.2) Corruption Control

Figure 14 Corruption control

Three Elite Groups

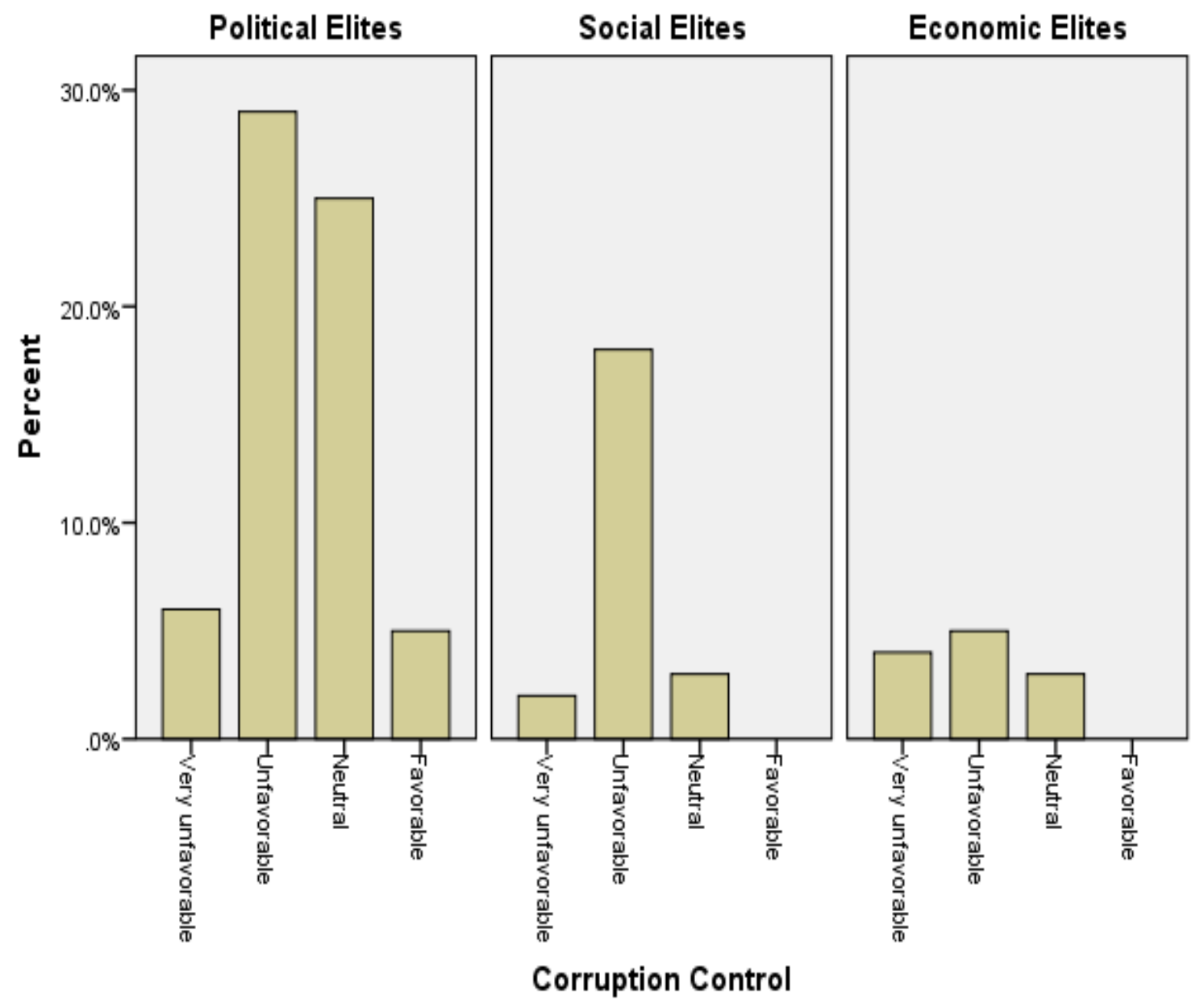


Table $38 \quad$ Corruption control by three groups of elites

\begin{tabular}{lccccc}
\hline & SS & df & Mean Square & F & P \\
\hline Between group & 4.655 & 2 & 2.328 & 4.522 & .013 \\
Within groups & 49.935 & 97 & .515 & & \\
Total & 54.590 & 99 & & & \\
\hline
\end{tabular}

$\mathrm{F}(2,97)=4.52, \mathrm{p}<.05$

Table 39 Corruption control -Means (SD)

\begin{tabular}{lcc}
\hline Three Elites Groups & Mean (SD) & $\mathrm{N}$ \\
\hline Political Elites & $2.45(.771)$ & 65 \\
Social Elites & $2.04(.475)$ & 23 \\
Economic Elites & $1.92(.793)$ & 12 \\
Total & $2.29(.743)$ & 100 \\
\hline
\end{tabular}

Table 40 Corruption control-Chi-square

\begin{tabular}{llll}
\hline & Value & df & $\chi^{2}$ \\
\hline Pearson Chi Square & 15.545 & 6 & .016 \\
\hline
\end{tabular}

$\chi 2(6, N=100)=15.55, \mathrm{p}=.016$. 
Table 41 Corruption control - Cross Tabulations

\begin{tabular}{|c|c|c|}
\hline Elites' Beliefs & $\mathrm{N}$ & $\%$ \\
\hline Political & 65 & $65 \%$ \\
\hline Very unfavorable & 6 & 9.2 \\
\hline Unfavorable & 29 & 44.6 \\
\hline Neutral & 25 & 38.5 \\
\hline Favorable & 5 & 7.7 \\
\hline Social & 23 & $23 \%$ \\
\hline Very unfavorable & 2 & 8.7 \\
\hline Unfavorable & 18 & 78.3 \\
\hline Neutral & 3 & 13 \\
\hline Favorable & 0 & 0 \\
\hline Economic & 12 & $12 \%$ \\
\hline Very unfavorable & 4 & 33.3 \\
\hline Unfavorable & 5 & 41.7 \\
\hline Neutral & 3 & 25 \\
\hline Favorable & 0 & 0 \\
\hline Total & 100 & 100 \\
\hline
\end{tabular}


(Q .106.5) Ending Nepotism

Figure 15 Ending nepotism

Three Elite Groups

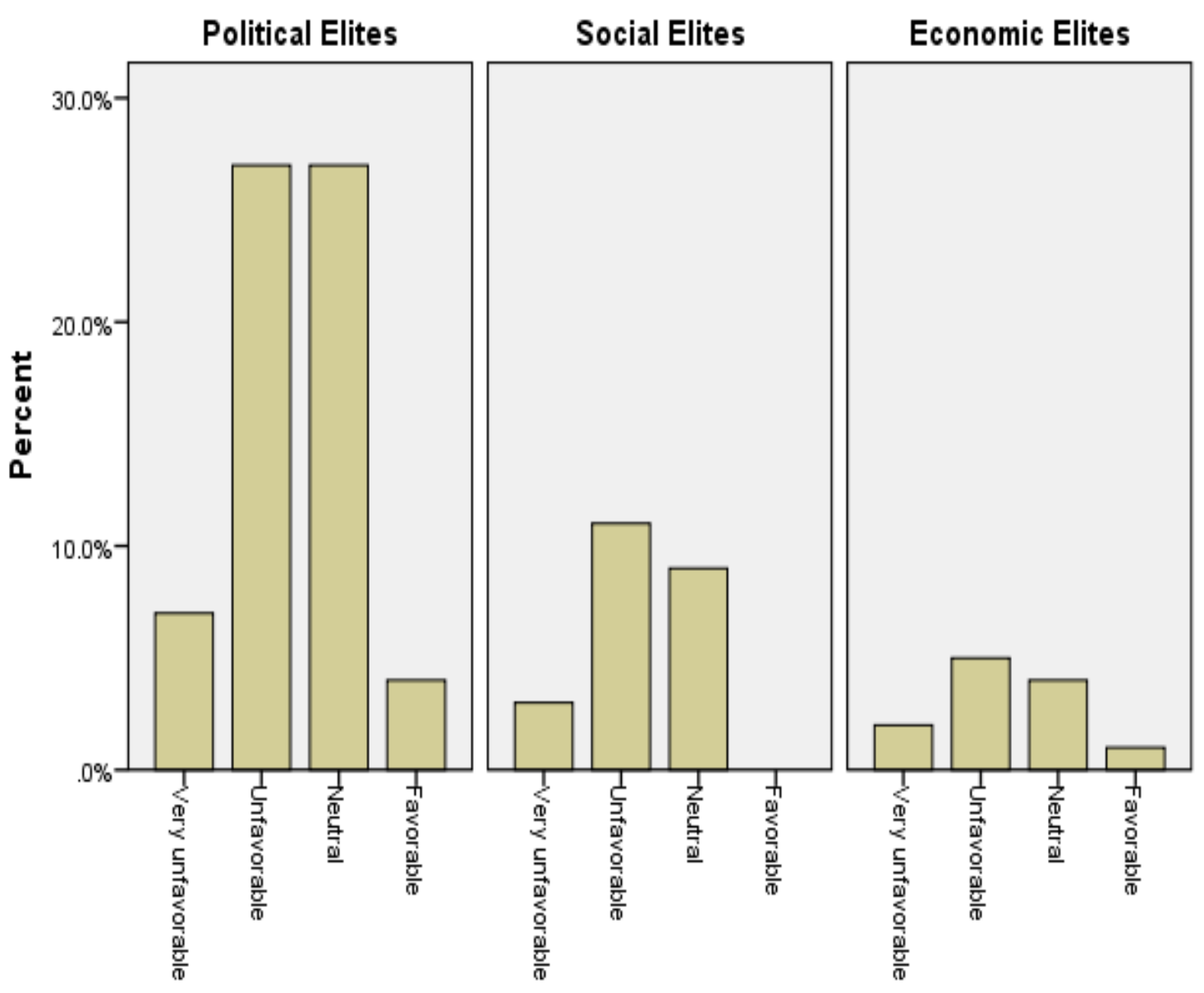

Fighting nepotism 
Table 42 Ending nepotism by three groups of elites

\begin{tabular}{lrcccc}
\hline & SS & df & Mean Square & F & P \\
\hline Between groups & .520 & 2 & .260 & .442 & .644 \\
Within groups & 57.040 & 97 & .588 & & \\
Total & 57.560 & 99 & & & \\
\hline
\end{tabular}

$\mathrm{F}(2,97)=.442, \mathrm{p}=\mathrm{ns}$

Table 43 Ending nepotism -Means (SD)

\begin{tabular}{lcc}
\hline Three Elites Groups & Mean (SD) & $\mathrm{N}$ \\
\hline Political Elites & $2.43(.770)$ & 65 \\
Social Elites & $2.26(.689)$ & 23 \\
Economic Elites & $2.33(.888)$ & 12 \\
Total & $2.38(.763)$ & 100 \\
\hline
\end{tabular}


(Q. 106.6) Merit system

Figure 16 Frequencies of attitudes towards a merit system by three groups of elites

Three Elite Groups

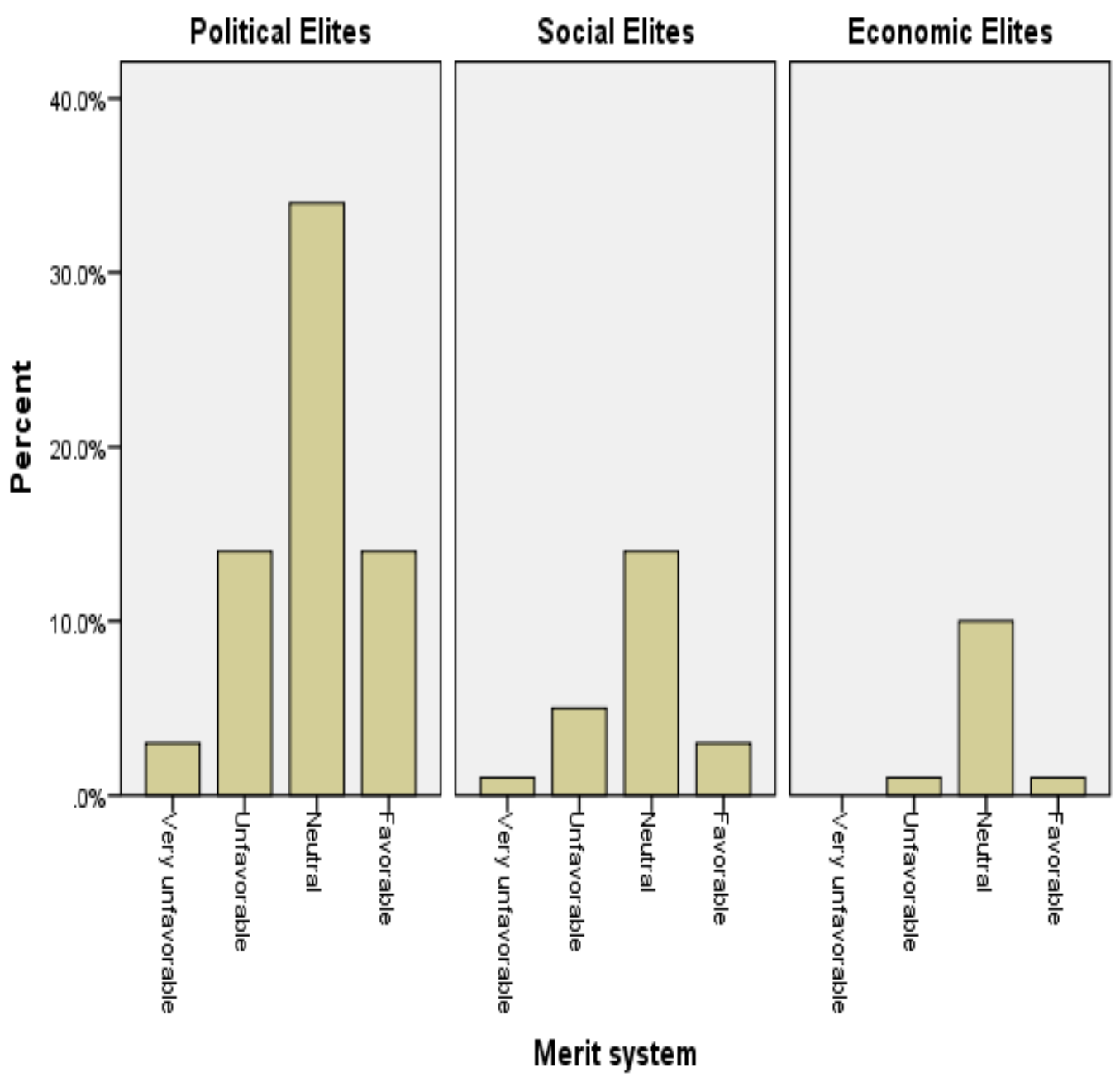


Table $44 \quad$ Merit system by three groups of elites

\begin{tabular}{lrcccc}
\hline & SS & df & Mean Square & F & P \\
\hline Between groups & .249 & 2 & .125 & .229 & .795 \\
Within groups & 52.751 & 97 & .544 & & \\
Total & 53.000 & 99 & & & \\
\hline
\end{tabular}

$$
\mathrm{F}(2,97)=.229, \mathrm{p}=\mathrm{ns} \text {. }
$$

Table $45 \quad$ Merit system - Means (SD)

\begin{tabular}{lcc}
\hline Three Elites Groups & Mean (SD) & $\mathrm{N}$ \\
\hline Political Elites & $2.91(.785)$ & 65 \\
Social Elites & $2.83(.717)$ & 23 \\
Economic Elites & $3.00(.426)$ & 12 \\
Total & $2.90(.732)$ & 100 \\
\hline
\end{tabular}


(Q. 108) Financial Disclosure Law

Elites were asked another question about corruption control in terms of a recent law that was issued enforcing transparency and holding Parliament members and those who occupy high incumbencies in the government accountable. This value question inquired about the effectiveness of "Financial Disclosure Law" and if it controls corruption and ensures accountability and transparency in the political system. The respondents were asked to rate the value or effectiveness of the law using a 4-point scale (1=extremely ineffective to $4=$ =effective). The provisions of this law shall apply to the following positions: prime minister and cabinet; senate president; speaker of the house and members of both houses; judges; heads of official public institutions; military and civilian managers; senior level staff; officials in public institutions and ambassadors; mayors, heads, and members of the large municipalities; heads and members of bidding and procurement of civil and military committees; officials of government, public institutions, and municipalities; incumbents of cabinets; heads of the Boards of Directors of companies that contribute $50 \%$ more than the government. 
Figure 17 Financial disclosure law

Three Elite Groups

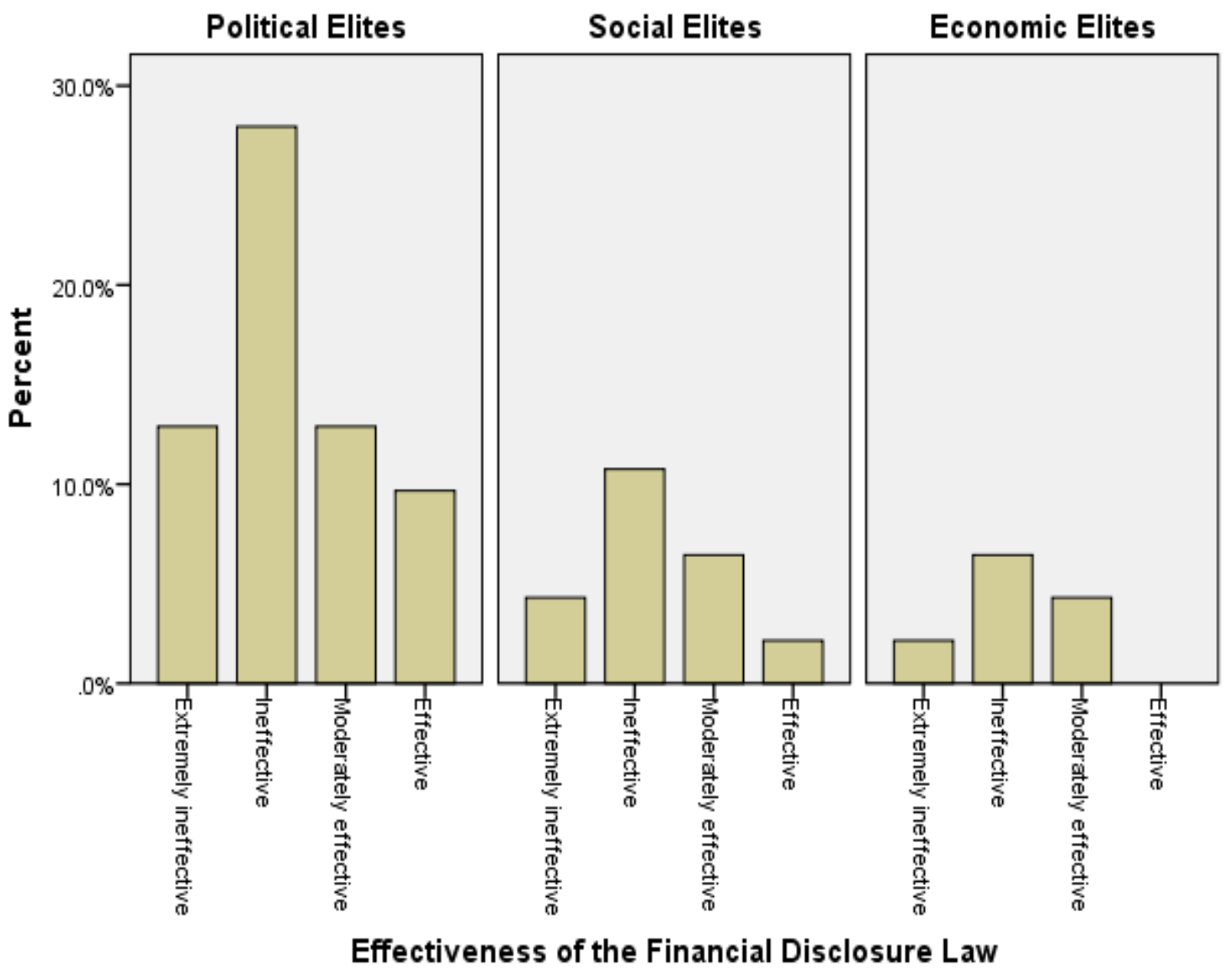


Table $46 \quad$ Financial disclosure law by three groups of elites

\begin{tabular}{lrcccc}
\hline & SS & df & Mean Square & F & P \\
\hline Between groups & .192 & 2 & .096 & .113 & .893 \\
Within groups & 76.539 & 90 & .850 & & \\
Total & 76.731 & 92 & & & \\
\hline
\end{tabular}

$\mathrm{F}(2,90)=.113, \mathrm{p}=. \mathrm{ns}$

Table 47 Financial disclosure law - Means (SD)

\begin{tabular}{lll}
\hline Three Elites Groups & Mean (SD) & $\mathrm{N}$ \\
\hline Political Elites & $2.31(.969)$ & 59 \\
Social Elites & $2.27(.883)$ & 22 \\
Economic Elites & $2.17(.718)$ & 12 \\
Total & $2.28(.913)$ & 93 \\
\hline
\end{tabular}

(Q. 109) Qualitative Analysis: Efficiency and productivity Levels

The following reforms were categorized as core themes and classified under (Theme 1): improving individuals' performance, applying the hiring codes and conducts, enforcing transparency and accountability, reinforcing the democratic values into the organizational culture, reforming managements, organizational development, and policy coordination. But, the core themes that registered high frequencies in this analysis were these three following themes: 1) improving the individual's performance, 2) applying the hiring codes and conducts, 3) enforcing transparency and accountability. See below tables for core and subordinate themes: 
Table 48 Core themes of improving efficiency

Core Themes

Improving the individual's performance

Applying the hiring codes and conducts

Enforcing transparency and accountability
Frequency

128

44

28

In addition, in their explanations and elaborations, the respondents underlined several subordinate and secondary themes that were categorized as (Theme 2) and (Theme 3). For example, training, education, incentives, assigning retreats, or improving the work environment were all subordinate themes to the most frequent core theme of improving the individual's performance. The vocational training theme and the enforcement of the national allegiance through schools' curricula and including the educational level of candidates as a criterion for certain job positions were classified secondary themes (Theme 3). 
The following is a demonstration of core and subordinate themes:

Table $49 \quad$ Core $\&$ subordinate themes of efficiency and productivity levels

\begin{tabular}{|c|c|c|c|}
\hline Theme 1 & Theme 2 & Theme 3 & $\begin{array}{l}\text { Elites' Quotations } \\
\text { from the Survey }\end{array}$ \\
\hline & & & $\begin{array}{l}\text { Managers and all employees } \\
\text { should be assigned training }\end{array}$ \\
\hline Improving & & & and vocational training \\
\hline individuals' & & Vocational & sessions to stay efficient and \\
\hline performances & Training & Training & productive. \\
\hline & & & $\begin{array}{l}\text { Applicants should be } \\
\text { selected lawfully \& hired } \\
\text { based on their qualifications, } \\
\text { or their knowledge, skills, } \\
\text { and abilities; not on their }\end{array}$ \\
\hline $\begin{array}{l}\text { Abiding by the } \\
\text { organizational codes }\end{array}$ & Merit & & $\begin{array}{l}\text { personal relations with a } \\
\text { parliament member or a }\end{array}$ \\
\hline$\&$ conducts & system & KSAs & minister \\
\hline & & & Improving the levels of \\
\hline Enforcing & & & proficiency and efficiency by \\
\hline transparency and & & & holding officers accountable \\
\hline accountability & & & and enforce transparency. \\
\hline
\end{tabular}


The distribution of frequencies:

Table $50 \quad$ Identification of core themes

\begin{tabular}{lccc}
\hline Core Themes & Political Elites & Social Elites & Economic Elites \\
& $(\mathrm{N}=65)$ & $(\mathrm{N}=23)$ & $(\mathrm{N}=12)$ \\
\hline Improving performances & 7 & 33 & 17 \\
& $120.0 \%$ & $143.2 \%$ & $141.6 \%$ \\
Hiring codes \& conducts & 31 & 9 & 4 \\
& $47.7 \%$ & $39.1 \%$ & $33.3 \%$ \\
Transparency & & & \\
\& Accountability & $30.8 \%$ & 5 & 3 \\
& & $21.7 \%$ & $25.0 \%$ \\
& & & \\
\hline
\end{tabular}




\section{(Q. 110) Institution-building}

Table $51 \quad$ Beliefs in Institution-building $-\mathrm{N}(\%)-$ Chi-square

\begin{tabular}{lcccc}
\hline Elite Groups & No $(\%)$ & Yes $(\%)$ & Incomplete & $\chi^{2}$ \\
\hline Political & $29(46)$ & $12(19)$ & $22(34.9)$ & .027 \\
Soc & $11(47)$ & $2(8.7)$ & $10(43.5)$ & \\
Econ & $2(16.7)$ & $00(00)$ & $10(83.3)$ & \\
\hline
\end{tabular}

Chi square result indicates significance: $\chi 2(4, \mathrm{~N}=100)=10.93, \mathrm{p}<.05$.

Table 52 Institution-building - Means (SD)

\begin{tabular}{lcc}
\hline Three Elites Groups & Mean & N \\
\hline Political Elites & $.89(.900)$ & 63 \\
Social Elites & $.96(.976)$ & 23 \\
Economic Elites & $1.67(.778)$ & 12 \\
Total & $1.00(.931)$ & 98 \\
\hline
\end{tabular}


(Q. 111) Qualitative Analysis: Attitudes towards institution-building

Table 53 Institution-building frequency of core themes

\begin{tabular}{lc}
\hline Core Themes & Frequency \\
\hline Seriousness in Implementing Reforms & 57 \\
Decreasing the Authority of the Royal Court & 33 \\
Enforcing Democratic Values & 22 \\
\hline
\end{tabular}

The below table demonstrates the frequency distribution of core and subordinate themes:

Table $54 \quad$ Identification of core themes by three groups of elites

\begin{tabular}{lccc}
\hline Core Themes & Political Elites & Social Elites & Economic Elites \\
& $(\mathrm{N}=65)$ & $(\mathrm{N}=23)$ & $(\mathrm{N}=12)$ \\
\hline Serious implementation & 31 & 17 & 7 \\
of reforms & $47.7 \%$ & $73.9 \%$ & $58.3 \%$ \\
Reducing Royal & 30 & 9 & 3 \\
Court's power & $46.2 \%$ & $39.1 \%$ & $25.0 \%$ \\
& 13 & 4 & 5 \\
Enforcing democratic & 13 & $17.4 \%$ & $41.6 \%$ \\
values & $20.0 \%$ & 4 & \\
\hline
\end{tabular}




\section{Political Participation}

(Q. 104.6) Political Party Reform Policy

Figure 19 Political party affiliation by three groups of elites

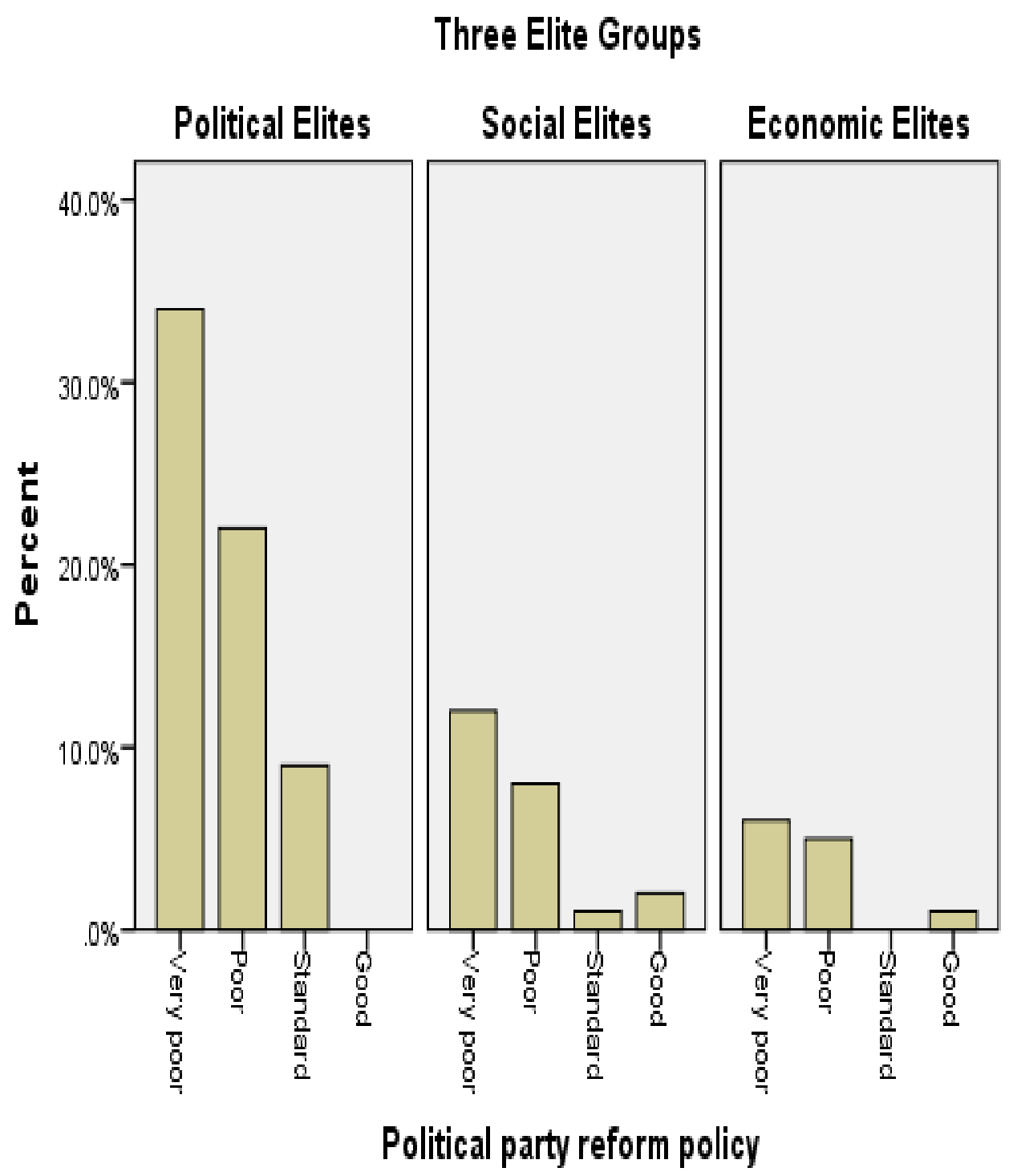


Table $55 \quad$ Political party reform policy- One way ANOVA

\begin{tabular}{lrcccc}
\hline & SS & df & Mean Square & F & P \\
\hline Between groups & .119 & 2 & .060 & .095 & .910 \\
Within groups & 60.921 & 97 & .628 & & \\
Total & 61.040 & 99 & & & \\
\hline
\end{tabular}

$$
\mathrm{F}(2,97)=.095, \mathrm{p}=\mathrm{ns}
$$

Table $56 \quad$ Political party reform policy -Means (SD)

\begin{tabular}{lcc}
\hline Three Elites Groups & Mean (SD) & $\mathrm{N}$ \\
\hline Political Elites & $1.62(.722)$ & 65 \\
Social Elites & $1.70(.926)$ & 23 \\
Economic Elites & $1.67(.888)$ & 12 \\
Total & $1.64(.785)$ & 100 \\
\hline
\end{tabular}


Table 57 Political party reform policy - Cross Tabulation

\begin{tabular}{|c|c|c|}
\hline Three Elites Groups & $\mathrm{N}$ & $\%$ \\
\hline Political Elites & 65 & \\
\hline Very poor & 34 & $52.3 \%$ \\
\hline Poor & 22 & $22.8 \%$ \\
\hline Standard & 9 & $13.8 \%$ \\
\hline Good & 00 & 00 \\
\hline Very good & 00 & 00 \\
\hline Excellent & 00 & 00 \\
\hline Social Elites & 23 & \\
\hline Very poor & 12 & $52.2 \%$ \\
\hline Poor & 08 & $34.8 \%$ \\
\hline Standard & 01 & $04.3 \%$ \\
\hline Good & 02 & $08.7 \%$ \\
\hline Very good & 00 & 00 \\
\hline Excellent & 00 & 00 \\
\hline Economic Elites & 12 & \\
\hline Very poor & 06 & $50.0 \%$ \\
\hline Poor & 05 & $41.7 \%$ \\
\hline Standard & 00 & 00 \\
\hline Good & 01 & $08.3 \%$ \\
\hline Very good & 00 & 00 \\
\hline Excellent & 00 & 00 \\
\hline Total & 100 & \\
\hline
\end{tabular}


(Q. 119) Elites' affiliation with political party

Figure 20 Elites' affiliations with political parties

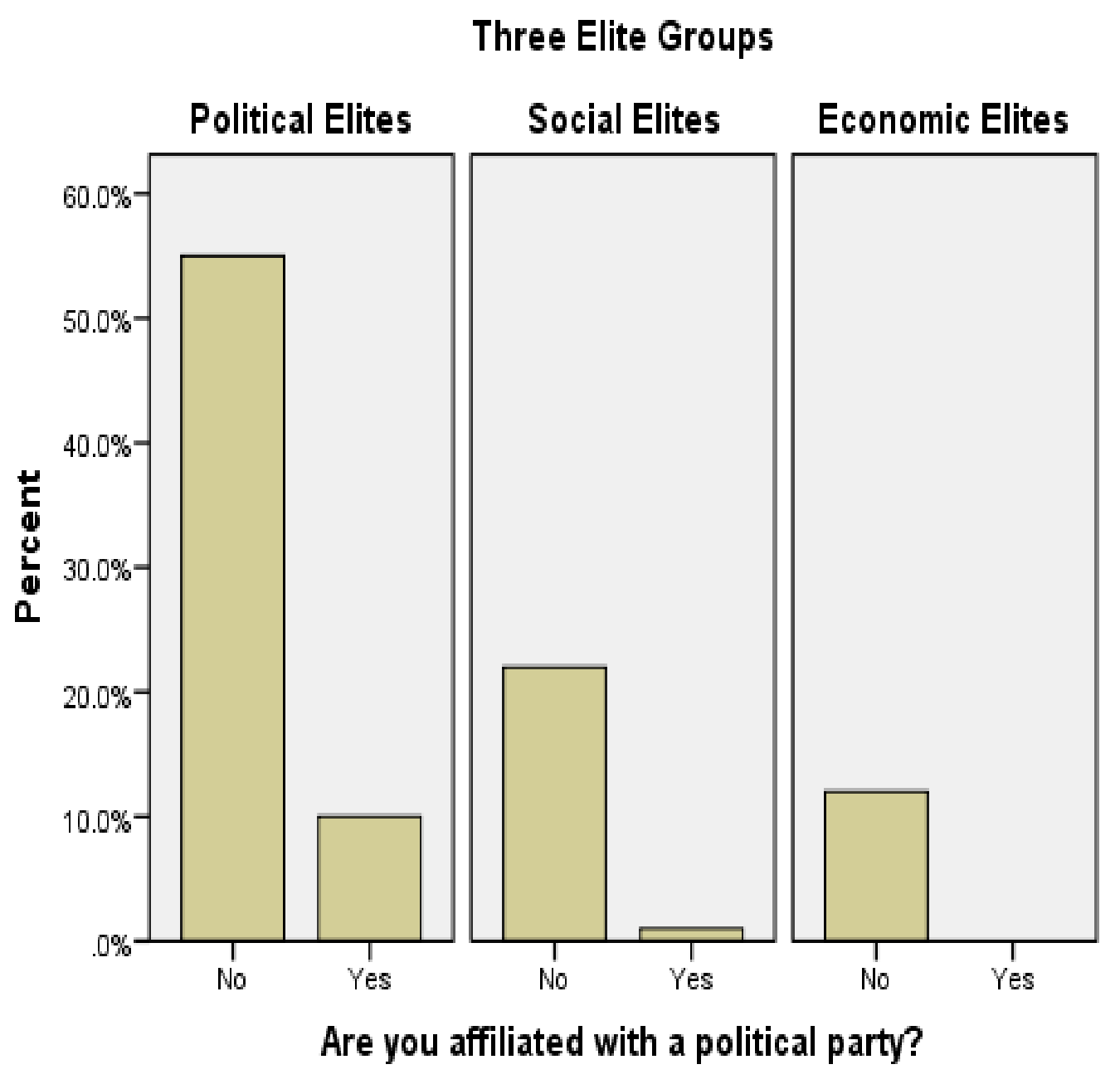


Table $58 \quad$ Elites' affiliation with political party -Means (SD)

\begin{tabular}{lcc}
\hline Three Elites Groups & Mean (SD) & $\mathrm{N}$ \\
\hline Political Elites & $2.74(.644)$ & 65 \\
Social Elites & $2.70(.635)$ & 23 \\
Economic Elites & $2.67(.492)$ & 12 \\
Total & $2.72(.621)$ & 100 \\
\hline
\end{tabular}

Table 59 Elites' affiliation with political party $-\mathrm{N}(\%)-$ Chi-square

\begin{tabular}{lcccc}
\hline Three Elite Groups & No & Yes & $\chi 2$ & Total \\
\hline Political & $55(61.8)$ & $10(90.0 \%)$ & .150 & \\
Social & $22(24.7 \%)$ & $1(9.1 \%)$ & & \\
Economic & $12(100 \%)$ & $0(0 \%)$ & & 100 \\
Total & $89(89 \%)$ & $11(11 \%)$ & & \\
\hline
\end{tabular}

$\chi^{2}(2, \mathrm{~N}=100)=3.8 \mathrm{p}=\mathrm{ns}$ 
(Q. 121) Campaigning culture: mottos, missions, and vision statements

Figure $21 \quad$ Value distribution of elites' campaigning culture

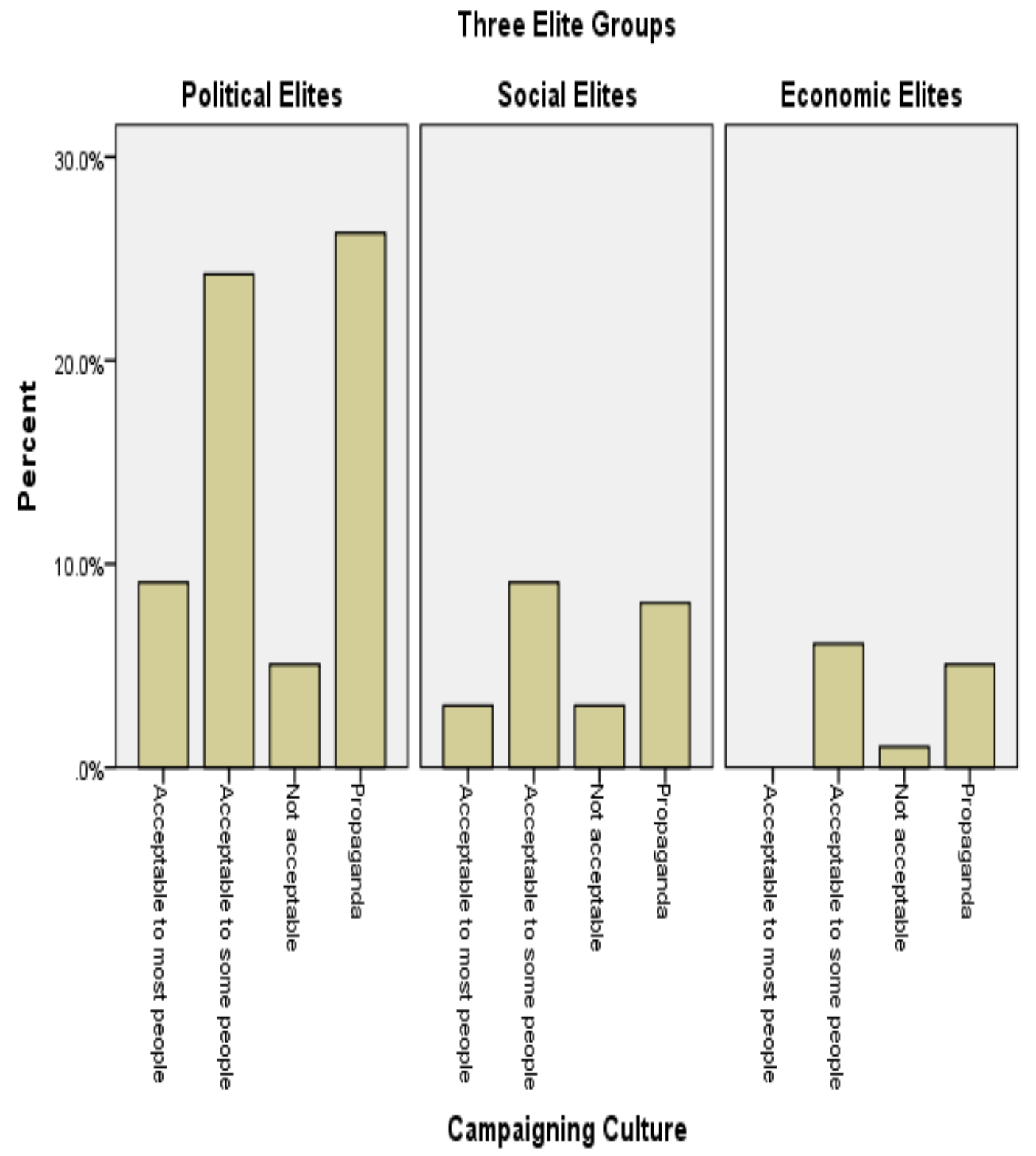


Table $60 \quad$ Campaigning culture by three groups of elites

\begin{tabular}{lrcccc}
\hline & \multicolumn{1}{c}{ SS } & df & Mean Square & F & P \\
\hline Between groups & .396 & 2 & .198 & .159 & .854 \\
Within groups & 119.786 & 96 & 1.248 & & \\
Total & 120.182 & 98 & & & \\
\hline
\end{tabular}

$\mathrm{F}(2,96)=.159, \mathrm{p}=\mathrm{ns}$

Table $61 \quad$ Campaigning culture -Mean (SD)

\begin{tabular}{lll}
\hline Three Elites Groups & Mean (SD) & N \\
\hline Political Elites & $2.75(1.141)$ & 64 \\
Social Elites & $2.70(1.105)$ & 23 \\
Economic Elites & $2.92(0.996)$ & 12 \\
Total & $2.76(1.107)$ & 99 \\
\hline
\end{tabular}


Table 62 Campaigning culture - Cross Tabulation

Three Elites Groups

Political Elites

Appealing and engaging to most Jordanians Appealing and engaging to some Jordanians Neither Appealing nor engaging

Used as campaign propaganda

Social Elites

Appealing and engaging to most Jordanians Appealing and engaging to some Jordanians Neither Appealing nor engaging

Used as campaign propaganda

$\mathrm{N} \quad \%$

64

$09 \quad 14.1 \%$

$24 \quad 37.5 \%$

$05 \quad 07.8 \%$

$26 \quad 40.6 \%$

23

$03 \quad 13.0 \%$

$09 \quad 39.1 \%$

$03 \quad 13.0 \%$

$08 \quad 34.8 \%$

Economic Elites

Appealing and engaging to most Jordanians

$0 \quad 00.0 \%$ Appealing and engaging to some Jordanians $06 \quad 50.0 \%$ Neither Appealing nor engaging $01 \quad 08.3 \%$

Used as campaign propaganda

$05 \quad 41.7 \%$




\section{(Q. 122) Qualitative Thematic Analysis: Political Party Weakness}

In the open-ended question (122), elites expressed their beliefs of the weakness of political parties. The below table displays the core themes that registered the highest frequencies:

Table 63 Frequencies of core themes: Political party weakness

\begin{tabular}{lc}
\hline Core Themes & Frequency \\
\hline Authoritarianism & 52 \\
Absence of Programs & 51 \\
Past Failures & 34 \\
\hline
\end{tabular}

The frequency distribution of core and subordinate themes in percentages:

Table 64 Core themes for political party weakness

\begin{tabular}{|c|c|c|c|c|}
\hline Core Themes & $\begin{array}{l}\text { Political Elites } \\
\qquad(\mathrm{N}=65)\end{array}$ & $\begin{array}{l}\text { Social Elites } \\
\qquad(\mathrm{N}=23)\end{array}$ & $\begin{array}{l}\text { Economic Elites } \\
\qquad(\mathrm{N}=12)\end{array}$ & $\begin{array}{c}\text { Total } \\
(\mathrm{N}=100)\end{array}$ \\
\hline \multirow[t]{2}{*}{ Authoritarianism } & 31 & 15 & 6 & 52 \\
\hline & $47.7 \%$ & $65.2 \%$ & $50 \%$ & $52 \%$ \\
\hline \multicolumn{2}{|c|}{ Absence of Programs 30} & 15 & 6 & 51 \\
\hline & $46.2 \%$ & $65.2 \%$ & $50 \%$ & $51 \%$ \\
\hline \multirow[t]{2}{*}{ Past Failures } & 21 & 9 & 4 & 34 \\
\hline & $32.3 \%$ & $39.1 \%$ & $33.3 \%$ & $34 \%$ \\
\hline
\end{tabular}


(Q. 123) Qualitative Analysis Activating and Empowering Political Parties

A variation of reforms was illustrated by the respondents and sorted in the following most frequent core themes as demonstrated in the below table:

Table 65 Core themes for activating and empowering political parties

\begin{tabular}{lc}
\hline Core Themes & Frequency \\
\hline Reforming Political Parties & 86 \\
Legislative Amendment & 44 \\
Raising Awareness Levels & 40 \\
\hline
\end{tabular}


Elites' elaborations on core and subordinate themes:

Table 66 Activating Political Parties: Core and Subordinate Themes

\begin{tabular}{|c|c|c|c|}
\hline Theme 1 & Theme 2 & Theme 3 & $\begin{array}{l}\text { Elites' Quotations from } \\
\text { the Survey }\end{array}$ \\
\hline $\begin{array}{l}\text { Reforming political } \\
\text { parties }\end{array}$ & $\begin{array}{l}\text { Activating } \\
\text { political party } \\
\text { programs }\end{array}$ & $\begin{array}{l}\text { Emphasizing } \\
\text { the national } \\
\text { roles of } \\
\text { political parties }\end{array}$ & $\begin{array}{l}\text { The absence of programs } \\
\text { weakens the national } \\
\text { roles of political party } \\
\text { institutions; therefore, } \\
\text { they must be allowed to } \\
\text { pursue the political, } \\
\text { social, and economic } \\
\text { goals on their agendas. }\end{array}$ \\
\hline $\begin{array}{l}\text { Legislative } \\
\text { amendment }\end{array}$ & $\begin{array}{l}\text { Amending } \\
\text { political party } \\
\text { law }\end{array}$ & $\begin{array}{l}\text { Voiding out } \\
\text { the One Man } \\
\text { One Vote Law }\end{array}$ & $\begin{array}{l}\text { The one-man, one-vote } \\
\text { rule leads to } \\
\text { disproportionate results; } \\
\text { election laws must be } \\
\text { based on the population } \\
\text { in each district not on } \\
\text { who populates the } \\
\text { district. }\end{array}$ \\
\hline $\begin{array}{l}\text { Raising awareness } \\
\text { levels }\end{array}$ & $\begin{array}{l}\text { Understanding } \\
\text { the negative } \\
\text { effect of } \\
\text { tribalism on } \\
\text { political parties }\end{array}$ & & $\begin{array}{l}\text { The tribal affiliation } \\
\text { should never replace the } \\
\text { political party affiliation. }\end{array}$ \\
\hline
\end{tabular}


(Q. 124) Electoral laws: One-man, One-vote

Figure 22 One-man, One-vote Laws

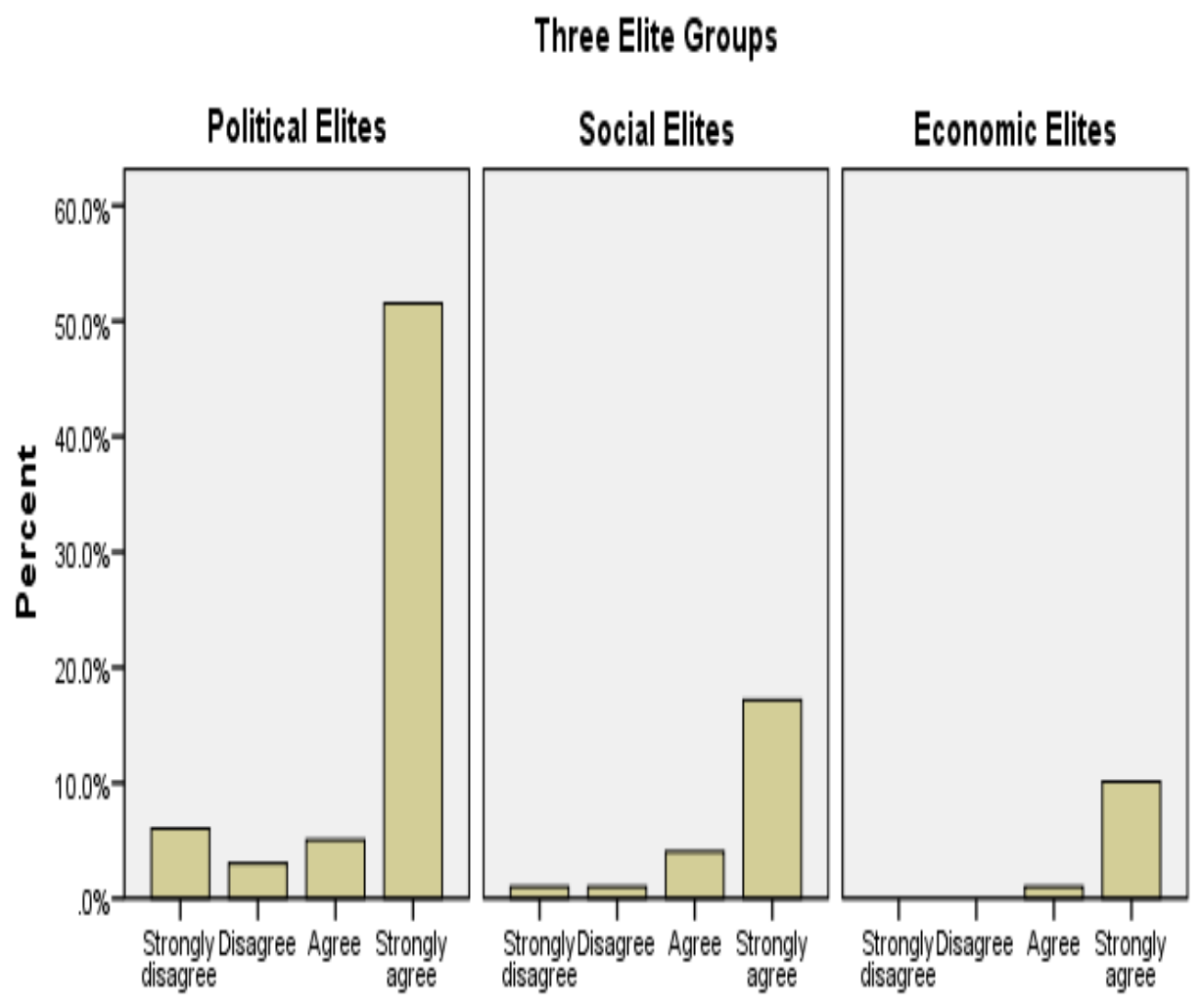

The one-man, one- vote law 
A One-way ANOVA testing differences between elites' beliefs:

Table 67 One-man, one-vote by three groups of elites

\begin{tabular}{lccccc}
\hline & SS & df & Mean Square & F & P \\
\hline Between groups & 1.187 & 2 & .594 & .787 & .458 \\
Within groups & 72.449 & 96 & .755 & & \\
Total & 73.636 & 98 & & & \\
\hline
\end{tabular}

$\mathrm{F}(2,96)=.787 \mathrm{p}=\mathrm{ns}$.

Table 68 One-man, One-vote law -Mean (SD)

\begin{tabular}{lll}
\hline Three Elites Groups & Mean (SD) & N \\
\hline Political Elites & $3.55(.952)$ & 65 \\
Social Elites & $3.61(.783)$ & 23 \\
Economic Elites & $3.91(.302)$ & 12 \\
Total & $3.61(.867)$ & 100 \\
\hline
\end{tabular}


Table 69 One-man, One-vote - Cross Tabulation

\begin{tabular}{|c|c|c|}
\hline Elites' beliefs in the One-man, One-vote Law & $\mathrm{N}$ & $\%$ \\
\hline Political & 65 & $65 \%$ \\
\hline Strongly disagree & 6 & 9.2 \\
\hline Disagree & 3 & 4.6 \\
\hline Agree & 5 & 7.7 \\
\hline Strongly agree & 51 & 78.5 \\
\hline Social & 23 & $23 \%$ \\
\hline Strongly disagree & 1 & 4.3 \\
\hline Disagree & 17 & 73 \\
\hline Agree & 4 & 17.4 \\
\hline Strongly agree & 17 & 73.9 \\
\hline Economic & 12 & $12 \%$ \\
\hline Strongly disagree & 0 & 0 \\
\hline Disagree & 0 & 0 \\
\hline Agree & 1 & 9.1 \\
\hline Strongly agree & 10 & 90.9 \\
\hline Total & 100 & 100 \\
\hline
\end{tabular}


(Q. 116) Lobbying

Figure 23 Practicing lobbying distribution

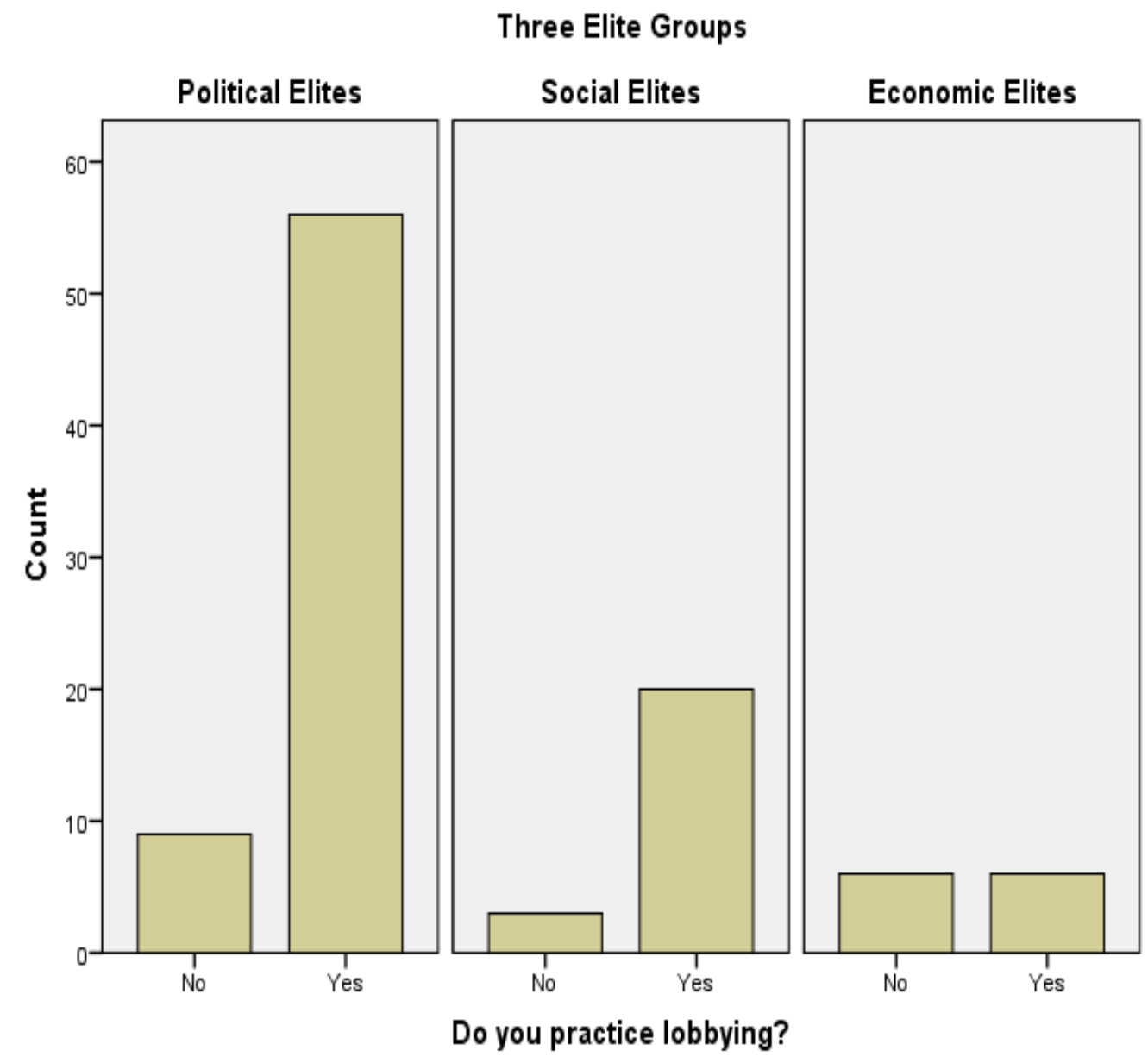


Table $70 \quad$ Practicing lobbying $-\mathrm{N}(\%)-$ Chi-square

\begin{tabular}{lllll}
\hline Three Elite Groups & No $(\%)$ & Yes $(\%)$ & $\chi^{2}$ & Total
\end{tabular}

\begin{tabular}{lccc}
\hline Political & $9(13.8)$ & $56(86.2)$ & .009 \\
Social & $3(13.0)$ & $20(87.0)$ & \\
Economic & $6(50.0)$ & $6(50.0)$ & \\
Total & $18(18)$ & $82(82.0)$ & 100 \\
\hline
\end{tabular}

$$
\chi^{2}(2, \mathrm{~N}=100)=9.45, \mathrm{p}<.05
$$


(Q. 117) Lobbying Reasons

Figure 24 Elites' reasons for lobbying?

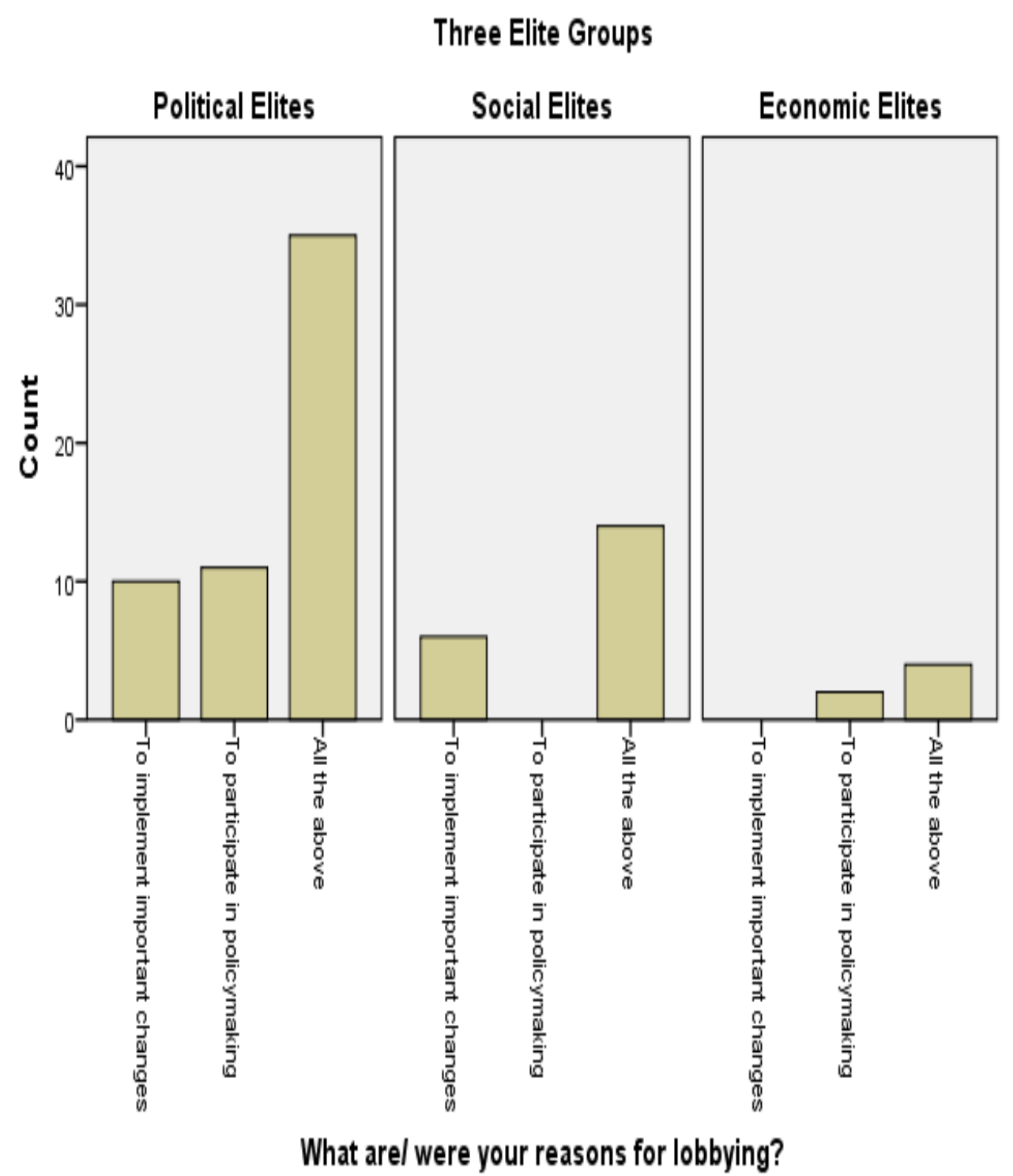


Table 71 Lobbying reasons by three groups of elites

\begin{tabular}{lccccc}
\hline & SS & df & Mean Square & F & P \\
\hline Between groups & 3.608 & 2 & 1.804 & .738 & .481 \\
Within groups & 193.078 & 79 & 2.444 & & \\
Total & 196.695 & 81 & & & \\
\hline
\end{tabular}

$\mathrm{F}(2,79)=.738, \mathrm{p}=\mathrm{ns}$

Table 72 Lobbying reasons Cross-Tabulation

\begin{tabular}{|c|c|c|}
\hline Three Elites Groups & $\mathrm{N}$ & $\%$ \\
\hline Political Elites & 56 & $68.3 \%$ \\
\hline To implement important changes & 10 & $18.0 \%$ \\
\hline To pursue my democratic values & 00 & 00 \\
\hline To support pluralism & 00 & 00 \\
\hline To participate in policy making & 11 & $20.0 \%$ \\
\hline All the above & 35 & $63.0 \%$ \\
\hline Social Elites & 20 & $24.4 \%$ \\
\hline To implement important changes & 06 & $30.0 \%$ \\
\hline To pursue my democratic values & 00 & 00 \\
\hline To support pluralism & 00 & 00 \\
\hline To participate in policy making & 00 & 00 \\
\hline All the above & 14 & $70.0 \%$ \\
\hline Economic Elites & 06 & $\mathbf{0 7 . 3 \%}$ \\
\hline To implement important changes & 00 & 00 \\
\hline To pursue my democratic values & 00 & 00 \\
\hline To support pluralism & 00 & 00 \\
\hline To participate in policy making & 02 & $33.0 \%$ \\
\hline All the above & 04 & $67.0 \%$ \\
\hline Total & 82 & 100 \\
\hline
\end{tabular}


Social Development

(Q.103.2) Social change through modernizing schools' curricula

Figure 25 School curricula reform

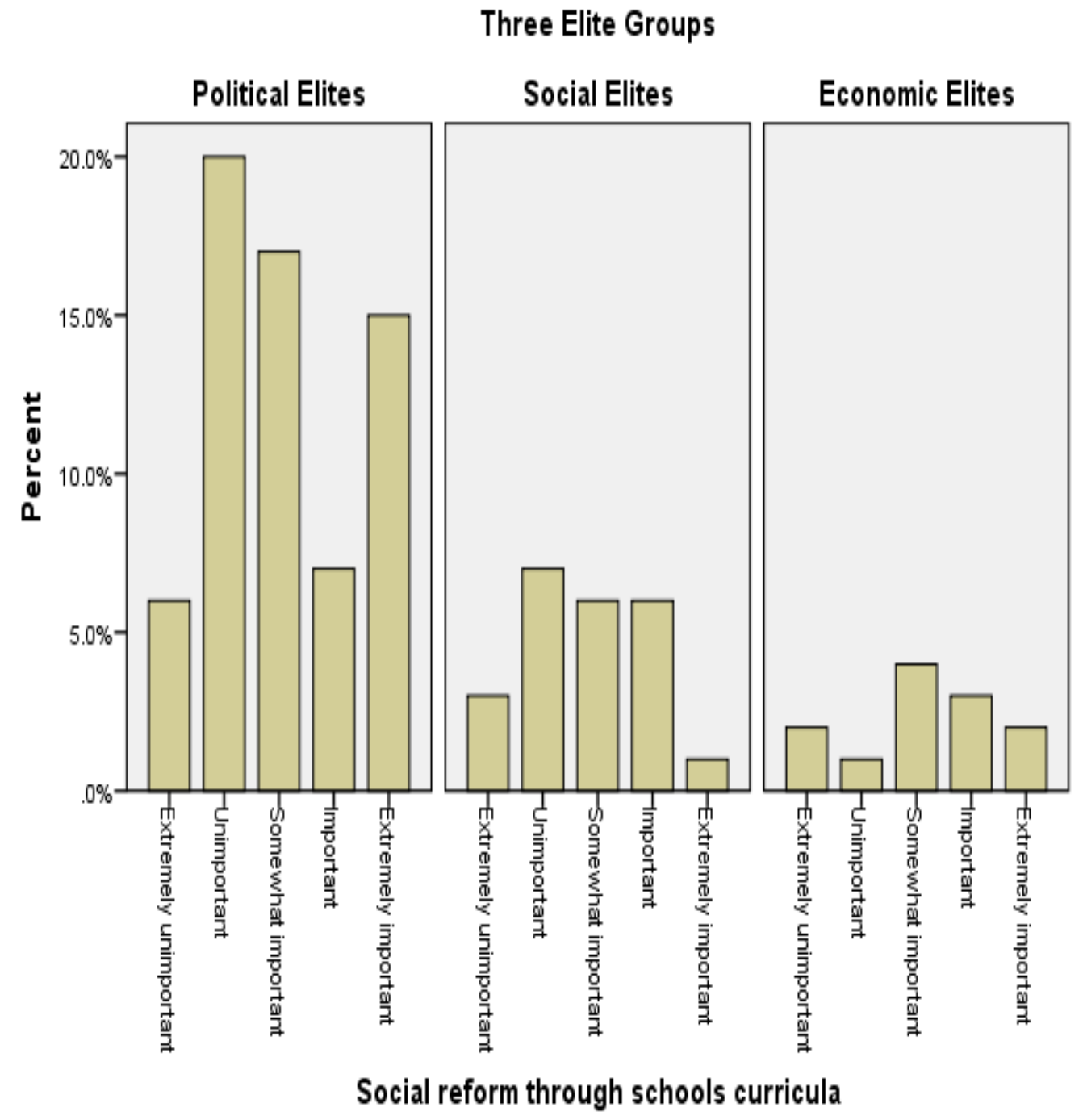


A one-way ANOVA test result was not significant:

Table 73 School curricula reform- One way ANOVA

\begin{tabular}{lrrccc}
\hline & SS & df & Mean Square & F & P \\
\hline Between groups & 1.765 & 2 & .882 & .541 & .584 \\
Within groups & 158.19 & 97 & 1.631 & & \\
Total & 159.96 & 99 & & & \\
\hline
\end{tabular}

$\mathrm{F}(2,97)=.541, \mathrm{p}=\mathrm{ns}$

Table 74 School curricula reform -Means (SD)

\begin{tabular}{lll}
\hline Three Elites Groups & Mean (SD) & $\mathrm{N}$ \\
\hline Political Elites & $3.08(1.315)$ & 65 \\
Social Elites & $2.78(1.126)$ & 23 \\
Economic Elites & $3.17(1.337)$ & 12 \\
Total & $3.02(1.271)$ & 100 \\
\hline
\end{tabular}


Table 75 Importance of education policy reform \& school curricula values - Cross Tabulation

\begin{tabular}{|c|c|c|}
\hline Modernizing School Curricula Value & $\mathbf{N}$ & $\%$ \\
\hline Political Elites & 65 & $65 \%$ \\
\hline Extremely unimportant & 6 & 6.0 \\
\hline Unimportant & 20 & 20 \\
\hline Somewhat important & 17 & 17. \\
\hline Important & 7 & 7.0 \\
\hline Extremely important & 15 & 15. \\
\hline Social Elites & 23 & $23 \%$ \\
\hline Extremely unimportant & 3 & 3.0 \\
\hline Unimportant & 7 & 7.0 \\
\hline Somewhat important & 6 & 6.0 \\
\hline Important & 6 & 6.0 \\
\hline Extremely important & 1 & 1.0 \\
\hline Economic Elites & 12 & $12 \%$ \\
\hline Extremely unimportant & 2 & 2.0 \\
\hline Unimportant & 1 & 1.0 \\
\hline Somewhat important & 4 & 4.0 \\
\hline Important & 3 & 3.0 \\
\hline Extremely important & 2 & 2.0 \\
\hline Total & 100 & $100 \%$ \\
\hline
\end{tabular}


(Q. 103.5) Importance of tribal values to policymakers

Figure 26 Tribal values by three groups of elites

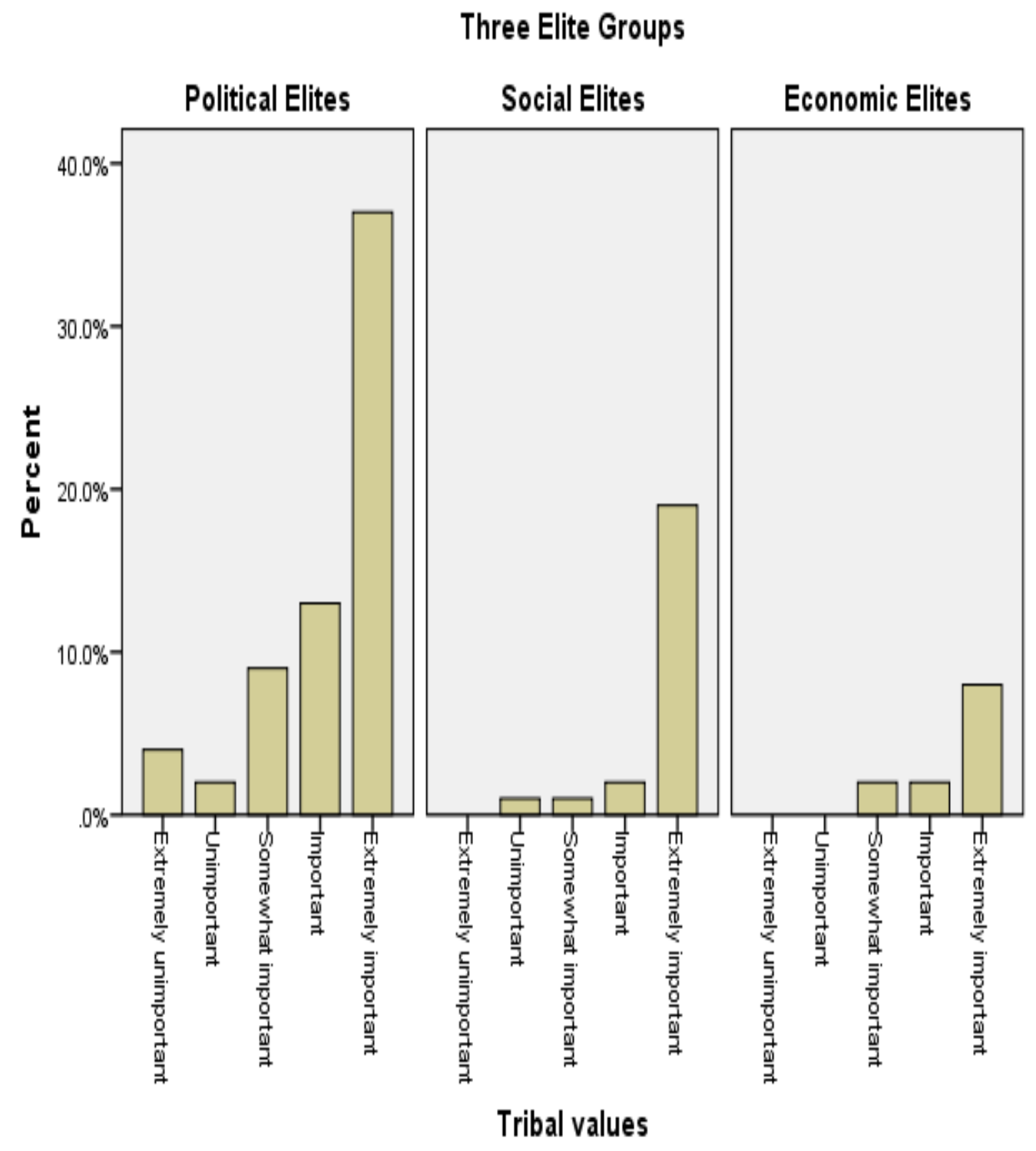


Table 76 Tribal values- One way ANOVA

\begin{tabular}{lrcccc}
\hline & \multicolumn{1}{c}{ SS } & df & Mean Square & F & P \\
\hline Between groups & 4.786 & 2 & 2.393 & 2.156 & .121 \\
Within groups & 107.654 & 97 & 1.110 & & \\
Total & 112.440 & 99 & & & \\
\hline
\end{tabular}

$\mathrm{F}(2,97)=2.16, \mathrm{p}=\mathrm{ns}$.

Table 77 Importance of tribal values to policymakers - Means (SD)

\begin{tabular}{llll}
\hline Three Elites Groups & Mean & $\mathrm{N}$ \\
\hline Political Elites & $4.18(1.171)$ & 65 & \\
Social Elites & $4.70(.765)$ & 23 & \\
Economic Elites & $4.50(.798)$ & 12 & \\
Total & $4.34(1.066)$ & 100 & 1.066 \\
\hline
\end{tabular}


Table 78 The tribal values by three elite groups

\begin{tabular}{ll}
\hline Elites' Tribal Values & $\mathrm{N}$
\end{tabular}

Political Elites

Extremely unimportant

Unimportant

Somewhat important

Important

Extremely important

Social Elites

Extremely unimportant

Unimportant

Somewhat important

Important

Extremely important

Economic Elites

Extremely unimportant

Unimportant

Somewhat important

Important

Extremely important

Total
65

$04 \quad 06.2 \%$

$02 \quad 03.1 \%$

$09 \quad 13.8 \%$

$13 \quad 20.0 \%$

$37 \quad 56.9 \%$

23

$00 \quad 00.0 \%$

$01 \quad 04.3 \%$

$01 \quad 04.3 \%$

$02 \quad 08.7 \%$

$19 \quad 82.6 \%$

12

$00 \quad 00.0 \%$

$00 \quad 00.0 \%$

$02 \quad 16.7 \%$

$02 \quad 16.7 \%$

$08 \quad 66.7 \%$

$100 \quad 100 \%$ 
(Q. 126) Tribal impact on development

Figure 27 Beliefs distribution of tribal impact on development

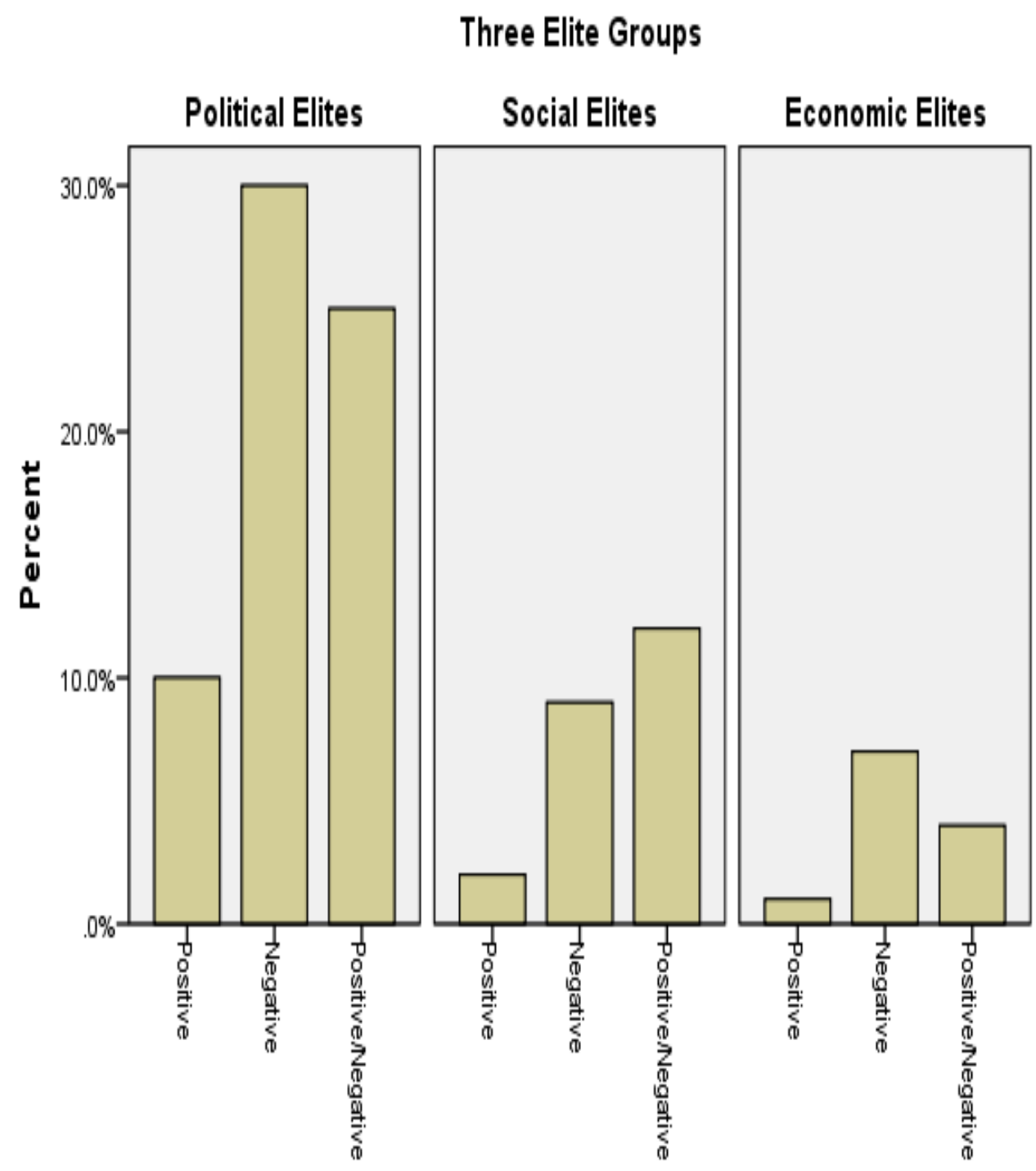

How does tribalism impact the political and social developments?

Table 79 Tribal impact on development - Means (SD) 


\begin{tabular}{lll}
\hline Three Elites Groups & Mean (SD) & $\mathrm{N}$ \\
\hline Political Elites & $2.23(.702)$ & 65 \\
Social Elites & $2.43(.662)$ & 23 \\
Economic Elites & $2.25(.622)$ & 12 \\
Total & $2.28(.638)$ & 100 \\
\hline
\end{tabular}

Table $80 \quad$ Beliefs in tribalism impact on development - Cross Tabulation

\begin{tabular}{|c|c|c|}
\hline Tribalism Impact & $\mathrm{N}$ & $\%$ \\
\hline Political & 65 & $65 \%$ \\
\hline Positive & 10 & $15.4 \%$ \\
\hline Negative & 30 & $46.2 \%$ \\
\hline Positive/Negati & 25 & $38.5 \%$ \\
\hline Social & 23 & $23 \%$ \\
\hline Positive & 02 & $08.7 \%$ \\
\hline Negative & 09 & $39.1 \%$ \\
\hline Positive/Negative & 12 & $52.2 \%$ \\
\hline Economic & 12 & $12 \%$ \\
\hline Positive & 01 & $08.3 \%$ \\
\hline Negative & 07 & $58.3 \%$ \\
\hline Positive/Negati & 04 & $33.3 \%$ \\
\hline Total & 100 & $100 \%$ \\
\hline
\end{tabular}


Table $81 \quad$ Tribalism impact on development- N (\%) - Chi-square

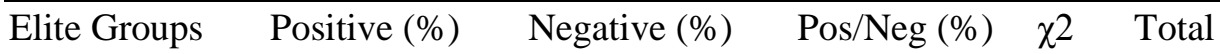

\begin{tabular}{|c|c|c|c|c|}
\hline Political & $10(15)$ & $30(86.2)$ & $25(39)$ & .009 \\
\hline Social & $2(9.0)$ & $9(87.0)$ & $12(52)$ & \\
\hline Economic & $1(8.0)$ & $7(50.0)$ & $4(33)$ & \\
\hline Total & $13(13 \%)$ & $46(82 \%)$ & $41(41 \%)$ & 100 \\
\hline
\end{tabular}

$$
\chi 2(4, \mathrm{~N}=100)=.659, \mathrm{p}<\mathrm{ns}
$$


(Q. 127) Qualitative analysis: Reasons behind tribalism impact on development

Table 82 Frequencies of core themes: tribalism impact

\begin{tabular}{lc}
\hline Core Themes & Frequency \\
\hline Sociopolitical imbalances \& disloyalty & 49 \\
Compound impact & 37 \\
Smooth developments & 14 \\
\hline
\end{tabular}

Elites' elaborations on core and subordinate themes:

Table 83 Tribalism impact on development: core and subordinate themes

\begin{tabular}{|c|c|c|c|}
\hline Theme 1 & Theme 2 & Theme 3 & $\begin{array}{l}\text { Elites' Quotations } \\
\text { from the Survey }\end{array}$ \\
\hline $\begin{array}{l}\text { Hindrance \& } \\
\text { regression }\end{array}$ & $\begin{array}{l}\text { Tribalism } \\
\text { delays } \\
\text { democratic } \\
\text { governance }\end{array}$ & & $\begin{array}{l}\text { Loyalty for the tribe } \\
\text { overcomes the } \\
\text { national loyalty, and } \\
\text { tribal rules } \\
\text { overcome the rule } \\
\text { of law; it creates } \\
\text { fanaticism, } \\
\text { extremism, and } \\
\text { spreads corruption. }\end{array}$ \\
\hline $\begin{array}{l}\text { Confuses } \\
\text { Loyalty }\end{array}$ & $\begin{array}{l}\text { Substitutes for } \\
\text { political parties } \\
\text { and } \\
\text { Nationalism }\end{array}$ & $\begin{array}{l}\text { Weakens } \\
\text { Modernity }\end{array}$ & $\begin{array}{l}\text { Fills the gap that the } \\
\text { absent political } \\
\text { parties could not } \\
\text { fill, but it weakens } \\
\text { the modern state } \\
\text { and generates non- }\end{array}$ \\
\hline
\end{tabular}


democratic

measures.

Enhancing

development
Tribalism

strengthens the

social cohesion
Tribalism enhances

its members'

stability, solidarity, unity, economic

situations; it

controls crime. 
Table 84 Tribalism impact on development $-\mathrm{N}(\%)$

\begin{tabular}{lccc}
\hline Core Themes & Political Elites & Social Elites & Economic Elites \\
& $(\mathrm{N}=65)$ & $(\mathrm{N}=23)$ & $(\mathrm{N}=12)$ \\
\hline $\begin{array}{l}\text { Hindrance and } \\
\text { regression }\end{array}$ & 30 & 11 & 8 \\
Confused & $46.2 \%$ & $47.8 \%$ & 66.6 \\
Loyalty & 25 & 9 & 3 \\
Enhancing & $38.5 \%$ & $39.1 \%$ & 25.0 \\
Development & 10 & 3 & 1 \\
& $5.4 \%$ & $13.0 \%$ & $8.3 \%$
\end{tabular}

(Q. 128) Tribalism influence on elites' political culture

Table 85 Tribal influence on elites' political culture by three groups of elites

\begin{tabular}{lccccc}
\hline & SS & df & Mean Square & F & P \\
\hline Between groups & .747 & 2 & .374 & .436 & .648 \\
Within groups & 82.243 & 96 & .857 & & \\
Total & 82.990 & 98 & & & \\
\hline
\end{tabular}

$\mathrm{F}(2,96)=.436, \mathrm{p}=\mathrm{ns}$ 
Figure 28 Tribal influence on elites' political culture

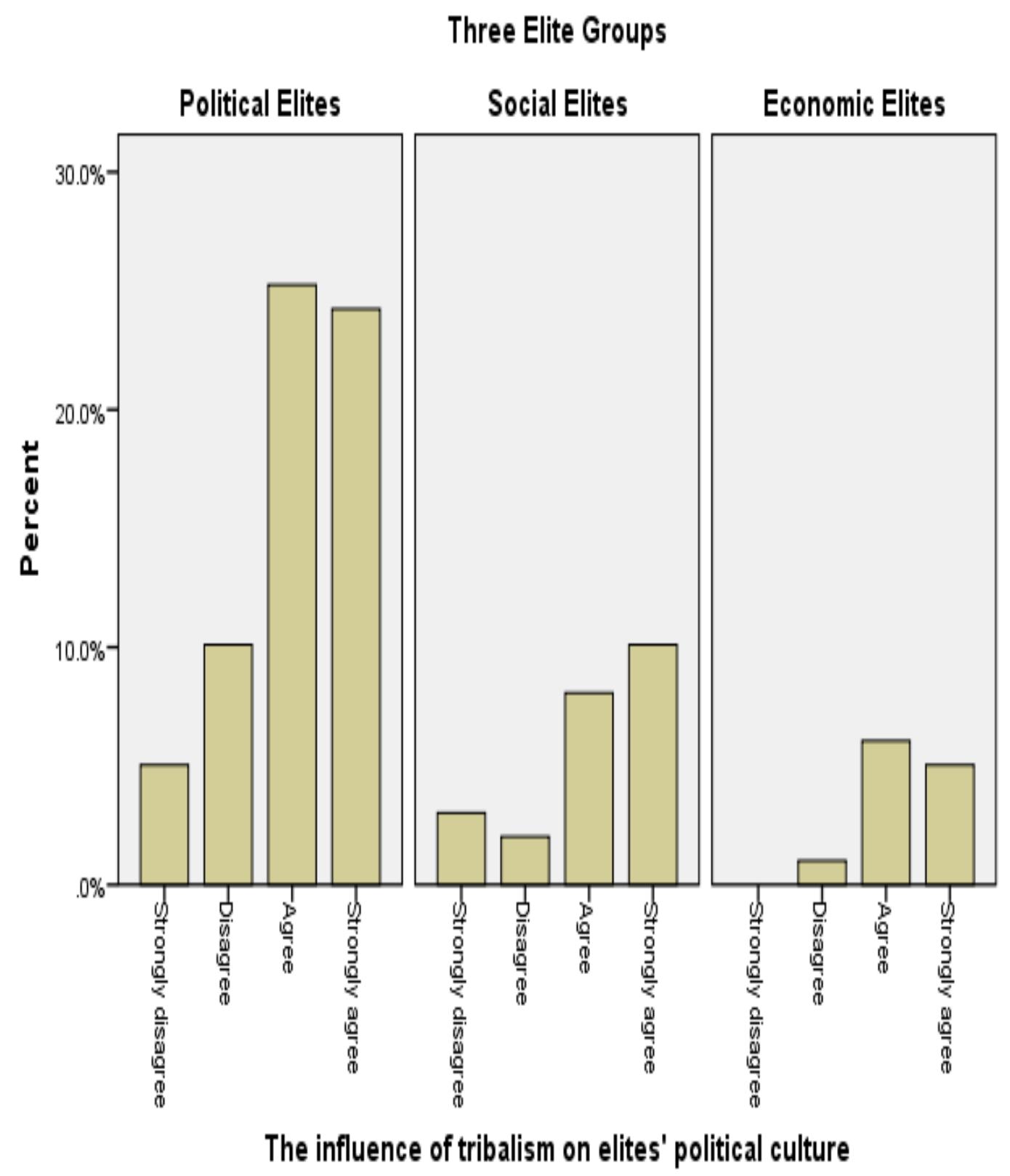


Table 86 Tribal influence on elites' political culture: Means (SD)

\begin{tabular}{lll}
\hline Three Elites Groups & Mean (SD) & $\mathrm{N}$ \\
\hline Political Elites & $3.06(.924)$ & 64 \\
Social Elites & $3.09(1.041)$ & 23 \\
Economic Elites & $3.33(.651)$ & 12 \\
Total & $3.10(.920)$ & 99 \\
\hline
\end{tabular}

Table 87 Tribal influence on elites' political culture -Cross Tabulation

\begin{tabular}{|c|c|c|}
\hline Elites' Values on Tribal Influence & $\mathrm{N}$ & $\%$ \\
\hline Political & 64 & $64 \%$ \\
\hline Strongly disagree & 5 & 5.1 \\
\hline Disagree & 10 & 10.1 \\
\hline Agree & 25 & 25.3 \\
\hline Strongly agree & 24 & 24.2 \\
\hline Social & 23 & $23 \%$ \\
\hline Strongly disagree & 3 & 3.0 \\
\hline Disagree & 2 & 2.0 \\
\hline Agree & 8 & 8.1 \\
\hline Strongly agree & 10 & 10.1 \\
\hline Economic & 12 & $12 \%$ \\
\hline Strongly disagree & 0 & 0 \\
\hline Disagree & 1 & 1.0 \\
\hline Agree & 6 & 6.1 \\
\hline Strongly agree & 5 & 5.1 \\
\hline Total & 99 & $100 \%$ \\
\hline
\end{tabular}


(Q. 103.4) Importance of religious values in social development

Figure $29 \quad$ Religious values by three groups of elites

\section{Three Elite Groups}

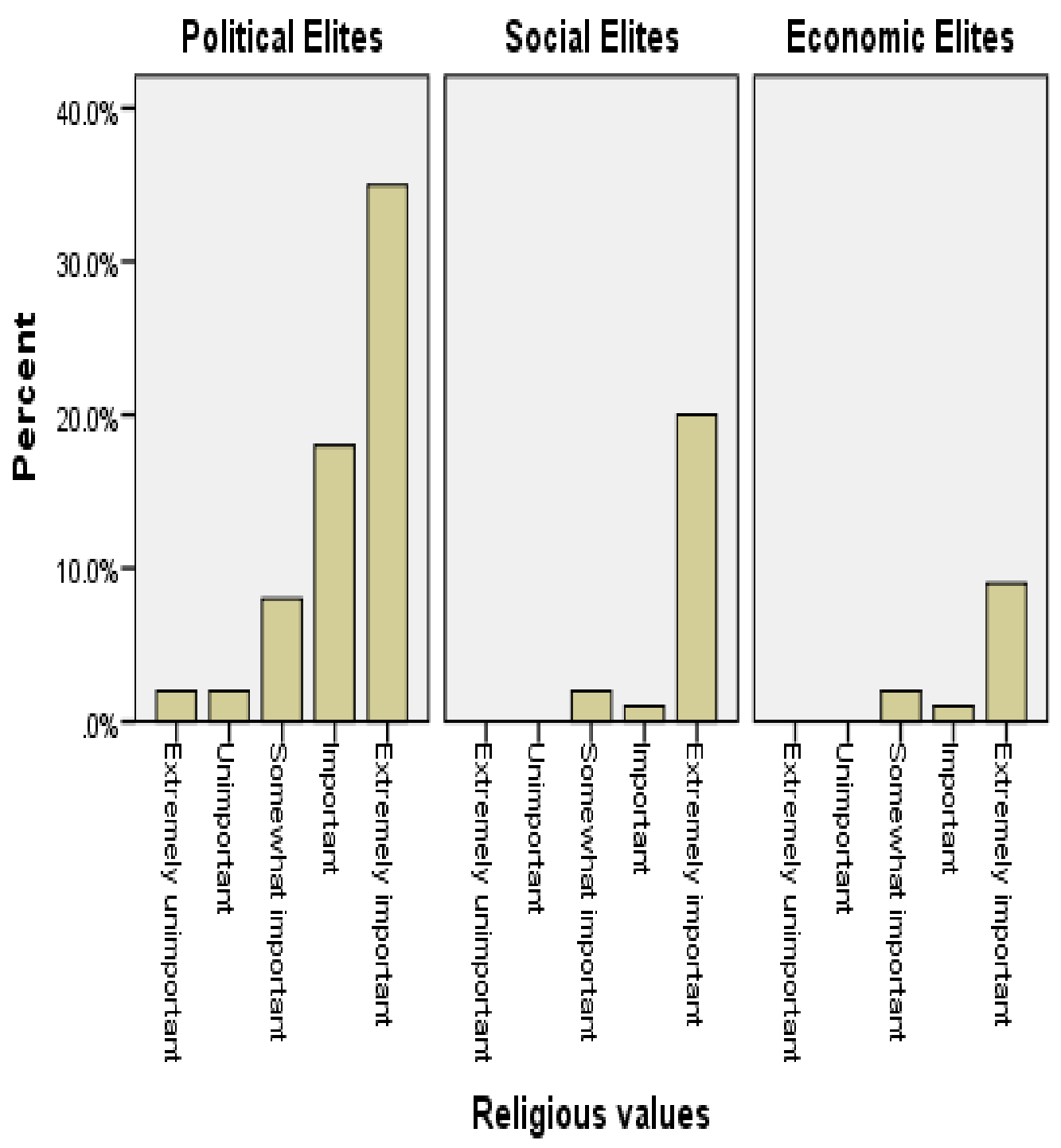


Table 88 Religious values- One way ANOVA

\begin{tabular}{lccccc}
\hline & SS & df & Mean Square & F & P \\
\hline Between groups & 4.976 & 2 & 2.488 & 3.040 & .052 \\
Within groups & 79.384 & 97 & .818 & & \\
Total & 84.360 & 99 & & & \\
\hline
\end{tabular}

$$
\mathrm{F}(2,97)=3.04, \mathrm{p}=\mathrm{ns}
$$

Table $89 \quad$ Importance of Religious Values - Means (SD)

\begin{tabular}{lcc}
\hline Three Elites Groups & Mean (SD) & $\mathrm{N}$ \\
\hline Political Elites & $4.26(1.004)$ & 65 \\
Social Elites & $4.78(.600)$ & 23 \\
Economic Elites & $4.58(.793)$ & 12 \\
Total & $4.42(.923)$ & 100 \\
\hline
\end{tabular}


Table 90 Importance of religious values - Cross Tabulation

\begin{tabular}{|c|c|c|}
\hline Elites' Religious Values & $\mathrm{N}$ & $\%$ \\
\hline Political Elites & 65 & $65 \%$ \\
\hline Extremely unimportant & 2 & 2.0 \\
\hline Unimportant & 2 & 2.0 \\
\hline Somewhat important & 8 & 8.0 \\
\hline Important & 18 & 18. \\
\hline Extremely important & 35 & 35. \\
\hline Social Elites & 23 & $23 \%$ \\
\hline Extremely unimportant & 0 & 0 \\
\hline Unimportant & 0 & 0 \\
\hline Somewhat important & 2 & 2.0 \\
\hline Important & 1 & 1.0 \\
\hline Extremely important & 20 & 20. \\
\hline Economic Elites & 12 & $12 \%$ \\
\hline Extremely unimportant & 0 & 0 \\
\hline Unimportant & 0 & 0 \\
\hline Somewhat important & 2 & 2.0 \\
\hline Important & 1 & 1.0 \\
\hline Extremely important & 9 & 9.0 \\
\hline Total & 100 & $100 \%$ \\
\hline
\end{tabular}


(Q.115.a) Women's political, social, and economic participation

Figure 30 Women's Political Participation by Three Groups of Elites

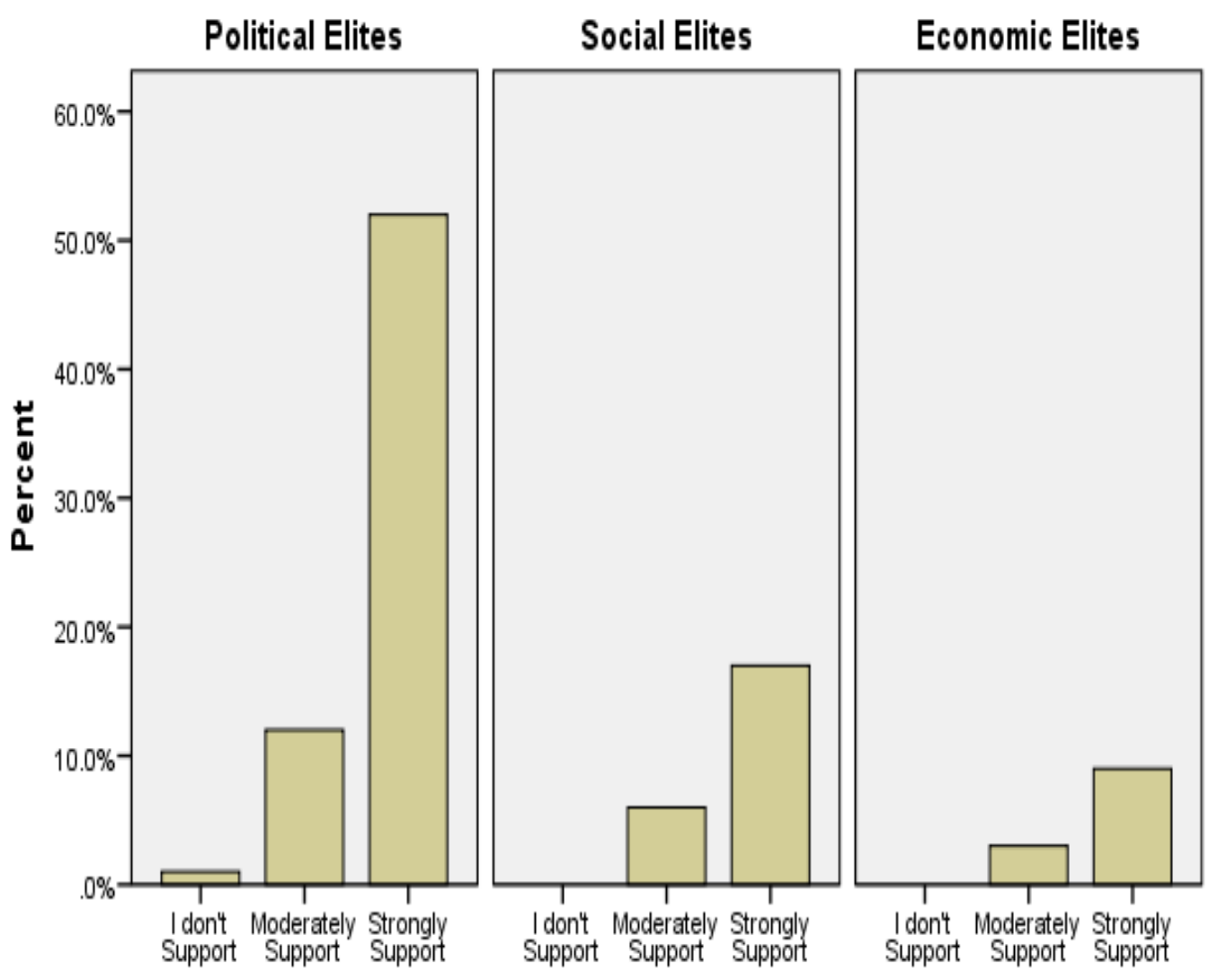

Elites' support to women's political participation 
Table $91 \quad$ Women's political participation by three groups of elites

\begin{tabular}{lrcccc}
\hline & SS & df & Mean Square & F & P \\
\hline Between groups & .041 & 2 & .020 & .100 & .905 \\
Within groups & 19.669 & 97 & .203 & & \\
Total & 19.710 & 99 & & & \\
\hline
\end{tabular}

$\mathrm{F}(2,97)=.100, \mathrm{p}=\mathrm{ns}$ 
Figure $31 \quad$ Women's social participation by three groups of elites

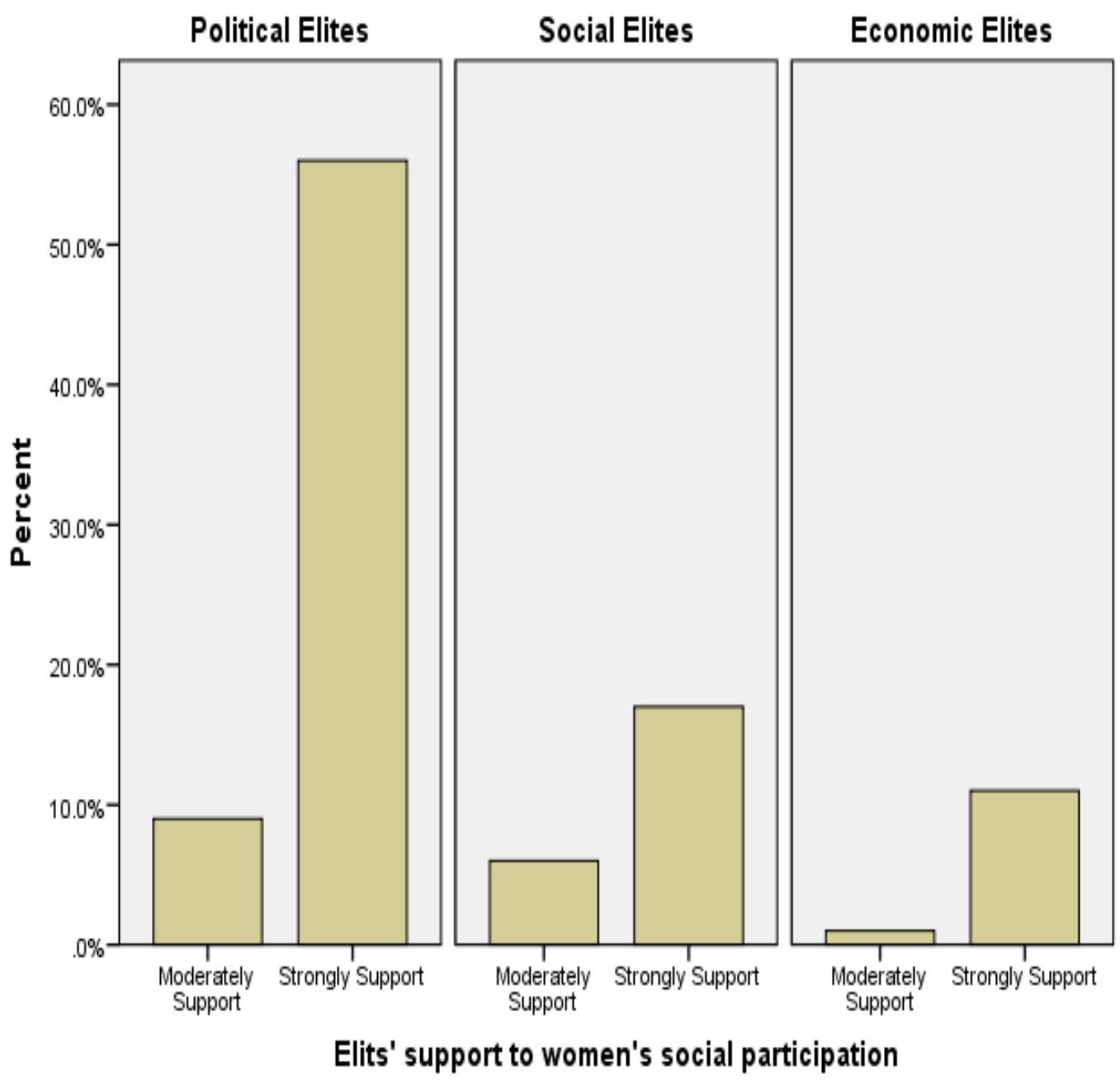


Figure 32 Women's social participation by three groups of elites

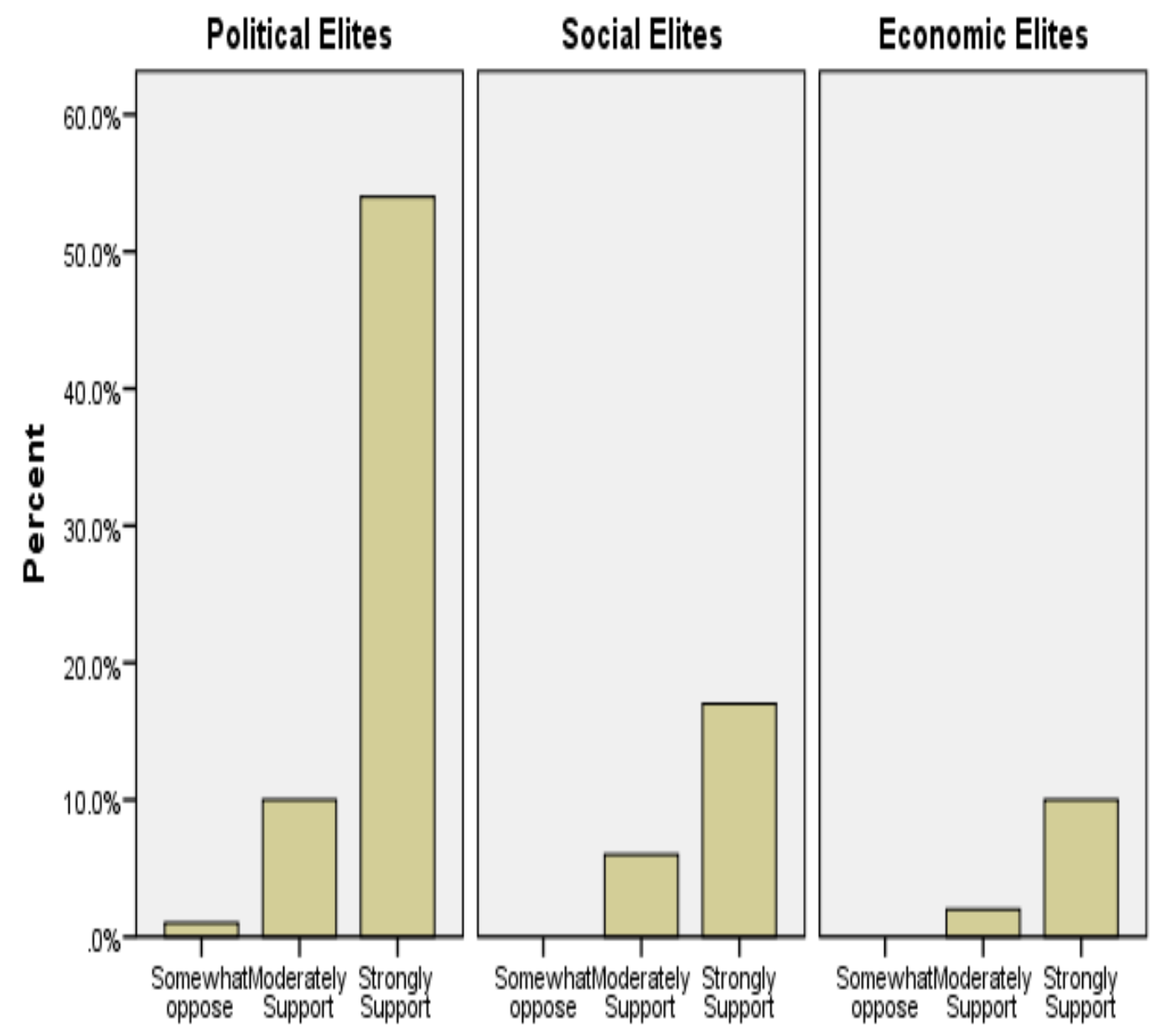

Elites' support to women's economic participation 
Table 92 Women's social participation-One way ANOVA

\begin{tabular}{lrcccc}
\hline & SS & df & Mean Square & F & P \\
\hline Between groups & .335 & 2 & .167 & 1.239 & .294 \\
Within groups & 13.105 & 97 & .135 & & \\
Total & 13.440 & 99 & & & \\
\hline
\end{tabular}

$$
\mathrm{F}(2,97)=1.24, \mathrm{p}=\mathrm{ns}
$$

Table 93 Women's economic participation by three groups of elites

\begin{tabular}{lrcccc}
\hline & SS & df & Mean Square & F & P \\
\hline Between groups & .114 & 2 & .057 & .309 & .735 \\
Within groups & 17.886 & 97 & .184 & & \\
Total & 18.000 & 99 & & & \\
\hline
\end{tabular}

$$
\mathrm{F}(2,97)=.309, \mathrm{p}=\mathrm{ns}
$$


Table 94 Women's Political, Social, and Economic Participation Means (SD)

The Participation of Women Mean (SD) N

Political Participation

Political elites

$3.78(.056)$

65

Social elites

$3.74(.094)$

23

Economic elites

$3.75(.131)$

12

Total

$3.77(.045)$

100

Social Participation

$\begin{array}{llc}\text { Political elites } & 3.86(.348) & 65 \\ \text { Social elites } & 3.74(.449) & 23 \\ \text { Economic elites } & 3.92(.289) & 12 \\ & 3.84(.368) & 100\end{array}$

Economic Participation

$\begin{array}{lll}\text { Political elites } & 3.82(.429) & 65 \\ \text { Social elites } & 3.74(.449) & 23 \\ \text { Economic elites } & 3.83(.389) & 12\end{array}$

Total

$3.80(.429)$

100 
Table 95 Women's Political, Social, and Economic Participation - Cross Tabulation

\begin{tabular}{|c|c|c|c|c|c|c|c|c|}
\hline \multirow[t]{2}{*}{$\begin{array}{l}\text { Women's Participation by } \\
\text { Three Groups of Elites }\end{array}$} & \multicolumn{2}{|c|}{ Strongly Oppose } & \multicolumn{2}{|c|}{$\begin{array}{c}\text { Moderately } \\
\text { Oppose }\end{array}$} & \multicolumn{2}{|c|}{$\begin{array}{c}\text { Moderately } \\
\text { Support }\end{array}$} & \multicolumn{2}{|c|}{$\begin{array}{l}\text { Strongly } \\
\text { Support }\end{array}$} \\
\hline & $\mathrm{N}$ & $\%$ & $\mathrm{~N}$ & $\%$ & $\mathrm{~N}$ & $\%$ & $\mathrm{~N}$ & $\%$ \\
\hline \multicolumn{9}{|l|}{ 1. Political Participation } \\
\hline Political Elites & 0 & $0 \%$ & 1 & $1.5 \%$ & 12 & $18.3 \%$ & 52 & $80.0 \%$ \\
\hline Social Elites & 0 & $0 \%$ & 0 & $0 \%$ & 6 & $26.1 \%$ & 17 & $73.9 \%$ \\
\hline Economic Elites & 0 & $0 \%$ & 0 & $0 \%$ & 3 & $25.0 \%$ & 9 & $75.0 \%$ \\
\hline Total $\%$ & 0 & $0 \%$ & 1 & $1.5 \%$ & 21 & $21.0 \%$ & 78 & $78.0 \%$ \\
\hline \multicolumn{9}{|l|}{ 2. Social Participation } \\
\hline Political Elites & 0 & $0 \%$ & 0 & $0 \%$ & 9 & $13.8 \%$ & 56 & $86.2 \%$ \\
\hline Social Elites & 0 & $0 \%$ & 0 & $0 \%$ & 6 & $26.1 \%$ & 17 & $73.9 \%$ \\
\hline Economic Elites & 0 & $0 \%$ & 0 & $0 \%$ & 1 & $08.3 \%$ & 11 & $91.7 \%$ \\
\hline Total \% & 0 & $0 \%$ & 0 & $0 \%$ & 16 & $16.0 \%$ & 84 & $84.0 \%$ \\
\hline \multicolumn{9}{|l|}{ 3. Economic participation } \\
\hline Political Elites & 0 & $0 \%$ & 1 & $1.5 \%$ & 10 & $15.4 \%$ & 54 & $83.1 \%$ \\
\hline Social Elites & 0 & $0 \%$ & 0 & $0 \%$ & 6 & $26.1 \%$ & 17 & $73.9 \%$ \\
\hline Economic Elites & 0 & $0 \%$ & 0 & $0 \%$ & 2 & $16.7 \%$ & 10 & $83.3 \%$ \\
\hline Total \% & 0 & $0 \%$ & 1 & $1.5 \%$ & 18 & $18.0 \%$ & 81 & $81 . \%$ \\
\hline
\end{tabular}


(Q. 115.b) Qualitative Thematic Analysis: Women's participation

Table 96 Frequencies of core themes: Women's participation

\begin{tabular}{lc} 
Core Themes & Frequency \\
\hline Traditionalism & 47 \\
Social Underdevelopment & 27 \\
Propaganda & 27 \\
\hline
\end{tabular}

Table 97 Women's participation: core and subordinate themes

\begin{tabular}{llll}
\hline Theme 1 & Theme 2 & Theme 3 & $\begin{array}{l}\text { Elites' Quotations } \\
\text { from the Survey }\end{array}$ \\
\hline Traditionalism & $\begin{array}{l}\text { Obsolete traditions } \\
\text { \& beliefs }\end{array}$ & $\begin{array}{l}\text { Both men and women } \\
\text { believe in obsolete } \\
\text { beliefs, which slow } \\
\text { down the response for }\end{array}$ \\
& & & $\begin{array}{l}\text { social development. } \\
\text { Social } \\
\text { underdevelopment }\end{array}$ \\
& Gender inequality/ & Female sub- \\
& patriarchy & $\begin{array}{l}\text { Women in the suburbs } \\
\text { are not empowered } \\
\text { due to high levels of } \\
\text { patriarchy. }\end{array}$ \\
& & & \\
Propaganda & &
\end{tabular}


Table $98 \quad$ Women's participation by three groups of elites

\begin{tabular}{lccc}
\hline Core Themes & Political Elites & Social Elites & Economic Elites \\
& $(\mathrm{N}=65)$ & $(\mathrm{N}=23)$ & $(\mathrm{N}=12)$ \\
\hline Traditionalism & 31 & 9 & 7 \\
& $47.7 \%$ & $39.1 \%$ & $58.3 \%$ \\
& & & \\
Social Under- & 12 & 12 & 3 \\
Development & $18.5 \%$ & $52.2 \%$ & $25.0 \%$ \\
& & & \\
Propaganda & 20 & 5 & 2 \\
& $30.8 \%$ & $21.7 \%$ & $16.7 \%$ \\
\hline
\end{tabular}


(Q. 104.5) Volunteerism

Figure $33 \quad$ Volunteerism

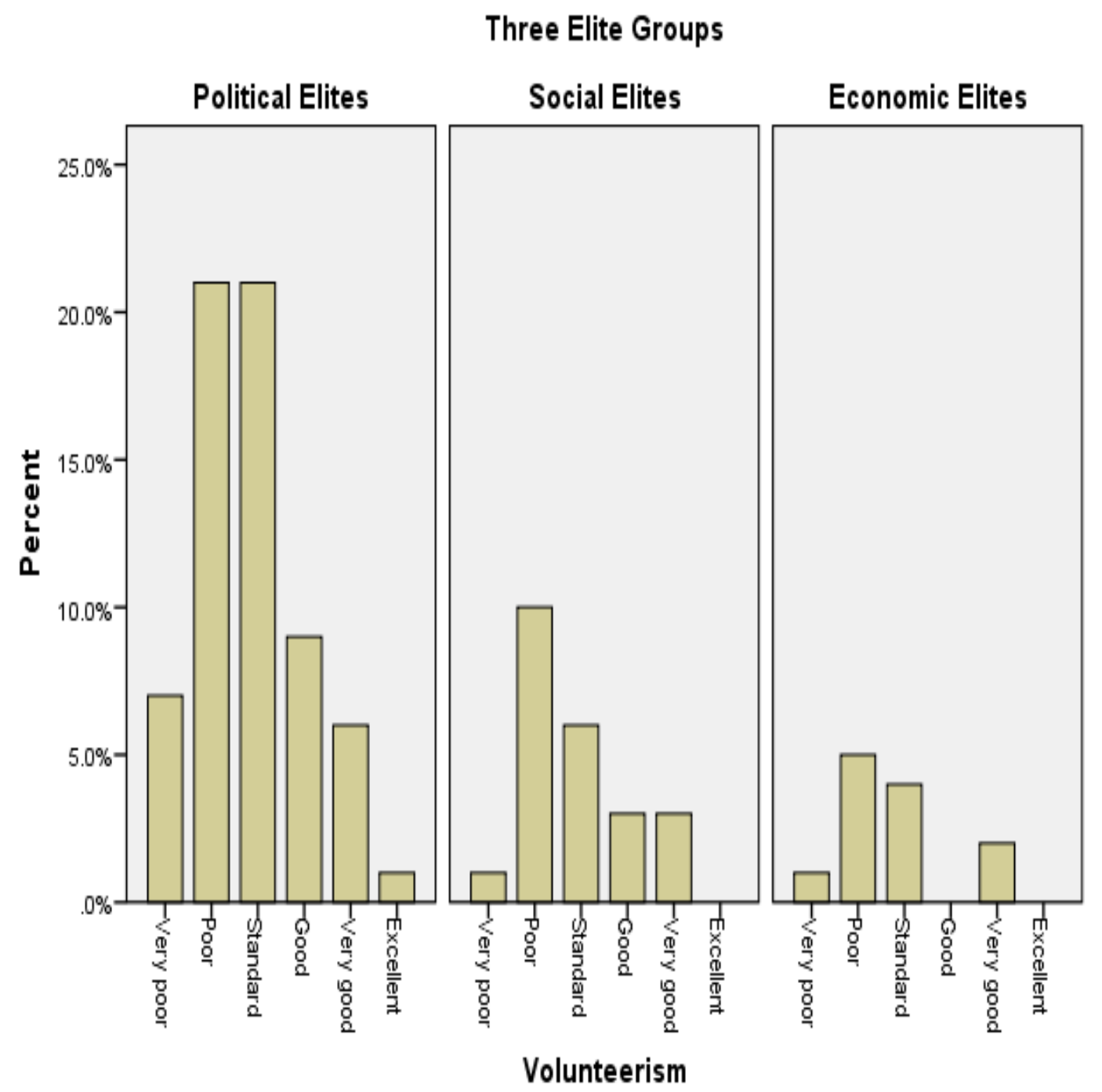


Table 99 Volunteerism- One way ANOVA

\begin{tabular}{lccccc}
\hline & SS & df & Mean Square & F & P \\
\hline Between groups & .113 & 2 & .056 & .041 & .960 \\
Within groups & 133.997 & 97 & 1.381 & & \\
Total & 134.110 & 99 & & \\
\hline \multicolumn{5}{c}{$\mathrm{F}(2,97)=.041, \mathrm{p}=\mathrm{ns}$}
\end{tabular}

Table 100 Volunteerism - Mean (SD)

\begin{tabular}{llll}
\hline Three Elites Groups & Mean & (SD) & $\mathrm{N}$ \\
\hline Political Elites & 2.83 & $(1.180)$ & 65 \\
Social Elites & 2.87 & $(1.140)$ & 23 \\
Economic Elites & 2.75 & $(1.215)$ & 12 \\
Total & 2.83 & $(1.164)$ & 100 \\
\hline
\end{tabular}


Table $101 \quad$ Volunteerism Beliefs - Cross Tabulation

\begin{tabular}{|c|c|c|}
\hline Three Elites Groups & $\mathrm{N}$ & $\%$ \\
\hline Political Elites & 65 & \\
\hline Very poor & 07 & $10.8 \%$ \\
\hline Poor & 21 & $32.3 \%$ \\
\hline Standard & 21 & $32.3 \%$ \\
\hline Good & 09 & $13.8 \%$ \\
\hline Very good & 06 & $09.2 \%$ \\
\hline Excellent & 01 & $01.5 \%$ \\
\hline Social Elites & 23 & \\
\hline Very poor & 01 & $04.3 \%$ \\
\hline Poor & 10 & $43.5 \%$ \\
\hline Standard & 06 & $26.1 \%$ \\
\hline Good & 03 & $13.0 \%$ \\
\hline Very good & 03 & $13.0 \%$ \\
\hline Excellent & 00 & $00.0 \%$ \\
\hline Economic Elites & 12 & \\
\hline Very poor & 01 & $08.3 \%$ \\
\hline Poor & 05 & $41.7 \%$ \\
\hline Standard & 04 & $33.3 \%$ \\
\hline Good & 00 & $00.0 \%$ \\
\hline Very good & 02 & $16.7 \%$ \\
\hline Excellent & 00 & $00.0 \%$ \\
\hline Total & 100 & \\
\hline
\end{tabular}


(Q. 129) Civic engagement: involvement with voluntary organizations

Figure 34 Cultural organizations by three groups of elites

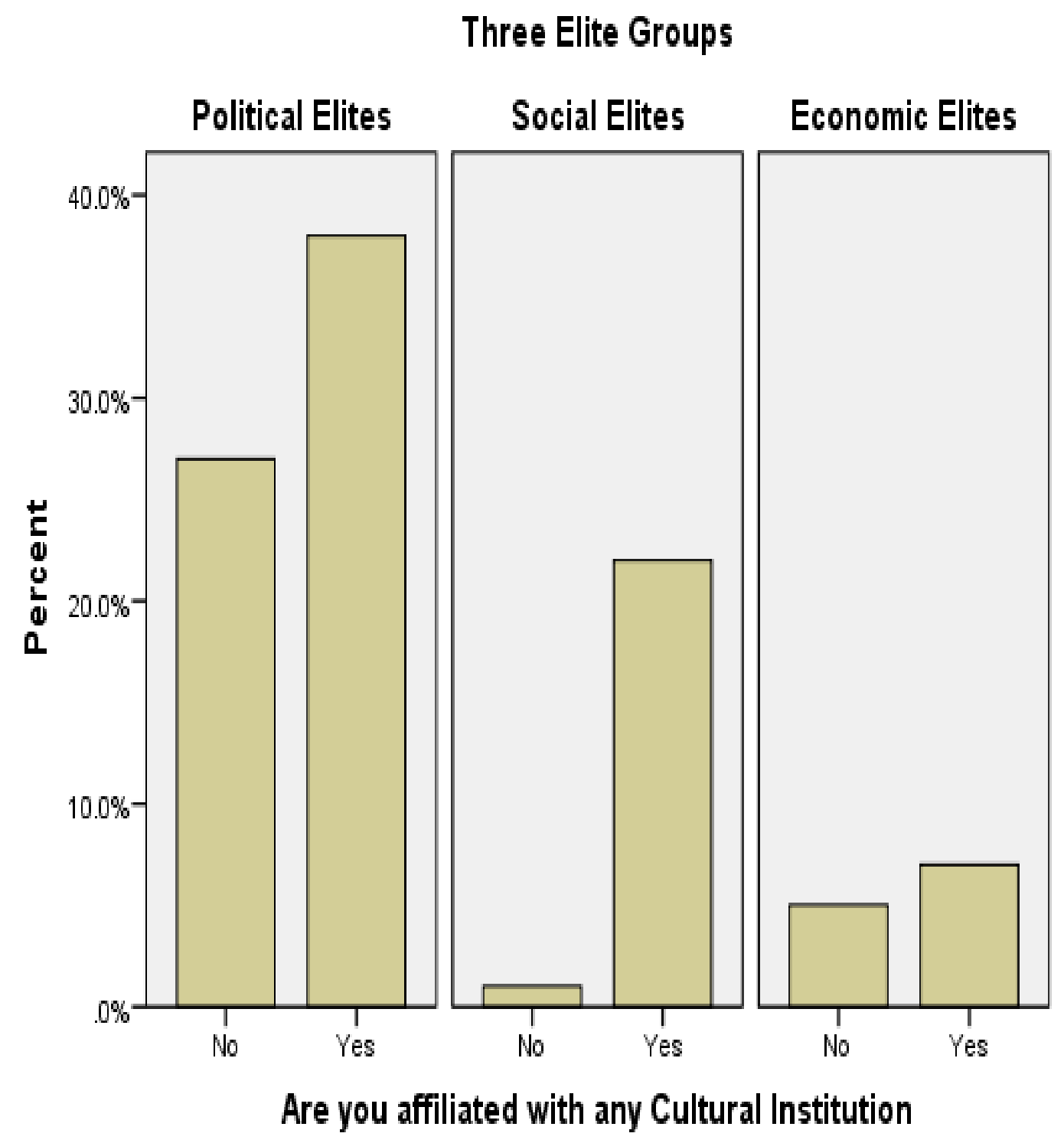


Figure 35 Involvement with national and international foundations by three groups of elites

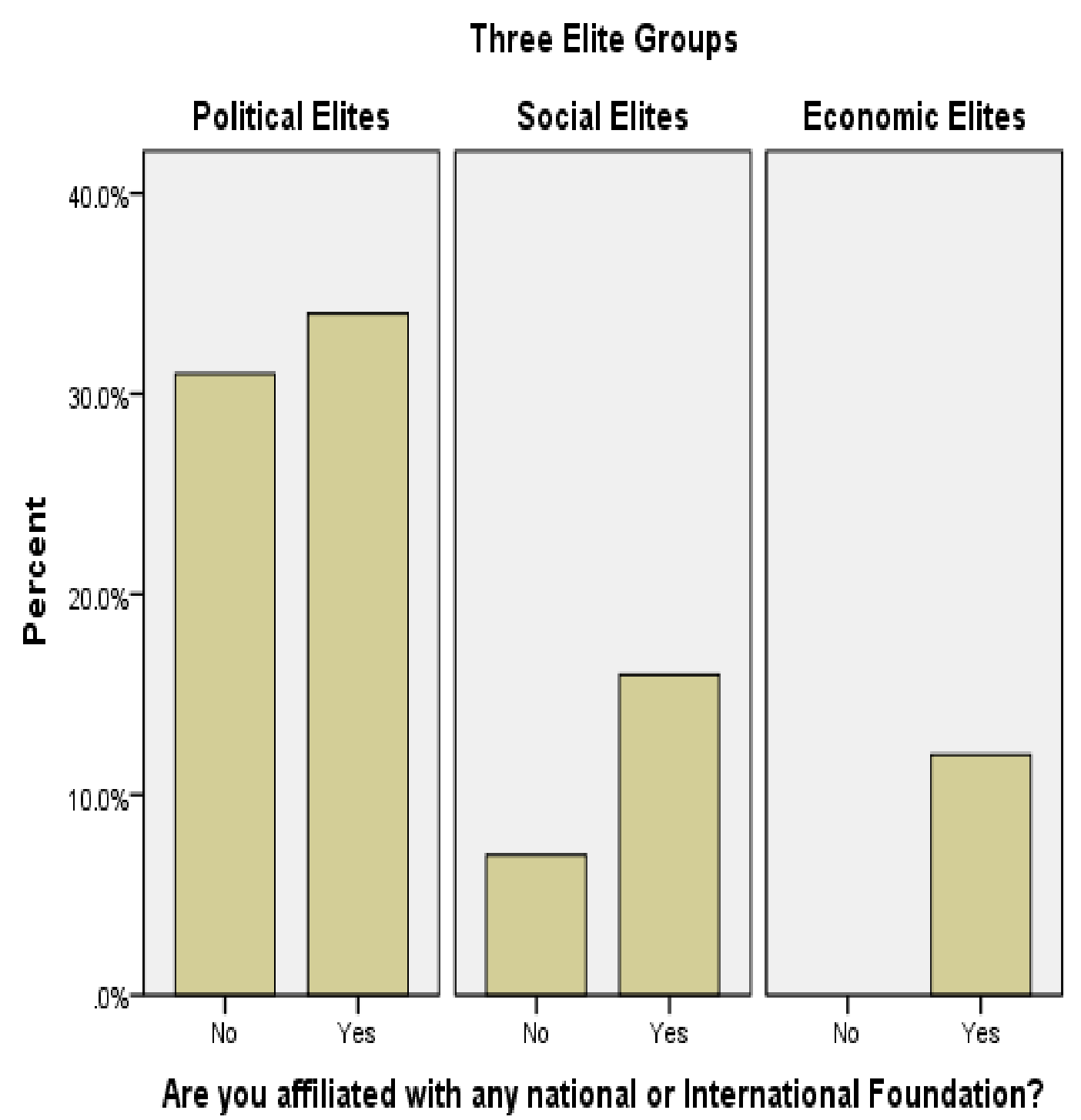


Table 102 Affiliation with cultural and national/international -Means (SD)

\begin{tabular}{lccc}
\hline Affiliations with NGOs & Mean & (SD) & N \\
\hline Cultural Institutions & & & \\
Political elites & 1.42 & $(.497)$ & 65 \\
$\quad$ Social elites & 1.04 & $(.209)$ & 23 \\
$\quad$ Economic elites & 1.41 & $(.515)$ & 12 \\
Total $\quad 1.33$ & $(.473)$ & 100 \\
$\quad$ Political elites & & & \\
National and International Foundations & & & 65 \\
$\quad$ Social elites & 1.46 & $(.502)$ & 23 \\
Eotal & 1.30 & $(.470)$ & 12 \\
\hline
\end{tabular}


Chi-square test results confirmed the significance of the two affiliations:

Table 103 Affiliations with cultural and national/international NGOs

\begin{tabular}{lccccc}
\hline NGO Type & No $(\%)$ & Yes $(\%)$ & $\chi^{2}$ & $\eta^{2}$ \\
\hline $\begin{array}{c}\text { Cultural Institutions } \\
\text { Political }\end{array}$ & $27(41.5)$ & 38 & $(58.5)$ & .004 & .333 \\
Social & $1(04.3)$ & 22 & $(95.7)$ & & \\
Economic & $5(41.7)$ & 7 & $(58.3)$ & & \\
& & & & & \\
National/International & & & & & \\
Political & $30(46.2)$ & 35 & $(53.8)$ & & \\
Social & $7(30.4)$ & 16 & $(69.6)$ & & \\
Economic & 0 & $(0.0)$ & 12 & $(100)$ & \\
\hline
\end{tabular}

Chi-square result: $\chi 2(2, N=100)=11.091, p<.05$

Chi-square result: $\chi 2(2, N=100)=9.809, \quad p<.05$ 
(Q. 130) Government interference in NGO affairs

Figure 36 Government interference in NGO affairs by three groups of elites

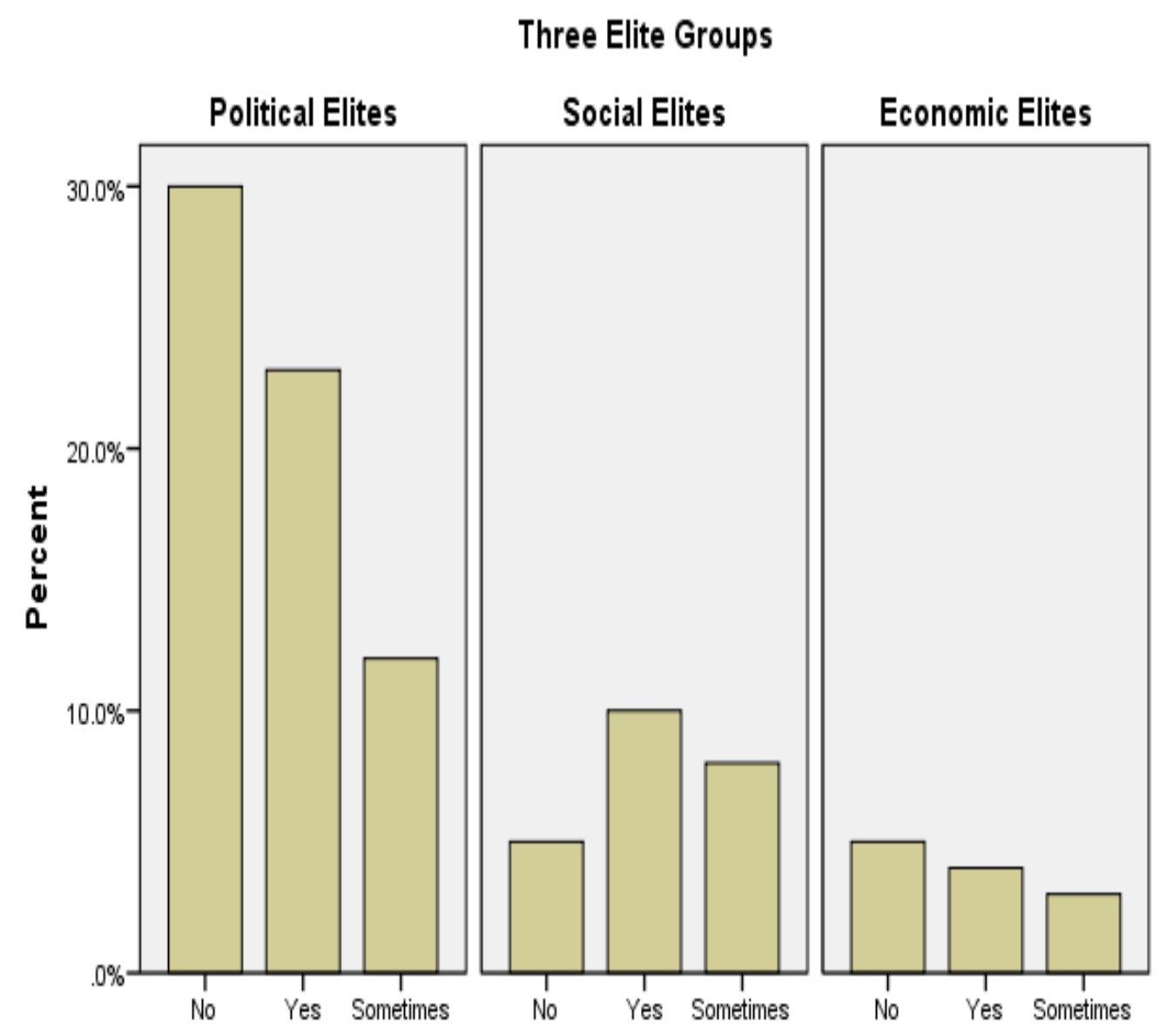

Does the government interfere in the affairs of NGOs? 
Table 104 Government interference in NGO affairs - Means (SD)

\begin{tabular}{lcc}
\hline Three Elites Groups & Mean (SD) & $\mathrm{N}$ \\
\hline Political Elites & $.72(.761)$ & 65 \\
Social Elites & $1.13(.751)$ & 23 \\
Economic Elites & $.83(.853)$ & 12 \\
& $.83(.779)$ & 100 \\
\hline
\end{tabular}

Table 105 Government interference in NGO affairs - N (\%) - Chi-square

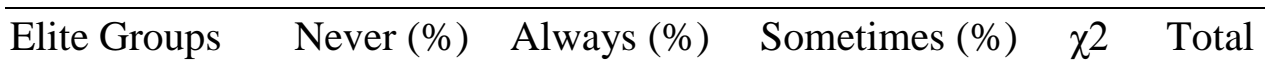

\begin{tabular}{|c|c|c|c|c|c|}
\hline Political & $30(47)$ & $5(21)$ & $5(41)$ & .300 & 40 \\
\hline Social & $23(35)$ & $10(44)$ & $4(33)$ & & 37 \\
\hline Economic & 12 (19) & $8(35)$ & $3(25)$ & & 23 \\
\hline Total & & & & & 100 \\
\hline
\end{tabular}

$$
\chi 2(4, \mathrm{~N}=100)=4.88, \mathrm{p}<.05
$$

Q. 131) Qualitative Thematic Analysis: Government Interference in NGO Affairs

Most elites consider that "authoritarianism/national security," is the core reason behind interfering in the affairs of voluntary organizations. This core theme occurred by $56 \%$ across the sample. 
Economic Development

(Q. 103.6) Prosperity and work value

Figure 37 Prosperity and work value by three groups of elites

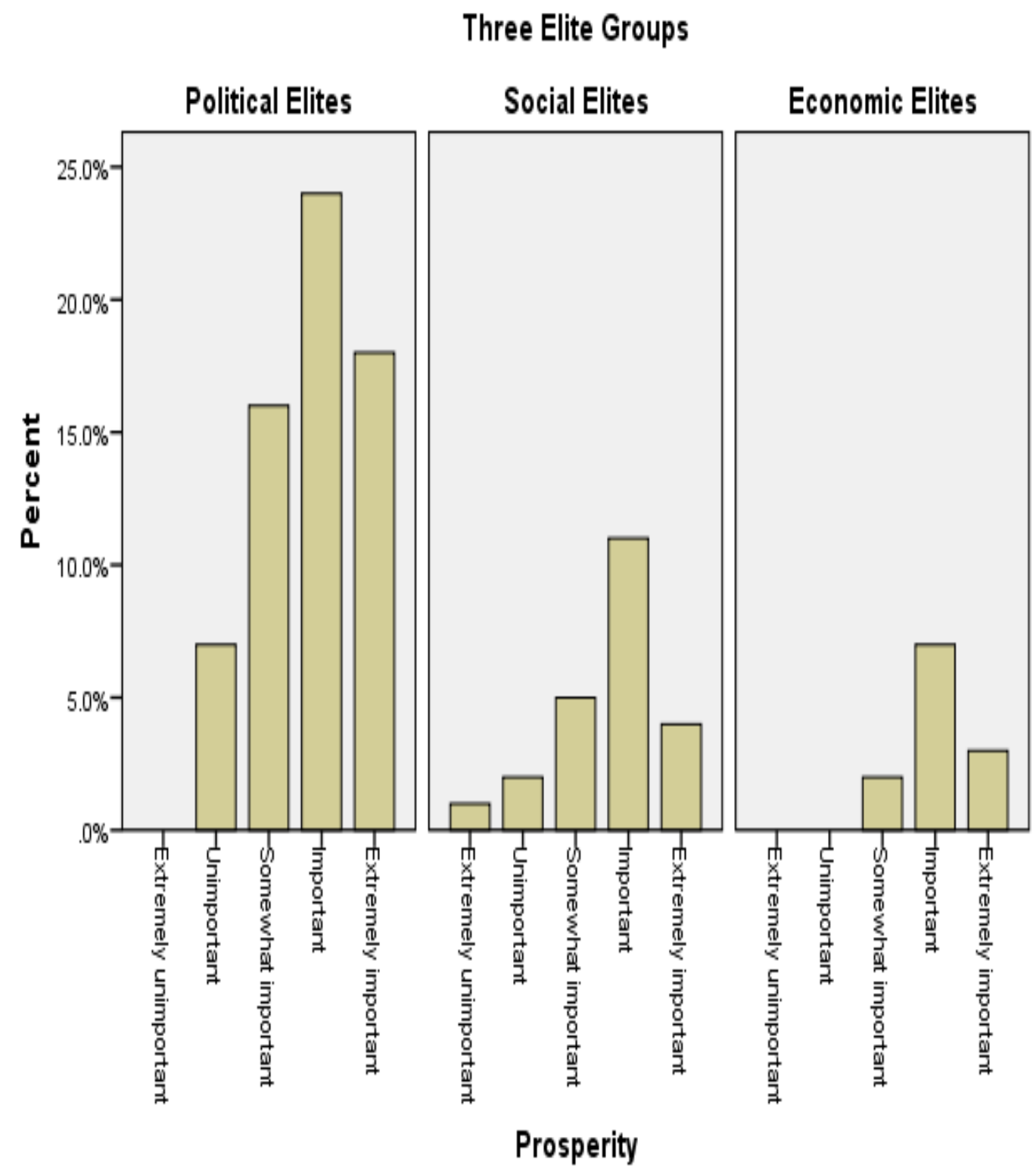


A one-way ANOVA test results are displayed below:

Table 106 Prosperity by three groups of elites

\begin{tabular}{lccccc}
\hline & SS & df & Mean Square & F & P \\
\hline Between groups & 1.471 & 2 & .071 & .812 & .447 \\
Within groups & 87.919 & 97 & 1.257 & & \\
Total & 89.390 & 99 & & & \\
\hline
\end{tabular}

$$
\mathrm{F}(2,97)=.812, \mathrm{p}=\mathrm{ns}
$$

Table 107 Prosperity - Means (SD)

\begin{tabular}{lll}
\hline Three Elites Groups & Mean (SD) & $\mathrm{N}$ \\
\hline Political Elites & $3.82 \quad(.967)$ & 65 \\
Social Elites & $3.65(1.027)$ & 23 \\
Economic Elites & $4.08 \quad(.669)$ & 12 \\
Total & $3.81 \quad(.950)$ & 100 \\
\hline
\end{tabular}


(Q.104.4) Economic liberalization

Figure 38 Economic liberalization by three groups of elites

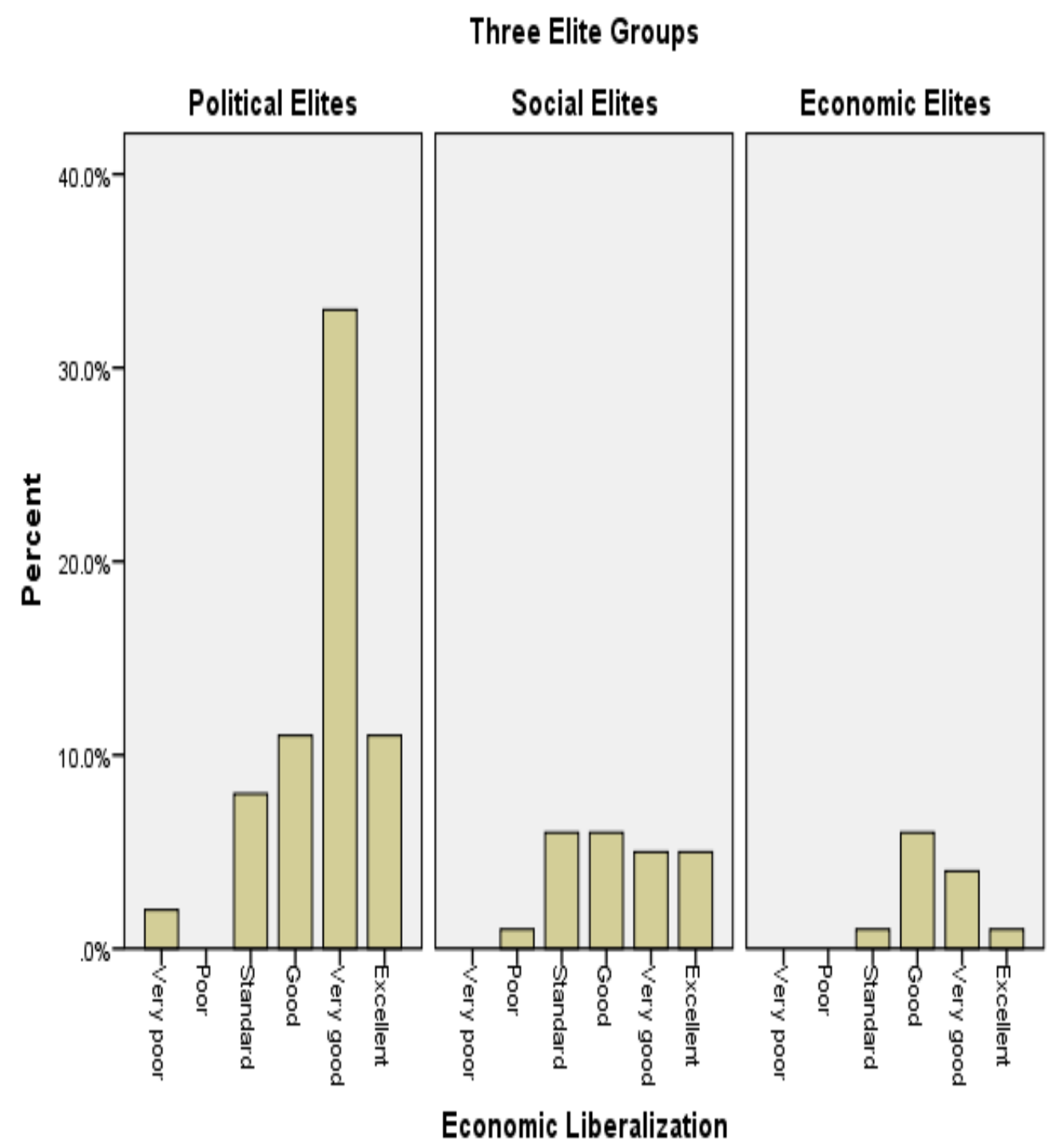


Table 108 Economic Liberalization by Three Groups of Elites

\begin{tabular}{lccccc}
\hline & SS & df & Mean Square & F & P \\
\hline Between groups & 1.985 & 2 & .071 & .823 & .442 \\
Within groups & 116.925 & 97 & 1.257 & & \\
Total & 118.910 & 99 & & \\
\hline \multicolumn{5}{c}{$\mathrm{F}(2,97)=.823, \mathrm{p}=\mathrm{ns}$}
\end{tabular}

Table 109 Economic Liberalization - Means (SD)

\begin{tabular}{lll}
\hline Three Elites Groups & Mean (SD) & $\mathrm{N}$ \\
\hline Political Elites & $4.63(1.098)$ & 65 \\
Social Elites & $4.30(1.222)$ & 23 \\
Economic Elites & $4.42(.793)$ & 12 \\
Total & $4.53(1.096)$ & 100 \\
\hline
\end{tabular}


Table 110 Economic Liberalization: Cross Tabulation

\begin{tabular}{|c|c|c|}
\hline Three Elite Groups & $\mathrm{N}$ & $\%$ \\
\hline Political Elites & 65 & \\
\hline Very poor & 02 & 03.1 \\
\hline Poor & 00 & 00. \\
\hline Standard & 08 & 12.3 \\
\hline Good & 11 & 16.9 \\
\hline Very good & 33 & 50.8 \\
\hline Excellent & 11 & 16.9 \\
\hline Social Elites & 23 & \\
\hline Very poor & 00 & 00. \\
\hline Poor & 01 & 4.3 \\
\hline Standard & 06 & 26.1 \\
\hline Good & 06 & 26.1 \\
\hline Very good & 05 & 21.7 \\
\hline Excellent & 05 & 21.7 \\
\hline Economic Elites & 12 & \\
\hline Very poor & 00 & 00. \\
\hline Poor & 00 & 00. \\
\hline Standard & 01 & 08.3 \\
\hline Good & 06 & 50.0 \\
\hline Very good & 04 & 00. \\
\hline Excellent & 01 & 08.3 \\
\hline Total & 100 & \\
\hline
\end{tabular}


(Q.132) Development precedence Economic verses Political

Figure 39 Economic development precedence

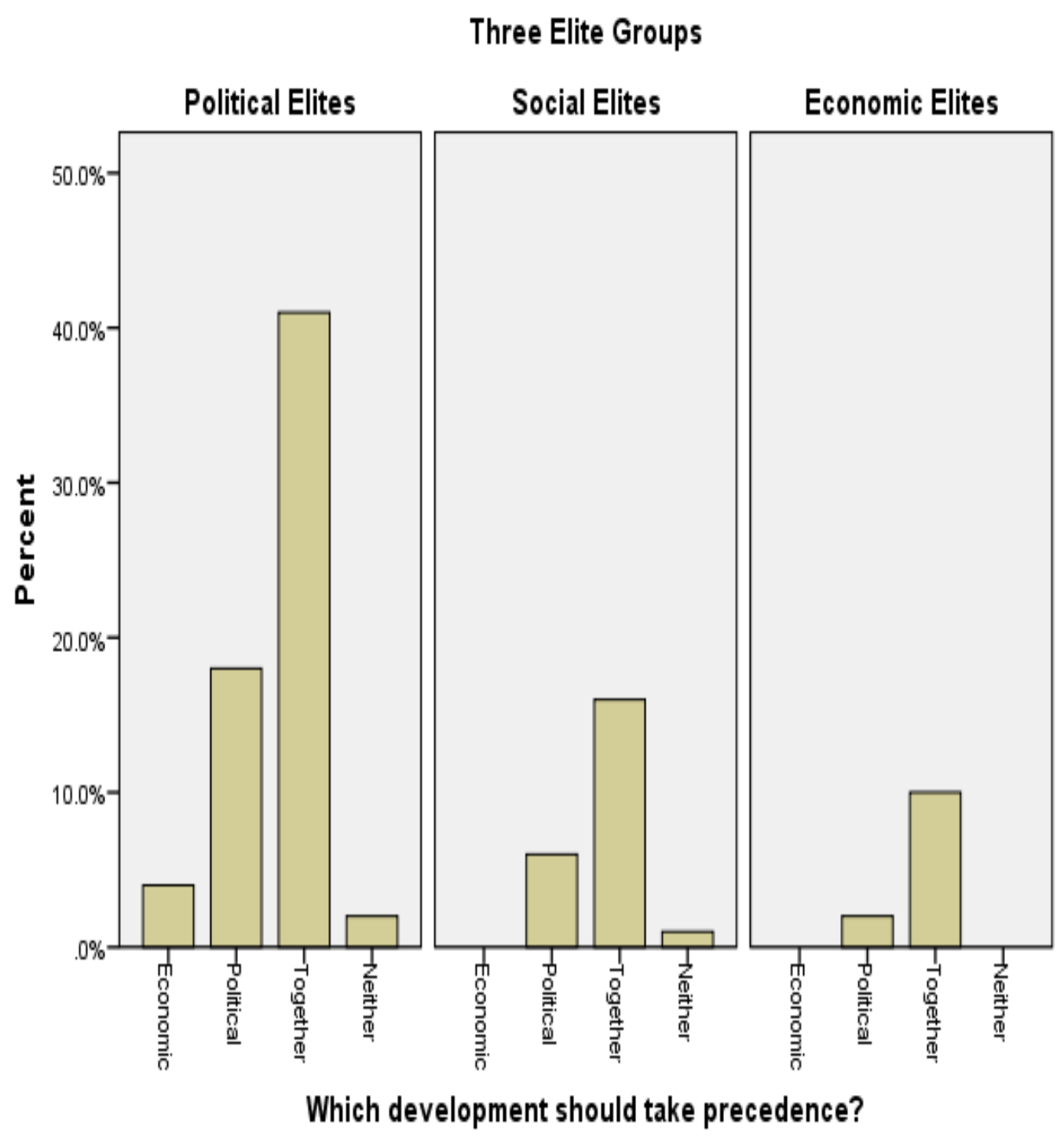


Table 112 Economic Development Precedence by Three Groups of Elites

\begin{tabular}{lccccc}
\hline & SS & df & Mean Square & F & P \\
\hline Between groups & .672 & 2 & .336 & .939 & .395 \\
Within groups & 34.718 & 97 & .358 & & \\
Total & 35.390 & 99 & & \\
\hline \multicolumn{4}{c}{$\mathrm{F}(2,97)=.939, \mathrm{p}=\mathrm{ns}$}
\end{tabular}

Table 113 Economic Development Precedence-Means (SD)

\begin{tabular}{lcc}
\hline Three Elites Groups & Mean (SD) & $\mathrm{N}$ \\
\hline Political Elites & $2.63(.651)$ & 65 \\
Social Elites & $2.78(.518)$ & 23 \\
Economic Elites & $2.83(.389)$ & 12 \\
Total & $2.69(.598)$ & 100 \\
\hline
\end{tabular}


Table 114 Economic development precedence by three groups of elites

\begin{tabular}{lcc}
\hline Three Elite Groups & $\mathrm{N}$ & $\%$ \\
\hline Political & 65 & $65 \%$
\end{tabular}

1. The economic development should take precedence

$4 \quad 4 \%$

2. The political development and civil liberties should take precedence

$18 \quad 18 \%$

3. Both developments should occur simultaneously Neutral

$41 \quad 41 \%$

4. Neither, both are imposed by

$2 \quad 2 \%$

external powers

Social

$23 \quad 23 \%$

1. The economic development should take precedence

$0 \quad 0 \%$

2. The political development and civil liberties should take precedence

$6 \quad 6 \%$

3. Both developments should occur simultaneously Neutral

4. Neither, both are imposed by external powers

Economic

1. The economic development should take precedence

$0 \quad 0 \%$

2. The political development and civil liberties should take precedence

$2 \quad 2 \%$

3. Both developments should occur simultaneously Neutral $10 \quad 10 \%$

4. Neither, both are imposed by external powers

$0 \quad 0 \%$ 
(Q.133) Qualitative Thematic Analysis: The relationship between the economic \& political developments

Table $115 \quad$ Political and economic development plan choice by elites

\begin{tabular}{lc}
\hline Core Themes & Frequency \\
\hline Political and economic Stability & 64 \\
Reinstatement of Freedoms & 29 \\
Economic Development & 4 \\
\hline
\end{tabular}

The following table illustrates elites' core and subordinate themes and their elaborations on their responses on the development plan that they chose in (Q. 132). 
Table 116 Political and economic development plan choice: core and subordinate themes

\begin{tabular}{|c|c|c|c|}
\hline Theme 1 & Theme 2 & Theme 3 & $\begin{array}{l}\text { Elites' Quotations from } \\
\text { the Survey }\end{array}$ \\
\hline $\begin{array}{l}\text { Political \& } \\
\text { Economic Stability }\end{array}$ & $\begin{array}{l}\text { Ensures higher } \\
\text { growth \& } \\
\text { productivity at } \\
\text { all levels }\end{array}$ & & $\begin{array}{l}\text { The achievement of } \\
\text { higher levels of growth } \\
\text { and productivity } \\
\text { enhances the government } \\
\text { credibility and improves } \\
\text { its relative political } \\
\text { capacity. }\end{array}$ \\
\hline $\begin{array}{l}\text { Reinstatement of } \\
\text { freedoms }\end{array}$ & $\begin{array}{l}\text { Establishment } \\
\text { of Free } \\
\text { Enterprising } \\
\text { Economy }\end{array}$ & $\begin{array}{l}\text { Protection } \\
\text { from } \\
\text { globalization }\end{array}$ & $\begin{array}{l}\text { The Globalization led } \\
\text { Jordanians to discontents } \\
\text { because it did not lead to } \\
\text { economic development. }\end{array}$ \\
\hline $\begin{array}{l}\text { Economic } \\
\text { development }\end{array}$ & $\begin{array}{l}\text { Open economy } \\
\& \text { globalization }\end{array}$ & Free markets & $\begin{array}{l}\text { Liberalization \& } \\
\text { globalization open the } \\
\text { door for modernity, } \\
\text { encourage the world } \\
\text { investments, and } \\
\text { accentuate freedoms. }\end{array}$ \\
\hline
\end{tabular}


The below table demonstrates the distribution of elites' beliefs in the effectiveness of their chosen development plan:

Table117 Political and economic development plan choice (N \%)

\begin{tabular}{lccc}
\hline Core Themes & Political Elites & Social Elites & Economic Elites \\
& $(\mathrm{N}=65)$ & $(\mathrm{N}=23)$ & $(\mathrm{N}=12)$ \\
\hline $\begin{array}{l}\text { Political \& Economic } \\
\text { Stability }\end{array}$ & 38 & 16 & 10 \\
& $58.5 \%$ & $69.6 \%$ & $83.3 \%$ \\
Reinstatement of & 21 & & \\
Freedoms & $32.3 \%$ & 6 & 2 \\
& & $26.0 \%$ & $16.6 \%$ \\
& 4 & 0 & 0 \\
Economic & $6.2 \%$ & $00.0 \%$ & $00.0 \%$ \\
Development & & & \\
\hline
\end{tabular}

